\title{
Peri- and extravascular inflammation : impact on atherosclerosis
}

Citation for published version (APA):

Daissormont, I. T. M. N. (2012). Peri- and extravascular inflammation : impact on atherosclerosis.

[Doctoral Thesis, Maastricht University]. Uitgeverij BOXPress. https://doi.org/10.26481/dis.20120413id

Document status and date:

Published: 01/01/2012

DOI:

10.26481/dis.20120413id

Document Version:

Publisher's PDF, also known as Version of record

\section{Please check the document version of this publication:}

- A submitted manuscript is the version of the article upon submission and before peer-review. There can be important differences between the submitted version and the official published version of record.

People interested in the research are advised to contact the author for the final version of the publication, or visit the DOI to the publisher's website.

- The final author version and the galley proof are versions of the publication after peer review.

- The final published version features the final layout of the paper including the volume, issue and page numbers.

Link to publication

\footnotetext{
General rights rights.

- You may freely distribute the URL identifying the publication in the public portal. please follow below link for the End User Agreement:

www.umlib.nl/taverne-license

Take down policy

If you believe that this document breaches copyright please contact us at:

repository@maastrichtuniversity.nl

providing details and we will investigate your claim.
}

Copyright and moral rights for the publications made accessible in the public portal are retained by the authors and/or other copyright owners and it is a condition of accessing publications that users recognise and abide by the legal requirements associated with these

- Users may download and print one copy of any publication from the public portal for the purpose of private study or research.

- You may not further distribute the material or use it for any profit-making activity or commercial gain

If the publication is distributed under the terms of Article $25 \mathrm{fa}$ of the Dutch Copyright Act, indicated by the "Taverne" license above, 


\section{Peri- and extravascular inflammation: Impact on atherosclerosis}


Printed and lay-out: Proefschriftmaken.nl

Cover design: Proefschriftmaken.nl

Cover illustration: Corbis Images

Published by: Uitgeverij BOXPress, Oisterwijk

ISBN 978-90-8891-377-8

(C) Copyright Isabelle Daissormont, Maastricht April 2012 


\title{
Peri- and extravascular inflammation: Impact on atherosclerosis
}

\author{
PROEFSCHRIFT \\ ter verkrijging van de graad van doctor aan \\ de Universiteit Maastricht, \\ op gezag van de Rector Magnificus, \\ Prof. Mr. G.P.M.F. Mols, \\ volgens het besluit van het College van Decanen, \\ in het openbaar te verdedigen \\ op vrijdag 13 april 2012 om 14.00 uur \\ door
}

Isabelle Truda Marie Nadine Daissormont

geboren op 10 juli 1985 te Luik, België 


\section{Promotor}

Prof. dr. E.A. Biessen

\section{Beoordelingscommissie}

Prof. dr. W.A. Buurman (voorzitter)

Prof. dr. P. Aukrust (University Hospital Oslo)

Prof. dr. E. Janssen (Cincinnati Children's Hospital Medical Center)

Prof. dr. E. Lutgens (Academisch Medisch Centrum Amsterdam)

The research described in this thesis was supported by a grant of the Dutch Heart Foundation (NHS-2006B228).

Financial support by the Dutch Heart Foundation for the publication of this thesis is gratefully acknowledged.

Printing of this thesis was financially supported by Greiner-Bio One, Peprotech and Special Diets Services.

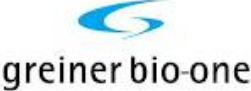




\section{Contents}

Chapter $1 \quad$ General introduction 11

Chapter 2 Chemokines as therapeutic targets for atherosclerotic plaque 45 destabilization and rupture

Chapter 3 CXCR4 blockade induces atherosclerosis by perturbing neutrophil apoptosis and senescence

Chapter $4 \quad$ Increased levels of the homeostatic chemokine CXCL13 in human atherosclerosis: potential role in plaque stabilization

Chapter 5 Interruption of the CXCL13/CXCR5 axis attenuates atherosclerosis by perturbing monocyte/granulocyte homeostasis in mice

Chapter 6 Plasmacytoid dendritic cells protect against atherosclerosis 157 by tuning $T$ cell proliferation and activity

Chapter 7 Adventitial lymphatic capillaries in plaque T cell drainage and progression: an explorative study

Chapter 8 General discussion

Summary 


\section{List of abbreviations}

\begin{tabular}{|c|c|}
\hline 1-MT & 1-methyl tryptophan \\
\hline $\mathrm{AHA}$ & American Heart Association \\
\hline $\mathrm{ApoE}^{-/-}$ & apolipoprotein E knockout \\
\hline BLR1 & Burkitt lymphoma receptor 1 \\
\hline BSA & bovine serum albumin \\
\hline CCR & CC chemokine receptor \\
\hline $\mathrm{CDC}$ & conventional dendritic cell \\
\hline CSF & colony stimulating factor \\
\hline DC & dendritic cell \\
\hline DNA & deoxyribonucleic acid \\
\hline EC & endothelial cell \\
\hline Foxp3 & forkhead box P3 \\
\hline HSP & heat-shock protein \\
\hline ICAM-1 & intracellular adhesion molecule-1 \\
\hline ICOS-L & inducible costimulator-ligand \\
\hline IDO & indoleamine 2,3-dioxygenase \\
\hline IFN & interferon \\
\hline IGF-1 & insulin-like growth factor-1 \\
\hline IL & interleukin \\
\hline
\end{tabular}




\begin{tabular}{|c|c|}
\hline IP-10 & Interferon- $\gamma$ inducible protein 10 \\
\hline $\mathrm{IPH}$ & intraplaque hemorrhage \\
\hline IT & intimal thickening \\
\hline $\operatorname{LDLr}^{-/-}$ & low density lipoprotein receptor knockout \\
\hline LN & lymph node \\
\hline LPS & lipopolysaccharide \\
\hline MCP-1 & monocyte chemotactic protein-1 \\
\hline M-CSF & macrophage-colony stimulating factor \\
\hline MHC-II & major histocompatibility complex class-II \\
\hline MMP & matrix metalloproteinase \\
\hline OVA & ovalbumin \\
\hline oxLDL & oxidized low density lipoprotein \\
\hline PBS & phosphate-buffered saline \\
\hline PCR & polymerase chain reaction \\
\hline PDC & plasmacytoid dendritic cell \\
\hline PDGF & platelet derived growth factor \\
\hline PD-L1 & programmed death-ligand 1 \\
\hline PI3K & phosphatidylinositol 3-kinase \\
\hline RNA & ribonucleic acid \\
\hline ROS & reactive oxygen species \\
\hline
\end{tabular}




$\begin{array}{ll}\text { RT-PCR } & \text { real-time polymerase chain reaction } \\ \text { SDF-1 } \alpha & \text { stromal derived factor-1 } \alpha \\ \text { TCR } & \text { T cell receptor } \\ \text { TGF } & \text { transforming growth factor } \\ \text { Th } & \text { Thelper } \\ \text { TfCA } & \text { thick fibrous cap atheroma } \\ \text { TLR } & \text { toll-like receptor } \\ \text { TNF } & \text { tumor necrosis factor } \\ \text { TRAIL } & \text { tumor necrosis factor-related apoptosis-inducing ligand } \\ \text { Treg } & \text { regulatory T cell } \\ \text { VCAM-1 } & \text { vascular cell adhesion molecule-1 } \\ \text { VEGF } & \text { vascular endothelial growth factor } \\ \text { VLDL } & \text { very-low-density lipoprotein } \\ \text { VSMC } & \text { vascular smooth muscle cell }\end{array}$






\section{Chapter 1}

General Introduction 


\section{Introduction to atherosclerosis}

Atherosclerosis is a chronic inflammatory disease which is typified by the accumulation of lipids and inflammatory cells into the vessel wall, resulting in the formation of an atherosclerotic plaque or lesion. Destabilization of an atherosclerotic plaque can lead to severe acute clinical manifestations such as a myocardial infarction, stroke or peripheral arterial occlusion, which are still the leading cause of death in Western Society. ${ }^{1,2}$ Atherosclerosis is a progressive disease starting at early adolescence and progressing with age. ${ }^{3,4}$ Initially, early lesions develop, referred to as fatty streaks. At later stages, these lesions develop into more advanced and unstable lesions, leading to blood flow restriction and upon plaque rupture potentially to occlusive thrombus formation.

Middle- and large-sized arteries are particularly prone to atherosclerotic plaque formation, especially the coronary arteries, the carotid arteries at the bifurcation site and all main branching points of the aorta., ${ }^{5,6}$ The high susceptibility of these artery segments to atherosclerosis can be attributed to hemodynamic flow factors, such as low shear stress, oscillatory flow and turbulent flow. ${ }^{7}$ Despite genetic pre-disposition, various behavioral features can influence the progression of atherosclerosis, such as smoking, ${ }^{8}$ high fat diet, ${ }^{9}$ stress ${ }^{10,11}$ and physical inactivity. ${ }^{12,13}$ In addition, also hypertension, ${ }^{8}$ diabetes $^{14-16}$ and obesity ${ }^{17,18}$ are associated with cardiovascular disease.

\section{Atherosclerotic plaque development}

\section{Plaque initiation}

The vessel wall consists of three layers. The inner layer, called intima, consists of a single layer of endothelial cells and some residential leukocytes. The intima covers the media, which consists of several layers of smooth muscle cells (SMC) and is flanked by the internal and external lamina elastica. Finally, the adventitia borders the outside of the vessel wall and consists of stromal tissue, leukocytes, blood vessels (vasa vasorum) and lymphatic capillaries.

The trigger for atherosclerosis development is endothelial dysfunction caused by low turbulent or oscillatory shear stress in combination with pro-atherogenic stimuli such as high levels of lipoproteins (very-low-density lipoprotein (VLDL), low 
density lipoprotein (LDL)). ${ }^{19,20}$ Lipoproteins can enter into and accumulate in the subendothelial space at sites of endothelial injury and in response to such injury endothelial cells will increase the expression of adhesion molecules, such as Eand P-selectin, which will enable rolling of monocytes on top of the endothelium. ${ }^{21,22}$ While rolling, monocytes adhere to the endothelium via vascular cell adhesion molecule-1 (VCAM-1), intracellular adhesion molecule-1 (ICAM-1) and dedicated CC-Chemokine Receptors (CCRs), which are also upregulated by endothelial cells. ${ }^{23,24}$ Finally, monocytes migrate through the endothelial layer into the intima, a process called diapedesis, where they differentiate into macrophages in response to pro-inflammatory cytokines, such as MacrophageColony Stimulating Factor (M-CSF), Tumor Necrosis Factor $\alpha$ (TNF $\alpha$ ), Interferon $\gamma$ (IFNY), Interleukin-1 (IL1) and growth factors like Transforming Growth Factor $\beta$ (TGF $\beta$ ) , Platelet Derived Growth Factor (PDGF) and Insulin-like Growth Factor-1 $\left(\right.$ IGF-1). ${ }^{25,26}$

At this stage, the initial lesion is classified as intimal thickening (fatty streak according to the previous American Heart Association (AHA) classification system introduced in 1995), ${ }^{27,28}$ according to the new classification of Virmani et al.. ${ }^{29}$ Macrophages take up modified lipids (mainly oxidized Low-Density Lipoprotein (oxLDL)) that have accumulated within the intima via scavenger receptors (CD36), progressing into foam cells. ${ }^{30}$ Intimal thickening lesions progress into intimal xanthomas, which are further enriched in foam cells and contain also granulocytes and T cells. At this stage, $v S M C$ start to migrate from the media into the intima towards the endothelium in response to growth factors, such as Fibroblast Growth Factor (FGF), Platelet-Derived Growth Factor (PDGF) and Tumor Growth Factor $\beta$ (TGF $\beta)^{31,32}$

\section{Plaque progression}

Intimal xanthomas in turn develop into pathological intimal thickenings, which contain small dispersed lipid depositions at the medial border and have a fibrous cap rich in SMC and proteoglycans overlaying the lipid rich areas. Pathological intimal thickening lesions can be regarded as the transition stage between early and advanced lesions. The more advanced lesion, or fibrous cap atheroma, harbors a true necrotic core, due to apoptosis/necrosis of foam cells or to 


\section{Chapter 1}

retention of infiltrated lipoproteins, containing cholesterol esters, free cholesterol, phospholipids and triglycerides. At this stage, the fibrous cap consists of SMC in a proteoglycan-collagen matrix and lesions possess small capillaries that most likely originate from the vasa vasorum in the adventitia. These lesions are prone to become clinically symptomatic. Fibrous cap atheromas can be divided in three groups. Fibroatheromas with intraplaque hemorrhage, in literature referred to as intraplaque hemorrhaged lesions, which contain red blood cells and fibrin in the necrotic core, carry a matured fibrous cap and have areas of calcification deep within the intima. Thin fibrous cap atheromas, have a large necrotic core containing numerous cholesterol clefts. The overlaying fibrous cap has eroded due to the release of proteases, making these lesions vulnerable for rupture. Fibrocalcific lesions are referred to as stable advanced lesions. These lesions are heavily calcified and are composed of dense collagen, and when present the necrotic core is small. Ruptured lesions originate from thin fibrous cap atheromas and have luminal thrombi. These lesions have an extensive necrotic core containing cholesterol crystals. Lesions with luminal thrombi are being classified in three groups. Ruptured lesions, which have a thin fibrous cap and of which the luminal thrombus is in direct contact with the necrotic core. Eroded lesions have a thick fibrous cap and a luminal thrombus but lack direct contact with the necrotic core. Finally, calcified nodules are lesions with luminal thrombi showing calcified nodules protruding into the lumen through a disrupted thin fibrous cap. 

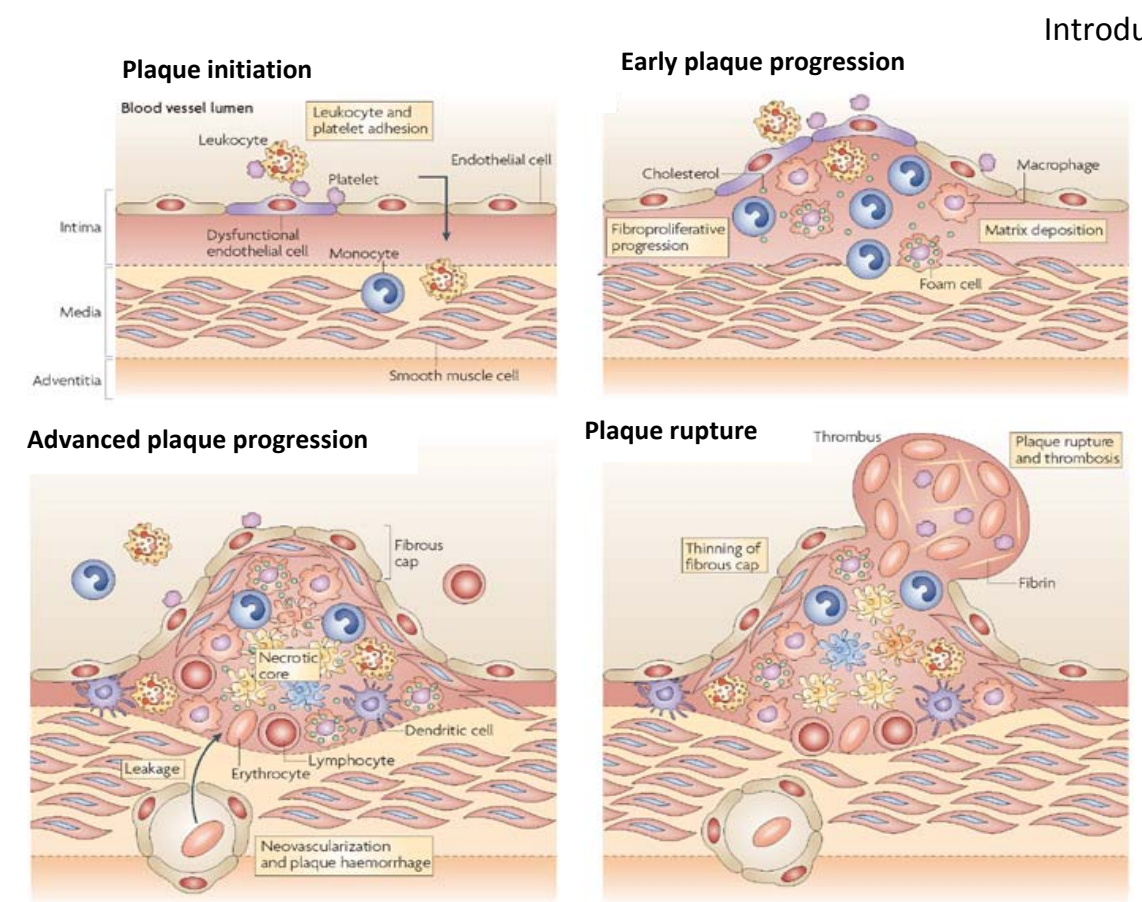

Figure 1. Development and progression of atherosclerosis. (Adapted from Weber et al. Nature Rev Immunol 2008). ${ }^{33}$

\section{The unstable plaque}

Thin fibrous cap atheromas, intraplaque hemorrhage lesions and ruptured lesions are considered "unstable" and give rise to the majority of clinical manifestations as stroke and myocardial infarction. Features that are associated with plaque instability are enlargement of necrotic core, thinning of the fibrous cap and increased leukocyte infiltration. Under normal conditions, there is a balance between the size of necrotic core and the thickness of the fibrous cap. When the necrotic core expands, the fibrous cap is under high tension and in combination with the release of matrix metalloproteinases (MMPs) the fibrous cap can rupture, leading to the release of the highly thrombogenic plaque content into circulation and consequently thrombus formation. 


\section{The role of the immune system in atherosclerosis}

As mentioned in the introduction, the immune system plays an indispensable role in the development of atherosclerosis. In the below paragraph, we will describe the role of different leukocyte subsets in atherosclerosis based on innate and adaptive immune responses. In addition, we will briefly describe the role of chemokines in atherosclerosis, which will be further elaborated in Chapter 2 .

\section{Innate immunity in atherosclerosis}

The innate immune response is the first line of defense against pathogens and is characterized by the recruitment of phagocytes (macrophages, neutrophils and dendritic cells) to the site of injury. Phagocytosis, the ingestion of particular matter into cells via the release of radicals and anti-bacterial agents resulting in degradation, is a rapid defense mechanism against invading pathogens or particles. Innate immune responses have also been shown to have major impact on the initiation but also progression of atherosclerosis. ${ }^{36}$ In this chapter, we will zoom in on the role of monocytes/macrophages, neutrophils, dendritic cells and mast cells in atherosclerosis.

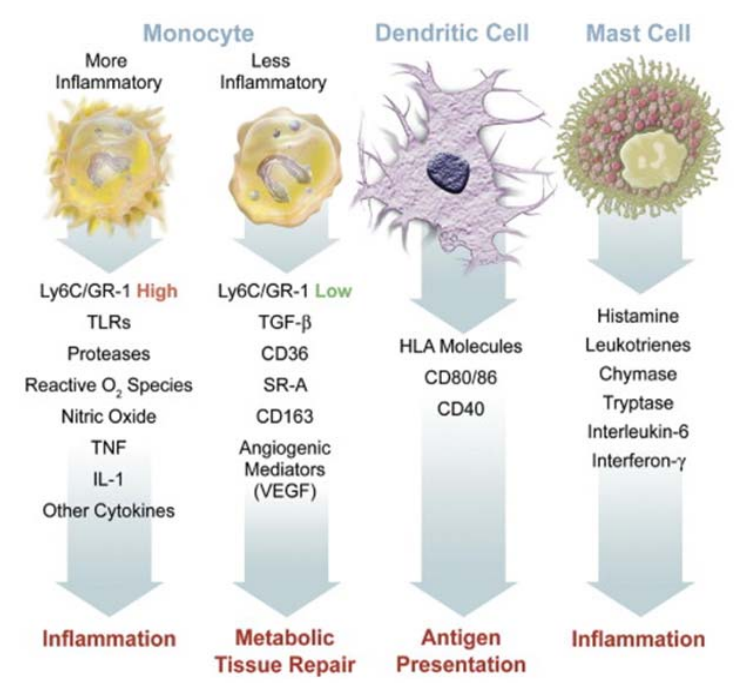

Figure 2. Immune cells involved in innate immune responses relevant to atherosclerosis. (Adapted from Libby et al. JACC 2009). ${ }^{37}$ 


\section{Monocytes/Macrophages}

Macrophages are the predominant leukocyte subset present in atherosclerotic vessels and the first cell type to be associated with atherosclerosis ${ }^{38-40}$ and since then has continued to be subject of investigation in many atherosclerosis studies. ${ }^{41-45}$ During the pathogenesis of atherosclerosis, blood monocytes are the first leukocytes being recruited to the vessel wall into the intima. Monocyte recruitment to the vessel wall has been shown to be mainly mediated by chemokines CCL2 (also known as monocyte chemotactic protein-1 (MCP-1)) ${ }^{46}$ and CCL5 (also known as RANTES), ${ }^{47}$ but also by adhesion molecules $\mathrm{P} / \mathrm{L}$ selectin, ${ }^{48,49}$ ICAM/VCAM-1 ${ }^{50}$ and PECAM-1. ${ }^{51}$ Upon arrival in the intima, monocytes differentiate into macrophages in order to take up modified lipids. The most common modified lipids in atherosclerotic lesions are oxLDLs. OxLDL is formed when LDL particles react with free radicals in circulation. When oxidized, LDL enters the intima where it will be taken up by macrophages via scavenger receptors (CD36, CD68, SRA-1, SRA-2, MARCO, SR-B1, LOX-1 and PSOX). ${ }^{52-54}$ In response, macrophages undergo activation and accumulate in the intima. Excessive uptake of oxLDL by macrophages will lead to the formation of foam cells, which will eventually become necrotic and release their lipid content into the intima, thereby contributing to necrotic core formation and consequently plaque progression and destabilization. In addition, macrophages secrete cytokines and matrix-degrading proteases causing the fibrous cap to thin. ${ }^{55}$

Monocytes are continuously being recruited to the lesion during atherogenesis and this accumulation increases proportionally with lesion size. ${ }^{43}$ An adaptive transfer study examining mouse blood monocyte homing and differentiation in vivo identified two functional subsets: the pro-inflammatory subset ( $C X_{3} \mathrm{CR} 1^{\text {low }} \mathrm{CCR} 2^{+} \mathrm{Gr}^{+} / \mathrm{Ly}_{6 \mathrm{C}} \mathrm{C}^{\mathrm{hi}}$ ) that is recruited to inflamed tissues and gives rise to inflammatory macrophages and dendritic cells, and a resident subset ( $\mathrm{CX}_{3} \mathrm{CR}_{1}{ }^{\text {hi }} \mathrm{CCR} 2^{-} \mathrm{Gr}^{-} / \mathrm{Ly}_{6 \mathrm{C}} \mathrm{C}^{\text {low }}$ ) that is characterized by $\mathrm{CX}_{3} \mathrm{CR} 1$-dependent patrolling and homing to non-inflamed tissues. ${ }^{56}$ In human, these subsets are represented by $\mathrm{CD} 14^{+} \mathrm{CD} 16^{-}$and $\mathrm{CD} 14^{\text {low }} \mathrm{CD} 16^{+}$monocytes. ${ }^{57}$ The chemokine receptors CX3CR1 in combination with CCR2 and CCR5 are involved in $\mathrm{Gr}^{+} / \mathrm{Ly}_{6 \mathrm{C}} \mathrm{hi}^{\mathrm{hi}}$ monocyte recruitment in atherosclerosis. ${ }^{58,59}$ Surprisingly, CCR5 is critical for $\mathrm{CCR}^{+}{ }^{+} \mathrm{Ly} 6 \mathrm{C}^{\text {low }} / \mathrm{Gr} 1^{-}$monocyte recruitment but not $\mathrm{CX}{ }_{3} \mathrm{CR} 1$ and CCR2 and the number of circulating $\mathrm{Gr}^{\circ} / \mathrm{Ly}_{6 \mathrm{C}} \mathrm{C}^{\text {low }}$ cells correlated with lesion size. ${ }^{44,60}$ Resident 


\section{Chapter 1}

monocytes patrol healthy tissues by crawling on the endothelium, which allows their rapid tissue invasion at sites of infection, where they will differentiate into macrophages. ${ }^{61}$ Monocytes might enter lymphatic vessels and travel to draining lymph nodes, or they might migrate across the endothelium into the lumen and enter the circulation. ${ }^{62}$

\section{Neutrophils}

Not much attention has been paid to the role of neutrophils in the pathogenesis of atherosclerosis. Despite their short half-life, neutrophils have been identified within human atherosclerotic lesions at sites of plaque rupture and erosion, ${ }^{63,64}$ suggesting that they might be involved in plaque destabilization. Moreover, neutrophil counts in blood have been associated with coronary atherosclerosis. ${ }^{65}$ Conversely, depletion of circulating neutrophils in mice has been shown to attenuate plaque formation, ${ }^{66}$ while disruption of the CXCR4/CXCL12 axis was seen to aggravate atherosclerosis in mice by increasing neutrophil influx into the plaque, possibly by disturbed granulopoiesis and increased release of neutrophils from bone marrow into the circulation.

\section{Dendritic cells}

The presence of dendritic cells (DCs) in human atherosclerotic lesions was first reported in $1995 .{ }^{67}$ There are two types of DCs: conventional DC (cDC), which are the classical antigen-presenting cells, and plasmacytoid $D C(\mathrm{pDC})$, which are poor $T$ cell activators due to low expression of major histocompatibility complex class-II (MHC-II) and co-stimulatory molecules.

\section{Conventional $D C s(C D C s)$}

CDCs are antigen-presenting cells derived from myeloid precursor cells in bone marrow and are specialized in activation of T cells. They are constitutively present at low numbers within the subendothelial space of healthy non-diseased arteries $^{67}$ but their presence increases with severity of disease. ${ }^{68}$ Within the 
lesions, $C D C$ are found to be organized in clusters with T cells, suggesting that they play an important role in modulation of T cell adaptive immunity. ${ }^{69,70}$ Monocytes that infiltrate into the intima may differentiate into DCs and contribute to an increased DC population. ${ }^{71}$ In mice, DC accumulation in the intima of atherosclerotic lesions has been shown to be mediated via VCAM1 and $\mathrm{CX}_{3} \mathrm{CR} 1{ }^{68,72}$ It is believed that within vascular lesions CDCs will encounter atherosclerosis-related antigens (oxLDL, heat-shock proteins (HSP)), become activated and mature to migrate back to lymph nodes via CCR7 in order to activate naïve T cells. ${ }^{73}$ In addition, DCs have been shown to regulate regulatory $\mathrm{T}$ cell homeostasis in mice in a CCL17 dependent manner. ${ }^{74}$ Several studies have shown the usefulness of DCs as therapy against atherosclerosis. ${ }^{75,76}$ These expanded Thelper (Th) cell clones will recognize oxLDL epitopes for instance via $T$ cell receptor (TCR), and become activated which will trigger plaque inflammation and/or, depending on the Th cell subset augment the production of anti-oxLDL antibodies by $\mathrm{B}$ cells. DCs can be rendered tolerogenic by ex vivo pulsing with IL10 and oxLDL or ApoB100. Injection of these DCs into atherosclerotic mice has been shown to induce regulatory $\mathrm{T}$ cell and inhibit effector $\mathrm{T}$ cell responses. ${ }^{76}$

\section{Plasmacytoid DCs ( $p D C s)$}

PDCs are the main type I interferon (IFN) producing cells and have a critical role not only in detection of and host defense against bacterial and viral infection, but also in sensing RNA/DNA and immune complexes. PDC are derived from both myeloid and lymphoid precursors in bone marrow and constitute only $0.1-0.5 \%$ of total leukocytes in blood and peripheral lymphoid tissue. Upon stimulation, pDC produce large amounts of type I interferons (IFN- $\alpha$, IFN- $\beta$, IFN- $\omega$, IFN- $\lambda$ ) in a tolllike receptor (TLR) 7 and 9 dependent manner. ${ }^{77}$ PDC have been shown to be present in human atherosclerotic lesions where they are believed to regulate $T$ cell function. ${ }^{78} \mathrm{CpG}$ induced IFN- $\alpha$ release by $\mathrm{pDC}$ effected a 10 -fold up regulation of tumor necrosis factor-related apoptosis-inducing ligand (TRAIL) expression on $\mathrm{CD}^{+} \mathrm{T}$ cell surface, thereby promoting apoptosis of $\mathrm{VSMC}$ and endothelial cells in vitro, processes that are generally deemed deleterious for plaque stability in vivo. However, these in vitro data leave unaddressed whether pDC indeed are instrumental in plaque instability. 


\section{Chapter 1}

Mast cells

Mast cells are large granular cells which play an important role in allergy and anaphylaxis by the rapid release of granules containing histamine and heparin. In addition, mast cells also have been shown to be involved in wound healing and in the defense against pathogens. Mast cells have been identified in the shoulder region of human atherosclerotic lesions and their presence was found to be associated with plaque progression and lipid accumulation, as they mediate degradation of high-density lipoprotein (HDL) and impair cholesterol efflux. ${ }^{79-82}$ In mouse lesions on the other hand, mast cells are mainly present in the adventitia. ${ }^{83}$ Mast cells have been associated with plaque progression and destabilization in mice by releasing amongst others proteolytic enzymes, such as chymase and tryptase, which induce SMC apoptosis and degrade matrix components, resulting in thinning of the fibrous cap and consequently increased risk for plaque rupture. $^{84-86}$ In addition, mast cells have been associated with plaque neovascularization as they have the capacity to release angiogenic factors Vascular Endothelial Growth Factor-C/D (VEGF-C, VEGF-D). ${ }^{87,88}$ Moreover, mast cells have been shown to promote atherosclerosis by the secretion of the proinflammatory cytokines II-6 and IFN- $\gamma^{83,89}$

\section{Adaptive immunity in atherosclerosis}

Upon activation of the innate immune system to clear pathogens, the adaptive immune system will be activated as well, which will induce an antigen-specific immune response. Adaptive immunity also includes a "memory" to facilitate future responses against that same specific antigen. Components of adaptive immunity are present in human atherosclerotic lesions and several studies have indicated an important role for antigen-specific adaptive immune responses in atherogenesis. $^{90}$ In this chapter, we will describe the role of lymphocytes, as central mediator in adaptive immune responses, in atherosclerosis. 


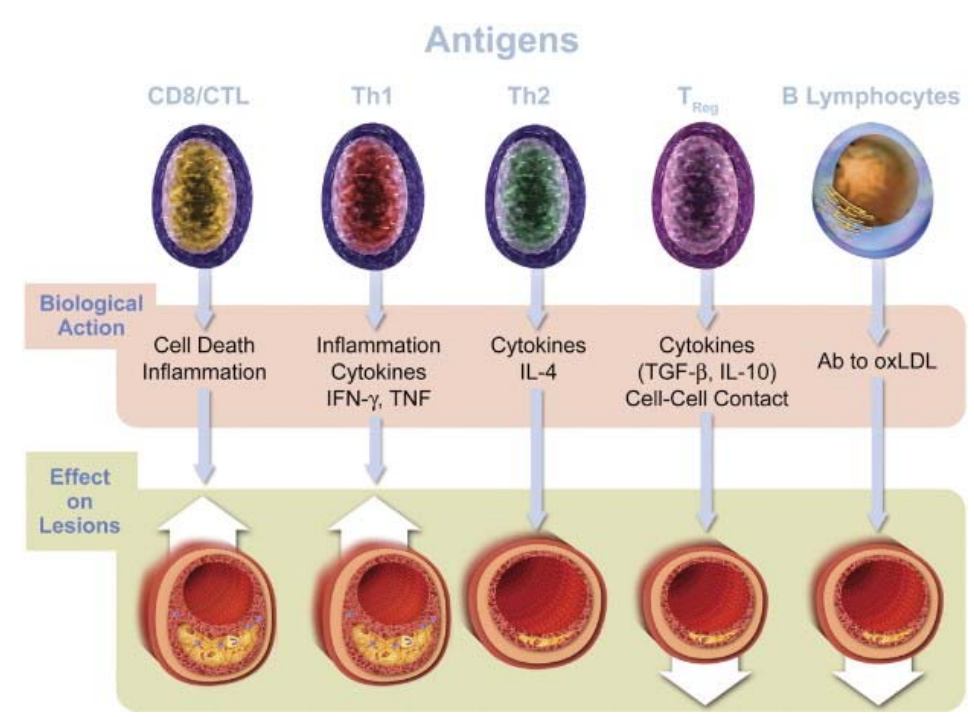

Figure 3. Immune cells involved in adaptive immunity in atherosclerosis. (Libby et al. JACC 2009). ${ }^{37}$

\section{T cells}

Substantial numbers of $\mathrm{T}$ cells have been shown to be present in atherosclerotic lesions at all stages of disease progression in mouse and man. Most of these $T$ cells are $\mathrm{CD} 4^{+}$helper $\mathrm{T}$ cells and have been found to be correlated with disease severity. ${ }^{91,92} \mathrm{CD}^{+}$helper $\mathrm{T}$ cells can be divided in two subsets based on their cytokine profile. Type 1 helper (Th1) T cells are pro-inflammatory T cells and induce cellular immunity by the production of IFN- - , TNF- $\alpha$ and IL-2; whereas type 2 helper (Th2) T cells induce an anti-inflammatory humoral response by the production of IL-4, IL-5, IL- 6 and IL-10 and the activation of B cells to produce antibodies. ${ }^{93,94}$ Under normal conditions, there is a balance between Th1/Th2, while during inflammation the response is skewed towards either Th1 or Th2. In mice, Th1 cells predominate over Th2 cells in early lesion formation. It is believed that $\mathrm{CD}^{+}$Th1 cells are activated in lymphoid tissue upon antigen presentation (oxLDL) by plaque DCs and in response migrate towards the atherosclerotic vessel wall. However, it cannot be excluded that $\mathrm{CD} 4^{+} \mathrm{Th} 1$ cells are activated within the lesions by plaque DCs, although this process may be less efficient than in a specialized environment offered by lymphoid tissue. $\mathrm{CD} 4^{+}$Th1 cells are attracted 


\section{Chapter 1}

to the plaque via DC-derived chemokines such as CCL19. ${ }^{95}$ Once inside the plaque, $\mathrm{CD}^{+}$Th1 cells produce high levels of IFN- $\gamma$ and pro-inflammatory cytokines in response to mature DCs, leading to the activation of monocytes/macrophages and DCs. ${ }^{96}$ In contrast to Th1 cells, $\mathrm{CD}^{+}$Th2 cells are barely detectable within atherosclerotic lesions. However, severe hypercholesterolemia has been shown to induce a Th1 to Th2 shift in T cells in mouse plaques which was accompanied with a loss of IFN- $\gamma$ producing Th1 cells and with the formation of IgG1 autoantibodies to oxLDL. ${ }^{97}$ Overall, Th2 cells are believed to exhibit anti-atherogenic properties. ${ }^{98}$ However, the role of Th2 cells in the development of atherosclerosis remains controversial depending on the stage of disease, site of the lesion and experimental model being used. For instance, IL-4 deficiency was shown to decrease atherosclerotic lesion formation in a site-specific manner in $\mathrm{LDLr}^{-1}$ mice, ${ }^{99}$ while in another study deficiency of IL-4 had no substantial effect on lesion development. ${ }^{100}$

In addition to Th1 and Th2, a new lineage has been identified referred to as Th17 cells (IL-17 producing T cells). Besides IL-17, Th17 cells also secrete IL-21 and IL-22. The role of Th17 cells in atherosclerosis is poorly understood and findings are contradictory. Hematopoietic deficiency of IL-17R in $\mathrm{LDLr}^{-1-}$ mice was shown to decrease plaque formation. ${ }^{101}$ However, IL-17R is also expressed by nonhematopoietic cells such as SMC and endothelial cells, which makes the relevance of these data difficult to assess. Moreover, the presence of various isoforms of IL17 (IL-17A, II-17B, IL-17C, IL-17D, II-17E and IL-17F) and its receptor (IL-17RA, IL$17 R B$ and IL-17RC) makes it difficult to interpret these findings. ${ }^{102}$

In another study, neutralization of IL-17 activity in $\mathrm{ApoE}^{-/-}$mice reduced atherosclerosis. ${ }^{103,104}$ On the other hand, there are studies that point to a protective role of IL-17 in atherosclerosis. Administration of recombinant IL-17 to $\mathrm{LDLr}^{-/}$mice was found to reduce VCAM-1 expression on endothelial cells and plaque $\mathrm{T}$ cell infiltration, thereby limiting plaque development. ${ }^{105}$ In addition, increased IL-17 expression in human carotid atherosclerotic lesions was associated with a stable plaque phenotype.

Regulatory $T$ cells (Treg) are present at very low levels within atherosclerotic lesions. There are two types of Treg cells, natural and induced Treg cells, depending on their origin. Natural Treg (nTreg), characterized by the expression of CD4, CD25 and the transcription factor forkhead box P3 (Foxp3), develop in the 
thymus and recognize specific self-antigen. They home to peripheral tissues to maintain self-tolerance thereby preventing autoimmunity through the inhibition of lymphocytes. Inducible Treg (iTreg), characterized by the expression of CD4 and IL-10, develop in the periphery during an active immune response. Inducible Treg induced by IL-10 are called Tr1 cells, whereas cells induced by TGF- $\beta$ are called Th3 cells. Both nTreg and iTreg are important to protect against atherosclerosis either by direct effects on T cells or through effects on antigen-presenting cells. ${ }^{106-}$ ${ }^{110}$ In addition, a protective role for Tr1 and Th3 cells in the development of atherosclerosis has been reported in several studies. ${ }^{111-115}$

B cells

B cells are antibody producing cells, linking innate with adaptive immunity. B cells are present in the adventitia rather than in plaques. ${ }^{116}$ There is some controversy about the role of B cells in atherosclerosis. So far, B cell activation has been associated with protection against atherosclerosis by production of natural IgM and adaptive IgG type anti-oxLDL autoantibodies. ${ }^{117-121}$ However, more recently mature B cell depletion by CD20 mAb was seen to reduce development of atherosclerosis in mice by attenuating $T$ cell activation, ${ }^{122}$ challenging the current paradigm that $B$ cells act atheroprotective.

Leukocyte recruitment to the inflammatory plaque in atherosclerosis: role of chemokines

Both the initiation and progression of an atherosclerotic plaque towards a rupture-prone unstable lesion is driven by the recruitment of specific leukocyte subsets, a process which is at least in part mediated by chemokines (also known as chemotactic cytokines). The chemokine family is organized into 2 major ( $C C$ and $\mathrm{CXC}$ ) and 2 minor $\left(\mathrm{C}\right.$ and $\mathrm{CX}_{3} \mathrm{C}$ ) families based on their $\mathrm{N}$-terminal residues. So far, about 50 different chemokines have been identified of which about 30, together with their receptors, have been reported to be present in atherosclerotic lesions. ${ }^{123}$ Chemokines signal through G-protein coupled chemokine receptors, thereby governing a variety of cell responses including cell activation and 
chemotaxis. It is believed that different sets of chemokines come into play during plaque initiation and progression, as each chemokine has its own specific function (induction of cell adhesion, activation, migration, proliferation, etc.) and acts on one or more specific cell types. Several studies have already extensively addressed the role of certain chemokines in experimental models of atherosclerosis, e.g. CCL2 (MCP-1), CCL5 (RANTES), CXCL12 (SDF-1 $\alpha$ ), CXCL10 (interferon- $\gamma$ inducible protein-10 (IP-10)), etc., some of which are already being included in clinical trials in relation to atherosclerosis. ${ }^{123,124}$ An extensive description of the chemokines that have been associated with atherosclerosis and their exact role is given in Chapter 2.

\section{The role of extra- and perivascular inflammation in atherosclerosis}

Thus far, much attention has been paid to events inside the plaque contributing to the pathogenesis of atherosclerosis. However, most of the inflammatory processes relevant to atherosclerosis may well take place outside the lesion, in the adventitia and lymphoid organs. In this chapter we will summarize the most important findings in relation to the role of extra- and perivascular inflammation in atherosclerosis.

\section{The role of the adventitia in atherosclerosis}

The adventitia is defined as the perivascular tissue (peri=surrounding the vessel wall) and consists of many inflammatory cells, blood vessels (vasa vasorum), lymphatic capillaries, fibroblasts and sensory nerves. ${ }^{125-127}$ In recent years, more and more attention is being paid to the role and importance of the adventitia in atherosclerosis development and progression. Evidence is mounting that the adventitia is actively involved in disease progression. For instance, the size and inflammatory content of the adventitia has been shown to expand with plaque progression. ${ }^{128-130}$ In addition, the expression of cytokines in the adventitia has been associated with plaque progression. ${ }^{131}$ Moreover, an induction of adventitial angiogenesis is accompanied by increased plaque development in mice. ${ }^{132}$ 
The adventitia is a unique environment in that certain leukocytes are expressed in the adventitia but are absent within the atherosclerotic lesions themselves. For instance, Tregs are rarely expressed within mouse lesions, but are expressed in the adventitia. ${ }^{133}$ The same holds for pDC (Chapter 6), B cells ${ }^{134}$ and mast cells, ${ }^{135}$ suggesting that the adventitia plays a unique role in atherosclerosis. Although compelling evidence for this notion is lacking so far, it is suggested that leukocytes not only enter the intima via the luminal side, but in addition may infiltrate into the intima from the adventitia, a process termed the "outside-in" hypothesis. ${ }^{130}$ It is not clear yet whether leukocyte migration from the adventitia into the lesion takes place via the media or via blood vessels sprouting from vasa vasorum into the lesion.

Not much is known about the role of lymphatic capillaries in the adventitia. It is believed that lymphatic vessels in the adventitia drain local inflammatory cells, most probably antigen-presenting cells, to the draining lymph node where $T$ cells are sensitized and activated. ${ }^{136} \mathrm{~A}$ positive correlation has been shown between the number of lymphatic capillaries in the adventitia and progression of disease. ${ }^{137,138}$ Moreover, inflammatory cells within the adventitia such as macrophages but also SMC are able to release lymphangiogenic factors (VEGF-C and PDGF-B), thereby promoting adventitial lymphangiogenesis. ${ }^{139,140}$ In addition, lymphatic capillaries could also directly guide inflammatory cells to efferent lymphatic vessels in order to dampen inflammation (Chapter 7).

\section{The role of lymphoid organs in atherosclerosis}

During atherosclerosis, the immune system is activated by specific atherosclerosis-associated antigens. Most studies so far have addressed inflammatory processes within the lesions, however lymphoid organs play an important role in regulating immune responses. The spleen, the primary lymphoid organ and a major reservoir for monocytes, plays an important role in immune function by trapping and processing antigens and by activating lymphocytes. Interestingly, splenectomy dramatically accelerates atherosclerosis development in $\mathrm{ApoE}^{-1-}$ mice. ${ }^{141}$ In addition, transfer of $\mathrm{B}$ and $\mathrm{T}$ cells was shown to rescue the effect on atherosclerosis in these mice. These results support previous findings in which splenectomy in humans and rabbits led to enhanced lesion 
development. ${ }^{142,143}$ The increase in lesion development in splenectomized animals might also be explained by changes in lipid metabolism in the absence of the spleen. ${ }^{144}$ Altogether, these data point to an atheroprotective role of the spleen, although the underlying mechanism remains elusive.

Lymph nodes, the secondary lymphoid organs, are the major site for antigenpresentation and T cell activation, but also for antibody production by B cells. As has been mentioned previously, plaque dendritic cells that have encountered atherosclerosis-specific antigens (oxLDL, HSP) are believed to migrate to the draining lymph node where they will present antigens to $T$ cells. $T$ cells are activated and in response migrate to the plaque to regulate inflammation. In addition, lymph nodes can also drain cytokines from the atherosclerotic vessel wall in order to dampen inflammation.

\section{The role of systemic infection in atherosclerosis}

Acute systemic infections may affect atherosclerotic disease progression. A relationship between these two phenomena was first proposed in the beginning of the $20^{\text {th }}$ century. ${ }^{145}$ Several infectious agents have already been linked to atherosclerosis, including Chlamydia pneumonia, Phorphyromonas gingivalis, enterovirus, and, more recently, influenza virus. ${ }^{146-148}$ It is hypothesized that acute infections may trigger destabilization and possibly rupture of vulnerable lesions by acutely increasing inflammation through release of inflammatory cytokines and MMPs, antigenic-cross-reactivity, etc.. ${ }^{149}$ Interestingly, atherosclerotic patients diagnosed with acute systemic infection, were shown to have increased plaque macrophage and dendritic cell content. In addition, T cell content in the adventitia was increased as well. Moreover, bacteria and their release of lipopolysaccharide (LPS), peptidoglycans or exotoxins, can induce vascular endothelial dysfunction and monocyte infiltration into the vessel wall, resulting in increased plaque development and/or progression. ${ }^{150}$ In addition to acute infections, also chronic infections, such as cytomegalovirus and Helicobacter pylori, may contribute to atherogenesis, as the presence of chronic infections in humans has been shown to increase the risk for atherosclerosis development. ${ }^{151}$ 


\section{Study aims}

It is increasingly appreciated that peripheral inflammation can impact local processes in the plaque. A better understanding of extra- and perivascular events during atherosclerosis development and progression will enable us to develop more effective and personalized therapy. The aim of this study was to explore the impact of peripheral inflammation on local processes within the plaque. To this end, we investigated effects of chemokine deficiency or leukocyte depletion on inflammatory processes in the adventitia, peripheral lymph nodes and bone marrow in relation to atherosclerosis.

\section{Thesis outline and hypothesis}

\section{Part I: Chemokines and extravascular immunity in the context of atherosclerosis}

In Chapter 2, the potential of chemokines as biomarker and/or therapeutic target in atherosclerotic plaque destabilization and rupture and outcome of current chemokine targeted clinical trials is reviewed.

Chapter 3, addresses the role of one of these chemokines, CXCL12, and its receptor CXCR4, in neutrophil senescence in the context of atherosclerosis. CXCR4 blockage has been shown to aggravate atherosclerosis in part by releasing neutrophils from the bone marrow. ${ }^{66}$ As CXCR4 is also important for guiding senescent neutrophils back towards bone marrow, we hypothesized that blockage of the CXCL12/CXCR4 axis might also lead to accumulation of activated senescent neutrophils in the circulation, which may have consequences for lesion progression. Via functional inhibition of CXCR4 in vivo, either via a lentiviral construct encoding a CXCR4 degrakine or via pharmacological intervention, we were able to study the effects of neutrophil senescence on atherosclerosis progression.

In Chapter 4, the role of another homeostatic chemokine, CXCL13, and its receptor, CXCR5, in cardiovascular disease has been addressed in patients. CXCL13 is constitutively expressed in stromal tissue, including the plaque adventitia and is implicated in guidance of $B$ and $T$ cells in the lymphoid compartment. We were able to demonstrate that patients with angina pectoris and carotid artery 
atherosclerosis had increased CXCL13 plasma levels, making this chemokine a potential biomarker for disease progression. To study whether CXCL13 and CXCR5 expression correlates with plaque progression, we have mapped CXCL13 and CXCR5 expression in human atherosclerotic lesions at several stages of disease progression. Surprisingly, CXCL13 was seen to be expressed by plaque macrophages, both in early and advanced atherosclerotic lesions. We addressed the role of CXCL13 expression by plaque macrophages in relation to atherosclerosis in vitro. This study was conducted in close collaboration with Prof. Aukrust's lab.

While CXCL13 being expressed in the adventitia and also by plaque macrophages, we set out in Chapter $\mathbf{5}$ to investigate the causal involvement of CXCL13 expression in atherosclerosis. Hereto, we reconstituted irradiated $\mathrm{LDLr}^{-1}$ mice with bone marrow deficient in CXCL13 or CXCR5 and analyzed effects of hematopoietic CXCL13 and CXCR5 deficiency on atherosclerosis development as well as on perivascular immunity.

\section{Part II: Peri- and extravascular immunity and atherosclerosis}

The second part of this thesis will focus more on peri- and extravascular inflammation.

In Chapter 6 we have addressed the role of plasmacytoid dendritic cells (pDC) in atherosclerosis. PDC were found to be expressed in human atherosclerotic lesions ${ }^{78}$ but their role in atherosclerosis remains unknown. We were able to study effects of pDC depletion using a specific depletion antibody, 120G8, on atherosclerosis development and progression in $\mathrm{LDLr}^{-/-}$mice. This study is the first to identify protective activity of $\mathrm{pDC}$ in atherosclerosis and we were able to attribute this effect to their $T$ cell suppressive effect.

In Chapter $\mathbf{7}$ we have explored the impact of lymphatic capillaries in the adventitia on plaque development and inflammation. We mapped the expression of lymphatic capillaries in the adventitia at several stages of disease progression in mouse atherosclerotic vessels, showing progressive expansion of perivascular lymph vessels during atherosclerosis, corresponding with findings in humans. In order to investigate local fluxes of inflammatory cells between the adventitia and 
draining lymph nodes, we performed a lymph node dissection study. Moreover, we examined CXCR3 dependent $\mathrm{T}$ cell migration towards the adventitia.

Finally, Chapter 8 provides a summary and discussion of the most relevant results of this thesis and discusses future perspectives. 


\section{References}

1. Libby P. Molecular bases of the acute coronary syndromes. Circulation. 1995;91:2844- 2850.

2. Lee RT and Libby P. The unstable atheroma. Arterioscl Thromb Vasc Biol. 1997;17:1859-1867.

3. Stary HC. Macrophage foam cells in the coronary artery intima of human infants. Ann N Y Acad Sci. 1985;454:5-8.

4. Stary HC. Evolution and progression of atherosclerotic lesions in coronary arteries of children and young adults. Arteriosclerosis. 1989;9:119-131.

5. Caro CG, Fitz-Gerald JM, Schroter RC. Arterial wall shear and distribution of early atheroma in man. Nature. 1969;223:1159-1160.

6. Zarins CK, Giddens DP, Bharadvaj BK, Sottiurai VS, Mabon RF, Glagov S. Carotid bifurcation atherosclerosis. Quantitative correlation of plaque localization with flow velocity profiles and wall shear stress. Circ Res. 1983;53:502-514.

7. VanderLaan PA, Reardon CA, Getz GS. Site specificity of atherosclerosis: site-selective responses to atherosclerotic modulators. Arterioscler Thromb Vasc Biol. 2004;24:1222.

8. Glasser SP, Selwyn AP, Ganz P. Atherosclerosis: risk factors and the vascular endothelium. Am Heart J. 1996;131:379-384.

9. Kritchevsky D. Diet and atherosclerosis. Am Heart J. 1999;138:S426-429.

10. Everson-Rose SA, Lewis TT. Psychosocial factors and cardiovascular diseases. Annu Rev Public Health. 2005;26:469-500.

11. Hauss $\mathrm{WH}$, Bauch $\mathrm{HJ}$, Schulte $\mathrm{H}$. Adrenaline and noradrenaline as possible chemical mediators in the pathogenesis of arteriosclerosis. Ann N Y Acad Sci. 1990;598:91101.

12. Kamphuis $\mathrm{MH}$, Geerlings MI, Tijhuis MA, Giampaoli S, Nissinen A, Grobbee DE, Kromhout D. Physical inactivity, depression, and risk of cardiovascular mortality. Med Sci Sports Exerc. 2007;39:1693-1699.

13. Kadoglou NP, Iliadis F, Liapis CD. Exercise and carotid atherosclerosis. Eur J Vasc Endovasc Surg. 2008;35:264-272.

14. Steiner G. Diabetes and atherosclerosis: an overview. Diabetes. 1981;30:1-7.

15. Criqui $\mathrm{MH}$. Epidemiology of atherosclerosis: an updated overview. Am J Cardiol. 1986; 57:18C-23C.

16. Ordovas JM. Genetic links between diabetes mellitus and coronary atherosclerosis. Curr Atheroscler Rep. 2007;9:204-210.

17. Shively CA, Clarkson TB. Regional obesity and coronary artery atherosclerosis in females: a non-human primate model. Acta Med Scand Suppl. 1988;723:71-78. 
18. Egan BM, Bassett DR, Block WD. Comparative effects of overweight on cardiovascular risk in younger versus older men. Am J Cardiol. 1991;67:248-252.

19. Ross R, Glomset JA. Atherosclerosis and the arterial smooth muscle cell: Proliferation of smooth muscle is a key event in the genesis of the lesions of atherosclerosis. Science. 1973;180:1332-1339.

20. Ross R, Glomset J, Harker L. Response to injury and atherogenesis. Am J Pathol. 1977;86:675-684.

21. Scott RF, Kim DN, Schmee J, Thomas WA. Atherosclerotic lesions in coronary arteries of hyperlipidemic swine. Part 2. Endothelial cell kinetics and leukocyte adherence associated with early lesions. Atherosclerosis. 1986;62:1-10.

22. Bylock AL, Lewis JC. Visualization of monocyte recruitment into atherosclerotic arteries using fluorescent labeling. Atherosclerosis. 1988;71:17-25.

23. Watanabe T, Fan J. Atherosclerosis and inflammation mononuclear cell recruitment and adhesions molecules with reference to the implication of ICAM-1/LFA-1 pathway in atherogenesis. Int J Cardiol. 1998;66(Suppl 1):S45-53.

24. Cybulsky MI, Gimbrone MA. Endothelial expression of a mononuclear leukocyte adhesion molecule during atherogenesis. Science. 1991;251:788-791.

25. Ross R, Raines E, Bowen-Pope D. Growth factors from platelets, monocytes and endothelium: their role in cell proliferation. Ann N Y Acad Sci. 1982;397:18-24.

26. Libby $\mathrm{P}$, Galis ZS. Cytokines regulate genes involved in atherogenesis. Ann $N$ Y Acad Sci. 1995;748:158-168.

27. Stary HC, Chandler AB, Glagov S, Guyton JR, Insull W Jr, Rosenfeld ME, Schaffer SA, Schwartz CJ, Wagner WD, Wissler RW. A definition of initial, fatty streak, and intermediate lesions of atherosclerosis. A report from the Committee on Vascular Lesions of the Council on Arteriosclerosis, American Heart Association. Circulation. 1994;89:2462-2478.

28. Stary HC, Chandler AB, Dinsmore RE, Fuster V, Glagov S, Insull W Jr, Rosenfeld ME, Schwartz CJ, Wagner WD, Wissler RW. A definition of advanced types of atherosclerotic lesions and a histological classification of atherosclerosis. A report from the Committee on Vascular lesions of the Council on Arteriosclerosis, American Heart Association. Circulation. 1995;e92:1355-1374.

29. Virmani R, Kolodgie FD, Burke AP, Farb A, Schwartz SM, Lessons from sudden coronary death: a comprehensive morphological classification scheme for atherosclerotic lesions. Arterioscl Thromb Vasc Biol. 2000;20:1262-1275.

30. Nicholson AC, Frieda S, Pearce A, Silverstein RL. Oxidized LDL binds to CD36 on human monocyte-derived macrophages and transfected cell lines. Evidence implicating the lipid moiety of the lipoprotein as the binding site. Arterioscler Thromb Vasc Biol. 1995;15:269-275. 
31. Ferns GA, Raines EW, Sprugel KH, Motani AS, Reidy MA, Ross R. Science. 1991;253: 1129-1132.

32. Jovinge $S$, Hultgårdh Nilsson A, Regnström J, Nilsson J. Tumor necrosis factor-alpha activates smooth muscle cell migration in culture and is expressed in the ballooninjured rat aorta. Arterioscler Thromb Vasc Biol. 1997;17:490-497.

33. Weber C, Zernecke A, Libby P. The multifaceted contributions of leukocyte subsets to atherosclerosis: lessons from mouse models. Nat Rev Immunol. 2008;8:802-815.

34. Johnson $\mathrm{JL}$, Jackson CL. Atherosclerotic plaque rupture in the apolipoprotein $\mathrm{E}$ knockout mouse. Atherosclerosis. 2001;154:399-406.

35. Calara F, Silvestre M, Casanada F, Yuan N, Napoli C, Palinski W. Spontaneous plaque rupture and secondary thrombosis in apolipoprotein E-deficient and LDL receptor deficient mice. J Pathol. 2001;195:257-263.

36. Lundberg AM, Hansson GK. Innate immune signals in atherosclerosis. Clin Immunol. 2010;134:5-24.

37. Libby $\mathrm{P}$, Ridker PM, Hansson GK; Leducq Transatlantic Network on Atherothrombosis. J Am Coll Cardiol. 2009;54:2129-2138. Review.

38. Gerrity RG, Naito HK, Richardson M, Schwartz CJ. Dietary induced atherogenesis in swine. Morphology of the intima in prelesion stages. Am J Pathol. 1979;95:775-792.

39. Watanabe T, Hirata M, Yoshikawa Y, Nagafuchi Y, Toyoshima H, Watanabe T. Role of macrophages in atherosclerosis. Sequential observations of cholesterol-induced rabbit aortic lesion by the immunoperoxidase technique using monoclonal antimacrophage antibody. Lab Invest. 1985;53:80-90.

40. Gown AM, Tsukada T, Ross R. Human atherosclerosis. II. Immunocytochemical analysis of the cellular composition of human atherosclerotic lesions. Am J Pathol. 1986;125:191-207.

41. Rosenfeld ME, Ross R. Macrophage and smooth muscle cell proliferation in atherosclerotic lesions of WHHL and comparably hypercholesterolemic fat-fed rabbits. Atherosclerosis. 1990;10:680-687.

42. Garner B, Baoutina A, Dean RT, . Regulation of serum-induced lipid accumulation in human monocyte-derived macrophages by interferon-gamma. Correlations with apolipoprotein $\mathrm{E}$ production, lipoprotein lipase activity and LDL receptor-related protein expression. Atherosclerosis. 1997;128:47-58.

43. Swirski FK, Pittet MJ, Kircher MF, Aikawa E, Jaffer FA, Libby P, Weissleder R. Monocyte accumulation in mouse atherogenesis is progressive and proportional to extent of disease. Proc Natl Acad Sci. 2006;103:10340-10345.

44. Combadiére $C$, Potteaux $S$, Rodero $M$, Simon T, Pezard A, Esposito B, Merval R, Proudfoot A, Tedgui A, Mallat Z. Combined inhibition of CCL2, CX3CR1, and CCR5 
abrogates Ly6C(hi) and Ly6C(lo) monocytosis and almost abolishes atherosclerosis in hypercholesterolemic mice. Circulation. 2008;117:1649-1657.

45. Woollard KJ, Geissmann F. Monocytes in atherosclerosis: subsets and functions. Nat Rev Cardiol. 2010;7:77-86.

46. Ylä-Herttuala S, Lipton BA, Rosenfeld ME, Särkioja T, Yoshimura T, Leonard EJ, Witztum JL, Steinberg D. Expression of monocyte chemoattractant protein 1 in macrophage-rich areas of human and rabbit atherosclerotic lesions. Proc Natl Acad Sci U S A. 1991;88:5252-5256.

47. Schober A, Manka D, von Hundelshausen P, Huo Y, Hanrath P, Sarembock IJ, Ley K, Weber $C$. Deposition of platelet RANTES triggering monocyte recruitment requires $\mathrm{P}$ selectin and is involved in neointima formation after arterial injury. Circulation. 2002;106:1523-1529.

48. Giuffré L, Cordey AS, Monai N, Tardy Y, Schapira M, Spertini O. Monocyte adhesion to activated aortic endothelium: role of L-selectin and heparin sulfate proteoglycans. J Cell Biol. 1997;136:945-956.

49. Johnson RC, Chapman SM, Dong ZM, Ordovas JM, Mayadas TN, Herz J, Hynes RO, Schaefer EJ, Wagner DD. Absence of P-selectin delays fatty streak formation in mice. J Clin Invest. 1997;99:1037-1043.

50. Calderon TM, Factor SM, Hatcher VB, Berliner JA, Berman JW. An endothelial cell adhesion protein for monocytes recognized by monoclonal antibody IG9. Expression in vivo in inflamed human vessels and atherosclerotic human and Watanabe rabbit vessels. Lab Invest. 1994;70-836:849.

51. Rattan V, Sultana C, Shen Y, Kalra VK. Oxidant stress-induced transendothelial migration of monocytes is linked to phosphorylation of PECAM-1. Am J Physiol. 1997,273:E453-461.

52. Endemann G, Stanton LW, Madden KS, Bryant CM, White RT, Protter AA. CD36 is a receptor for oxidized low density lipoprotein. J Biol Chem. 1993;268:11811-11816.

53. Sakai M, Miyazaki A, Hakamata H, Kodama T, Suzuki H, Kobori S, Shichiri M, Horiuch S. The scavenger receptor serves as a route for internalization of lysophosphatidylcholine in oxidized low density lipoprotein-induced macrophage proliferation. J Biol Chem. 1996;271:27346-27352.

54. Greaves Dr, Gordon S. The macrophage scavenger receptor at 30 years of age: current knowledge and future challenges. J Lipid Res. 2009;50:S282-S286.

55. Newby AC. Dual role of matrix metalloproteinases (matrixins) in intimal thickening and atherosclerotic plaque rupture. Physiol Rev. 2005;85:1-31.

56. Geissmann F, Jung S, Littman DR. Blood monocytes consist of two principal subsets with distinct migratory properties. Immunity. 2003;19:71-82. 
57. Weber C, Belge KU, von Hundelshausen P, Draude G, Steppich B, Mack M, Frankenberger M, Weber KS, Ziegler-Heitbrock HW. Differential chemokine receptor expression and function in human monocyte subpopulations. J Leukoc Biol. 2000;67:699-704.

58. Lesnik P, Haskell CA, Charo IF. Decreased atherosclerosis in CX3CR1-/- mice reveals a role for fractalkine in atherogenesis. J Clin Invest. 2003;111:333-340.

59. Saederup N, Chan L, Lira SA, Charo IF. Fractalkine deficiency markedly reduces macrophage accumulation and atherosclerotic lesion formation in CCR2-/- mice: evidence for independent chemokine functions in atherogenesis. Circulation. 2008;117:1642-1648.

60. Tacke F, Alvarez D, Kaplan TJ, Jakubzick C, Spanbroek R, Llodra J, G arin A, Liu J, Mack M, van Rooijen N, Lira SA, Habenicht AJ, Randolph GJ. Monocyte subsets differentially employ CCR2, CCR5 and CX3CR1 to accumulate within atherosclerotic plaques. J Clin Invest. 2007;117:185-194.

61. Auffray C, Fogg D, Garfa M, Elain G, Join-Lambert O, Kayal S, Sarnacki S, Cumano A, Lauvau G, Geissmann F. Monitoring of blood vessels and tissues by a population of monocytes with patrolling behavior. Science. 2007;317:666-670.

62. Randolph GJ. Emigration of monocyte-derived cells to lymph nodes during resolution of inflammation and its failure in atherosclerosis. Curr Opin Lipidol. 2008;19:462-468.

63. Dinerman JL, Mehta JL, Saldeen TG, Emerson S, Wallin R, Davda R, Davidson A. Increased neutrophil elastase release in unstable angina pectoris and acute myocardial infarction. J. Am Coll Cardiol. 1990;15:1559-1563.

64. Naruko T, Ueda M, Haze K, van der Wal AC, van der Loos CM, Ithoh A, Komatsu R, Ikura Y, Ogami M, Shimada Y, Ehara S, Yoshiyama M, Takeuchi K, Yoshikawa J, Becker AE. Neutrophil infiltration of culprit lesions in acute coronary syndromes. Circulation. 2002;106:2894-2900.

65. Kawaguchi H, Mori T, Kawano T, Kono S, Sasaki J, Arakawa K. Band neutrophil count and the presence and severity of coronary atherosclerosis. Am Heart J. 1996;132:912.

66. Zernecke A, Bot I, Djalali-Talab Y, Shagdarsuren E, Bidzhekov K, Meiler S, Krohn A, Sperandio M, Soehnlein O, Bornemann J, Tacke F, Biessen EA, Weber C. Protective role of CXC receptor 4/CXC ligand 12 unveils the importance of neutrophils in atherosclerosis. Circ Res. 2008;102:209-217.

67. Bobryshev $\mathrm{YV}$, Lord RS. Ultrastructural recognition of cells with dendritic cell morphology in human aortic intima. Contacting interactions of vascular dendritic cells in athero-resistant and athero-prone areas of the normal aorta. Arch Histol Cytol. 1995;58:307-322. 
68. Liu P, Yu Y-RA, Spencer JA, Johnson AE, Vallanat CT, Fong AM, Patterson C, Patel DD. $\mathrm{CX}_{3} \mathrm{CR} 1$ deficiency impairs dendritic cell accumulation in arterial intima and reduces atherosclerotic burden. Arterioscler Thromb Vasc Biol. 2008;28:243-250.

69. Mallat Z, Taleb S, Ait-Oufella H, Tedgui A. The role of adaptive T cell immunity in atherosclerosis. J Lipid Res. 2009;50:S364-369.

70. Weber C, Meiler S, Döring Y, Koch M, Drechsler M, Megens R, Rowinska Z, Bidzhekov K, Fecher C, Ribechini E, van Zandvoort M, Binder CJ, Jelinek I, Hristov M, Boon L, Jung S, Korn T, Lutz MB, Förster I, Zenke M, Hieronymus T, Junt T, Zernecke A. CCL17expressing dendritic cells drive atherosclerosis by restraining regulatory $\mathrm{T}$ cell homeostasis in mice. J Clin Invest. 2011;121:2898-2910.

71. Randolph G, Beaulieu S, Lebecque S, Steinman RM, Muller WA. Differentiation of monocytes into dendritic cells in a model of transendothelial trafficking. Science. 1998;282:480-483.

72. Jongstra-Bilen J, Haidari M, Zhu SN, Chen M, Guha D, Cybulsky MI. Low-grade chronic inflammation in regions of the normal mouse arterial intima predisposed to atherosclerosis. J Exp Med. 2006;203:2073-2083.

73. Luchtefeld M, Grothusen C, Gagalick A, Jagavelu K, Schuett H, Tietge UJ, Pabst O, Grote K, Drexler H, Förster R, Schieffer B. Chemokine receptor 7 knockout attenuates atherosclerotic plaque development. Circulation. 2010;122:1621-1628.

74. Weber C, Meiler S, Döring Y, Koch M, Drechsler M, Megens RT, Rowinska Z, Bidzhekov K, Fecher C, Ribechini E, van Zandvoort MA, Binder CJ, Jelinek I, Hristov M, Boon L, Jung S, Korn T, Lutz MB, Förster I, Zenke M, Hieronymus T, Junt T, Zernecke A. J Clin Invest. 2011;121:2898-2910.

75. Habets KL, van Puijvelde GH, van Duivenvoorde LM, van Wanrooij EJ, de Vos P. Tervaert JW, van Berkel TJ, Toes RE, Kuiper J. Vaccination using oxidized low-density lipoprotein-pulsed dendritic cells reduces atherosclerosis in LDL receptor-deficient mice. Cardiovasc Res. 2010;85:622-630.

76. Hermansson A, Johansson DK, Ketelhuth DF, Zhou X, Hansson GK. Immunotherapy with tolerogenic apolipoprotein B-100-loaded dendritic cells attenuates atherosclerosis in hypercholesterolemic mice. Circulation. 2011;123:1083-1091.

77. Kadowaki N, Ho S, Antonenko S, Malefyt R, Kastelein R, Bazan F, Liu Y. Subsets of human dendritic cell precursors express different toll-like receptors and respond to different microbial antigens. J Exp Med. 2001;194:863-869.

78. Niessner A, Sato K, Chaikof EL, Colmegna I, Goronzy JJ, Weyand CM. Pathogen sensing plasmacytoid dendritic cells stimulate cytotoxic $T$ cell function in the atherosclerotic plaque through interferon- $\alpha$. Circulation. 2006;114:2482-2489. 


\section{Chapter 1}

79. Jeziorska M, McCollum C, Woolley DE. Mast cell distribution, activation, and phenotype in atherosclerotic lesions of human carotid arteries. I Pathol. 1997;182:115-122.

80. Kaartinen M, Penntilä A, Kovanen PT. Accumulation of activated mast cells in the shoulder region of human coronary atheroma, the prediction site of atheromatous rupture. Circulation. 1994;90:1669-1678.

81. Kovanen PT, Kaartinen M, Paavonen T. Infiltrates of activated mast cells at the site of coronary atheromatous erosion or rupture in myocardial infarction. Circulation. 1994;90:1669-1678.

82. Lee-Rueckert M, Kovanen PT. Mast cell proteases: physiological tools to study functional significance of high density lipoproteins in the initiation of reverse cholesterol transport. Atherosclerosis. 2006;189:8-18.

83. Bot I, de Jager SC, Zernecke A, Lindstedt KA, Van Berckel TJ, Weber C, Biessen EA. Perivascular mast cells promote atherogenesis and induce plaque destabilization in apolipoprotein E-deficient mice. Circulation. 2007;115:2516-2525.

84. Leskinen MJ, Wang Y, Leszczynski D, Lindstedt KA, Kovanen PT. Mast cell chymase induces apoptosis of vascular smooth muscle cells. Arterioscler Thromb Vasc Biol. 2001;21:516-522.

85. Leskinen MJ, Kovanen PT, Lindstedt KA. Regulation of smooth muscle cell growth, function and death in vitro by activated mast cells: a potential mechanism for the weakening and rupture of atherosclerotic plaques. Biochem Pharmacol. 2003;66:1493-1498.

86. Bot I, Bot $M$, van Heiningen $\mathrm{SH}$, van Santbrink PJ, Lankhuizen IM, Hartman P, Gruener $\mathrm{S}$, Hilpert $\mathrm{H}$, van Berckel TJ, Fingerle J, Biessen EA. Mast cell chymase inhibition reduces atherosclerotic plaque progression and improves plaque stability in ApoE-/mice. Cardiovasc Res. 2011;89:244-252.

87. Kaartinen M, Penttila A, Kovanen PT. Mast cells accompany microvessels in human coronary atheromas: implications for intimal neovascularization and hemorrhage. Atherosclerosis. 1996;123:123-131.

88. Lappalainen $H$, Laine $P$, Pentikainen MO, Sajantila A, Kovanen PT. Mast cells in neovascularized human coronary plaques store and secrete basic fibroblast growth factor, a potent angiogenic mediator. Arterioscler Thromb Vasc Biol. 2004;24:18801885.

89. Sun J, Sukhova GK, Wolters PJ, Yang M, Kitamoto S, Libby P, MacFarlane LA, MallenSt Clair J, Shu GP. Mast cells promote atherosclerosis by releasing proinflammatory cytokines. Nat Med. 2007;13:719-724.

90. Andersson J, Libby P. Hansson GK. Adaptive immunity and atherosclerosis. Clin Immunol. 2010;134:33-46. 
91. Mallat Z, Taleb S, Ait-Oufella H, Tedgui A. The role of adaptive T cell immunity in atherosclerosis. J Lipid Res. 2009;50 Suppl:S364-369. Review.

92. Xinghua Z, Nicoletti A, Elhage R, Hansson GK. Transfer of CD4+ T cells aggravates atherosclerosis in immunodeficient apolipoprotein $\mathrm{E}$ knockout mice. Circulation. 2000;102:2919.

93. Garside $P$, Mowat AM. Polarization of Th-cell responses: a phylogenetic consequence of nonspecific immune defense? Immunol Today. 1995;16:220-223.

94. Del Prete G. The concept of type-1 and type-2 helper T cells and their cytokines in humans. Int Rev Immunol. 1998;16:427-455.

95. Damås JK, Smith C, Øie E, Fevang B, Halvorsen B, Waehre T, Boullier A, Breland U, Yndestad A, Ovchinnikova O, Robertson AK, Sandberg WJ, Kjekshus J, Taskén K, Frøland SS, Gullestad L, Hansson GK, Quehenberger O, Aukrust P. Arterioscler Thromb Vasc Biol. 2007;27:614-620.

96. Tedgui A, Mallat Z. Cytokines in atherosclerosis: pathogenic and regulatory pathways. Physiol Rev. 2006;86:515-581.

97. Zhou X, Paulsson G, Stemme S, Hansson GK. Hypercholesterolemia is associated with a T helper (Th) 1/Th2 switch of the autoimmune response in atherosclerotic Apo Eknockout mice. J Clin Invest. 1998;101:1717-1725.

98. Schulte S, Sukhova GK, Libby P. Genetically programmed biases in Th1 and Th2 immune responses modulate atherogenesis. Am J Pathol. 2008;172:1500-1508.

99. King VL, Szilvassy SJ, Daugherty A. Interleukin-4 deficiency decreases atherosclerotic lesion formation in a site-specific manner in female $\mathrm{LDLr}^{-/-}$mice. Arterioscler Thromb Vasc Biol. 2002;22:456-461.

100. King VL, Cassis LA, Daugherty A. Interleukin-4 does not influence development of hypercholesterolemia or angiotensin II-induced atherosclerotic lesions in mice. Am J Pathol. 2007;171:2040-2047.

101. Van Es T, van Puijvelde GH, Ramos OH, Segers FM, Joosten LA, van den Berg WB, Michon IM, de Vos P, van Berkel TJ, Kuiper J. Attenuated atherosclerosis upon IL-17R signaling disruption in LDLr deficient mice. Biochem Biophys Res Commun. 2009;288:261-265.

102. Colls JK, Linden A. Interleukin-17 family members and inflammation. Immunity. 2004;21:467-476.

103. Erbel C, Chen L, Bea F, Wangler S, Celik S, Lasitschka F, Wang Y, Bockler D, Katus HA, Dengler TJ. Inhibition of IL-17A attenuates atherosclerotic lesion development in ApoE-deficient mice. J Immunol. 2009;183:8167-8175.

104. Smith E, Prasad KM, Butcher M, Dobrian A, Kolls JK, Ley K, Galkina E. Blockade of interleukin-17A results in reduced atherosclerosis in apolipoprotein E-deficient mice. Circulation. 2010;121:1746-1755. 
105. Taleb S, Romain M, Ramkhelawon B, Uyttenhove C, Pasterkamp G, Herbin O, Esposito B, Perez N, Yasukawa H, Van Snick J, Yoshimura A, Tedgui A, Mallat Z. Loss of SOCS3 expression in $T$ cells reveals a regulatory role for interleukin-17 in atherosclerosis. J Exp Med. 2009;206:2067-2077.

106. Ait-Oufella H, Salomon BL, Potteaux S, Robertson AK, Gourdy P, Zoll J, Merval R, Esposito B, Cohen JL, Fisson S, Flavell RA, Hansson GK, Klatzmann D, Tedgui A, Mallat Z. Natural regulatory $T$ cells control the development of atherosclerosis in mice. Nat Med. 2006;12:178-180.

107. Gotsman I, Gupta R, Lichtman AH. The influence of the regulatory T lymphocytes on atherosclerosis. Arterioscler Thromb Vasc Biol. 2007;27:2493-2495.

108. Mor A, Planer D, Luboshits G, Afek A, Metzger S, Chajek-Shaul T, Keren G, George J. Role of naturally occurring $C D 4+C D 25+$ regulatory $T$ cells in experimental atherosclerosis. Arterioscler Thromb Vasc Biol. 2007;27:893-900.

109. Sasaki N, Yamashita T, Takeda M, Shinohara M, Nakajima K, Tawa H, Usui T, Hirata K. Oral anti-CD3 antibody treatment induces regulatory $\mathrm{T}$ cells and inhibits the development of atherosclerosis in mice. Circulation. 2009;120:1996-2005.

110. van Es T, van Puijvelde GH, Foks AC, Habets KL, Bot I, Gilboa E, van Berkel TJ, Kuiper J. Vaccination against Foxp3(+) regulatory $T$ cells aggravates atherosclerosis. Atherosclerosis. 2010;209:74-80.

111. Mallat Z, Besnard S, Duriez M, Deleuze V, Emmanuel F, Bureau MF, Sobrier F, Esposito B, Duez H, Fievet C, Staels B, Duverger N, Scherman D, Tedgui A. Protective role of interleukin-10 in atherosclerosis. Circ Res. 1999;85:e17-e24.

112. Grainger DJ, Mosedale DE, Metcalfe JC, Bottinger EP. Dietary fat and reduced levels of TGFbeta1 act synergistically to promote activation of the vascular endothelium and formation of lipid lesions. J Cell Sci. 2000;113:2355-2361.

113. Mallat Z, Gojova A, Marchiol-Fournigault C, Esposito B, Kamate C, Merval R, Fradelizi $D$, Tedgui A. Inhibition of transforming growth factor-beta signaling accelerates atherosclerosis and induces an unstable plaque phenotype in mice. Circ Res. 2001;89:930-934.

114. Pinderski LJ, Fischbein MP, Subbanagounder G, Fischbein MC, Kubo N, Cheroutre $H$, Curtiss LK, Berliner JA, Boisvert WA. Overexpression of interleukin-10 by activated T lymphocytes inhibits atherosclerosis in LDL receptor-deficient mice by altering lymphocyte and macrophage phenotypes. Circ Res. 2002;90:1064-1071.

115. Lutgens E, Gijbels M, Smook M, Heeringa P, Gotwals P, Koteliansky VE, Daemen MJ. Transforming growth factor-beta mediates balance between inflammation and fibrosis during plaque progression. Arterioscler Thromb Vasc Biol. 2002;22:975-982.

116. Ramshaw AL, Parums DV. Immunohistochemical characterization of inflammatory cells associated with advanced atherosclerosis. Histopathology. 1990;17:543-552. 
117. Shaw PX, Hörkkö S, Chang MK, Curtiss LK, Palinski W, Silverman GJ, Witztum JL. Natural antibodies with the T15 idiotype may act in atherosclerosis, apoptotic clearance, and protective immunity. J Clin Invest. 2000;105:1731-1740.

118. Major AS, Fazio S, Linton MF. B-lymphocyte deficiency increases atherosclerosis in LDL receptor-null mice. Arterioscler Thromb Vasc Biol. 2002;22:1892-1898.

119. Caligiuri G, Nicoletti A, Poirier B, Hansson GK. Protective immunity against atherosclerosis carried by $\mathrm{B}$ cells of hypercholesterolemic mice. J Clin Invest. 2002;109:745-753.

120. Binder CJ, Hartvigsen K, Chang MK, Miller M, Broide D, Palinski W, Curtiss LK, Corr M, Witztum JL. IL-5 links adaptive and natural immunity specific for epitopes of oxidized LDL and protects from atherosclerosis. J Clin Invest. 2004;114:427-437.

121. Miller AM, Xu D, Asquith DL, Denby L, Li Y, Sattar N, Baker AH, Mclnnes IB, Liew FY. IL-33 reduces the development of atherosclerosis. J Exp Med. 2008;205:339-346.

122. Ait-Oufella H, Herbin O, Bouaziz JD, Binder CJ, Uytenhove C, Laurans L, Taleb S, Van Vré E, Eposito B, Vilar J, Sirvent J, Van Snick J, Tedgui A, Tedder TF, Mallat Z. B cell depletion reduces the development of atherosclerosis in mice. J Exp Med. 2010;207:1579-1587.

123. Daissormont IT, Kraaijeveld AO, Biessen EA. Chemokines as therapeutic targets for atherosclerotic plaque destabilization and rupture. Future Cardiol. 2009;5:273-284.

124. Koenen RR, Weber C. Manipulating the chemokine system: therapeutic perspectives for atherosclerosis. Curr Opin Investig Drugs. 2010;11:265-272.

125. McGeachie J, Campbell P, Simpson S, Prendergast F. Arterial vasa vasorum: a quantitative study in the rat. J Anat. 1982;134:193-197.

126. Gulbenkian S, Saetrum Opgaard O, Ekman R, Costa Andrade N, Wharton J, Polak JM, Queiroz e Melo J, Edvinsson L. Peptidergic innervation of human epicardial coronary arteries. Circ Res. 1993;73:579-588.

127. Houtkamp MA, de Boer OJ, van der Loos CM, van der Wal AC, Becker AE. Adventitial infiltrates associated with advanced atherosclerotic plaques: structural organization suggests generation of local humoral immune responses. J Pathol. 2001;193:263269.

128. Moreno PR, Purushothaman KR, Fuster V, O'Connor WN. Intimomedial interface damage and adventitial inflammation is increased in beneath disrupted atherosclerosis in the aorta: implications for plaque vulnerability. Circulation. 2002;105:2504-2511.

129. Higuchi ML, Gutierrez PS, Bezerra HG, Palomino SA, Aiello VD, Silvestre VM, Libby P, Ramires JA. Comparison between adventitial and intimal inflammation of ruptured and nonruptured atherosclerotic plaques in human coronary arteries. Arq Bras Cardiol. 2002;79:20-24. 
130. Maiellaro K, Taylor WR. The role of the adventitia in vascular inflammation. Cardiovasc Res. 2007;75:640-648.

131. Ramshaw AL, Roskell DE, Parums DV. Cytokine gene expression in aortic adventitial inflammation is associated with advanced atherosclerosis. J Clin Pathol. 1994;47:721-727.

132. Tanaka K, Nagata D, Hirata $Y$, Tabata $Y$, Nagari R, Sata M. Augmented angiogenesis in adventitia promotes growth of atherosclerotic plaque in apolipoprotein E-deficient mice. Atherosclerosis. 2011;215:366-373.

133. de Boer OJ, van der Meer JJ, Teeling $P$, van der Loos CM, van der Wal AC. Low numbers of Foxp3 positive regulatory $T$ cells are present in all developmental stages of human atherosclerotic lesions. PLoS ONE. 2007;2:e779.

134. Moos MP, John N, Gräbner R, Nossmann S, Günther B, Vollandt R, Funk CD, Kaiser B, Habenicht AJ. The lamina adventitia is the major site of immune cell accumulation in standard chow-fed apolipoprotein E-deficient mice. Arterioscler Thromb Vasc Biol. 2005;25:2386-2391.

135. Bot I, de Jager SC, Bot M, Van Heiningen SH, de Groot $P$, Veldhuizen RW, van Berkel TJ, von der Thüsen JH, Biessen EA. The neuropeptide substance $P$ mediates adventitial mast cell activation and induces intraplaque hemorrhage in advanced atherosclerosis. Circ Res. 2010;106:89-92.

136. Xu X, Lin H, Lv H, Zhang M, Zhang Y. Adventitial lymphatic vessels - An important role in atherosclerosis. Med Hypotheses. 2007.

137. Drozdz K, Janczak D, Dziegiel P, Podhorska M, Patrzalek D, Ziolkowski P, Andrzejak R, Szuba A. Adventitial lymphatics of internal carotid artery in healthy and atherosclerotic vessels. Folia Histochem Cytobiol. 2008;46:433-436.

138. Xu X, Lu H, Lin H, Li X, Ni M, Sun H, Li C, Jiang H, Li F, Zhang M, Zhao Y, Zhang Y. Aortic adventitial angiogenesis and lymphangiogenesis promote intimal inflammation and hyperplasia. Cardiovasc Pathol. 2009;18:269-278.

139. Xu X, Lu H, Lin H, Ni M, Sun H, Li C, Jiang H, Li F, Zhao Y, Zhang M, Zhang Y. Lymphangiogenesis promotes inflammation and neointimal hyperplasia after adventitia removal in the rat carotid artery. Int J Cardiol. 2009;134:426-427.

140. Nakano T, Nakashima Y, Yonemitsu Y, Sumiyoshi S, Chen YX, Akishima Y, Ishii T, Lida $M$, Sueishi K. Angiogenesis and lymphangiogenesis and expression of lymphangiogenic factors in the atherosclerotic intima of human coronary arteries. Human Pathol. 2005;36:330-340.

141. Caligiuri G, Rudling M, Ollivier V, Jacob MP, Michel JB, Hansson GK, Nicoletti A. Interleukin-10 deficiency increases atherosclerosis, thrombosis, and low-density lipoproteins in apolipoprotein E knockout mice. Mol Med. 2003;9:10-17. 
142. Robinette CD, Fraumeni JF Jr. Splenectomy and subsequent mortality in veterans of the 1939-45 war. Lancet. 1977;2:127-129.

143. Asai K, Kuzuya M, Naito M, Funaki C, Kuzuya F. Effects of splenectomy on serum lipids and experimental atherosclerosis. Angiology. 1988;39:497-504.

144. Fatouros M, Bourantas K, Bairaktari E, Elisaf M, Tsolas O, Cassioumis D. Role of the spleen in lipid metabolism. BJS. 1995;82:1675-1677.

145. Jones NW, Rogers AL. Chronic infection and atherosclerosis: some additional experimental data. Arch Pathol. 1948;45:271-277.

146. Libby P, Egan D, Skarlatos S. Roles of infectious agents in atherosclerosis and restenosis: an assessment of the evidence and need for future research. Circulation. 1997;96:4095-4103.

147. Muhlestein JB, Anderson JL, Hammond EH, Zhao L, Trehan S, Schwobe EP, Carlquist JF. Infection with Chlamydia pneumonia accelerates the development of atherosclerosis and treatment with azithromycin prevents it in a rabbit model. Circulation. 1998; 97:633-636.

148. Epstein SE, Zhou YF, Zhou J. Infection and atherosclerosis: emerging mechanistics paradigms. Circulation. 1999;100:e20-28.

149. Madjid M, Aboshady I, Awan I, Litovsky S, Casscells SW. Influenza and cardiovascular disease: is there a causal relationship? Tex Heart Inst J. 2004;31:4-13.

150. Moazed TC, Campbell LA, Rosenfeld ME, Grayston JT, Kuo CC. Chlamydia Pneumoniae infection accelerates the progression of atherosclerosis in apolipoprotein E-deficient mice. J Infect Dis. 1999;180:238-241.

151. Kiechl S, Egger G, Mayr M, Wiedermann CJ, Bonora E, Oberhollenzer F, Muggeo M, $\mathrm{Xu} \mathrm{Q}$, Wick G, Poewe W, Willeit J. Chronic infections and the risk of carotid atherosclerosis. Prospective results from a large population study. Circulation. 2001;103:1064-1070. 
Part I 



\section{Chapter 2}

\section{Chemokines as therapeutic targets for atherosclerotic plaque destabilisation and rupture}


Chapter 2

\section{Abstract}

Chemokines are instrumental in the initiation and progression of atherosclerosis. Recent advances in genomic technologies and the recognition of atherosclerosis as an inflammatory disease have given great impetus to studies addressing the relevance of chemokines for the clinically manifest stages of atherosclerosis and acute cardiovascular syndromes. In this paper we will review the current status of these studies, highlighting those chemokines that already have been associated with plaque destabilisation and rupture. We will recapitulate recent epidemiologic, genomic, histopathological and experimental support for the prominent role of particular chemokines in acute cardiovascular syndromes. Collectively these data underpin the potential of chemokines as biomarker and/or therapeutic target but also expose the lacunae in our understanding of the precise function of chemokines in the atherosclerosis related disorders and in the efficacy of chemokine targeted clinical trials. 


\section{Introduction}

Atherosclerosis is currently viewed as a chronic inflammatory disease. ${ }^{1,2}$ Despite the efficacy of drug therapy (e.g. statins and blood pressure lowering drugs) in the treatment and prevention of cardiovascular disease, clinical manifestations of atherosclerosis (f.e. myocardial infarction (MI) or stroke) continue to be the most prominent cause of death in Western societies. Both the initiation and progression of atherosclerotic plaques towards a rupture-prone, unstable plaque is driven by the influx of specific leukocyte subsets, a process orchestrated by chemokines (chemotactic cytokines). They are categorized into 2 major (CC and $\mathrm{CXC}$ ) and 2 minor $\left(\mathrm{C}\right.$ and $\mathrm{CX}_{3} \mathrm{C}$ ) classes based on their $\mathrm{N}$-terminal residues. So far, about 50 different chemokines have been identified, 20 of which have been reported to be present in atherosclerotic lesions. It is believed that different sets of chemokines come into play during plaque initiation and progression. Extensive study has led to the identification of chemokines that are involved in plaque destabilisation and plaque rupture. In this review, we will highlight current knowledge on chemokine homeostasis in atherosclerosis (and cardiovascular disease) and discuss their perspective/use as therapeutic targets in plaque rupture.

\section{From a stable towards an unstable rupture-prone plaque}

A stable atherosclerotic lesion is characterized by a lipid core, a thick fibrous cap and the presence of inflammatory cells. Atherosclerosis remains asymptomatic during the initial stages of disease. The advanced stages of disease development are characterized by destabilisation and rupture of an atherosclerotic plaque, often a sudden and acute event which may cause major ischemic syndromes such as MI or stroke.

These rupture-prone lesions are typified by a large lipid core rich in cholesterol, lipids and cellular debris. In fact, autopsy of human aortas showed that ruptured lesions have larger lipid cores than their stable counterparts. ${ }^{3,4}$ The lipid core is rich in highly thrombogenic and pro-inflammatory lipids, such as platelet activating factor and lysophosphatidic acid. Moreover, it contains microparticles (MP), which are small membrane vesicles that originate from apoptotic leukocytes. MP express phosphatidylserine and activated tissue factor, 
which both are highly thrombogenic factors that can promote atherothrombosis upon plaque rupture. ${ }^{5} \mathrm{~A}$ second feature of unstable plaques is thinning of the stabilising fibrous cap overlying the lipid core. Cap erosion is mainly attributable to macrophage and mast cell derived matrix metalloproteinases (MMPs), cathepsins and proteases which in turn can degrade matrix components (collagen, elastin and proteoglycans) of the fibrous cap. Furthermore, cap smooth muscle cells (SMC) are particularly prone to apoptosis leading to a decreased vascular SMC (VSMC) content of the cap and consequently increased plaque vulnerability. ${ }^{6}$ -

${ }^{8}$ Since VSMCs are the most prominent producers of matrix components in the plaque, their loss will result in a decrease in cap matrix synthesis. In addition, rupture-prone lesions are characterized by the abundant infiltration of inflammatory leukocyte subsets into the plaque which release a plethora of proteases, cytokines and growth factors but also induce migration of even more inflammatory cells, culminating in fulminant inflammation and progressive degradation of the fibrous cap. These inflammatory cells may enter the plaque from the luminal site or through neovessels projecting from adventitial vasa vasora into the plaque. ${ }^{9}$ Neovessels in the plaque are dysfunctional and will readily rupture, leading to intraplaque haemorrhage and plaque destabilisation. ${ }^{10}$ Therefore, intimal neovascularization is a major hallmark for plaque destabilisation and rupture.

Plaque rupture is defined as the physical disruption of an atherosclerotic lesion, generally, due to disruption of the fibrous cap. Cap disruption will expose the highly thrombogenic content of the plaque to the circulation, activating the coagulation cascade and platelets and inducing thrombus formation. A second type of plaque rupture is caused by disruption of microvessels within the plaque, also known as intraplaque haemorrhage. These microvessels express high levels of adhesion molecules (VCAM-1, ICAM-1, CD40 and E-selectin) through which inflammatory cells, mainly macrophages, can migrate into the plaque resulting in more inflammation and plaque destabilisation. ${ }^{11}$ These vessels are thought to be dysfunctional, fragile and prone to rupture and thereby induce an unstable plaque phenotype. Finally, plaque rupture can be caused by erosion of endothelial cells that overlie the intima shielding the plaque content from the blood. Plaque erosion is a frequent event in highly fibrotic non-inflammatory lesions. Erosion will result in platelet activation and adhesion to the subendothelial collagen and VSMC 
and induction of von Willebrand factor, which may serve as template for thrombus formation. ${ }^{12}$

\section{Chemokines in plaque destabilisation and rupture: lessons from epidemiology}

Patients with coronary artery disease (CAD) have been shown to express increased serum levels of specific chemokines. Several studies have focused on whether serum markers can be indicative of plaque instability and therefore could be useful as predictor for plaque rupture.

In humans, $\mathrm{CC}$ chemokine ligand-2 (CCL2/ monocyte chemoattractant protein1 (MCP-1)) serum levels were increased in patients at risk for CAD. ${ }^{13}$ Further, MCP-1 serum levels were increased in patients with ischemic stroke and $\mathrm{MI}^{14}$ These data are concordant with a large cohort study of 2270 patients with acute coronary syndromes (i.e. OPUS-TIMI 16 trial), in which MCP-1 plasma levels were significantly increased compared with healthy volunteers. Elevated MCP-1 levels were associated with traditional risk factors for atherosclerosis (dyslipidemia, hypertension, diabetes, obesity and older age) and an increased risk for $\mathrm{MI}$ and death. ${ }^{15}$ However, more recently the MONICA/KORA case-cohort study showed that increased MCP-1 serum levels precede CAD but do not represent independent risk factors. ${ }^{16}$ This last finding raised the question whether increases in MCP-1 serum levels are secondary to rather than directly correlated with atherosclerosis and can be considered as a causal marker for plaque destabilisation. Patients with unstable angina pectoris (UAP), a clinical manifestation of atherosclerosis, show a strong increase in CC chemokine ligand-5 (CCL5/RANTES) and CC chemokine ligand-18 (CCL18/ pulmonary and activationregulated chemokine (PARC)) serum levels during cardiac ischemia. ${ }^{17}$ Furthermore, natural deficiency of RANTES receptor, CCR5, in human individuals has been shown to protect against premature $\mathrm{MI}$ in that carriers of this CCR5 allele were underrepresented in the group of patients that had suffered a MI. ${ }^{18}$ Plasma levels of CC chemokine ligand-3 (CCL3/monocyte chemoattractant protein-1 $\alpha$ (MIP-1 $\alpha)$ ) were seen to be increased both in patients with acute $\mathrm{MI}^{19}$ and in UAP patients compared with controls.

Plasma levels of CXC chemokine ligand-12 (CXCL12/stromal cell-derived factor $1-\alpha($ SDF-1 $\alpha)$ ) were significantly lower in patients with stable AP and UAP 
compared with healthy controls, despite that SDF-1 $\alpha / C X C R 4$ both are hypoxia/ischemia sensitive. ${ }^{20}$ These findings support the hypothesis that SDF-1 $\alpha$ protects against plaque instability, despite the fact that SDF-1 $\alpha$ also was shown to activate platelets pointing to an adverse role in atherothrombosis. ${ }^{21}$ Moreover, $\mathrm{CX}_{3} \mathrm{C}$ chemokine ligand-1 ( $\mathrm{CX}_{3} \mathrm{CL} 1 /$ fractalkine) serum levels were markedly enhanced in UAP patients. ${ }^{22}$ Mutation of the fractalkine receptor was shown to be associated with a lower risk of cardiovascular disease (CVD) by impairing fractalkine binding and consequently reducing leukocyte migration. ${ }^{23}$

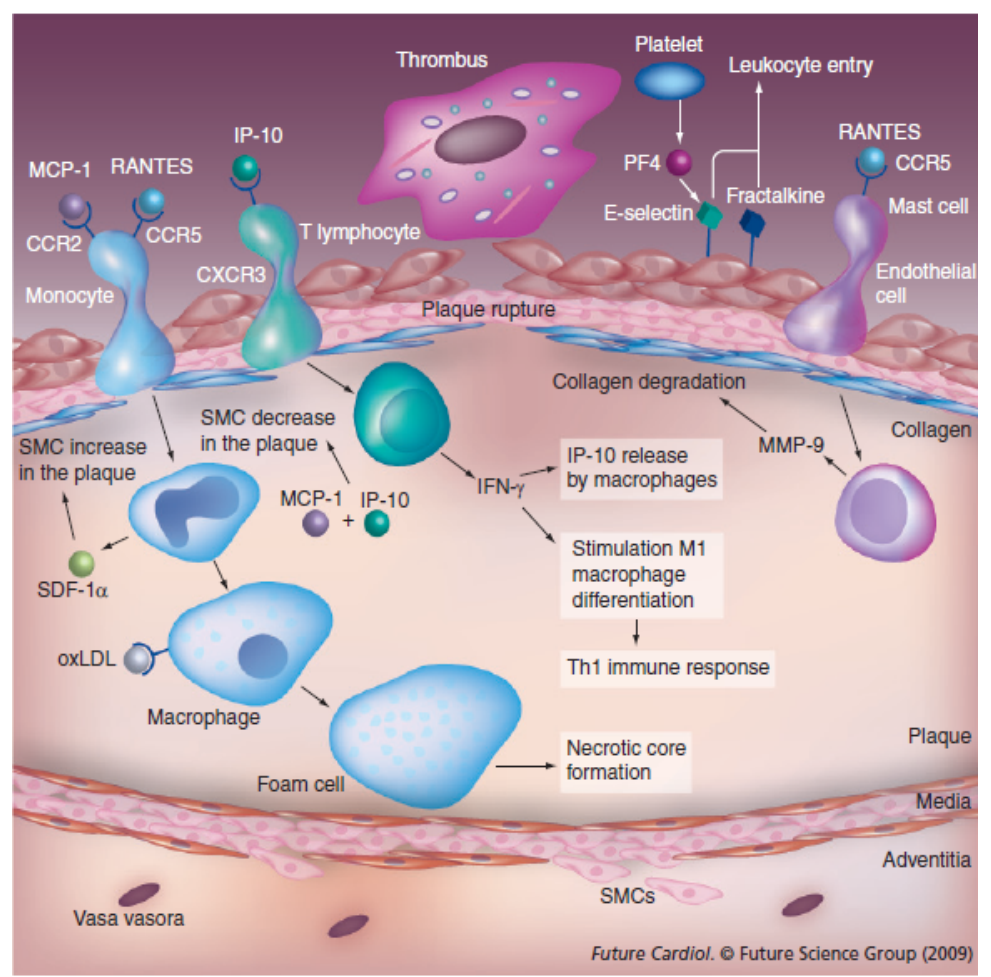

Figure 1. The role of chemokines in plaque progression and destabilisation. Monocytes are recruited to the vessel wall through MCP-1/CCR2 or rantes/CCR5 interaction. T lymphocyte entry is mainly mediated through the IP-10/CXCR3 pathway. After up-take of oxLDL, monocytes differentiate into macrophages which eventually die by apoptosis and form the necrotic core. Monocytes release IP-10, leading to continuous T cell migration towards the plaque. In addition, IP-10 has been shown to induce plaque destabilisation by decreasing the SMC content through a mechanism which is unknown. In addition, monocytes release MCP-1 which also has been shown to decrease the SMC content in the plaque. SDF-1 $\alpha$ helps maintaining plaque stability by maintaining the number of SMCs in 
the plaque and thereby stabilizing the fibrous cap. T lymphocytes release IFN- $\gamma$, which stimulates differentiation of macrophages towards a M1 phenotype and consequently induces a Th1 immune response and subsequent plaque progression. Moreover, they stimulate IP-10 release by macrophages. Mast cells migrate towards the plaque via RANTES/CCR5 interaction and release MMP-9. By degrading collagen and the fibrous cap structure, MMP-9 induces plaque destabilisation, which can eventually result in plaque rupture. Platelets release PF4, which increases endothelial expression of E-selectin and promotes leukocyte adhesion and entry. In addition, fractalkine also contributes to leukocyte entry. MCP-1: monocyte-chemoattractant protein-1, IP-10: interferon-gammainducible protein-10, oxLDL: oxidized low density lipoprotein, SMC: smooth muscle cell, Th1: T helper 1, MMP-9: matrix metalloproteinase-9, SDF-1 $\alpha$ : stromal cell-derived factor$1 \alpha$, PF4: platelet factor 4 .

\section{Genomic studies and histopathology}

Gene expression and immunohistochemistry analyses of chemokine patterns during the different stages of disease progression have provided detailed insight into the chemokines that might be involved in plaque destabilisation and rupture. Moreover, immunohistochemistry allows to precisely pinpoint differences in protein expression to specific compartments within the atherosclerotic plaque. From genomic analysis a few chemokines were found to be strongly upregulated or downregulated in unstable compared with stable atherosclerotic lesions (Table 1). 
Table 1. Overview of chemokines that might be involved in plaque rupture.

\begin{tabular}{|c|c|c|c|c|}
\hline Chemokine & $\begin{array}{l}\text { Plasma levels in } \\
\text { coronary artery } \\
\text { disease patients }\end{array}$ & $\begin{array}{l}\text { Gene expression } \\
\text { in human } \\
\text { stable lesions }\end{array}$ & $\begin{array}{l}\text { Gene expression } \\
\text { in human } \\
\text { unstable lesions }\end{array}$ & Ref. \\
\hline CCL2/MCP-1 & $\uparrow$ & $\uparrow$ & $\uparrow \uparrow$ & {$[13,15,24]$} \\
\hline CCL3 /MIP-1 $\alpha$ & $\uparrow$ & (?) & (?) & [19] \\
\hline CCL5/RANTES & $\uparrow$ & $\uparrow$ & $\uparrow$ & {$[17,37,38]$} \\
\hline CCL18/PARC & $\uparrow$ & $\uparrow \uparrow$ & $\uparrow$ & {$[17,24,39]$} \\
\hline CXCL4 /PF4 & (?) & (?) & (?) & {$[47,48]$} \\
\hline CXCL10/IP-10 & (?) & $\uparrow$ & (?) & {$[41,42]$} \\
\hline CXCL12/SDF1- $\alpha$ & $\downarrow$ & $\uparrow$ & (?) & [20] \\
\hline $\mathrm{CX}_{3} \mathrm{CL} 1 /$ Fractalkine & $\uparrow$ & $\uparrow$ & (?) & {$[22,50]$} \\
\hline
\end{tabular}

MCP-1 expression has been shown to be upregulated in human unstable lesions obtained from carotid endarterectomy. ${ }^{24}$ However, previously MCP-1 and -2 gene expression was shown to be decreased in atherosclerotic lesions from patients with unstable angina obtained from coronary atherectomy. ${ }^{25}$ These seemingly contradictory findings suggest that regulation of MCP-1 expression in human lesions might be site-specific. Also in mice MCP-1 gene expression was shown to be increased. In $\mathrm{ApoE}^{-/-}$mice, micro-array analysis showed an increased MCP-1 expression in advanced atherosclerotic lesions. ${ }^{26} \mathrm{MCP}-1$ is a member of the small inducible gene (SIG) family and mediates its effects through interaction with CCR2. MCP-1 mainly induces migration of monocytes to sites of inflammation but can also recruit memory T cells, dendritic cells (DC), basophils and eosinophils. ${ }^{27-29}$ In human atherosclerotic lesions, MCP-1 is highly expressed in macrophage-rich regions ${ }^{30}$ and to a lesser extent in $\mathrm{VSMC}^{31}$ and endothelial cells $(E C){ }^{32} \mathrm{~A}$ recent publication showed that MCP-1 and CCR2 are highly expressed in the endothelial as well as intimal cells in advanced atherosclerotic lesions in human carotid arteries. ${ }^{33}$ MCP-1 secretion by ECs is also believed to be induced by activated platelets. $^{34}$

RANTES induces chemotaxis of leukocytes through interaction with its receptors CCR5, CCR1 and CCR3 ${ }^{35}$ It is chemotactic for T cells, monocytes, mast cells, eosinophils and basophils and induces endothelial arrest of these leukocyte 
subsets. RANTES expression has been demonstrated in aortic lesions in $\mathrm{ApoE}^{-1-}$ mice. ${ }^{36}$ Surprisingly, micro-array analysis showed that RANTES expression was decreased in advanced atherosclerotic lesions in $\mathrm{ApoE}^{-/}$mice on Western-type diet. ${ }^{26}$ In fact, it has been detected in human atherosclerotic lesions, both during the plaque initiation and the plaque progression and destabilisation stage, ${ }^{37}$ indicating that RANTES contributes to atherogenesis at all stages of disease progression. Also one of its receptors, CCR3, was found to be highly expressed in human atherosclerotic lesions. Its overexpression was related to inflammatory cell recruitment, suggesting that CCR3 overexpression may contribute to plaque instability. ${ }^{38}$ Nevertheless, CCR3 expression has only been investigated in human stable atheromas, and its expression pattern in human unstable lesions remains to be addressed.

Moreover, PARC gene expression was also upregulated in human unstable lesions obtained from carotid endarterectomy. ${ }^{24}$ PARC, a small cytokine expressed in lung and lymphoid tissue of humans only, is mainly chemotactic for naive lymphocytes ( $B$ and $T$ cells). PARC has been shown to be highly expressed in human carotid plaques, both in stable and unstable lesions, and PARC protein expression is most pronounced in macrophage-rich regions. ${ }^{39}$ There was no difference in PARC expression between lipid-loaded and naive macrophages, implying that PARC expression in macrophages is not dependent on lipid accumulation.

CXC chemokine ligand-10 (CXCL10/interferon- $\nu$ inducible protein-10 (IP-10)) has been implicated as a critical proinflammatory chemokine in atherosclerosis and acts by interacting with its receptor CXCR3 ${ }^{40} \mathrm{IP}-10$ gene expression was found to be increased in the early phase of low shear stress (LSS) induced plaque formation. ${ }^{41}$ Moreover, its major inducer, IFN- $\gamma$, has been associated with the formation of unstable lesions, suggesting that IP-10 could be of importance in the induction of plaque destabilisation. ${ }^{42}$ IP-10 could, by inducing interferon- $\gamma$ (IFN- $\gamma$ ) secretion, indirectly promote skewing towards a M1 macrophage phenotype and a Th1 proinflammatory immune response, thereby aggravating plaque progression. ${ }^{43}$ In human atherosclerotic lesions IP-10 is expressed by macrophages, vSMCs and ECs and is the main chemoattractant for CD4 $4^{+}$Th1 and $\mathrm{CD}^{+}{ }^{+}$cells. ${ }^{44}$ However, immunohistochemistry data about IP-10 protein expression in human unstable atherosclerotic lesions are still lacking and 
therefore it remains unclear whether IP-10 is involved in plaque destabilisation and rupture.

SDF- $1 \alpha$ is a chemoattractant for lymphocytes, neutrophils, monocytes and (endothelial) progenitor cells, which all express its cognate receptor, CXCR4. Recently, SDF- $1 \alpha$ has been reported to interact with CXCR7. ${ }^{45}$ SDF- $1 \alpha$ was found to have plaque stabilizing effects by inhibiting neutrophil entry and MMP-9 expression. ${ }^{46}$ However, information is lacking about SDF-1 $\alpha$ and CXCR4 expression in human unstable - ruptured and intraplaque haemorrhaged - lesions. Comparison in protein expression between different stages of disease progression will provide more information about plaque stabilizing effects of SDF-1 $\alpha$.

CXC chemokine ligand-4 (CXCL4/platelet factor 4 (PF4)) is primarily released by activated platelets. It is expressed in the cytoplasm of luminal and neovascular endothelium, in macrophages and in regions of plaque calcification. ${ }^{47}$ Moreover, PF4 has been shown to upregulate E-selectin expression by ECs. ${ }^{48}$ Collectively, these findings suggest that PF4 contributes to leukocyte infiltration into the plaque and consequently plaque progression.

Fractalkine is a member of the $\mathrm{CX}_{3} \mathrm{C}$ chemokine family and has chemotactic activity for monocytes and T cells. It functions not only as a chemokine but also as an adhesion molecule on ECs. ${ }^{49}$ Fractalkine is expressed by macrophages in human advanced atherosclerotic lesions, especially at sites of neovascularisation. ${ }^{50}$ Its receptor, $\mathrm{CX}_{3} \mathrm{CR} 1$, is highly expressed by vSMCs, which undergo migration in response to fractalkine. ${ }^{51}$ Whether fractalkine in fact is involved in plaque destabilisation still has to be investigated.

\section{Experimental studies in mice}

A key role of chemokines in atherogenesis and plaque destabilisation has been established in several mouse models; although it should be noted that considerable debate exists on whether mouse models for vulnerable plaque formation are in every aspect reflective of the human pathophysiology. Generally, surrogate parameters of plaque stability and rupture were used to infer the role of chemokines in human advanced atherosclerosis and plaque rupture. Of the many chemokines that play a role in atherosclerosis, only a few have been described to play a role in plaque destabilisation and rupture. In this section we 
will summarize those chemokines (MCP-1, RANTES, MIP-1 $\alpha$, IP-10, SDF-1 $\alpha$, PF4 and fractalkine) which have been studied so far in experimental mouse studies for plaque (de)stabilising activity (Table 2). For other chemokines, such as CXCL11, CCL19, CCL20, CCL21 and CXCL16, a role has so far been demonstrated, in plaque initiation, but not plaque stability.

Table 2. Experimental studies: role of chemokines in plaque destabilisation.

\begin{tabular}{|c|c|c|c|}
\hline Mouse model & Effect on plaque formation or stability & Effect on plaque content & Ref. \\
\hline \multicolumn{4}{|l|}{ CCL2/MCP-1 } \\
\hline$C C R 2^{-1-} A p o E^{-1-}$ & Plaque formation $\downarrow$ (aortic root) & Monocyte migration $\downarrow$ & [52] \\
\hline$M C P-1 \% L D L r^{\prime-}$ & Plaque formation $\downarrow$ (aorta) & $\begin{array}{l}\text { Lipid deposition } \downarrow \\
\text { Macrophage accumulation } \downarrow\end{array}$ & [53] \\
\hline 7ND-MCP-1 in ApoE-1- & $\begin{array}{l}\text { Plaque progression and destabilization } \downarrow \\
\text { (aortic root) }\end{array}$ & $\begin{array}{l}\text { Macrophages, lymphocytes } \downarrow \\
\text { vSMCs, collagen } \uparrow\end{array}$ & [54] \\
\hline \multicolumn{4}{|l|}{ CCL3/MIP-1 $\alpha$} \\
\hline$C C R 1^{-1-L D L r^{-1}}$ & Plaque formation (thoracic aorta) & $\begin{array}{l}\text { Macrophages, T cells } \\
\text { vSMC } \downarrow\end{array}$ & {$[61,62]$} \\
\hline \multicolumn{4}{|l|}{ CCL5/RANTES } \\
\hline$C C R 5^{-1-} A p o E^{-1-}$ & $\begin{array}{l}\text { No effect on plaque formation } \\
\text { (aortic sinus) }\end{array}$ & No effect & [56] \\
\hline Met-RANTES & $\begin{array}{l}\text { Plaque formation } \downarrow \text { (aortic root and } \\
\text { thoracoabdominal aorta) } \\
\text { Plaque progression } \downarrow \text { (aortic root) }\end{array}$ & $\begin{array}{l}\text { Macrophages, lymphocytes } \downarrow \\
\text { vSMCs and collagen } \uparrow\end{array}$ & [57] \\
\hline$C C R 5^{-1-} \mathrm{BM}$ in $L D L r^{-1}$ & Plaque formation $\downarrow$ (aortic sinus, NS) & IL-10 and TNF- $\alpha \downarrow$ & [59] \\
\hline$C C R 5^{-1-} A P O E^{-1-}$ & $\begin{array}{l}\text { No effect on plaque formation } \\
\text { Plaque progression } \downarrow \text { (aortic sinus) }\end{array}$ & $\begin{array}{l}\text { Macrophages, lymphocytes } \downarrow \\
\text { MCP-5 } \downarrow\end{array}$ & [60] \\
\hline 44-AANA7-RANTES & Progression of established plaques $\downarrow$ (aortic root) & vSMCs, collagen $\uparrow$ & [58] \\
\hline \multicolumn{4}{|l|}{ CXCL4/PF4 } \\
\hline $\mathrm{PF}^{-/} \mathrm{APOE} \mathrm{E}^{-/}$ & Plaque formation $\downarrow$ (aortic root) & Macrophages $\downarrow$ & [67] \\
\hline \multicolumn{4}{|l|}{ CXCL10/IP-10 } \\
\hline 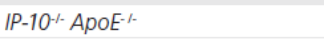 & Plaque formation $\downarrow$ (aortic arches) & CD4+ $T$ cells $\downarrow$, Treg $\uparrow$ & [63] \\
\hline $\begin{array}{l}\text { CXCR3 antagonist (NBI-74330) } \\
\text { in } L D L r^{\prime-}\end{array}$ & Plaque formation $\downarrow$ (collar-induced carotid artery) & CD4+ T cells $\downarrow$, Treg $\uparrow$ & [64] \\
\hline$C X C R 3^{-\mu} A p O E^{-/}$ & $\begin{array}{l}\text { Plaque formation } \downarrow \text { (thoracoabdominal aorta) } \\
\text { No effect on plaque formation (aortic root) }\end{array}$ & $\begin{array}{l}\text { Lipid deposition } \downarrow \\
\text { Macrophages, Th1 cells } \downarrow \\
\text { vSMCs } \uparrow\end{array}$ & [65] \\
\hline \multicolumn{4}{|l|}{$C X C L 12 / S D F-1 \alpha$} \\
\hline $\begin{array}{l}\text { CXCR4 blockage with AMD3465 } \\
\text { in } A p \circ E^{-/ .}\end{array}$ & Vulnerable plaque phenotype (aortic root) & NC, neutrophil content $\uparrow$ & [46] \\
\hline \multicolumn{4}{|l|}{$C X_{3}$ CL1/Fractalkine } \\
\hline $\mathrm{CX}_{3} C R 1^{-1-} \mathrm{ApoE^{-1 }}$ & $\begin{array}{l}\text { Plaque formation } \downarrow \text {, plaque stabilization } \\
\text { (thoracic aorta, aortic sinus) }\end{array}$ & $\begin{array}{l}\text { Macrophages, NC } \downarrow \\
\text { vSMCs, collagen }\end{array}$ & [68] \\
\hline $\begin{array}{l}\text { Antifractalkine neutralizing } A b \\
\text { in } A p \circ E^{-/}\end{array}$ & Plaque stabilization (carotid artery) & $\begin{array}{l}\text { Macrophages, NC } \downarrow \\
\text { vSMCs, collagen and cap } \\
\text { thickness } \uparrow\end{array}$ & [41] \\
\hline
\end{tabular}


Deletion of CCR2 in $\mathrm{ApoE}^{-1-} \mathrm{CCR} 2^{-/-}$mice strongly reduced lesion formation by significantly impairing monocyte migration towards the plaque. ${ }^{52}$ Atherosclerosis was also reduced in the aorta of MCP-1 ${ }^{-1-} \mathrm{LDLr}^{-/-}$mice. ${ }^{53}$ Anti-MCP-1 gene therapy has been shown to reduce lesion progression and destabilisation in $\mathrm{ApoE}^{-/-}$mice. Blockage of the MCP-1/CCR2 signalling pathway with a MCP-1 mutant (7ND-MCP1) strongly reduced macrophage and lymphocyte plaque content, while increasing VSMC and collagen content in established atherosclerotic lesions, thus promoting a stable plaque phenotype. ${ }^{54}$ Expression of CD40 and CD40 ligand (CD40L) was decreased and chemokine expression of RANTES and MCP-1 was decreased as well as cytokine expression (tumor necrosis factor $\alpha$ (TNF $\alpha$ ), interleukin-6 (IL-6), IL-1 $\beta$ and transforming growth factor beta 1 (TGF $\beta 1)$ ). In addition, blockage of MCP-1 with 7ND-MCP-1 was shown to suppress angiotensin-II induced progression and destabilisation of established atherosclerotic lesions. ${ }^{55}$ These data indicate that MCP-1 is mainly involved in development of atherosclerosis but also could potentially play a role in plaque progression and destabilisation as well.

CCR5 deficiency in ApoE/CCR5 double knockout mice did not affect atherosclerotic plaque formation. Although $\mathrm{ApoE}^{-1-} \mathrm{CCR}^{-/-}$mice displayed defects in macrophage trafficking, lesion area did not differ between $\mathrm{ApoE}^{-/-}$and $\mathrm{ApoE}^{-/}$ $\mathrm{CCR}^{-/-}$mice. ${ }^{56}$ However, the RANTES antagonist Met-RANTES and more recently 44-AANA47-RANTES both were able to reduce the progression of (established) atherosclerotic lesions in LDLr ${ }^{-/}$mice. ${ }^{57,58}$ AANA-RANTES was reported to prevent plaque progression and destabilisation in the thoraco-abdominal aortas and aortic roots of $\mathrm{LDLr}^{-/-}$mice after intraperitoneal administration. AANA-RANTES treatment resulted in a more stable plaque phenotype, which was characterized by a reduction in leukocyte content and MMP-9 expression and increased VSMC and collagen content. In addition, more recently a bone marrow transplantation study in $\mathrm{LDLr}^{-/-}$mice showed that bone marrow-derived CCR5 favours the development of atherosclerotic lesions by reducing macrophage IL-10 production and increasing $T$ cell-derived TNF- $\alpha .^{59}$ A more recent study showed that CCR5 deficiency in $\mathrm{ApoE}^{-/}$mice does influence late but not early stages of atherosclerosis. ApoE ${ }^{-/} \mathrm{CCR}^{-/}$mice fed a normal chow or a high-fat diet were protected against advanced atherosclerosis. ${ }^{60}$ All together, these data indicate that RANTES could be a suitable candidate for therapeutical intervention in atherosclerosis and more specifically plaque rupture. 
Information on a possible role of MIP-1 $\alpha$ in plaque destabilisation and plaque rupture is lacking at the moment. In a mouse model of MI, MIP-1 $\alpha$ plasma levels were seen to be increased after $\mathrm{MI} .{ }^{19}$ These data coincide with human data of $\mathrm{MI}$ and UAP patients in which MIP-1 $\alpha$ plasma levels were also seen to be increased and suggest that this increase in MIP-1 $\alpha$ plasma levels may be of ischemic rather than atherogenic origin. ${ }^{19}$ MIP- $1 \alpha$ functions by interacting with three different chemokine receptors, CCR1, CCR3 and CCR5. CCR1 deficiency has been shown to enhance atherosclerotic plaque development in $\mathrm{LDLr}^{-/-}$mice, ${ }^{61,62}$ suggestive of a protective or regulatory role of this receptor.

Complete deletion of IP-10 in $\mathrm{ApoE}^{-/}$mice was earlier seen to attenuate atherosclerosis by diminishing the influx of effector T cells, thereby correcting the local balance with regulatory $T$ cells. ${ }^{63}$ Similar results were obtained by blocking IP-10 receptor function in LDLr ${ }^{-/-}$mice with a CXCR3 antagonist, ${ }^{64}$ albeit effects of this CXCR3 antagonist on other chemokines and chemokine receptors cannot be excluded. Moreover, complete deletion of CXCR3 in an ApoE CXCR3 double knockout mouse strongly reduced atherosclerosis in the thoraco-abdominal aorta. However, lesion size in the aortic root of the same mice did not differ, implying that the contribution of CXCR3 to lesion formation might be site-specific. ${ }^{65}$ Recently, IP-10 was shown to act protective against aneurysm formation and rupture, ${ }^{66}$ which emphasizes once again that we should consider the application of chemokine based therapies for the treatment of atherosclerosis related disorders with caution as it might adversely influence the outcome of other vascular diseases.

Plaque formation in LDLr-- mice with haematopoietic deficiency of CXCR4 or with pharmacologically blocked CXCR4 function (AMD3465) was sharply increased. In keeping, ApoE ${ }^{-/}$mice treated with AMD3465 showed a more vulnerable plaque phenotype with increased necrotic core area and neutrophil content. ${ }^{46}$ These data indicate that the SDF-1 $\alpha /$ CXCR4 axis protects against plaque rupture.

Elimination of PF4 from platelets reduced atherosclerosis development in the aortic root of $\mathrm{C} 57 \mathrm{BI} / 6$ and $\mathrm{ApoE}^{-1}$ mice fed a Western-type diet. ${ }^{67}$ These data show that PF4 contributes to plaque formation. Whether PF4 is also involved in plaque destabilisation still has to be investigated. 


\section{Chapter 2}

Deletion of $\mathrm{CX}_{3} \mathrm{CR} 1$ in $\mathrm{ApoE}^{-/-}$mice strongly reduced atherosclerotic lesion formation but had no effect on plaque stability, as the number of VSMCs and collagen was unaffected [68]. Fractalkine has been found to be expressed in low shear stress (LSS) induced atherosclerotic lesions in $\mathrm{ApoE}^{-/-}$mice. Inhibition of fractalkine function by a neutralizing anti-mouse fractalkine antibody stabilized atherosclerotic lesions. Mice showed a decrease in plaque area and leukocyte content and an increase in collagen content. Moreover, cap thickness was increased and necrotic core size decreased. ${ }^{41}$ These findings suggest that fractalkine may have plaque destabilizing effects.

Therapeutic potential of chemokine intervention in plaque destabilisation and rupture

Several chemokine ligand and chemokine receptor antagonists are currently being developed to be used for the treatment of several inflammatory disorders and viral infection. Some of these antagonists already have entered clinical trial phase II or III studies and some are even approved for clinical use (f.e. Maraviroc). Given the key role of various chemokines in plaque rupture and ensuing acute cardiovascular syndromes, it is conceivable that chemokine receptor antagonists will have potential for the treatment of these indications. In this paragraph we will present the current status of the clinical trial studies on chemokine receptor antagonists as well as future options for chemokine receptor targeted therapy.

CCR2 antagonists have been developed for the treatment of diseases in which MCP-1 and CCR2 have been shown to play a prominent role. To date phase Ila clinical trial studies have been performed for a human CCR2 blocking antibody (MLN1202) in patients with active rheumatoid arthritis (RA). ${ }^{69}$ Blockage of the MCP-1 receptor significantly reduced CCR2 expression on monocytes, but did not ameliorate the disease status. This was tentatively attributed to incomplete CCR2 blockage which may not have sufficed to improve clinical manifestations of RA. A synthetic CCR2 antagonist, the imidazole JNJ-27141491, was shown to display overt anti-inflammatory activity, and potently blocked MCP-1 binding to monocytes. It is a non-competitive and orally active functional antagonist, ${ }^{70}$ and as such may be a good candidate for the treatment of other acute inflammatory disorders such as atherosclerosis. 
RANTES antagonism may even hold greater promise for plaque stabilising therapy as discussed before. For instance, treatment of $\mathrm{LDLr}^{-/-}$mice with TAK-779, a moderately specific CCR5 antagonist, was shown to reduce atherosclerotic lesion formation in the aortic root and carotid artery. TAK-779 was initially developed as therapeutic modality to inhibit HIV cell entry through CCR5. It may be particularly effective in the treatment of atherosclerosis as it also intervenes in CXCR3 activity. ${ }^{71}$ A synthetic RANTES analogue, AANA-RANTES was developed, which contains mutations in the RANTES/glycosaminoglycan binding site and as a result impairs with heparin binding and chemokine oligomerization and displays potent antagonistic activity. ${ }^{72}$ AANA-RANTES was reported to prevent plaque progression and destabilisation in mice ${ }^{58}$ RANTES is also believed to be involved in the pathogenesis of psoriasis. A randomized placebo-controlled clinical trial in 32 psoriasis patients was performed with the CCR5 antagonist SCH351125. Administration of this inhibitor did not significantly improve the disease status however. These results point to a lack of clinical efficacy of SCH351125 in humans despite promising results in animal models for psoriasis. ${ }^{73}$

In between, a whole series of new synthetic CCR5 antagonists, which are being tested in clinical trials in disorders such as HIV infection and type 1 diabetes, have been developed. One of these inhibitors, maraviroc has recently been approved for clinical use, while vicriviroc has progressed to phase III trials and several others are at earlier stages of clinical trials. ${ }^{74}$

Intervention in CXCR4 function has been subject of many clinical trial studies. Many CXCR4 antagonists have been developed since the identification of the key role of CXCR4 in many diseases such as human immunodeficiency virus (HIV) infection, cancer and in haematopoietic stem cell mobilisation. The most commonly used CXCR4 antagonist is AMD3100 (plerixafor), which was shown to be very effective in the treatment of HIV patients by inhibiting the CXCR4 dependent re-entry of HIV-1 into $\mathrm{CD} 4^{+}$T cells. ${ }^{75}$ Since the SDF-1 $\alpha /$ CXCR4 axis is regarded atheroprotective, the use of antagonists such as AMD3100 in the treatment of atherosclerosis related disorders is not likely to be beneficial. Rather, we propose that patients on CXCR4 targeted therapy should be scrutinously screened for their cardiovascular risk profile.

PF4 is a platelet-derived chemokine which has been shown to interact with CXCL8 and CCL5. Blockage of PF4-CCL5 interaction by peptide inhibitors was 
recently seen to reduce atherosclerosis and monocyte migration in hyperlipidemic mice ${ }^{76}$ thereby preventing plaque destabilisation. However, these studies leave unaddressed to what extent PF4 antagonism in itself will be beneficial for plaque stability in humans.

Therapeutic effects of fractalkine inhibition have been studied in animal models of RA. Treatment of mice with an anti-fractalkine monoclonal antibody strongly reduced clinical manifestations of RA. ${ }^{77}$ Also for the treatment of cancer, anti-fractalkine therapy has been proven to be very effective. Anti-fractalkine gene therapy in neuroblastomic mice strongly reduced the immune response. ${ }^{78}$ However, the efficacy of fractalkine antagonism in humans still remains to be studied.

\section{Conclusions}

Rupture of an atherosclerotic plaque underlies severe acute clinical manifestations of atherosclerosis such as $\mathrm{MI}$ and stroke and often results in death. Although extensive efforts have been made to unravel the mechanisms of plaque rupture in recent years, many details remain unknown. Chemokines are believed to be instrumental in plaque destabilisation and plaque rupture. Indeed, epidemiology studies have helped to identify various chemokines (e.g. MCP-1, RANTES, CCL3, CCL18 and fractalkine), of which plasma levels were significantly increased in CAD patients compared to controls. These and other chemokines are expressed in atherosclerotic lesions and in addition, a few of them, including RANTES and PARC, described to be more abundantly expressed in advanced and unstable atherosclerotic lesions. The expression pattern of the remaining chemokines in unstable lesions still remains to be investigated. A second issue hampering the advance in our understanding of the role of these chemokines in later stages of plaque development is the lack of a commonly accepted mouse model of plaque rupture. ${ }^{79-81}$ Until more representative animal models have been developed and in anticipation of new biomarkers that are indicative of plaque destabilisation and rupture, a set of generally accepted surrogate parameters in available mouse models should be defined to assess plaque vulnerability already at this stage. As demonstrated by Virmani and co-workers, intraplaque haemorrhage may represent a reliable feature of plaque vulnerability in humans 
and a similar role in mice could be surmised. The jury is still out on the value of cap thickness, cap/core ratio, collagen content and leukocyte density (in particular in the shoulder zone) and for each of these parameters, critical thresholds are awaited that represent mouse analogues of earlier defined human values. Moreover, chemokine knockout mouse models that are generally used for studying the role of chemokines in atherosclerosis may have intrinsic pitfalls. For instance life-long chemokine (receptor) deficiency may be accompanied by compensatory mechanisms or affect leukocyte differentiation in and extravasation from stromal tissue into the circulation, influencing both number and activity of leukocytes and thus plaque progression.

Now the clinically manifest stages of atherosclerosis are receiving increased attention, studies addressing the effects of chemokines on plaque rupture are beginning to emerge. In this review, we highlighted those chemokines which have been associated with plaque destabilisation and rupture. Obviously, while initial data from epidemiology, histopathology and experimental studies hold promise much research has yet to be done to pinpoint those chemokines that come into play in advanced rupture prone plaques and post-rupture injury repair in order to identify chemokine based targets for future intervention. Several chemokine and chemokine receptor antagonists have been developed as therapeutic tool to treat a variety of inflammatory and infection diseases. A few of these antagonists, such as AMD3100, which is currently being used for HIV treatment, proved to be very effective and well tolerated/safe, which illustrates the high potential of chemokine targeted therapy. Still, it should be noted that chemokines not only are involved in atherosclerosis but also may be vital to immune defence against exogenous pathogens and in immune surveillance. Many of these chemokines display a high degree of redundancy and serve to tune the activity of others. It is not unlikely that the effects of interference with a given chemokine receptor will be counteracted by increased activity of other chemokine(s) or will result in altered activity of non-targeted chemokines. Therapy should preferably be noninvasive, specific (minimal side-effects), safe and targeted (given the broad systemic mode of action of most chemokines). Such targeted therapy offers the advantage of a selective interference of the chemokine antagonist with processes in the vessel wall, preventing interference with other processes in the human body and systemic immune responses to be compromised. However, systemic 


\section{Chapter 2}

chemokine therapy is being implemented as well at the moment and appears to be effective. ${ }^{82,83}$ Moreover, the use of chemokine levels in plasma as a marker for CAD implies that chemokines should have a high stability (long half-life) in blood. Finally, the process of plaque rupture may vary from patient to patient, and depend on location within the arterial tree and a specific artery (e.g. branching points). Therefore, it is important to monitor lesion formation and stability at several arteries in experimental efficacy studies on chemokines first and, if feasible, develop site-specific chemokine therapy.

In conclusion, the use of chemokines as therapeutic target in plaque rupture is a very promising tool to treat plaque destabilisation. However, further research has yet to be done to define the role of chemokines in plaque rupture and to identify which chemokines exactly play a crucial role in this process. 


\section{References}

1. Ross R: Atherosclerosis-an inflammatory disease. N. Engl. J. Med. 340(2), 115-126 (1999).

2. Libby P, Ridker PM, Maseri A: Inflammation and atherosclerosis. Circulation 105(9), 1135-1143 (2002).

3. Felton CV, Crook D, Davies MJ, Oliver MF: Relation of plaque lipid composition and morphology to the stability of human aortic plaques. Arterioscler. Thromb. Vasc. Biol. 17(7), 1337-1345 (1997).

4. Davies MJ, Richardson PD, Woolf N, Katz DR, Mann J: Risk of thrombosis in human atherosclerotic plaques: role of extracellular lipid, macrophage, and smooth muscle cell content. Br Heart J 69(5), 377-381 (1993).

5. Leroyer AS, Tedgui A, Boulanger CM: Role of microparticles in atherothrombosis. $J$ Intern Med 263(5), 528-537 (2008).

6. Bennett MR, Evan GI, Schwartz SM: Apoptosis of human vascular smooth muscle cells derived from normal vessels and coronary atherosclerotic plaques. J Clin Invest 95(5), 2266-2274 (1995).

7. Lutgens E, de Muinck ED, Kitslaar PJ, Tordoir JH, Wellens HJ, Daemen MJ: Biphasic pattern of cell turnover characterizes the progression from fatty streaks to ruptured human atherosclerotic plaques. Cardiovasc Res 41(2), 473-479 (1999).

8. Clarke MC, Figg N, Maguire JJ et al.: Apoptosis of vascular smooth muscle cells induces features of plaque vulnerability in atherosclerosis. Nat Med 12(9), 10751080 (2006).

9. Yilmaz A, Lipfert B, Cicha I et al.: Accumulation of immune cells and high expression of chemokines/chemokine receptors in the upstream shoulder of atherosclerotic carotid plaques. Exp Mol Pathol 82(3), 245-255 (2007).

10. Takaya N, Yuan C, Chu B et al:: Presence of intraplaque hemorrhage stimulates progression of carotid atherosclerotic plaques: a high-resolution magnetic resonance imaging study. Circulation 111(21), 2768-2775 (2005).

11. de Boer OJ, van der Wal AC, Teeling P, Becker AE: Leucocyte recruitment in rupture prone regions of lipid-rich plaques: a prominent role for neovascularization? Cardiovasc Res 41(2), 443-449 (1999).

12. Farb A, Burke AP, Tang AL et al.: Coronary plaque erosion without rupture into a lipid core. A frequent cause of coronary thrombosis in sudden coronary death. Circulation 93(7), 1354-1363 (1996).

13. Martinovic I, Abegunewardene $\mathrm{N}$, Seul M et al.: Elevated monocyte chemoattractant protein-1 serum levels in patients at risk for coronary artery disease. Circ $J$ 69(12), 1484-1489 (2005). 
14. Arakelyan A, Petrkova J, Hermanova Z, Boyajyan A, Lukl J, Petrek M: Serum levels of the MCP-1 chemokine in patients with ischemic stroke and myocardial infarction. Mediators Inflamm 2005(3), 175-179 (2005).

15. de Lemos JA, Morrow DA, Sabatine MS et al.: Association between plasma levels of monocyte chemoattractant protein-1 and long-term clinical outcomes in patients with acute coronary syndromes. Circulation 107(5), 690-695 (2003).

16. Herder C, Baumert J, Thorand B et al.: Chemokines and incident coronary heart disease: results from the MONICA/KORA Augsburg case-cohort study, 1984-2002. Arterioscler. Thromb. Vasc. Biol. 26(9), 2147-2152 (2006).

17. Kraaijeveld $\mathrm{AO}$, de Jager SC, de Jager WJ et al.: CC chemokine ligand-5 (CCL5/RANTES) and CC chemokine ligand-18 (CCL18/PARC) are specific markers of refractory unstable angina pectoris and are transiently raised during severe ischemic symptoms. Circulation 116(17), 1931-1941 (2007).

18. Gonzalez $\mathrm{P}$, Alvarez $\mathrm{R}$, Batalla $\mathrm{A}$ et al:: Genetic variation at the chemokine receptors CCR5/CCR2 in myocardial infarction. Genes Immun 2(4), 191-195 (2001).

19. de Jager SC, Kraaijeveld AO, Grauss RW et al.: CCL3 (MIP-1 alpha) levels are elevated during acute coronary syndromes and show strong prognostic power for future ischemic events. J Mol Cell Cardiol 45(3), 446-452 (2008).

20. Damas JK, Waehre T, Yndestad A et al.: Stromal cell-derived factor-1alpha in unstable angina: potential antiinflammatory and matrix-stabilizing effects. Circulation 106(1), 36-42 (2002).

21. Abi-Younes S, Sauty A, Mach F, Sukhova GK, Libby P, Luster AD: The stromal cellderived factor-1 chemokine is a potent platelet agonist highly expressed in atherosclerotic plaques. Circ Res 86(2), 131-138 (2000).

22. Damas JK, Boullier A, Waehre $T$ et al.: Expression of fractalkine (CX3CL1) and its receptor, CX3CR1, is elevated in coronary artery disease and is reduced during statin therapy. Arterioscler. Thromb. Vasc. Biol. 25(12), 2567-2572 (2005).

23. McDermott DH, Fong AM, Yang $Q$ et al.: Chemokine receptor mutant CX3CR1-M280 has impaired adhesive function and correlates with protection from cardiovascular disease in humans. J Clin Invest 111(8), 1241-1250 (2003).

24. Papaspyridonos M, Smith A, Burnand KG et al:: Novel candidate genes in unstable areas of human atherosclerotic plaques. Arterioscler. Thromb. Vasc. Biol. 26(8), 1837-1844 (2006).

25. Randi AM, Biguzzi E, Falciani $F$ et al.: Identification of differentially expressed genes in coronary atherosclerotic plaques from patients with stable or unstable angina by cDNA array analysis. J Thromb Haemost 1(4), 829-835 (2003).

26. Lutgens E, Faber B, Schapira $\mathrm{K}$ et al.: Gene profiling in atherosclerosis reveals a key role for small inducible cytokines: validation using a novel monocyte chemoattractant protein monoclonal antibody. Circulation 111(25), 3443-3452 (2005). 
27. Carr MW, Roth SJ, Luther E, Rose SS, Springer TA: Monocyte chemoattractant protein 1 acts as a T-lymphocyte chemoattractant. Proc Natl Acad Sci U S A 91(9), 3652-3656 (1994).

28. $\mathrm{Xu} \mathrm{LL,} \mathrm{Warren} \mathrm{MK,} \mathrm{Rose} \mathrm{WL,} \mathrm{Gong} \mathrm{W,} \mathrm{Wang} \mathrm{JM:} \mathrm{Human} \mathrm{recombinant} \mathrm{monocyte}$ chemotactic protein and other $\mathrm{C}-\mathrm{C}$ chemokines bind and induce directional migration of dendritic cells in vitro. J Leukoc Biol 60(3), 365-371 (1996).

29. Garcia-Zepeda EA, Combadiere C, Rothenberg ME et al.: Human monocyte chemoattractant protein (MCP)-4 is a novel CC chemokine with activities on monocytes, eosinophils, and basophils induced in allergic and nonallergic inflammation that signals through the CC chemokine receptors (CCR)-2 and -3 . J Immunol 157(12), 5613-5626 (1996).

30. Yla-Herttuala S, Lipton BA, Rosenfeld ME et al.: Expression of monocyte chemoattractant protein 1 in macrophage-rich areas of human and rabbit atherosclerotic lesions. Proc Natl Acad Sci U S A 88(12), 5252-5256 (1991).

31. Yu X, Dluz S, Graves DT et al.: Elevated expression of monocyte chemoattractant protein 1 by vascular smooth muscle cells in hypercholesterolemic primates. Proc Natl Acad Sci U S A 89(15), 6953-6957 (1992).

32. Takahashi $M$, Masuyama J, Ikeda $U$ et al.: Induction of monocyte chemoattractant protein-1 synthesis in human monocytes during transendothelial migration in vitro. Circ Res 76(5), 750-757 (1995)

33. Papadopoulou C, Corrigall V, Taylor PR, Poston RN: The role of the chemokines MCP$1, \mathrm{GRO}$-alpha, IL-8 and their receptors in the adhesion of monocytic cells to human atherosclerotic plaques. Cytokine 43(2), 181-186 (2008).

34. Gawaz M, Neumann FJ, Dickfeld T et al.: Activated platelets induce monocyte chemotactic protein-1 secretion and surface expression of intercellular adhesion molecule-1 on endothelial cells. Circulation 98(12), 1164-1171 (1998).

35. Struyf S, De Meester I, Scharpe $S$ et al:: Natural truncation of RANTES abolishes signaling through the CC chemokine receptors CCR1 and CCR3, impairs its chemotactic potency and generates a CC chemokine inhibitor. Eur J Immunol 28(4), 1262-1271 (1998).

36. Veillard NR, Steffens S, Burger F, Pelli G, Mach F: Differential expression patterns of proinflammatory and antiinflammatory mediators during atherogenesis in mice. Arterioscler. Thromb. Vasc. Biol. 24(12), 2339-2344 (2004).

37. Wilcox JN, Nelken NA, Coughlin SR, Gordon D, Schall TJ: Local expression of inflammatory cytokines in human atherosclerotic plaques. J Atheroscler Thromb 1 Suppl 1, S10-13 (1994).

38. Haley KJ, Lilly CM, Yang JH et al.: Overexpression of eotaxin and the CCR3 receptor in human atherosclerosis: using genomic technology to identify a potential novel pathway of vascular inflammation. Circulation 102(18), 2185-2189 (2000). 
39. Hagg DA, Olson FJ, Kjelldahl J et al.: Expression of chemokine (C-C motif) ligand 18 in human macrophages and atherosclerotic plaques. Atherosclerosis, (2008).

40. Farber JM: Mig and IP-10: CXC chemokines that target lymphocytes. J Leukoc Biol 61(3), 246-257 (1997).

41. Cheng C, Tempel D, van Haperen $\mathrm{R}$ et al.: Shear stress-induced changes in atherosclerotic plaque composition are modulated by chemokines. J Clin Invest 117(3), 616-626 (2007).

42. Luster $A D$, Ravetch JV: Biochemical characterization of a gamma interferon-inducible cytokine (IP-10). J Exp Med 166(4), 1084-1097 (1987).

43. Martinez FO, Sica A, Mantovani A, Locati M: Macrophage activation and polarization. Front Biosci 13, 453-461 (2008).

44. Mach F, Sauty A, larossi AS et al.: Differential expression of three T lymphocyteactivating CXC chemokines by human atheroma-associated cells. J Clin Invest 104(8), 1041-1050 (1999).

45. Valentin G, Haas P, Gilmour D: The chemokine SDF1a coordinates tissue migration through the spatially restricted activation of Cxcr7 and Cxcr4b. Curr Biol 17(12), 1026-1031 (2007).

46. Zernecke A, Bot I, Djalali-Talab Y et al.: Protective role of CXC receptor 4/CXC ligand 12 unveils the importance of neutrophils in atherosclerosis. Circ Res 102(2), 209-217 (2008).

47. Pitsilos S, Hunt J, Mohler ER et al.: Platelet factor 4 localization in carotid atherosclerotic plaques: correlation with clinical parameters. Thromb Haemost 90(6), $1112-1120$ (2003).

48. Yu G, Rux AH, Ma P, Bdeir K, Sachais BS: Endothelial expression of E-selectin is induced by the platelet-specific chemokine platelet factor 4 through LRP in an NFkappaB-dependent manner. Blood 105(9), 3545-3551 (2005).

49. Bazan JF, Bacon KB, Hardiman $G$ et al.: A new class of membrane-bound chemokine with a CX3C motif. Nature 385(6617), 640-644 (1997).

50. Greaves DR, Hakkinen T, Lucas AD et al.: Linked chromosome 16q13 chemokines, macrophage-derived chemokine, fractalkine, and thymus- and activation-regulated chemokine, are expressed in human atherosclerotic lesions. Arterioscler. Thromb. Vasc. Biol. 21(6), 923-929 (2001).

51. Lucas AD, Bursill C, Guzik TJ, Sadowski J, Channon KM, Greaves DR: Smooth muscle cells in human atherosclerotic plaques express the fractalkine receptor CX3CR1 and undergo chemotaxis to the $\mathrm{CX} 3 \mathrm{C}$ chemokine fractalkine (CX3CL1). Circulation 108(20), 2498-2504 (2003).

52. Boring L, Gosling J, Cleary M, Charo IF: Decreased lesion formation in CCR2-/- mice reveals a role for chemokines in the initiation of atherosclerosis. Nature 394(6696), 894-897 (1998). 
53. Gu L, Okada Y, Clinton SK et al.: Absence of monocyte chemoattractant protein-1 reduces atherosclerosis in low density lipoprotein receptor-deficient mice. Mol Cell 2(2), 275-281 (1998).

54. Inoue S, Egashira K, Ni W et al.: Anti-monocyte chemoattractant protein-1 gene therapy limits progression and destabilization of established atherosclerosis in apolipoprotein E-knockout mice. Circulation 106(21), 2700-2706 (2002).

55. Ni W, Kitamoto S, Ishibashi $\mathrm{M}$ et al:: Monocyte chemoattractant protein-1 is an essential inflammatory mediator in angiotensin II-induced progression of established atherosclerosis in hypercholesterolemic mice. Arterioscler. Thromb. Vasc. Biol. 24(3), 534-539 (2004).

56. Kuziel WA, Dawson TC, Quinones M et al.: CCR5 deficiency is not protective in the early stages of atherogenesis in apoE knockout mice. Atherosclerosis 167(1), 25-32 (2003).

57. Veillard NR, Kwak B, Pelli G et al: Antagonism of RANTES receptors reduces atherosclerotic plaque formation in mice. Circ Res 94(2), 253-261 (2004).

58. Braunersreuther $\mathrm{V}$, Steffens $\mathrm{S}$, Arnaud $\mathrm{C}$ et al.: A novel RANTES antagonist prevents progression of established atherosclerotic lesions in mice. Arterioscler. Thromb. Vasc. Biol. 28(6), 1090-1096 (2008).

59. Potteaux S, Combadiere C, Esposito B et al.: Role of bone marrow-derived CCchemokine receptor 5 in the development of atherosclerosis of low-density lipoprotein receptor knockout mice. Arterioscler. Thromb. Vasc. Biol. 26(8), 18581863 (2006).

60. Quinones MP, Martinez HG, Jimenez F et al.: CC chemokine receptor 5 influences late-stage atherosclerosis. Atherosclerosis 195(1), e92-103 (2007).

61. Potteaux S, Combadiere C, Esposito B et al.: Chemokine receptor CCR1 disruption in bone marrow cells enhances atherosclerotic lesion development and inflammation in mice. Mol Med 11(1-12), 16-20 (2005).

62. Braunersreuther $\mathrm{V}$, Zernecke A, Arnaud C et al.: Ccr5 but not Ccr1 deficiency reduces development of diet-induced atherosclerosis in mice. Arterioscler. Thromb. Vasc. Biol. 27(2), 373-379 (2007).

63. Heller EA, Liu E, Tager AM et al:: Chemokine CXCL10 promotes atherogenesis by modulating the local balance of effector and regulatory T cells. Circulation 113(19), 2301-2312 (2006).

64. van Wanrooij EJ, de Jager SC, van Es T et al.: CXCR3 antagonist NBI-74330 attenuates atherosclerotic plaque formation in LDL receptor-deficient mice. Arterioscler. Thromb. Vasc. Biol. 28(2), 251-257 (2008).

65. Veillard NR, Steffens S, Pelli G et al.: Differential influence of chemokine receptors CCR2 and CXCR3 in development of atherosclerosis in vivo. Circulation 112(6), 870878 (2005). 
66. King $\mathrm{VL}$, Lin $\mathrm{AY}$, Kristo $\mathrm{F}$ et al.: Interferon-\{gamma\} and the Interferon-Inducible Chemokine CXCL10 Protect Against Aneurysm Formation and Rupture. Circulation 119(3), 426-435 (2009)

67. Sachais BS, Turrentine T, Dawicki McKenna JM, Rux AH, Rader D, Kowalska MA: Elimination of platelet factor 4 (PF4) from platelets reduces atherosclerosis in C57BI/6 and apoE-/- mice. Thromb Haemost 98(5), 1108-1113 (2007).

68. Combadiere C, Potteaux S, Gao JL et al.: Decreased atherosclerotic lesion formation in CX3CR1/apolipoprotein E double knockout mice. Circulation 107(7), 1009-1016 (2003).

69. Vergunst CE, Gerlag DM, Lopatinskaya L et al.: Modulation of CCR2 in rheumatoid arthritis: a double-blind, randomized, placebo-controlled clinical trial. Arthritis Rheum 58(7), 1931-1939 (2008).

70. Buntinx M, Hermans B, Goossens J et al.: Pharmacological profile of JNJ-27141491 [(S)-3-[3,4-difluorophenyl)-propyl]-5-isoxazol-5-yl-2-thioxo-2,3-dihydro-1 imidazole-4-carboxyl acid methyl ester], as a noncompetitive and orally active antagonist of the human chemokine receptor CCR2. J Pharmacol Exp Ther 327(1), 1-9 (2008).

71. van Wanrooij EJ, Happe H, Hauer AD et al.: HIV entry inhibitor TAK-779 attenuates atherogenesis in low-density lipoprotein receptor-deficient mice. Arterioscler. Thromb. Vasc. Biol. 25(12), 2642-2647 (2005).

72. Johnson $\mathrm{Z}$, Kosco-Vilbois $\mathrm{MH}$, Herren $\mathrm{S}$ et al.: Interference with heparin binding and oligomerization creates a novel anti-inflammatory strategy targeting the chemokine system. J Immunol 173(9), 5776-5785 (2004).

73. de Groot M, Teunissen MB, Ortonne JP et al.: Expression of the chemokine receptor CCR5 in psoriasis and results of a randomized placebo controlled trial with a CCR5 inhibitor. Arch Dermatol Res 299(7), 305-313 (2007).

74. Pugach P, Ketas TJ, Michael E, Moore JP: Neutralizing antibody and anti-retroviral drug sensitivities of HIV-1 isolates resistant to small molecule CCR5 inhibitors. Virology 377(2), 401-407 (2008).

75. Hendrix CW, Collier AC, Lederman MM et al.: Safety, pharmacokinetics, and antiviral activity of AMD3100, a selective CXCR4 receptor inhibitor, in HIV-1 infection. J Acquir Immune Defic Syndr 37(2), 1253-1262 (2004).

76. Koenen RR, von Hundelshausen P, Nesmelova IV et al.: Disrupting functional interactions between platelet chemokines inhibits atherosclerosis in hyperlipidemic mice. Nat Med 15(1), 97-103 (2009).

77. Nanki T, Urasaki Y, Imai T et al.: Inhibition of fractalkine ameliorates murine collageninduced arthritis. J Immunol 173(11), 7010-7016 (2004).

78. Zeng $\mathrm{Y}$, Jiang J, Huebener $\mathrm{N}$ et al.: Fractalkine gene therapy for neuroblastoma is more effective in combination with targeted IL-2. Cancer Lett 228(1-2), 187-193 (2005). 
79. Rosenfeld ME, Polinsky P, Virmani R, Kauser K, Rubanyi G, Schwartz SM: Advanced atherosclerotic lesions in the innominate artery of the ApoE knockout mouse. Arterioscler. Thromb. Vasc. Biol. 20(12), 2587-2592 (2000).

80. Johnson $\mathrm{JL}$, Jackson $\mathrm{CL}$ : Atherosclerotic plaque rupture in the apolipoprotein $\mathrm{E}$ knockout mouse. Atherosclerosis 154(2), 399-406 (2001).

81. Calara F, Silvestre M, Casanada F, Yuan N, Napoli C, Palinski W: Spontaneous plaque rupture and secondary thrombosis in apolipoprotein E-deficient and LDL receptordeficient mice. J Pathol 195(2), 257-263 (2001).

82. Soriano V, Geretti AM, Perno CF et al.: Optimal use of maraviroc in clinical practice. AIDS 22(17), 2231-2240 (2008).

83. Stiff $\mathrm{P}$, Micallef I, McCarthy $\mathrm{P}$ et al.: Treatment with plerixafor in non-Hodgkin's lymphoma and multiple myeloma patients to increase the number of peripheral blood stem cells when given a mobilizing regimen of G-CSF: implications for the heavily pretreated patient. Biol Blood Marrow Transplant 15(2), 249-256 (2009). 


\section{Chapter 3}

\section{CXCR4 blockade induces atherosclerosis by perturbing neutrophil apoptosis and senescence}

Ilze Bot*, Isabelle Daissormont*, Alma Zernecke, Birgit Kramp, Saskia de Jager, Marijke Westra, Martine Bot, Peter van Santbrink, Theo van Berckel, Lishan Su, Pal Aukrust, Rory Koenen, Christian Weber, Erik Biessen

* Both authors have contributed equally

In revision at European Heart Journal 


\section{Chapter 3}

\section{Abstract}

The SDF-1 $\alpha /$ CXCR4 dyad was previously shown by us and others to be instrumental in intimal hyperplasia as well as early stage atherosclerosis. We here sought to investigate its impact on clinically relevant stages of atherosclerosis in mouse and man. Immunohistochemical analysis of SDF-1 $\alpha$ and CXCR4 expression in human atherosclerotic lesions revealed a progressive reduction in SDF-1 $\alpha$ and a concomitant increase in CXCR4 expression during plaque progression. We next studied effects of perturbed SDF-1 $\alpha /$ CXCR4 signalling on advanced atherosclerosis in chimeric $\mathrm{LDLr}^{-/}$mice reconstituted with autologous bone marrow infected with virus encoding SDF-1 $\alpha$ antagonist or CXCR4 degrakine, which targets CXCR4 to the proteasome. Functional CXCR4 blockade led to progressive plaque expansion with disease progression, while also promoting intraplaque haemorrhage. Moreover, CXCR4 knockdown was seen to augment endothelial adhesion of neutrophils. Concordant with this finding, inhibition of CXCR4 function increased the adhesive capacity of neutrophils, and importantly, led to reduced neutrophil apoptosis with a concomitant hyperactivation of circulating neutrophils. The finding that CXCR4 expression by circulating neutrophils was almost ablated in patients with acute cardiovascular syndromes further substantiates the key role of neutrophil SDF$1 \alpha / C X C R 4$ axis in end-stage atherosclerosis. In conclusion, altered CXCR4 function profoundly impacts advanced atherosclerosis by perturbing neutrophil function. 


\section{Introduction}

Leukocyte recruitment to the plaque is a crucial step in the progression of atherosclerosis. ${ }^{1-3}$ Chemokines are chemotactic cytokines involved in the recruitment of leukocytes to the plaque $\mathrm{e}^{4-6}$ and several members of the CC- and CXC-chemokine family and their receptors have been implicated in the progression of cardiovascular disease. One of these CXC chemokines, CXCL12 (SDF-1 $\alpha$ ), was demonstrated to be expressed by vascular smooth muscle cells (VSMCs), endothelial cells, and macrophages in atherosclerotic but not healthy arteries. ${ }^{7,8}$ Although these findings may suggest a potential role in atherosclerosis, the exact role of the SDF-1 $\alpha / C X C R 4$ axis in atherosclerosis has long been unclear. A number of reports pointed to a pro-atherosclerotic role for SDF-1 $\alpha$ due to its participation in platelet activation and leukocyte chemotaxis, ${ }^{7,9}$ while blockade of the SDF-1 $\alpha / C X C R 4$ axis was demonstrated to inhibit neointima formation. ${ }^{10}$ Conversely, Damås and colleagues demonstrated reduced SDF-1 $\alpha$ levels in patients with unstable angina pectoris, and a causal role in this disease was inferred from the anti-inflammatory and matrix-stabilizing effects of SDF- $1 \alpha .{ }^{8}$ This notion was corroborated by recent study by us showing that systemic blockade of CXCR4 by the SDF-1 $\alpha$ antagonist AMD3465 enhanced plaque initiation due to increased neutrophil recruitment. ${ }^{11}$

In this study, we mapped the actual expression level of SDF-1 $\alpha$ and its receptor CXCR4 at different stages of human atherosclerosis. The observed progressive deregulation of SDF-1 $\alpha / C X C R 4$ expression in human atherosclerosis led us to investigate effects of CXCR4 blockade at different stages of plaque formation in mice by a loss-of-function approach using lentivirus encoding SDF-1 $\alpha$ antagonist P2G $^{12}$ (LV.SDF-1 $\alpha(P 2 G)$ ) or CXCR4 degrakine (LV.CXCR4deg), which effects proteasomal CXCR4 degradation. ${ }^{13}$ We here provide evidence for a clearcut adverse effect of CXCR4 blockade on advanced atherosclerosis in mice and man, by impairing the elimination of senescent neutrophils, and an associated increase in activation and adhesive capacity. 
Chapter 3

\section{Materials and methods}

\section{Human artery samples}

Tissue sampling: Carotid artery samples were obtained from patients undergoing carotid endarterectomy (Academic Hospital Maastricht or Maasland Hospital, Sittard, The Netherlands) or at autopsy (Department of Pathology, Academic Hospital Maastricht, The Netherlands). Tissue was obtained from the Maastricht Pathology Tissue Collection (MPTC), and collection, storage and use of tissue and patient data were performed in accordance with the "Code for Proper Secondary Use of Human Tissue". Samples were classified according to Virmani et $\mathrm{al}^{14}$ Healthy arteries were classified as non-diseased (ND), intimal thickening (IT) as early, thick fibrous cap atheroma (TfCA) as advanced and intraplaque haemorrhaged lesions (IPH) as ruptured lesions.

Immunohistochemistry: Paraffin sections (4 $\mathrm{mm}$ in thickness) from human autopsy carotid arteries were stained with a mouse anti-human SDF-1 $\alpha$ MAb (clone 79018; R\&D Systems; $25 \mu \mathrm{g} / \mathrm{mL}$ ). For CXCR4 staining, sections were stained with a mouse anti-human CXCR4 MAb (clone 44716; R\&D Systems; $1 \mu \mathrm{g} / \mathrm{mL}$ ). An IgG2b MAb (clone 73009; R\&D Systems; $1 \mu \mathrm{g} / \mathrm{mL}$ ) was used as isotype control.

RNA isolation: Total RNA was extracted from human carotid arteries obtained from surgery and autopsy. RNA was isolated by using the Guanidine Thiocyanate (GTC)/CsCl gradient method ${ }^{15}$ and a NucleoSpin RNA II kit.

Micro-array analysis: RNA was isolated from early $(n=9)$ and advanced $(n=8)$ stable carotid arteries collected at autopsy ${ }^{16}$ and stable $(n=3)$ and ruptured $(n=12)$ lesions from surgery (unpublished data). Plaque stage was determined by histological analysis of aligning slides. Samples were individually hybridized to HGU133 2.0 Plus arrays (Affymetrix, Santa Clara, California) according to the manufacturer's instructions. To determine fold changes between the groups, the error model of Rosetta Resolver (Rosetta Biosoftware, Seattle, Washington) was used.

\section{Lentivirus vector construction and production}

The SDF-1 $\alpha$ antagonist expression vector (pRRI-cPPt-CMV.SDF-1 $\alpha(P 2 G)$ : LV.SDF$1 \alpha(P 2 G)$ ) was constructed by inserting the SDF- $1 \alpha(P 2 G)^{17}$ construct in the 
expression vector pRRI-cPPt-CMV-PreSIN ${ }^{18,19}$ (LV.Empty) using Smal digestion. PRRI-CPPT-CMV.CXCR4degrakine (LV.CXCR4deg) was constructed by inserting the CXCR4degrakine construct by digestion from pHSPG-SDF-1 $\alpha-H A-V p u C .{ }^{20}$ A lentivirus vector containing a shRNA sequence targeting murine and human CXCR4 (shX4HM) was constructed as a positive control. Virus was produced as described $^{6}$ and virus titers were determined essentially as described by Sastry et al. ${ }^{21}$ Viral integrates were determined by qPCR analysis (forward primer: GTGCAGCAGCAGAACAATTTG, reverse primer: CCCCAGACTGTGAGTTGCAA).

\section{Chemokinesis assay}

FDCP-MixA4 cells were cultured at $1 * 10^{6}$ cells $/ \mathrm{mL}$ in RPMI supplemented with $20 \%$ Horse Serum (Invitrogen) and 5\% IL3-conditioned medium and were infected with LV.Empty, LV.SDF-1 $\alpha$ (P2G) or LV.CXCR4deg (m.o.i. $=15,+10 \mu \mathrm{g} / \mathrm{mL}$ DEAEdextran). After two days, a chemokinesis assay was performed essentially as described previously. ${ }^{22}$ In short, 5000 FDCP-MixA4 cells were plated on fibronectin ( $5 \mu \mathrm{g} / \mathrm{mL}$, Roche Diagnostics) coated plates at an angle of $70^{\circ}$. After attachment, cells were exposed to $100 \mathrm{ng} / \mathrm{mL}$ recombinant SDF-1 $\alpha$ (Peprotech, Halle-Zoersel, Belgium) and placed at an angle of $20^{\circ}$. After overnight incubation at $37^{\circ} \mathrm{C}$, migrated cells were counted.

\section{Animals}

All animal work was approved by the regulatory authority of Leiden and Maastricht University and performed in compliance with the Dutch government guidelines. $\mathrm{LDLr}^{-1-}$ mice were obtained from the local animal breeding facility (Leiden/Maastricht, the Netherlands). C57BI6 mice were obtained from Charles River Laboratories, Maastricht, The Netherlands. Bone marrow transplanted mice were housed in sterile filter-top cages and fed a chow diet (Special Diet Services, Witham, Essex, UK). Drinking water was infused with antibiotics $(83 \mathrm{mg} / \mathrm{L}$ ciprofloxacin and $67 \mathrm{mg} / \mathrm{L}$ polymyxin B sulfate) and $6.5 \mathrm{~g} / \mathrm{L}$ sugar and was provided ad libitum. To induce bone marrow aplasia, female $\mathrm{LDLr}^{-/}$mice (14 weeks of age) were exposed to a single dose of $9 \mathrm{~Gy}(0.19 \mathrm{~Gy} / \mathrm{min}, 200 \mathrm{kV}, 4 \mathrm{~mA})$ 
total body irradiation, using an Andrex Smart 225 Röntgen source (YXLON International, Copenhagen, Denmark) with a $6 \mathrm{~mm}$ aluminium filter, one day before transplantation. Subsequently, bone marrow cell suspensions were prepared from male $\mathrm{LDLr}^{-/-}$mice and $10^{7}$ cells/well were plated in a 12 well plate. Viral transductions were performed by incubating the cells with either LV.Empty, LV.SDF-1 $\alpha\left(\right.$ P2G) or LV.CXCR4deg (m.o.i. = 15). ${ }^{23}$ After 24 hours, cells were injected into the tail vein of the recipients. After 6 weeks of recovery, the mice were placed on a Western type diet, containing $0.25 \%$ cholesterol and $15 \%$ cacao butter (Special Diet Services, Witham, Essex, UK) for another 6 ( $n=8$ per group) and 10 weeks ( $n=8-11$ per group). During the experiment, antibody levels (IgG1, IgG2a and IgM levels) were determined using a mouse immunoglobulin isotype ELISA (BD Biosciences), as CXCR4 may indirectly influence atherogenesis by regulation of $B$ and $T$ cell responses. However, we did not observe any differences in immunoglobulin levels between the three groups (data not shown), suggesting that knockdown of leukocyte CXCR4 did not induce major systemic shifts in B cell activity or T cell polarization. At 12 and 16 weeks after transplantation, the mice were anaesthetized by a subcutaneous injection of ketamine $(60 \mathrm{mg} / \mathrm{kg}$, Eurovet Animal Health, Bladel, the Netherlands), fentanyl citrate and fluanisone (1.26 $\mathrm{mg} / \mathrm{kg}$ and $2 \mathrm{mg} / \mathrm{kg}$ respectively, Janssen Animal Health, Sauderton, UK) and in situ fixation through the left cardiac ventricle was performed. Lesions in the aortic root were analyzed for lesion quantification. Also, bone marrow was isolated from each individual mouse and viral copy number in the bone marrow was determined by PCR as described above.

\section{Flow cytometry analysis}

After erythrocyte lysis, blood and peritoneal leukocyte suspensions were incubated with $1 \%$ mouse serum in PBS and stained for surface markers $(0.25$ $\mu \mathrm{g} / 200,000$ cells, Immunosource, Halle-Zoersel, Belgium), after which surface marker expression was analyzed by FACS (FACScalibur, BD Biosciences). To differentiate cell populations, $T$ cells were stained with $\alpha C D 3, B$ cells with $\alpha C D 19$ and monocytes/macrophages with $\alpha \mathrm{F} 4 / 80$, while CXCR4 expression was detected with $\alpha C X C R 4$. Neutrophils were distinguished as the $\mathrm{CD} 11 \mathrm{~b}^{+} \mathrm{Gr} 1^{\text {high }} \mathrm{CD} 71^{-}$cell population. 


\section{Morphometry}

The atherosclerotic lesion areas in Oil-Red-O stained $10 \mu \mathrm{m}$ thick cryostat sections of the aortic root were quantified using the Leica image analysis system (Leica Ltd, Cambridge, UK). Mean lesion area (in $\mu^{2}$ ) was calculated from 10 Oil-Red-O stained sections. Iron staining was performed according to Perl's method. Macrophage content of the lesions was assessed from the MOMA-2 stained plaque area (Serotec, Kidlington, Oxford, UK). Collagen was stained using a Masson's Trichrome staining kit (Sigma-Aldrich). Neutrophils were stained with a Naphtol-AS-D chloroacetate esterase staining kit (Sigma-Aldrich). All morphometric analyses were performed in a blinded manner by an independent operator.

In vivo migration

To monitor in vivo migration of leukocytes and in particular neutrophils, LDLr $^{-1}$ mice that were transplanted with either LV.Empty or LV. CXCR4deg infected bone marrow received intraperitoneal injections of KC $(200 \mathrm{ng} / \mathrm{mL})$, SDF-1 $\alpha(200 \mathrm{ng} / \mathrm{mL}$, both from Peprotech) or PBS (control) at 6 weeks after transplantation. After 2 hours, blood was collected and peritoneal leukocytes were isolated. Blood (1:1 dilution), peritoneal leukocyte numbers and cellular differentiation were determined on a Sysmex differential cell counter (Goffin Meyvis, Etten-Leur, Nederland).

In vivo neutrophil recruitment in thioglycollate elicited peritonitis

Female C57BI6 mice were injected intraperitoneally with the CXCR4 receptor antagonist AMD3100 (2 $\mathrm{mg} / \mathrm{mouse}$, Sigma-Aldrich, Zwijndrecht, The Netherlands) or PBS and 4 hours later, the mice received an intraperitoneal injection of $3 \%$ Brewer's thioglycollate $(1 \mathrm{~mL})$. After 16 hours, peritoneal leukocytes were collected and cellular differentiation was analyzed on a Sysmex as described above. 


\section{Assessment of leukocyte turnover}

Female LDLr $^{-1-}$ mice, either treated with the CXCR4 antagonist AMD3100 (2 $\mu \mathrm{g} /$ mouse/day) or PBS (control) from 1 day prior to and during the experiment, received an intraperitoneal injection of cyclophosphamide $(6 \mathrm{mg} / \mathrm{mouse})$ to deplete blood neutrophils as described previously. ${ }^{24,25}$ Blood samples were taken via the tail vein regularly and blood cell differentiation was performed as described above.

\section{Neutrophil differentiation in vitro}

HL60 myeloblast cells were grown in IMDM, supplemented with 10\% FCS, Lglutamine, penicillin and streptomycin, and maintained at $0.2 * 10^{6}$ cells $/ \mathrm{mL}$. To differentiate HL60 cells into neutrophils, HL60 cells were incubated for 5-7 days in medium containing $2.5 \mu \mathrm{M}$ Retinoic Acid (RA) either in the presence or absence of AMD3100 (500 ng/mL). ${ }^{25,26}$ Differentiation was monitored microscopically and by FACS analysis ( $\left.\mathrm{CD} 11 \mathrm{~b}^{+} \mathrm{Gr1}{ }^{+} \mathrm{CD} 71^{-}\right)$. Cell adhesion was monitored by manual scoring of the number of adhered cells (10 microscopic fields/sample) to either uncoated wells or wells coated with $5 \mathrm{\mu g} / \mathrm{mL}$ fibronectin (Roche Diagnostics) or $1 \%(\mathrm{w} / \mathrm{v}$ ) of bovine skin gelatin (Sigma-Aldrich). To measure HL6O cell proliferation, the differentiated cells were incubated with $0.5 \mu \mathrm{Ci}\left[{ }^{3} \mathrm{H}\right]$ thymidine (Amersham, Uppsala, Sweden), after which the cells were incubated at $37^{\circ} \mathrm{C}$ overnight. After cell lysis, $\left[{ }^{3} \mathrm{H}\right]$ thymidine incorporation was quantified in a liquid scintillation counter (Packard 1500 Tricarb, USA). To measure cell survival, HL60 cells, differentiated as described above, were stained with Annexin $\mathrm{V}$ and propidium iodide according to the manufacturer's protocol (Sigma-Aldrich); cell survival rate (defined by non-apoptotic, non-necrotic cells) was determined using FACS analysis. To determine MPO activity in the differentiated HL60 cells ( \pm AMD3100), $10^{6}$ cells were lysed in $150 \mu \mathrm{L} 5 \%$ Triton X-100 (Fluka, Zwijndrecht, the Netherlands). $50 \mu \mathrm{L}$ cell lysate was diluted with $50 \mu \mathrm{L} 10 \mathrm{mM}$ citrate (pH 5) after which $50 \mu \mathrm{L}$ substrate $\left(100 \mu \mathrm{g} / \mathrm{mL}\right.$ TMB, $0.003 \% \mathrm{H}_{2} \mathrm{O}_{2}, 13 \mu \mathrm{g} / \mathrm{mL}$ recorsinol in 10 $\mathrm{mM}$ citrate $(\mathrm{pH} 5))$ was added. After 10 minutes, the reaction was stopped with $100 \mu \mathrm{L} 2 \mathrm{M} \mathrm{H}_{2} \mathrm{SO}_{4}$ and absorbance was read at $450 \mathrm{~nm}$. Total RNA was extracted from the differentiated HL60 cells, reverse transcribed using M-MuLV reverse transcriptase (RevertAid, MBI Fermentas, Leon-Roth, Germany) and expression of 
target genes (Table 1) was measured by qPCR on an ABI PRISM 7500 Taqman apparatus (Applied Biosystems, Foster City, CA) as described previously. ${ }^{27}$

Table 1. Primer sequences used for RT-PCR analysis ( $m=$ murine, $h=$ human)

\begin{tabular}{|c|c|c|}
\hline Gene & Forward (5'-3') & Reverse (5'-3') \\
\hline mFAK & GAGAATCCAGCTTTGGCTGTT & GGCTTCTTGAAGGAACTTCT \\
\hline mAKT & GGTATTTTGATGAGGAGTTCACG & ACACACTCCATGCTGTCATCTT \\
\hline mCXCR4 & GCCTTATCCTGCCTGGTATTGTC & GCGAAGAAAGCCAGGATGAGGA \\
\hline hCXCR4 & CTGCTGACTATTCCCGACTT & TGAAACTGGAACACAACCAC \\
\hline hSDF-1 $1 \alpha$ & GATTCTTCGAAAGCCATGTT & CACTTTAGCTTCGGGTCAAT \\
\hline
\end{tabular}

\section{Neutrophil senescence}

$\mathrm{LDLr}^{-1 /}$ mice fed a Western type diet for 3 weeks received daily an intraperitoneal injection of AMD3100 (2 $\mathrm{\mu g} /$ mouse) or PBS. Neutrophil senescence was assessed by flow cytometry analysis (Ly6G ${ }^{\text {high }} \mathrm{CD} 11 \mathrm{~b}^{\text {high }}$ Rhodamine $123^{+}$) on blood leukocytes, after incubation at $37^{\circ} \mathrm{C}$ with $1 \mu \mathrm{M}$ dihydrorhodamine 123 (DHR123) and subsequent stimulation for $30 \mathrm{~min}$ with $20 \mu \mathrm{g} / \mathrm{ml}$ phorbol myristate acetate (PMA) to allow generation of intracellular $\mathrm{H}_{2} \mathrm{O}_{2}$.

\section{CXCR4 protein expression on human circulating granulocytes}

Granulocytes were isolated from healthy controls $(n=13)$, carotid endarterectomy $(n=5)$ and unstable angina pectoris patients $(n=19)$. Granulocytes were isolated from whole blood samples (Lymphoprep ${ }^{\mathrm{TM}}$ Isolation). Granulocyte preps were lysed in lysate buffer ( $200 \mathrm{mM} \mathrm{NaCl}, 5 \mathrm{mM}$ EDTA, $10 \mathrm{mM}$ Tris, 10\% glycine, $1 \mathrm{mM}$ phenylmethanesulphonylfluoride, $1 \mu \mathrm{g} / \mathrm{ml}$ leupeptine and $28 \mu \mathrm{g} / \mathrm{ml}$ aprotinin) and used for detection of CXCR4 protein expression by western-blotting. In brief, samples $(25 \mu \mathrm{l})$ were separated by SDS-PAGE (12\%) and transferred to nitrocellulose with the iBlot dry blotting system (Invitrogen, Karlsruhe, Germany). Blots were reacted with $1 \mathrm{\mu g} / \mathrm{ml} \alpha \mathrm{CXCR} 4$ (Abcam, Cambridge, USA). As control, the same blots were reacted to aActin (Millipore, Billerica, USA). Blots were 
evolved with the Luminescent image analyzer LAS 3000 (Fujifilm, Düsseldorf, Germany) and quantification was performed with MultiGauge (Fujifilm). Patients for this study were recruited at the Department of Cardiology, University Hospital Oslo, Oslo, Norway. The study included 5 patients ( 4 male, 1 female, average age of 67 ) with high-grade internal carotid stenosis ( $270 \%)$, diagnosed and classified by precerebral color duplex and CT angiography according to consensus criteria, and 19 patients with unstable angina pectoris ( 14 male, 5 female, average age of 63). All patients with unstable angina had experienced ischemic chest pain at rest within the preceding 48 hours (ie, Braunwald's class IIIB), but with no evidence of myocardial necrosis by enzymatic criteria. Transient ST-T segment depression and/or T-wave inversion were present in all cases. For comparison, blood was collected from 13 healthy controls, comparable to the patients group for age, sex and smoking habits. The controls were health care workers, consecutively recruited from the same area of Norway as the patients. All human work was approved by the Ethical Committee of the University Hospital Oslo. Signed informed consent for participation in the study was obtained from all individuals.

\section{Statistical analysis}

Data are expressed as mean \pm SEM. A 2-tailed Student's t-test was used to compare individual groups. To determine the significance of the relative mRNA expression levels, statistical analysis was performed on $\mathrm{Ct}$ values. Non-parametric data were analyzed using a Mann-Whitney $U$ test. Frequency data analysis was performed by means of the Fisher's exact test. Data were considered statistically significant when $\mathrm{P}<0.05$. 


\section{Results}

Deregulated expression of the SDF-1 $\alpha /$ CXCR4 dyad in human atherosclerotic lesions

First we have mapped SDF-1 $\alpha$ and CXCR4 expression in diseased human endarterectomy specimen. Plaques were staged according to Virmani et al. ${ }^{14}$ Micro-array (Figure 1A) showed a trend towards increased SDF-1 $\alpha$ expression in advanced versus early atherosclerotic lesions, whereas SDF-1 $\alpha$ expression was significantly reduced in ruptured versus advanced lesions. CXCR4 expression was up-regulated during plaque progression in a stage dependent manner, being significantly higher in advanced versus early and most pronounced in ruptured lesions. SDF-1 $\alpha$ and CXCR4 mRNA expression data were verified at protein level by immunohistochemistry. Both proteins could be detected in normal arteries (Figure 1B). SDF-1 $\alpha$ expression was primarily localized in intimal leukocytes and medial vSMCs, and decreased during plaque progression (Figure 1B and C). CXCR4 expression by intimal leukocytes and VSMCs was increased in advanced and ruptured lesions (Figure 1B and $\mathbf{C}$ ), reflective of the increased plaque leukocyte content. A mouse lgG2b isotype control did not show any staining (Figure 1D). 
A

\begin{tabular}{ccc}
\hline & Fold change & P-value \\
\hline SDF-1 $\alpha$ & & \\
Early carotis versus advanced carotis & 1.41332 & 0.05061 \\
Advanced carotis versus ruptured & -2.74318 & 0.01817 \\
CXCR4 & & \\
Early carotis versus advanced carotis & 2.87612 & 0.00005 \\
Advanced carotis versus ruptured & 3.01448 & $1.810^{-6}$ \\
\hline
\end{tabular}

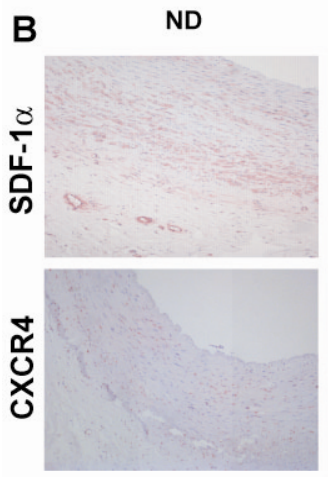

C

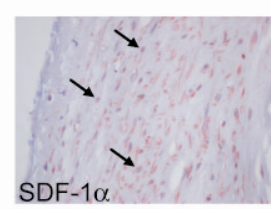

IT
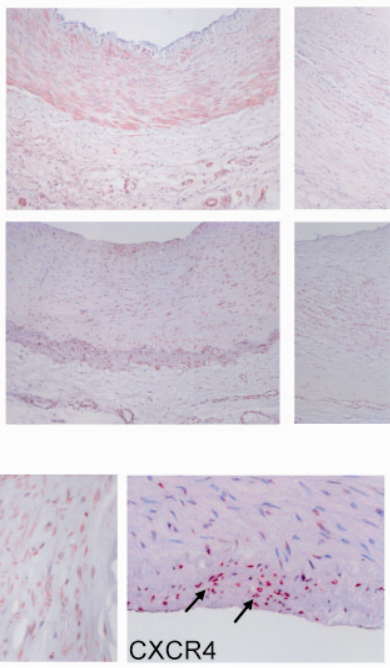

TfcA

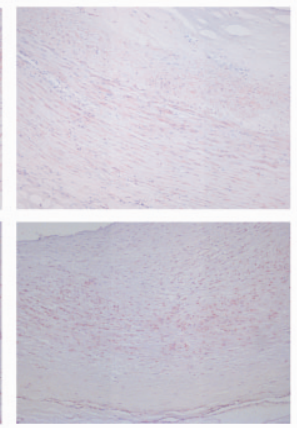

D

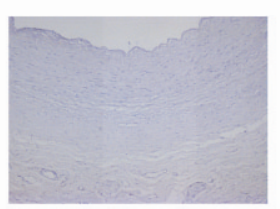

IPH

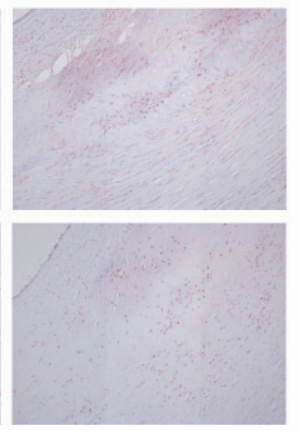

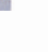

\section{.}

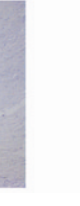

Figure 1. Human plaque analysis of SDF-1 $\alpha$ and CXCR4 expression. A, Microarray analysis of SDF- $1 \alpha$ and CXCR4 expression in early (intimal thickening (IT); $n=9$ ) versus advanced (thick fibrous cap atheroma (TfCA); $\mathrm{n}=8$ ) and advanced (thick fibrous cap atheroma (TfCA); $n=3$ ) versus ruptured (intraplaque hemorrhage (IPH); $n=12$ ) atherosclerotic lesions. B, SDF$1 \alpha$ is highly expressed in non-diseased (ND) arteries and early stable lesions, but expression decreases during plaque progression into advanced and ruptured lesions (upper panels), while in contrast, CXCR4 is only moderately expressed in non-diseased arteries and early lesions but expression increases in advanced and ruptured plaques (lower panels, magnification: 100x). C, SDF-1 $\alpha$ (left panel) and CXCR4 (right panel) expression by intimal cells (magnification: 400x). D, Mouse isotype lgG2b control (magnification: 100x). 


\section{Effective impairment of CXCR4 function by SDF-1 $\alpha$ antagonist and CXCR4 degrakine lentivirus in mice}

The deregulation of SDF-1 $\alpha / C X C R 4$ expression in human atherosclerosis led us to investigate effects of CXCR4 blockade at different stages of plaque formation by a lentivirus loss-of-function approach. Lentivirus was developed encoding CXCR4 degrakine (LV.CXCR4deg) or SDF-1 $\alpha$ antagonist (LV.SDF1 $\alpha(P 2 G)$ ) under the CMV promotor. An empty lentivector (LV.Empty) was used as control. To establish functionality of the lentivector, basal and SDF-1 $\alpha$ induced motility of FDCP-MixA4 cells in the absence or presence of LV.SDF1 $\alpha($ P2G) was measured in a slope-well assay (Figure 2A-C). SDF-1 $\alpha$ induced cell migration was completely blocked upon LV.SDF1 $\alpha(P 2 G)$ or LV.CXCR4deg (m.o.i.=15) infection (Figure 2D), comparable to infection with a lentivirus containing a shRNA sequence targeting CXCR4 ( $\mathrm{ShX} 4 \mathrm{HM}$ ), while SDF-1 $\alpha$ was able to induce LV.Empty infected cell migration. Of note, even basal cell migration was inhibited by blockade of CXCR4, which can probably be ascribed to endogenous SDF- $1 \alpha$ content in the bovine serum containing medium. Next, we tested LV.CXCR4deg functionality in vivo by reconstituting irradiated LDLr ${ }^{-/}$mice with LV.CXCR4deg infected bone marrow. The number of circulating $\mathrm{CXCR}^{+}$neutrophils was significantly reduced compared to that in control mice (Figure $2 \mathrm{E}$ ). CXCR4 expression on $\mathrm{CD}^{+} \mathrm{T}$ cells was reduced (-38\%, mean fluorescence intensity (MFI): $74.2 \pm 12.8$ in controls versus $45.5 \pm 5.8$ in LV.CXCR4deg mice), as well as on CD19 ${ }^{+}$B cells $(-30 \%, \mathrm{MFI}: 65.5 \pm 9.0$ versus $46.3 \pm 5.6)$ and F4/80 ${ }^{+}$monocytes $(-30 \%$, MFI: $55.9 \pm 11.7$ versus $31.8 \pm 1.6$ ) in LV.CXCR4deg bone marrow transplanted mice compared to LV.Empty controls at 16 weeks after bone marrow transplantation, demonstrating that LV.CXCR4deg is an efficient tool to reduce CXCR4 protein levels on leukocytes. 


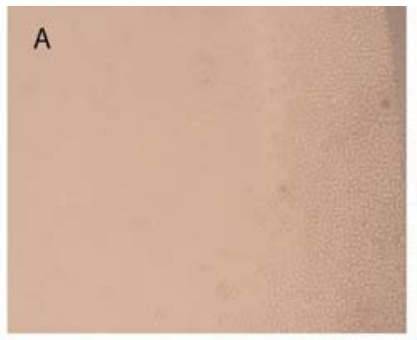

D

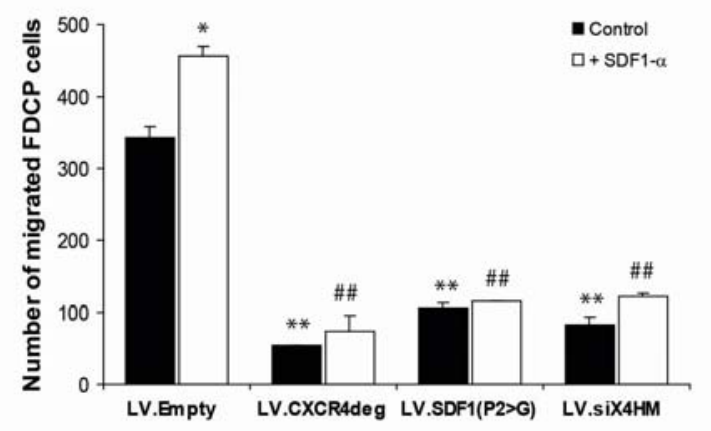

$E$

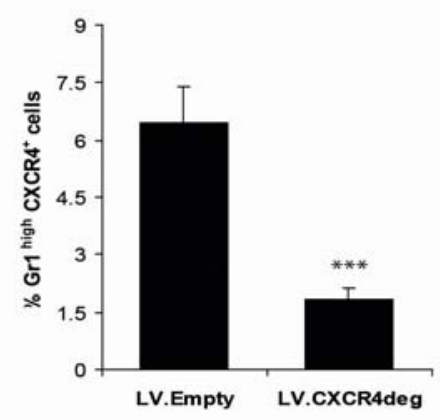

Figure 2. In vitro and in vivo analysis of functionality of lentiviral CXCR4 degrakine and SDF-1 $\alpha$ antagonist. FDCP-MixA4 cells were cultured in vitro and used to study migration in a slope well assay. A, Light microscopy image of non-stimulated FDCP-MixA4 cells, B, FDCP-MixA4 cells treated with recombinant SDF-1 $\alpha(100 \mathrm{ng} / \mathrm{mL})$ and C, FDCP-MixA4 cells expressing the SDF1- $\alpha(P 2 G)$ antagonist and treated with recombinant SDF- $1 \alpha(100 \mathrm{ng} / \mathrm{mL})$. D, Quantification of migrated FDCP-MixA4 cells infected with LV.Empty, LV.SDF1- $\alpha(P 2 G)$, LV.CXCR4deg or a shRNA targeting CXCR4 (shX4HM) without stimulation (black bars) or in response to SDF-1 $\alpha$ (white bars). $\left({ }^{\# \#} P<0.01,{ }^{*} P<0.05\right.$, $\left.{ }^{* *} P<0.01\right)$. E, Flow cytometry analysis of relative circulating $\mathrm{CXCR}^{+}$neutrophils in LV.CXCR4deg versus LV.Empty chimeras. $(* * * P<0.005)$

Hematopoietic CXCR4 deficiency aggravates atherosclerotic lesion progression and induces intraplaque hemorrhages in $\mathrm{LDLr}^{-/-}$mice

To address the role of CXCR4 blockade on atherosclerosis, we examined lesion development and progression in LDLr ${ }^{-/}$mice reconstituted with LV.CXCR4deg and LV.SDF-1 $\alpha(P 2 G)$ infected bone marrow and fed a Western type diet. For plaque initiation and progression, aortic root lesions were examined after 6 and 10 weeks 
of Western type diet feeding, respectively. During the experiments, no differences in total body weight and plasma total cholesterol levels were observed between the groups. CXCR4 blockade increased plaque progression in LV.CXCR4deg treated mice compared to control mice (10 weeks after Western type diet; Figure 3A, left panel). A similar aggravation of lesion progression was observed in LV.SDF$1 \alpha(P 2 G)$ bone marrow reconstituted mice. Atherosclerotic lesion development was not notably affected in the plaque initiation study ( 6 weeks of Western type diet feeding, right panel). Interestingly, more lesions (5/8) of LV.CXCR4deg chimeras in the plaque initiation study displayed intraplaque hemorrhages (IPH) compared to LV.Empty controls (1/8) (Figure 3B), and on average the area of extravasated intraplaque erythrocytes was larger in these lesions (Figure 3C). There was no difference in plaque collagen and VSMC content (data not shown), while plaque macrophage content was unaltered as well (Figure 3D).
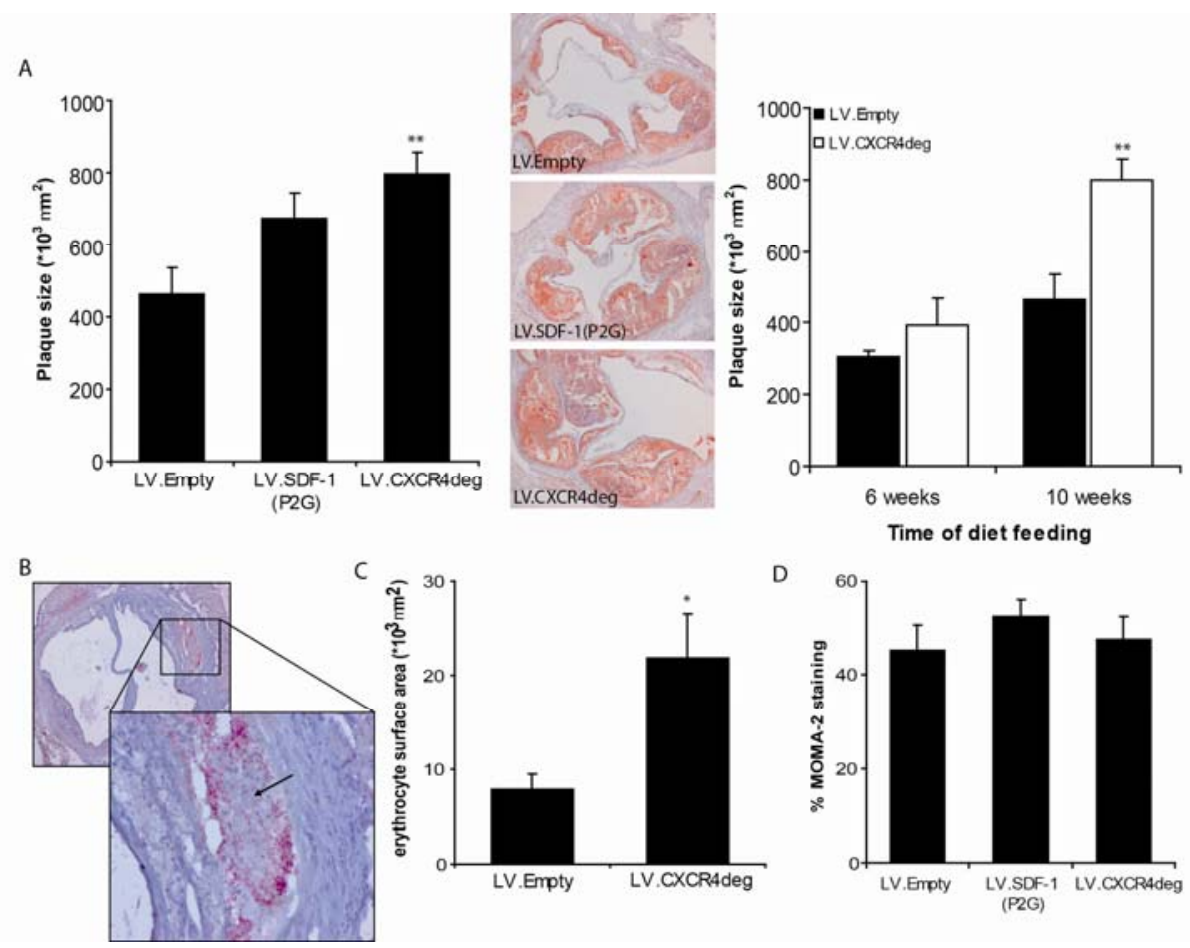

Figure 3. CXCR4 and SDF-1 $\alpha$ lentiviral blockade deteriorates atherosclerotic plaque progression. LDLr ${ }^{-1-}$ mice were transplanted with LV.empty, LV.CXCR4deg or LV.SDF1(P2G) bone marrow and placed on Western type diet for 6 (plaque initiation study, $n=8$ per 
group) and 10 weeks (plaque progression study, $n=8-11$ per group). A, Oil-Red-O staining of the aortic root. Blockade of CXCR4 by LV.CXCR4deg aggravated lesion progression in $\mathrm{LDLr}^{-1-}$ mice $\left({ }^{* *} P=0.002\right.$, left graph). Similarly, hematopoietic overexpression of the SDF$1 \alpha(P 2 G)$ antagonist induced lesion progression after 10 weeks of diet feeding $(P=0.06$, left graph). Right panel: representative lesions of each group (50x magnification). Plaque development was not affected by CXCR4 blockade ( $P=0.25$, right graph). B, Intraplaque hemorrhage in a LV.CXCR4deg plaque indicated by the arrow (upper left: 50x magnification, lower right: 200x magnification). C, Increased intraplaque hemorrhage was observed as measured by the relative erythrocyte surface area in plaques of CXCR4 degrakine chimeras $\left({ }^{*} P=0.01\right)$. Data are represented for the 6 weeks group. D, Plaque macrophage (MOMA-2) content, represented as the percentage of MOMA-2 ${ }^{+}$cells per plaque area. Data are represented for the 10 weeks group.

\section{Neutrophils show increased plaque adherence in the absence of CXCR4}

As the SDF-1/CXCR4 dyad is important for neutrophil homeostasis, we analyzed effects on neutrophils. The total number of $\mathrm{CD} 11 \mathrm{~b}^{+} \mathrm{Gr} 1^{\text {high }} \mathrm{CD} 71^{-}$blood neutrophils remained unaffected in LV.CXCR4deg versus LV.Empty transplanted chimeras (Figure 4A). The number of intraplaque neutrophils was somewhat increased in the plaque initiation study ( $32 \pm 10$ neutrophils versus $21 \pm 6$ in controls), while neutrophil numbers decreased during plaque progression in both groups (data not shown). Interestingly, neutrophil adhesion to the plaque was highly increased in the LV.CXCR4deg transplanted mice compared to LV.Empty control mice both at 6 and 10 weeks of Western type diet feeding (Figure 4B). Next, we addressed effects of CXCR4 blockage on neutrophil adherence in vitro. HL60 cells were differentiated into neutrophils with Retinoic Acid (RA) (Figure 4C). ${ }^{25,26}$ Flow cytometry analysis confirmed that RA induced neutrophil differentiation as demonstrated by increased $\mathrm{GrI}^{+} \mathrm{CD} 71^{-}$neutrophil numbers (data not shown). The adhesive capacity of HL60 cells differentiated in the presence of AMD3100 and RA was increased compared to HL60 cells differentiated only in the presence of RA (26 \pm 2 versus $18 \pm 2$ cells/microscopic field, Figure 4D). HL60 cell adherence to fibronectin coated wells was increased by $55 \%$, however that of HL60 cells differentiated in the presence of AMD3100 was even 2-fold higher (202\%) compared to uncoated wells. Adherence of differentiated HL60 cells to gelatin remained unaltered by AMD3100 treatment. The augmented adhesive capacity is 
linked to altered integrin signaling as the relative focal adhesion kinase (FAK) mRNA expression was 3-fold increased in HL60 derived neutrophils treated with AMD3100 (Figure 4E).

A
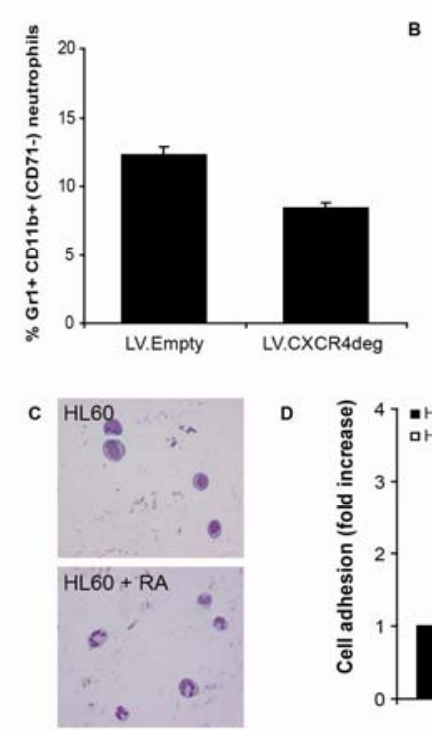

$B$

D
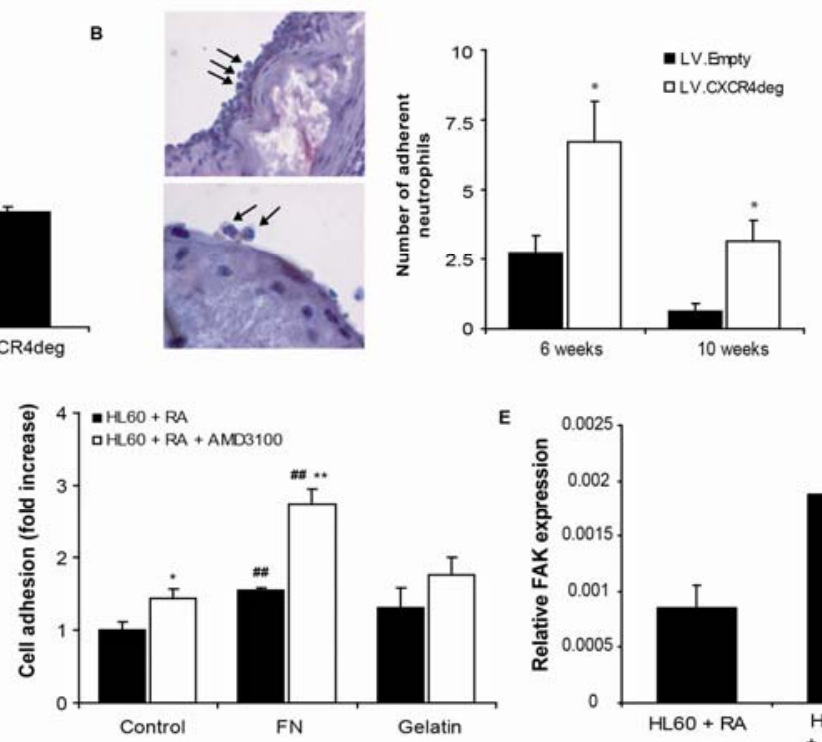

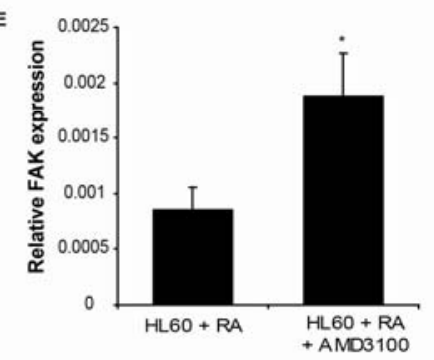

Figure 4. CXCR4 blockage induces neutrophil adhesion. A, Flow cytometry analysis of the percentage of $\mathrm{Gr}^{+} \mathrm{CD} 11 \mathrm{~b}^{+}\left(\mathrm{CD} 71^{-}\right)$neutrophils in blood from LV.Empty $(\mathrm{n}=4)$ versus LV.CXCR4deg $(n=4)$ bone marrow transplanted mice. Data are represented for the 6 weeks group. B, Napthol CAE staining showing adhering neutrophils to the plaque endothelium (left panel, upper picture: 400x magnification, lower picture: 1000x magnification). Represented in the graphs are the number of adhering neutrophils in LV.Empty versus LV.CXCR4deg transplanted LDLr ${ }^{-1-}$ bone marrow chimeras 6 and 10 weeks after Western type diet feeding $\left({ }^{*} P<0.05\right)$. C, HL60 cells were treated with retinoic acid to induce neutrophil development. D, Adhesion of non-treated versus AMD3100 treated neutrophils in control, fibronectin (FN) and gelatin coated wells. ${ }^{*} P<0.05$ compared to HL60 + RA, ${ }^{\#} P<0.01$ compared to uncoated controls, ${ }^{*} * P<0.01$ compared to HL60 + RA (FN). E, Relative gene expression of FAK in neutrophils differentiated in the presence or absence of AMD3100 $\left({ }^{*} P<0.05\right)$. 
Impaired in vivo homing of neutrophils in response to SDF-1 $\alpha$ but not KC and thioglycollate in LV.CXCR4deg transplanted mice

The increased adherent plaque neutrophils in LV.CXCR4deg mice led us to investigate effects of CXCR4 blockade on neutrophil migration in vivo. Leukocyte recruitment towards the peritoneum was measured in $\mathrm{LDLr}^{--}$mice, transplanted with either bone marrow infected with LV.Empty or LV.CXCR4deg, in response to either PBS (control), KC or SDF-1 $\alpha$. Peritoneal homing of CD11 $\mathrm{b}^{+} \mathrm{Gr} 1^{\text {high }}$ neutrophils in response to $K C$, which induces $C X C R 2$ dependent neutrophil chemotaxis, did not differ between LV.Empty and LV.CXCR4deg chimeras (Figure 5A). In sharp contrast, neutrophil migratory response to SDF-1 $\alpha$ was strongly attenuated (Figure 5B). Importantly, CXCR4 blockade on leukocytes did not affect thioglycollate elicited peritoneal neutrophil recruitment in $\mathrm{LDLr}^{-/}$mice treated with the CXCR4 antagonist AMD3100 (Figure 5C), demonstrating that decreased CXCR4 expression on leukocytes does not affect neutrophil migration in vivo. Apparently, while SDF-1 $\alpha$ induced neutrophil migration is impaired in LV.CXCR4 transplanted chimeras, the general migratory capacity of neutrophils is not affected.
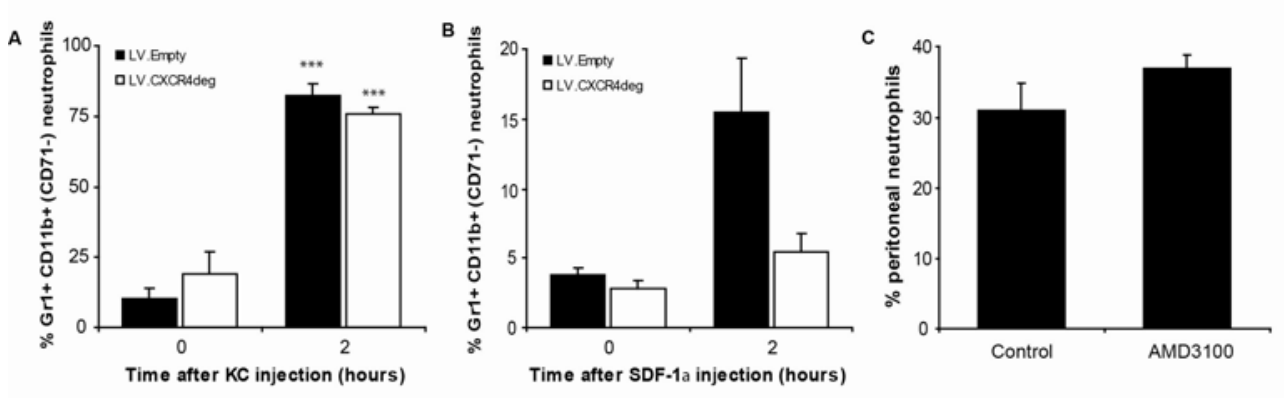

Figure 5. CXCR4 blockage does not alter neutrophil recruitment. In vivo chemokinesis assay in $\mathrm{LDLr}^{-/-}$mice, transplanted with either bone marrow infected with LV.Empty $(n=4)$ or LV.CXCR4deg $(n=4)$. A, Percentage of peritoneal $\mathrm{GrI}^{+} \mathrm{CD} 11 \mathrm{~b}^{+}\left(\mathrm{CD} 71^{-}\right)$neutrophils at 2 hours after KC injection. B, Percentage of recruited neutrophils in response to SDF-1 $\alpha$. C, Percentage of peritoneal neutrophils in response to $3 \%$ Brewer's Thioglycollate in control $(n=6)$ versus AMD3100 treated $(n=6)$ mice. 


\section{CXCR4 regulates neutrophil homeostasis and elimination of senescent} neutrophils

FAK expression could be linked to cell survival, therefore, we next studied the impact of CXCR4 dysfunction on neutrophil homeostasis. AMD3100 treatment throughout RA induced neutrophil differentiation was seen to inhibit the formation of $\mathrm{Gr}^{+} \mathrm{CXCR} 4^{+}$and $\mathrm{GR}^{+} \mathrm{CXCR2}{ }^{+}$neutrophil subsets (Figure 6A). Moreover, AMD3100 reduced HL60 cell proliferation during RA differentiation (Figure 6B), while augmenting neutrophil myeloperoxidase (MPO) activity (Figure 6C), illustrative of enhanced neutrophil activation. Furthermore, AMD3100 treated HL60 cells at 7 days after start of RA induced neutrophil differentiation showed increased cell survival (Figure 6D). In line, expression of cell survival factor AKT was enhanced (Figure 6E).
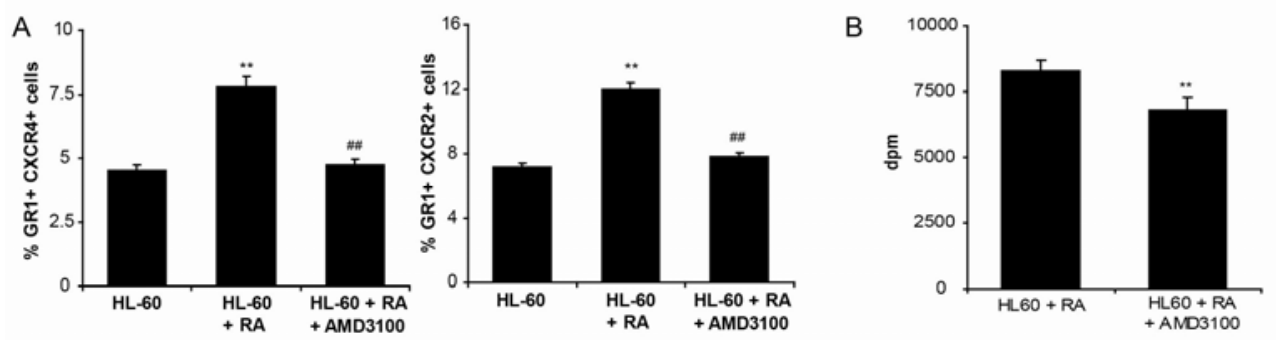

C

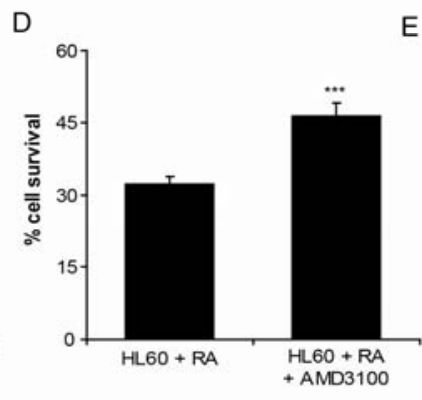

E
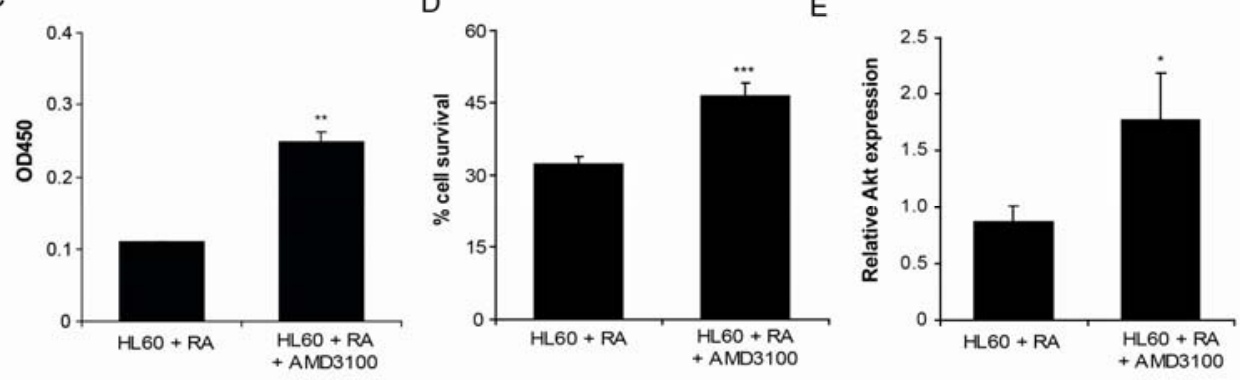

Figure 6. Neutrophils lacking functional CXCR4 expression show increased cell survival.

A, Treatment of HL60 cells with AMD3100 inhibits differentiation of HL60 cells into neutrophils as demonstrated by a reduction in the percentage of $\mathrm{GR} 1^{+} \mathrm{CXCR} 4^{+}$(left panel) and $\mathrm{GR} 1^{+} \mathrm{CXCR} 4^{+}$cells (right panel) $\left({ }^{*} P<0.01\right.$ compared to control HL60 cells, ${ }^{\# \#} P<0.01$ compared to RA differentiated HL60 cells). B, AMD3100 reduced neutrophil precursor proliferation during differentiation $\left({ }^{* *} P<0.01\right)$. C, Myeloperoxidase activity $\left({ }^{* *} P<0.01\right)$. D, 
Percentage of cell survival ( $* * * P<0.001)$. E, Relative gene expression of Akt in neutrophils differentiated in the presence or absence of AMD3100 ( $\left.{ }^{*} P<0.05\right)$.

The CXCR4 blockade associated increase in cell survival could well have impacted neutrophil senescence in vivo. Aged neutrophils upregulate CXCR4 expression and home back to bone marrow, where they undergo apoptosis in a TNF-related apoptosis-inducing ligand (TRAIL) dependent manner. ${ }^{28}$ To investigate whether defective CXCR4 expression leads to neutrophil retention in circulation, $\mathrm{LDLr}^{-/}$ mice were placed on Western type diet for 3 weeks and treated with AMD3100. AMD3100 treated mice showed higher Ly $6 G^{\text {high }} C D 11 b^{\text {high }}$ granulocyte counts in blood than control mice (Figure 7A). Flow cytometry of blood granulocytes for DHR123, an established $\mathrm{H}_{2} \mathrm{O}_{2}$ sensor, revealed that AMD3100 treatment resulted in higher intracellular $\mathrm{H}_{2} \mathrm{O}_{2}$ levels, an indicator of reactive oxygen species (ROS) production and senescent neutrophils (Figure 7B). Thus, CXCR4 dysfunction leads to an increase of neutrophil half-life, senescence and activation, which apparently promotes neutrophil adhesion to vascular endothelium, and in this way an aggravation of disease. Damås et al. have shown that coronary artery disease (CAD) patients have lowered plasma levels of SDF- $1 \alpha^{8} .^{8}$ In a final experiment we sought to investigate the relevance of our findings for human disease. Interestingly, CXCR4 protein expression on circulating neutrophils isolated from carotid endarterectomy and unstable angina patients was significantly lowered than compared to neutrophils from healthy controls (Figure $7 C$ ), suggesting that cardiovascular disease (CVD) patients have dysfunctional CXCR4 expression and consequently have higher blood counts of senescent neutrophils and thus increased neutrophil activity within lesions. Of note, these data also coincide with previous findings showing delayed neutrophil apoptosis in patients with unstable angina. ${ }^{29}$ 

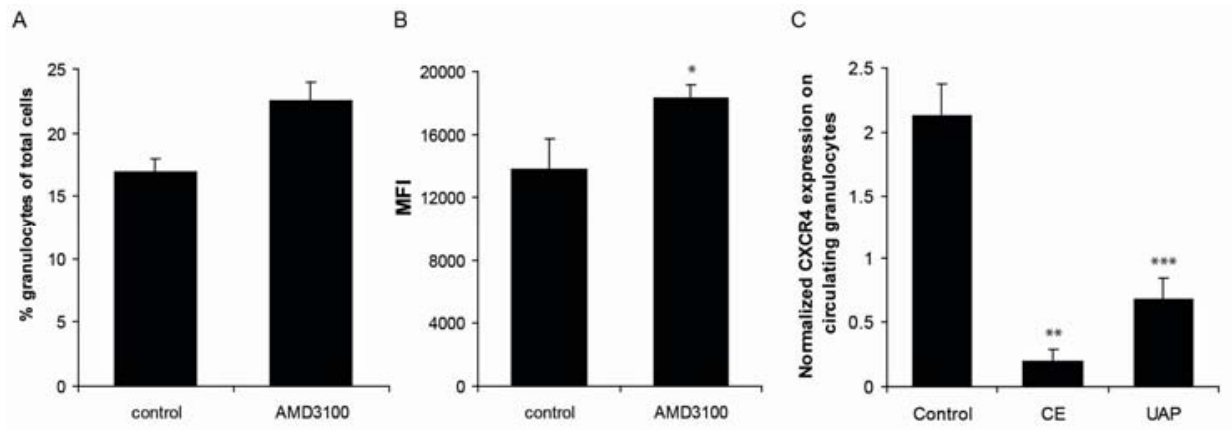

Figure 7. Increased numbers of senescent neutrophils in the absence of CXCR4. LDLr mice on western type diet were treated with AMD3100 $(n=5)$ for 3 weeks. Control mice $(n=4)$ received PBS injections. A, Circulating Ly6G ${ }^{\text {high }} C D 11 b^{\text {high }}$ granulocyte numbers. B, Mean fluorescence intensity for DHR123 (*P=0.05). C, Normalized CXCR4 protein expression on circulating granulocytes isolated from healthy (control) persons $(n=13)$ versus carotid endarterectomy $(n=5)(* * P=0.002)$ and unstable angina pectoris patients $(\mathrm{n}=19)(* * * P=0.0009)$.

\section{Discussion}

Previously we demonstrated that the SDF-1 $\alpha / C X C R 4$ axis is instrumental in early stage atherosclerosis by controlling circulating neutrophil counts. ${ }^{11}$ In this study we have extended this notion, focusing on later, clinically relevant stages of plaque development in mice and man. We show that plaque SDF-1 $\alpha / C X C R 4$ expression is progressively deregulated during disease progression. CXCR4 blockade considerably exacerbated advanced plaque formation and stability as judged by an increased frequency of intraplaque hemorrhages. Interestingly, endothelial adhesion of neutrophils increased after CXCR4 blockade, possibly by enhanced focal adhesion. The latter features may well be associated with increased survival and senescence, and subsequent hyperactivation of this subset.

Our histological data largely confirm previous findings of Abi-Younes et al. ${ }^{7}$ showing strong expression of SDF-1 $\alpha$ and to a lesser extent also CXCR4 by endothelium, vSMCs and macrophages in the atherosclerotic plaque but not in healthy vessels. In an extension of this study, we now clearly show that normal arteries do express SDF- $1 \alpha$, and that SDF-1 $\alpha$ expression gradually decreases during plaque progression, reflective of the progressively reduced plasma levels of 
this chemokine in patients with stable and even more so with unstable angina pectoris shown by Damås et al. ${ }^{8}$ In contrast, CXCR4 expression was increased in advanced and ruptured lesions. In particular plaque leukocytes displayed high CXCR4 expression, possibly due to the prevailing hypoxia. . $^{30,31}$

To delineate the contribution of leukocyte-derived SDF-1 $\alpha / C X C R 4$ to plaque development and progression, we generated lentivirus vectors encoding a SDF-1 $\alpha$ antagonist ${ }^{12}$ and CXCR4 degrakine, respectively. ${ }^{13} \mathrm{LDLr}^{-/-}$mice reconstituted with LV.CXCR4deg lentivirus transduced bone marrow indeed displayed partially reduced CXCR4 protein expression by leukocytes compared to LV.Empty mice. Early plaque development was not affected by the reduced hematopoietic CXCR4 expression, however we did observe an increase in intraplaque erythrocyte accumulation, which was described to be involved in plaque destabilization. ${ }^{32,33}$ The latter was confirmed by increased hemosiderin deposition in advanced plaques in both the LV.SDF-1 $\alpha$ (P2G) and the LV.CXCR4degrakine group. Interestingly, at this stage lesion progression was severely increased in mice in which SDF-1 $\alpha / C X C R 4$ signaling was inhibited, which may be explained by the increased accumulation of intraplaque erythrocytes with subsequent cholesterol deposition. $^{34}$

Blockage of CXCR4 has been shown to result in increased neutrophil release from bone marrow into circulation. ${ }^{35,36}$ In $\mathrm{ApoE}^{-/}$mice, complete and chronic blockage of CXCR4 with AMD3465, a CXCR4 antagonist, has been shown to increase blood neutrophil numbers, resulting in an increased accumulation of neutrophils within the atherosclerotic vessel wall and subsequently promoting plaque progression. ${ }^{11}$ Our data show that partial blockage of CXCR4 in LV.CXCR4deg transfected bone marrow chimeras does not induce an increase in neutrophil release into circulation, possibly due to compensatory effects such as reduced neutrophil production. However, plaque progression was induced as well, likely the resultant of increased neutrophil adherence to plaque endothelium. In addition, neutrophils with impaired CXCR4 function showed increased ROS activity. Activated neutrophils elaborate a range of enzymes such as neutrophil elastase and cathepsin $G$, which degrade extracellular matrix and antibacterial proteins, MPO and radicals, and chemokines and cytokines to attract other leukocyte subsets. Many of these products have been linked to acute cardiovascular syndromes. ${ }^{37}$ These data suggest that neutrophil adherence to the 
early atherosclerotic plaque may be a potent initiator of plaque progression by releasing several deleterious neutrophil products, promoting extracellular matrix degradation and smooth muscle cell death.

In addition to increased activity, neutrophils lacking functional CXCR4 expression showed increased cell survival, as witness the impaired apoptosis and increased expression of the cell survival factor Akt. Together with increased neutrophil activity, these data suggest a role for neutrophil senescence in atherosclerosis. As neutrophils age, they upregulate the expression of CXCR4 and acquire the ability to migrate back to bone marrow where they undergo apoptosis. ${ }^{30}$ If mature neutrophils fail to upregulate functional CXCR4 expression, they are retained in circulation to migrate towards inflamed tissue, such as the atherosclerotic vessel wall, where they can further promote inflammation. Finally, we show that patients with acute cardiovascular disease show impaired CXCR4 expression on circulating neutrophils, further substantiating the role of senescent neutrophils in atherosclerosis.

In conclusion, we provide evidence for perturbed vascular homeostasis of SDF- $1 \alpha$ and CXCR4 at later stages of atherogenesis in humans. Furthermore, we show that blockade of the SDF-1 $\alpha / C X C R 4$ axis on leukocytes induces atherosclerotic plaque progression. Interestingly, neutrophils lacking functional CXCR4 expression show increased adherence to plaque endothelium and increased activity. In addition, these neutrophils also show increased cell survival, suggesting an important role for neutrophil senescence in atherosclerosis.

\section{Acknowledgments}

We would like to thank Vigdis Bjerkeli for excellent technical assistance.

\section{References}


1. Libby P. Current concepts of the pathogenesis of the acute coronary syndromes. Circulation 2001;104:365-372.

2. Weber $\mathrm{C}$, Noels H. Atherosclerosis: current pathogenesis and therapeutic options. Nat Med, In press.

3. Shah PK. Molecular mechanisms of plaque instability. Curr Opin Lipidol 2007;18:492499.

4. Braunersreuther V, Mach F, Steffens S. The specific role of chemokines in atherosclerosis. Thromb Haemost 2007;97:714-721.

5. Charo IF, Ransohoff RM. The many roles of chemokines and chemokine receptors in inflammation. N Engl J Med 2006;354:610-621.

6. Weber C, Schober A, Zernecke A. Chemokines: key regulators of mononuclear cell recruitment in atherosclerotic vascular disease. Arterioscler Thromb Vasc Biol 2004;24:1997-2008.

7. Abi-Younes S, Sauty A, Mach F, Sukhova GK, Libby P, Luster AD. The stromal cellderived factor-1 chemokine is a potent platelet agonist highly expressed in atherosclerotic plaques. Circ Res 2000;86:131-138.

8. Damås JK, Waehre T, Yndestad A, Ueland T, Müller F, Eiken HG, Holm AM, Halvorsen B, Frøland SS, Gullestad L, Aukrust P. Stromal cell-derived factor-1alpha in unstable angina: potential antiinflammatory and matrix-stabilizing effects. Circulation 2002;106:36-42.

9. Gear AR, Camerini D. Platelet chemokines and chemokine receptors: linking hemostasis, inflammation, and host defense. Microcirculation 2003;10:335-350.

10. Zernecke A, Schober A, Bot I, von Hundelshausen P, Liehn EA, Möpps B, Mericskay $M$, Gierschik $P$, Biessen EA, Weber C. SDF-1alpha/CXCR4 axis is instrumental in neointimal hyperplasia and recruitment of smooth muscle progenitor cells. Circ Res 2005;96:784-791.

11. Zernecke A, Bot I, Djalali-Talab Y, Shagdarsuren E, Bidzhekov K, Meiler S, Krohn R, Schober A, Sperandio M, Soehnlein O, Bornemann J, Tacke F, Biessen EA, Weber C. Protective Role of CXC Receptor 4/CXC Ligand 12 Unveils the Importance of Neutrophils in Atherosclerosis. Circ Res 2008;102:209-217.

12. Crump MP, Gong JH, Loetscher P, Rajarathnam K, Amara A, Arenzana-Seisdedos F, Virelizier JL, Baggiolini M, Sykes BD, Clark-Lewis I. Solution structure and basis for functional activity of stromal cell-derived factor-1; dissociation of CXCR4 activation from binding and inhibition of HIV-1. EMBO J 1997;16:6996-7007.

13. Coffield VM, Jiang $Q$, Su L.. A genetic approach to inactivating chemokine receptors using a modified viral protein. Nat Biotechnol 2003;21:1321-1327. 
14. Virmani R, Kolodgie FD, Burke AP, Farb A, Schwartz SM. Lessons from sudden coronary death: a comprehensive morphological classification scheme for atherosclerotic lesions. Arterioscler Thromb Vasc Biol 2000; 20:1262-1275.

15. Sambrook J, Fritsch EF, Maniatis T. Molecular cloning: a laboratory manual, Vol 2. Cold Spring Harbor, NY: Cold Spring Harbor Laboratory Press, 1989.

16. Sluimer JC, Kisters N, Cleutjens KB, Volger OL, Horrevoets AJ, van den Akker LH, Bijnens AP, Daemen MJ. Dead or alive: gene expression profiles of advanced atherosclerotic plaques from autopsy and surgery. Physiol Genomics 2007;30:335341.

17. Crump MP, Gong JH, Loetscher P, Rajarathnam K, Amara A, Arenzana-Seisdedos F, Virelizier JL, Baggiolini M, Sykes BD, Clark-Lewis I. Solution structure and basis for functional activity of stromal cell-derived factor-1; dissociation of CXCR4 activation from binding and inhibition of HIV-1. EMBO J 1997;16:6996-7007.

18. Seppen J, Rijnberg M, Cooreman MP, Oude Elferink RP. Lentiviral vectors for efficient transduction of isolated primary quiescent hepatocytes. J Hepatol 2002;36:459-465.

19. Zufferey R, Dull T, Mandel RJ, Bukovsky A, Quiroz D, Naldini L, Trono D. Selfinactivating lentivirus vector for safe and efficient in vivo gene delivery. $J$ Virol 1998;72:9873-9880.

20. Coffield VM, Jiang $Q$, Su L. A genetic approach to inactivating chemokine receptors using a modified viral protein. Nat Biotechnol 2003;21:1321-1327.

21. Sastry L, Johnson T, Hobson MJ, Smucker B, Cornetta K. Titering lentiviral vectors: comparison of DNA, RNA and marker expression methods. Gene Ther 2002;9:11551162.

22. Strobel ES, Möbest D, von Kleist S, Dangel M, Ries S, Mertelsmann R, Henschler R. Adhesion and migration are differentially regulated in hematopoietic progenitor cells by cytokines and extracellular matrix. Blood 1997;90:3524-3332.

23. Bot I, Guo J, Van Eck M, Van Santbrink PJ, Groot PH, Hildebrand RB, Seppen J, Van Berkel TJ, Biessen EA. Lentiviral shRNA silencing of murine bone marrow cell CCR2 leads to persistent knockdown of CCR2 function in vivo. Blood 2005;106:1147-1153.

24. Zuluaga AF, Salazar BE, Rodriguez CA, Zapata AX, Agudelo M, Vesga O. Neutropenia induced in outbred mice by a simplified low-dose cyclophosphamide regimen: characterization and applicability to diverse experimental models of infectious diseases. BMC Infect Dis 2006;6:55.

25. Spellberg BJ, Collins M, French SW, Edwards JE Jr, Fu Y, Ibrahim AS. A phagocytic cell line markedly improves survival of infected neutropenic mice. J Leukoc Biol 2005;78:338-344. 
26. Wallington LA, Durham J, Bunce CM, Brown G. Growth of single HL60 cells in liquid culture: analysis of the influences of differentiative agents. Leuk Res 1996;20:821829.

27. 't Hoen PA, Van der Lans CA, Van Eck M, Bijsterbosch MK, Van Berkel TJ, Twisk J. Aorta of ApoE-deficient mice responds to atherogenic stimuli by a prelesional increase and subsequent decrease in the expression of antioxidant enzymes. Circ Res 2003;93:262-269.

28. Lum JJ, Bren G, McClure R, Badley AD. Elimination of senescent neutrophils by TNFrelated apoptosis-inducing ligand. J Immunol 2005;175:1232-1238.

29. Biasucci LM, Liuzzo G, Giubilato S, Della Bona R, Leo M, Pinnelli M Severino A, Gabriele M, Brugaletta S, Piro M, Crea F. Delayed neutrophil apoptosis in patients with unstable angina: relation to $\mathrm{C}$-reactive protein and recurrence of instability. Eur Heart J 2009;30:2220-2225.

30. Schioppa T, Uranchimeg B, Saccani A, Biswas SK, Doni A, Rapisarda A, Bernasconi S, Saccani S, Nebuloni M, Vago L, Mantovani A, Melillo G, Sica A. Regulation of the chemokine receptor CXCR4 by hypoxia. J Exp Med 2003;198:1391-1402.

31. Karshovska E, Zernecke A, Sevilmis G, Millet A, Hristov M, Cohen CD, Schmid H, Krotz F, Sohn HY, Klauss V, Weber C, Schober A. Expression of HIF-1alpha in injured arteries controls SDF-1alpha mediated neointima formation in apolipoprotein $E$ deficient mice. Arterioscl Thromb Vasc Biol 2007;27:2540-2547.

32. Kolodgie FD, Gold HK, Burke AP, Fowler DR, Kruth HS, Weber DK, Farb A, Guerrero L, Hayase M, Kutys R, Narula J, Finn AV, Virmani R. Intraplaque hemorrhage and progression of coronary atheroma. N Engl J Med 2003;349:2316-2325.

33. Bot I, de Jager SC, Zernecke A, Lindstedt KA, van Berkel TJ, Weber C, Biessen EA. Perivascular mast cells promote atherogenesis and induce plaque destabilization in apolipoprotein E-deficient mice. Circulation 2007;115:2516-2525.

34. Virmani R, Kolodgie FD, Burke AP, Finn AV, Gold HK, Tulenko TN, Wrenn SP, Narula J. Atherosclerotic plaque progression and vulnerability to rupture: angiogenesis as a source of intraplaque hemorrhage. Arterioscler Thromb Vasc Biol 2005;25:20542061.

35. Martin C, Burdon PC, Bridger G, Gutierrez-Ramos JC, Williams TJ, Rankin SM. Chemokines acting via CXCR2 and CXCR4 control the release of neutrophils from the bone marrow and their return following senescence. Immunity. 2003;19:583-593.

36. Eash KJ, Greenbaum AM, Gopalan PK, Link DC. CXCR2 and CXCR4 antagonistically regulate neutrophil trafficking from murine bone marrow. J Clin Invest. 2010;1:24232431. 
CXCR4 expression on neutrophils and atherosclerosis

37. Dinerman JL, Mehta JL, Saldeen TG, Emerson S, Wallin R, Davda R, Davidson A. Increased neutrophil elastase release in unstable angina pectoris and acute myocardial infarction. J Am Coll Cardiol 1990;15:1559-1563. 


\title{
Chapter 4
}

\author{
Increased levels of the homeostatic \\ chemokine CXCL13 in human \\ atherosclerosis - potential role in plaque \\ destabilization
}

Linda Smedbakken, Bente Halvorsen, Isabelle Daissormont, Trine Ranheim, Annika Michelsen, Mona Skjelland, Lasse Folkersen, Kirsten Krohg-Sørensen, David Russell, Sverre Holm, Thor Ueland, Børre Fevang, Ulf Hedin, Arne Yndestad, Lars Gullestad, Göran Hansson, Erik Biessen, Pal Aukrust 


\section{Abstract}

Based on the newly recognized role of homeostatic chemokines in inflammation, as well as recent reports of a potential role of CCL19 and CCL21 in atherosclerosis, we hypothesized that CXCL13, another homeostatic chemokine, could be involved in atherogenesis. The study included in vivo analyses in patients with carotid and coronary atherosclerosis as well as in vitro experiments in cells involved in atherogenesis (ie, monocytes/macrophages, vascular smooth muscle cells (vSMC), and platelets). Our main findings were: (i) Patients with carotid $(n=130)$ and coronary $(n=80)$ atherosclerosis had increased plasma levels of CXCL13 with particularly high levels in unstable disease. (ii) CXCL13 showed increased expression within atherosclerotic carotid plaques, and high CXCL13 expression tended to be associated with increased plaque echogenicity. (iii) Within the atherosclerotic lesions, CXCR5 and CXCL13 were expressed by macrophages and VSMC in all stages of plaque progression. (iv) Releasate from activated platelets enhanced the expression of CXCL13 in THP-1 monocytes and primary monocytes. (v) In vitro, CXCL13 exerted anti-apoptotic effects in primary monocytes, THP-1 macrophages, and vascular SMC. (vi) CXCL13 increased arginase-1, transforming growth factor- $\beta$, and interleukin-10 expression in THP-1 cells and samples from freshly isolated carotid plaques, and counteracted the interleukin-1 $\beta$-mediated decrease in collagen synthesis in SMC suggesting beneficial effects on tissue repair. In conclusion, levels of CXCL13 are increased in carotid and coronary atherosclerosis, with high CXCL13 expression associated with a fibrous plaque phenotype. Together with our in vitro findings, these data may suggest a plaque stabilizing effect of CXCL13-CXCR5 interaction. 


\section{Introduction}

Several lines of evidence suggest that chemokines are important mediators in the inflammatory arm of atherogenesis, leading to progression of atherosclerosis and plaque destabilization. ${ }^{1-4} \mathrm{~A}$ number of studies have reported raised chemokine levels in atherosclerotic disorders, both systemically and within the atherosclerotic lesion. Moreover, targeted disruption of the genes for monocyte chemoattractant protein-1 (MCP-1)/CCL2, CCR2 (ie, MCP-1 receptor), CXCR2 (ie, the interleukin-8 (IL-8)/CXCL8 receptor), CXCR6 (ie, CXCL16 receptor), and CX3CR1 (ie, fractalkine/CX3CL1 receptor) significantly decreases atherosclerotic lesion formation in mice prone to develop atherosclerotic-like lesions. ${ }^{5-9}$ However, the role of chemokines in atherogenesis is far from being completely understood. Studies in gene-modified mice indicate anti- rather than pro-atherogenic effects of some of these mediators (eg, deficiency in CXCL16, CXCR4, or CCR1 accelerates atherosclerosis), ${ }^{10-12}$ suggesting that chemokines also may possess atheroprotective properties.

Most chemokines have been linked to inflammatory processes in peripheral tissue, whereas the homeostatic chemokines (ie, CCL19, CCL21, and CXCL13) and their corresponding receptors (ie, CCR7 (CCL19 and CCL21) and CXCR5 (CXCL13)) have been associated with the entry of lymphocytes and dendritic cells to secondary lymphoid organs. ${ }^{13,14}$ Recently, reports have pointed to a broader role for these homeostatic chemokines, including modulation of inflammatory and anti-inflammatory responses in lymphoid and non-lymphoid tissue. ${ }^{15,16}$ Thus, an imbalanced regulation of CCL19 and CCL21 seems to be involved in the pathogenesis of various inflammatory disorders including rheumatoid arthritis, inflammatory bowel disease and more recently, also in atherosclerosis. ${ }^{17-20}$

CXCL13 is crucial for B cell trafficking, but has also been linked to T cell and monocyte activation as well as apoptosis. ${ }^{21-23}$ More recently, it has been suggested to play a pathogenic role in inflammatory disorders such as rheumatoid arthritis and inflammatory bowel disease. ${ }^{24,25}$ However, the regulatory determinants and the effects of CXCL13 in inflammation are poorly characterized. Based on the newly recognized role of the homeostatic chemokines in inflammation, as well as recent reports of a potential role of CCR7 in atherosclerosis, ${ }^{18,20}$ we hypothesized that CXCL13 could be involved in atherogenesis. Here, we investigated this hypothesis by differential experimental 
approaches including in vivo studies in patients with carotid and coronary atherosclerosis as well as in vitro studies in cells involved in atherogenesis (ie, monocytes/macrophages, VSMC, and platelets), particularly focusing on the regulation of the CXCL13/CXCR5 axis by inflammatory stimuli and its effect on cell survival.

\section{Materials and methods}

Patients and controls

In the plasma carotid stenosis study, 130 consecutive patients, with high-grade internal carotid stenoses ( $\geq 70 \%$ ), were recruited at the Department of Neurology, Oslo University Hospital Rikshospitalet (Table 1). Patients were classified into two groups depending on whether (symptomatic, $n=81$ ) or not (asymptomatic, $n=49$ ) the patients had experienced ipsilateral stroke, transient ischemic attack (TIA), or amaurosis fugax in the six months before inclusion. Asymptomatic carotid stenosis was detected during clinical examinations of patients with coronary artery disease (CAD), peripheral artery disease or stroke/TIA more than 6 months ago. The carotid stenoses was diagnosed and classified by precerebral color duplex and CT angiography according to consensus criteria. As for ultrasound examination, the total extracranial part of the carotid artery was examined with B-mode and doppler analyses. Ultrasound plaque appearance in terms of echogenisity was classified according to consensus criteria. ${ }^{26}$

In the plasma angina study, 80 CAD patients undergoing clinically indicated coronary angiography at the Department of Cardiology, Oslo University Hospital Rikshospitalet were consecutively recruited for the study (Table 2). All patients with unstable angina $(n=40)$ had experienced ischemic chest pain at rest within the preceding 48 hours (ie, Braunwald's class IIIB), but with no evidence of myocardial necrosis by enzymatic criteria. Transient ST-T segment depression and/or T-wave inversion were present in all cases. All patients with stable angina $(n=40)$ had stable effort angina of $>6$ months duration and a positive exercise test. The diagnosis of CAD was confirmed in all patients by coronary angiography showing at least 1-vessel disease ( $>50 \%$ narrowing of luminal diameter). 
Table 1. Baseline variables in patients according to symptomatic\# $(n=81)$ and asymptomatic carotid plaques $(n=49)$

\begin{tabular}{|c|c|c|c|}
\hline & $\begin{array}{l}\text { Symptomatic plaques } \\
\qquad(\mathrm{n}=81)\end{array}$ & $\begin{array}{l}\text { Asymptomatic plaques } \\
\qquad(n=49)\end{array}$ & $P$ \\
\hline Age, year & $67 \pm 1$ & $66 \pm 1$ & .298 \\
\hline Sex, females/males & $27 / 54$ & $15 / 34$ & .749 \\
\hline Smokers, \% & 58 & 55.1 & .720 \\
\hline Hypertension, \% & 66.7 & 61.2 & .438 \\
\hline Diabetes, \% & 21 & 16.3 & .416 \\
\hline \multicolumn{4}{|l|}{ Medication, \% } \\
\hline Aspirin & 87.7 & 87.8 & .958 \\
\hline Statins & 90.1 & 89.8 & .952 \\
\hline Warfarin & 12.3 & 14.3 & .758 \\
\hline $\mathrm{CRP}, \mathrm{mg} / \mathrm{l}$ & $5.4 \pm 0.8$ & $7.1 \pm 1.4$ & .242 \\
\hline Total cholesterol, $\mathrm{mmol} / \mathrm{l}$ & $4.4 \pm 0.1$ & $4.2 \pm 0.1$ & .500 \\
\hline LDL cholesterol, mmol/l & $2.6 \pm 0.13$ & $2.5 \pm 0.11$ & .517 \\
\hline HDL cholesterol, mmol/l & $1.3 \pm 0.5$ & $1.3 \pm 0.1$ & .670 \\
\hline Triglycerides, mmol/l & $1.6 \pm 0.1$ & $1.5 \pm 0.1$ & .820 \\
\hline \multicolumn{4}{|c|}{$\begin{array}{l}\text { \# Clinical symptoms include stroke, TIA or amaurosis fugax ipsilateral to the stenotic } \\
\text { internal carotid artery within the last } 6 \text { months. Data are mean } \pm \text { SEM. Statins, } \\
\text { hydroxymethylglutaryl coenzyme A reductase inhibitors. Characteristics of healthy controls }\end{array}$} \\
\hline
\end{tabular}

Exclusion criteria in both sub-studies were myocardial infarction or thrombolytic treatment within the previous six weeks, severe concomitant disease (eg, infections, connective tissue disease, or malignancies), heart failure, and liver or kidney disease. The controls $(n=20)$ were healthy health care workers, consecutively recruited from the same area of Norway as the patients (southeastern part), and comparable to the patients with regard to age, sex, smoking habits, and lipid profile. None of the controls used any medications and 
Chapter 4

had no history of cardiovascular or other chronic disease. The storage time for plasma samples were similar in patients and controls.

Table 2. Characteristics of the angina patients.

\begin{tabular}{lcccc}
\hline & $\begin{array}{c}\text { Controls } \\
(\mathrm{n}=20)\end{array}$ & $\begin{array}{c}\text { Stable angina } \\
(\mathrm{n}=40)\end{array}$ & $\begin{array}{c}\text { Unstable angina } \\
(\mathrm{n}=40)\end{array}$ & $\mathrm{P}$ \\
\hline Age, years & $59 \pm 6$ & $66 \pm 8$ & $61 \pm 11$ & .340 \\
Sex, females/males & $3 / 17$ & $5 / 35$ & $13 / 27$ & .032 \\
Smokers, \% & 10 & 20 & 16 & .346 \\
Hypertension, \% & 0 & 10 & 28 & .094 \\
Diabetes, \% & 0 & 5 & 10 & .396 \\
C-reactive protein, $\mathrm{mg} / \mathrm{l}$ & $1.01 \pm 0.3$ & $2.2 \pm 0.5$ & $3.4 \pm 0.7$ & .041 \\
Medication, \% & & & & \\
$\quad$ B-blockers & 0 & 83 & 100 & .006 \\
$\quad$ Aspirin & 0 & 75 & 92 & .034 \\
$\quad$ Statins & 0 & 80 & 86 & .556 \\
$\quad$ Warfarin & 0 & 20 & 8 & .104 \\
CRP, mg/l & $1.01 \pm 0.3$ & $2.2 \pm 0.5$ & $3.4 \pm 0.7$ & .041 \\
Total cholesterol, mmol/l & $4.3 \pm 0.6$ & $4.8 \pm 0.7$ & $4.9 \pm 0.8$ & .656 \\
LDL cholesterol, mmol/l & $2.6 \pm 0.6$ & $3.3 . \pm 0.6$ & $3.4 \pm 0.6$ & .833 \\
HDL cholesterol, $\mathrm{mmol} / \mathrm{l}$ & $1.4 \pm 0.3$ & $1.2 \pm 0.5$ & $1.2 \pm 0.6$ & .798 \\
Triglycerides, mmol/l & $1.5 \pm 0.4$ & $1.6 \pm 0.5$ & $1.7 \pm 0.6$ & .654 \\
\hline
\end{tabular}

Data are mean \pm SEM. Statins, hydroxymethylglutaryl coenzyme A reductase inhibitors. $P$, differences between stable and unstable angina patients.

\section{Blood sampling protocol}

Peripheral venous blood was drawn into pyrogen-free EDTA tubes that were immediately immersed in melting ice, and centrifuged within 20 minutes $(2,500 \mathrm{~g}$ 
for 25 minutes) to obtain platelet-poor plasma. All samples were stored at $-80^{\circ} \mathrm{C}$ and thawed only once.

\section{Culturing of atherosclerotic carotid plaques}

Biopsies from atherosclerotic carotid plaques $(n=7)$, obtained from patients that had been suffering from symptoms within 1 month, were placed in Dubach's modified Eagle's medium ([D-MEM]/F12; Gibco, Grand Island, NY) enriched with $30 \mathrm{mg} / \mathrm{ml}$ endotoxin free and fatty acid free bovine serum albumin (Sigma, St Louis, MO), and incubated with or without recombinant human (rh)CXCL13 (500 $\mathrm{ng} / \mathrm{ml}$, Peprotech) as described. ${ }^{27}$ Before collection, the atherosclerotic area was carefully evaluated, and a large part of the samples was used in the experiments to further minimize the problem with sampling error. After 6 hours the plaque pellets and plaque supernatants were snap-frozen in liquid nitrogen before being stored at $-80^{\circ} \mathrm{C}$.

\section{Tissue sampling from carotid plaques}

For immunohistochemistry, carotid artery was obtained from patients undergoing carotid endarterectomy (Maasland Hospital, Sittard, The Netherlands) or at autopsy (Department of Pathology, Academic Hospital Maastricht, Maastricht, The Netherlands) as previously described. ${ }^{28}$ Plaque progression stage was scored according to the criteria of Virmani and coworkers. ${ }^{29}$ Intimal thickening was classified as early, thick fibrous cap atheroma as advanced, and thin cap fibroatheroma with features of cap break, mural thrombi, plaque dissection and/or intraplaque haemorrhage were regarded ruptured lesions. For the Gene Array analysis, human plaque tissue was obtained from the Biobank of Karolinska Endarterectomies (BIKE) study (Stockholm, Sweden). ${ }^{30}$ Atherosclerotic tissue specimen, collected from patients with overt carotid stenosis $(n=106)$ by carotid endarterectomy, were washed in phosphate-buffered saline (PBS), and immediately frozen and stored at $-80^{\circ} \mathrm{C}$ until RNA extraction. Control tissue was obtained from iliac arteries of organ donors $(n=10)$. 
Chapter 4

Immunohistochemistry

Paraffin tissue sections from human carotid arteries were deparaffinized and rehydrated. After pre-treatment with pepsin for 30 minutes (1\% pepsin in $0.1 \%$ $\mathrm{HCl}$ ) for antigen retrieval and blocking with $5 \%$ normal rabbit serum, sections were incubated overnight at $4^{\circ} \mathrm{C}$ with primary goat anti-human CXCL13 (clone AF801; R\&D Systems), diluted in Tris-buffered saline (TBS) containing $1 \%$ bovine serum albumin (BSA) and $0.1 \%$ Tween-20. To detect CXCR5, sections were first pre-incubated with $0.3 \% \mathrm{H}_{2} \mathrm{O}_{2}$ in methanol. After pretreatment with antigen retrieval solution (DakoCytomation, Glostrup, Denmark) and blocking with a mixture of $6 \%$ normal sheep serum and $10 \%$ BSA, sections were incubated at room temperature with mouse anti-human CXCR5 monoclonal antibodies (clone 51505; R\&D Systems). Sections were washed in TBS, and incubated with a rabbit anti-goat (DakoCytomation) or a sheep anti-mouse (Amersham Pharmacia Biotech, Uppsala, Sweden) biotinylated secondary antibody for CXCL13 and CXCR5, respectively. Thereafter, the sections were incubated with streptavidin$A B C$-alkaline phosphatase (Vector Laboratories, Burlingame, $C A$ ), and color was developed with a Vector red staining kit (Vector Laboratories) followed by haematoxylin counterstaining. Negative controls received no primary antibody. In addition, a goat IgG antibody (R\&D Systems) and mouse IgG2b monoclonal antibody (clone 73009, R\&D Systems) served as isotype control for CXCL13 and CXCR5, respectively. For the co-localization stainings, a CD68 (Dako-KP1, DakoCytomation) or aSMA (Dako-1a4, DakoCytomation) antibody was included. For the co-localization with SMC, CXCL13 and CXCR5 were counterstained with vector red and aSMA with vector blue. For co-localization with macrophages, CXCL13 and CXCR5 were counterstained with vector blue and CD68 with vector red.

\section{Caspase measurements}

Total caspase activation was assessed by staining of PMA differentiated THP-1 macrophages, that had been incubated with or without rhCXCL13 $(200 \mathrm{ng} / \mathrm{ml}), 7-$ ketocholesterol $(40 \mu \mathrm{g} / \mathrm{ml})$, or a combination thereof for 24 hours, with the fluorescently labeled irreversible lipid soluble caspase inhibitor FITC-VAD-FMK (Promega, Maddison, WI). ${ }^{31}$ Caspase- 3 and -7 activities were assessed by staining 
of SMC with a luminogenic caspase-3/-7 substrate containing the tetrapeptide sequence DEVD (Promega) according to the manufacturer's instructions.

\section{Western blotting}

Frozen carotid plaques were homogenized and proteins were extracted using PBS with $1 \%$ TritonX-100 with protease inhibitor cocktail (Roche Applied Science) as described elsewhere. ${ }^{32}$ Western blotting was performed as previously described, ${ }^{32}$ separating equal amounts of protein $(20 \mathrm{mg}$ ) from each carotid plaque sample by SDS-PAGE (10\%) before transferring it onto polyvinyl difluoride membranes (NEN Life Science, Boston, MA). Plaque content of arginase-1 was detected by using mouse anti-arginase -1 IgG (Sigma). The immune complex was visualized by using the Supersignal West Pico Western blot detection system (Pierce), exposure to Hyperfilm ECL (Amersham Biosciences, Buckinghamshire, UK), and detected with the use of the Kodak $440 \mathrm{CF}$ imaging station (Boston, MA). The software Total Laboratory v.1 10 (Phoretix, Newcastle, UK) was used for quantification.

\section{Cell culture experiments}

The human monocytic cell line THP-1 (American Type Culture Collection, Rockville, $\mathrm{MD}$ ) or primary human monocytes, isolated from peripheral blood mononuclear cells of healthy controls by monodisperse immunomagnetic beads (Dynal, Oslo, Norway) as previously described, ${ }^{31}$ were cultured for 4 days ( 2 days for primary monocytes) in RPMI 1640 (PAA laboratories, Pasching, Austria), supplemented with $2.5 \%$ fetal bovine serum (Gibco), with and without recombinant human tumor necrosis factor $\alpha$ (rhTNF $\alpha \mathrm{ng} / \mathrm{ml}$; R\&D Systems, Minneapolis, MN), before further incubation with or without different concentrations of rhCXCL13 (R\&D Systems), lipopolysaccharide (LPS) from E. coli 026:B6 (5 ng/ml; Sigma), a toll-like receptor (TLR)2 agonist (Pam3Cys, $1 \mu \mathrm{g} / \mathrm{ml}$; Sigma), isoproterenol ( $20 \mu \mathrm{M}$, Sigma), rh-interleukin (IL)-1 1 ( $1 \mathrm{ng} / \mathrm{ml}, \mathrm{R} \& D$ Systems), and platelet releasate (see below). In studies on apoptosis related markers, the THP-1 cells were differentiated into macrophages by incubation for 24 hours with phorbol myristate acetate (PMA, $100 \mathrm{nM}$; Sigma) before resting for additional 48 hours, and further incubated with 7-ketocholesterol (40 $\mathrm{\mu g} / \mathrm{ml}$, Sigma), and in some experiments also with 
camptothecin (10 $\mu \mathrm{M}$, Sigma), for 24 hours, with and without co-incubation with rhCXCL13 $(200 \mathrm{ng} / \mathrm{ml})$. Human aortic vSMC were obtained from PromoCell $\mathrm{GmbH}$ (Heidelberg, Germany) and grown in SMC Growth Medium 2 with complete supplement mix (PromoCell). At 90\% confluence, the culture was trypsinized and replated. At experimental start, the cells were cultured in Optimem with Glutamax (Gibco-Invitrogen, Carlsbad, CA) with or without rhCXCL13 $(200 \mathrm{ng} / \mathrm{ml})$, 7-ketocholesterol $(40 \mu \mathrm{g} / \mathrm{ml})$, camptothecin $(10 \mu \mathrm{M})$, rhlL-1 $\beta(0.1 \mathrm{ng} / \mathrm{ml})$, or a combination thereof. In all experiments, camptothecin and 7-ketocholesterol were dissolved in dimethyl sulfoxide, stored at $-20^{\circ} \mathrm{C}$, and further diluted in medium prior to each experiment. At different time points, cell-free supernatants and cell pellets from THP-1 cells, primary monocytes, and SMC were harvested and stored at $-80^{\circ} \mathrm{C}$. The endotoxin levels of all stimulants, except for LPS, and culture media were $<10 \mathrm{pg} / \mathrm{ml}$ (Limulus Amebocyte Assay; BioWhittaker, Walkersville, MD). In all experiments, the vehicle of the stimulus was added as control. The toxicity in cell cultures was examined routinely for lactate dehydrogenase leakage using a cytotoxicity detection kit (Roche Applied Science, Indianapolis, IN), and we found no significant toxicity in the experiments that are included in the present study.

\section{Preparation of platelet releasate}

Platelet rich plasma (PRP) was prepared from citrated blood by centrifugation at $270 \mathrm{~g}$ for 10 minutes at $22^{\circ} \mathrm{C}$. Preparation of releasates from platelets was performed as previously described. ${ }^{33}$ Briefly, one fourth volume of acid-citratedextrose was added to PRP prior to centrifugation at $1,500 \mathrm{~g}$ for 7 minutes at $22^{\circ} \mathrm{C}$. Thereafter, the platelets were re-suspended in RPMI 1640 media (PAA laboratories) to $10 \times 10^{8}$ platelets $/ \mathrm{ml}$ before being stimulated with $0.1 \mathrm{U} / \mathrm{ml}$ thrombin (Sigma) for 90 minutes to induce release of platelet components to the media. The platelets were then removed by centrifugation at $10,000 \mathrm{~g}$ for 5 minutes at $12^{\circ} \mathrm{C}$, and the supernatant, representing platelet releasate from activated platelets, was added to THP-1 cells and primary monocytes (see above). Hirudin $(0.4 \mathrm{U} / \mathrm{ml}$, Sigma) was added to neutralize thrombin before platelet releasates were co-cultured with THP-1 cells and primary monocytes. Platelet-free supernatants of un-stimulated PRP that had been incubated for 90 minutes were 
also added to the cells, representing platelet releasate from un-stimulated platelets. In some experiments, a LIGHT neutralizing, a RANTES/CCL5 neutralizing, a CD40 ligand (CD4OL) neutralizing, a Dickkopf-1 (DKK-1) neutralizing, and an irrelevant isotype-matched antibody ( $10 \mu \mathrm{g} / \mathrm{ml}$ for all antibodies, R\&D Systems) were added to the platelet releasate before being exposed to THP-1 cells.

\section{Detection of apoptosis}

The degree of apoptosis in THP-1 cells was analyzed on a FACSCalibur flow cytometer (BD Biosciences, San Jose, CA) by using an Annexin V-fluorescein isothiocyanate (FITC) apoptosis detection kit (BD Biosciences) according to the manufacturer's instructions. The externalization of phosphatidylserine, as a marker of early-stage apoptosis, was detected by Annexin V-FITC, whereas membrane damage due to late-stage apoptosis or necrosis was detected by the binding of propidium iodide to nuclear DNA. Early-stage apoptosis was expressed as percentage of Annexin $\mathrm{V}$ positive cells. Apoptosis in vascular SMC and primary monocytes was quantified by enzyme immunoassay (EIA) measuring histoneassociated DNA fragments (mono- and oligonucleosomes) (Roche Diagnostics, Mannheim, Germany), normalized to cell protein content as assessed by the bicinchoninic acid protein assay kit (Pierce Biotechnology, Rockford, IL).

\section{Collagen synthesis}

At $80 \%$ confluence, the vSMCs were reefed with $1 \mu \mathrm{Ci} / \mathrm{ml}\left[2,3,4,5-{ }^{3} \mathrm{H}\right]-\mathrm{L}-$ proline (NEN Radiochemical, Perkin Elmer, Waltham, MA) in regular growth medium in the presence of either rhCXCL13 $(200 \mathrm{ng} / \mathrm{ml}), \mathrm{rhIL}-1 \beta(0.5 \mathrm{ng} / \mathrm{ml})$ or a combination thereof. Control cells were given vehicle. After 48 hours, the cell media were harvested and analyzed for Trichloroacetic acid (TCA) precipitated proteinassociated radioactivity measured by a TRI-CARB 2300 TR Scintillation Counter (Packard, Meriden, CT). Data are presented as percentage secreted TCA precipitated radioactivity. 
Chapter 4

Gene array hybridization and analysis of samples from carotid plaques and control arteries

For the analyses of carotid plaques and control arteries, biotinylated RNA was generated using $10 \mu \mathrm{g}$ of total RNA. The cRNA targets were then fragmented according to the Affymetrix ${ }^{\circledR}$ protocol (Santa Clara, CA). ${ }^{34}$ The fragmented biotinlabeled cRNA was hybridized to Affymetrix HG-U133 plus 2 Genechip ${ }^{\circledR}$ arrays, stained, washed, and scanned according to the standard Affymetrix protocol (www.affymetrix.com). The computer data files (*.cel), subsequently to be used in data analysis, were generated with Affymetrix software. The cel-files were normalized, background corrected and log-scaled using the Robust Microarray Analysis (RMA) as implemented in the Affymetrix Power Tools 1.12 .0 package aptprobeset-summarize.

\section{Real-time quantitative RT-PCR}

Total RNA was extracted from THP-1 cells, primary monocytes, samples from carotid plaques, and vascular SMC using MagNa Pure LC RNA isolation kit III (Roche Applied Science, Oslo, Norway) and stored at $-80^{\circ} \mathrm{C}$. Primers for CXCL13, arginase-1, IL-10, and transforming growth factor (TGF)- $\beta$ were designed by the Primer Express software, version 2.0 (Applied Biosystems, Foster City, CA). Primer sequences could be provided by request. Quantification of mRNA was performed by the ABI Prism 7500 (Applied Biosystems). Low density array (TaqMan Human Apoptosis Array, Applied Biosystem) was used to screen for apoptosis-related genes according to the manufacturer's description. Gene expression of the housekeeping gene $\beta$-actin was used for normalization.

\section{Enzyme immunoassays (EIAs)}

Plasma levels of CXCL13, IL-8 and transforming growth factor (TGF)- $\beta$ in plaque supernatants were measured by ElAs obtained from R\&D Systems (Minneapolis, $M N)$. The intra- and inter-assay coefficient of variation were $<10 \%$. 


\section{Ethics}

All the protocols were approved by the Regional Committee for Medical and Health Research Ethics in South-Eastern Norway Regional Health Authority (REK no.2769 and S-06172). Signed informed consent for participation in the study was obtained from all individuals. The investigation conforms to the principles outlined in the Declaration of Helsinki.

\section{Statistical analysis}

For comparisons of 2 groups of individuals, the Mann-Whitney $U$ test was used. When comparing 3 groups of individuals, the nonparametric Kruskal-Wallis test was used. If a significant difference was found, Mann-Whitney $U$ test was used to calculate the difference between each pair of groups. In the in vitro studies, Student's $t$ test (THP-1 cells and SMC) or Mann-Whitney $U$ test (primary monocytes and plaque samples) was used. In the dose-response experiments, the Bonferroni's multiple comparison test was used. The Chi-square test was used for analyzing contingency data. Coefficients of correlation were calculated by the Spearman rank test. Probability values (2-sided) were considered significant at $p<0.05$.

\section{Results}

\section{Plasma levels of CXCL13 in atherosclerotic disorders}

Both patients with asymptomatic $(n=49)$ and symptomatic $(n=81)$ carotid stenosis had significantly raised CXCL13 levels in plasma as compared with healthy controls $(n=20)$ with a trend for higher levels in those with symptomatic disease (Figure 1A). A similar pattern was found in CAD patients with significantly raised CXCL13 levels in both stable $(n=40)$ and unstable $(n=40)$ disease, with particularly high concentrations in those with unstable angina (Figure 1B). Some of the patients had additional risk factors that could interfere with inflammation (e.g., diabetes and hypertension), but importantly, the same pattern of CXCL13 levels was observed even if these patients were excluded from the study (data not shown). Also, the percentage of smokers was higher in angina patients and particularly in 
patients with carotid atherosclerosis as compared with controls, but we found no relation of CXCL13 to smoking status in either patients or controls (data not shown).
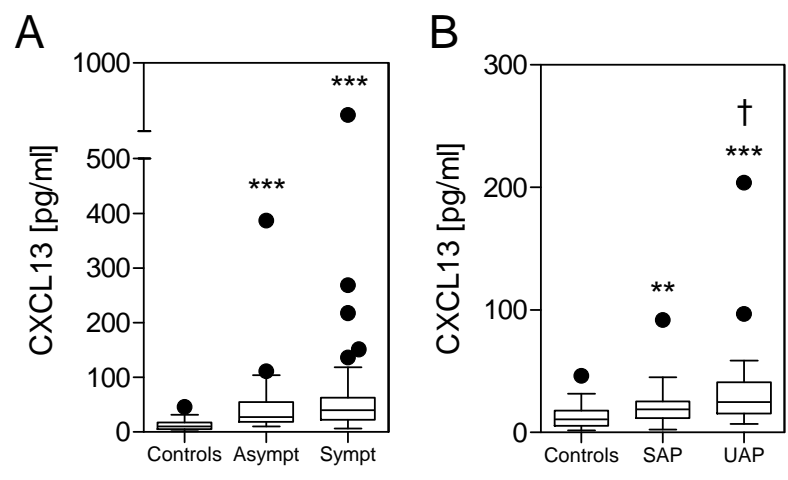

Figure 1. Plasma levels of CXCL13 in patients with atherosclerotic disease. A, Plasma levels of CXCL13 in patients with symptomatic (ie, symptoms within the latest 6 months) $(n=89)$ and asymptomatic $(n=41)$ carotid plaques. B, plasma levels of CXCL13 in patients with stable (SAP, $n=40$ ) and unstable (UAP, $n=40$ ) angina pectoris. The levels of CXCL13 in the patient groups were compared to CXCL13 levels in 20 sex- and aged-matched healthy controls. Data are given as medians, interquartile range and outliers (Tukey box and whiskers). ${ }^{* *} P<0.01$, and ${ }^{* * *} P<0.001$ versus controls. $+P<0.05$ versus SAP. Symptomatic versus asymptomatic carotid plaques, $P=0.17$.

\section{Expression of CXCL13 and CXCR5 mRNA in atherosclerotic carotid plaques}

The mRNA levels of CXCL13, but not mRNA levels of CXCR5, were markedly upregulated within the atherosclerotic carotid plaques $(n=106)$ as compared with non-atherosclerotic arteries $(n=10)$ obtained from iliac arteries of organ donors (Figure 2A). The mRNA levels of CXCL13 were positively correlated with time between latest symptom and surgery, and patients with echogenic plaques, often characterized by a higher content of fibrous tissue and calcification, tended to have higher levels of CXCL13 than those with echolucent plaques $(P=0.06)$, suggesting a relationship between high CXCL13 levels and stable carotid lesions (Figure 2B-C). In contrast, there were no associations between CXCL13 expression and traditional risk factors such as age, gender, C-reactive protein, diabetes, 
lipoprotein levels, smoking status, family history for cardiovascular disease, diabetes, and medicine use including statins (data not shown). Moreover, adjusting for statin use and other relevant confounders had no impact on the findings presented in Figure 1B-C (data not shown).
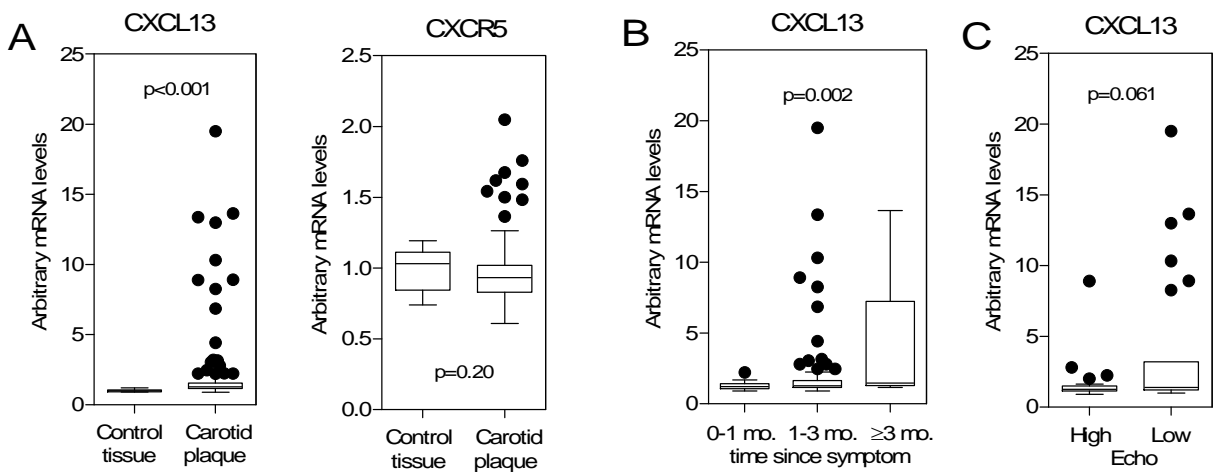

Figure 2. CXCL13 and CXCR5 mRNA in atherosclerotic tissue. A, mRNA levels of CXCL13 and CXCR5 in atherosclerotic carotid plaques $(n=106)$ and in control tissue, obtained from iliac arteries of organ donors $(n=10)$. B and $C, C X C L 13$ mRNA levels in relation to time between latest symptom and surgery (mo, month) (B) and in relation to plaque echogenicity (C). mRNA was quantified by means of Affymetrix Gene Array analysis and are given in arbitrary units. Data are given as medians, interquartile range and outliers (Tukey box and whiskers).

\section{Localization of CXCL13 and CXCR5 protein in atherosclerotic carotid plaques}

Immunostaining of carotid plaques $(n=15)$ showed that CXCL13 and CXCR5 were expressed at all stages of atherosclerosis development ranging from intimal thickening, via thick fibrous cap atheroma, to hemorrhaged and ruptured lesions (data not shown). Co-staining with markers of SMC and macrophages in advanced lesions showed that CXCL13 and CXCR5 were both highly expressed by medial SMC and macrophages inside the lesions (Figure 3). A similar localization to SMC and macrophages was also seen in plaque with intimal thickening and in thick fibrous cap atheroma (data not shown). 


\section{Chapter 4}
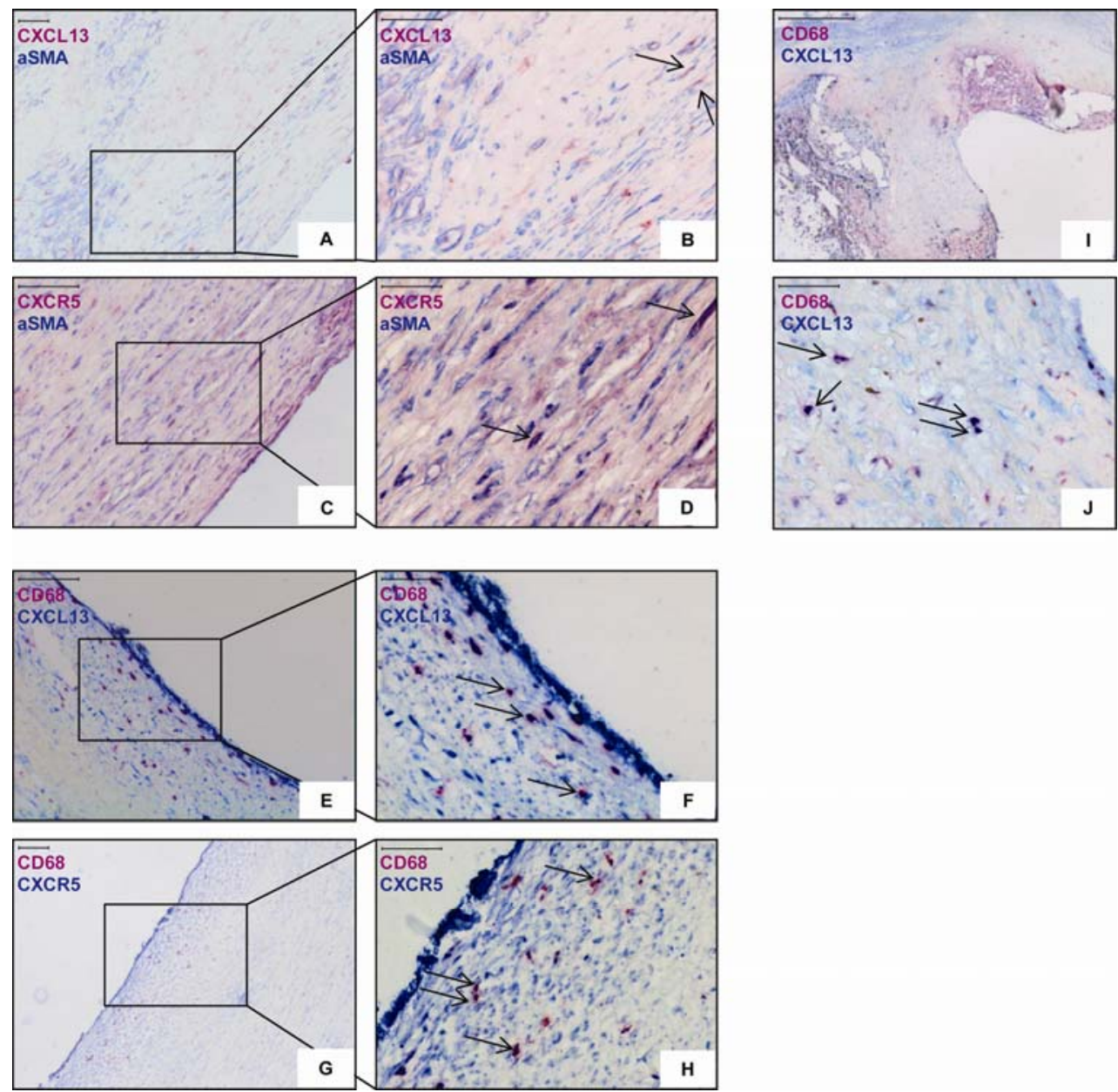

Figure 3. CXCL13 and CXCR5 co-expression with vascular SMC and macrophages in advanced human atherosclerotic lesions. CXCL13 and CXCR5 are both highly expressed by medial SMC: CXCL13(red)/aSMA(blue) A (20x, scale bar 100 $\mu \mathrm{m})$ and B (40x, scale bar $50 \mu \mathrm{m}$ ) and CXCR5(red)/aSMA(blue) C (20x, scale bar 100 $\mu \mathrm{m})$ and D (40x, scale bar 50 $\mu \mathrm{m})$. Macrophages inside the lesions are strongly positive for CXCL13 and CXCR5:

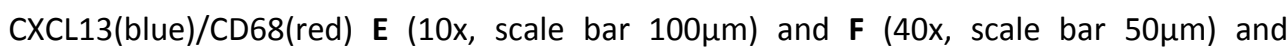
CXCR5(blue)/CD68(red) G (10x, scale bar $100 \mu \mathrm{m})$ and $\mathbf{H}(40 \mathrm{x}$, scale bar 50 $\mu \mathrm{m})$. CXCL13 is expressed by macrophages in intraplaque haemorrhage lesions as well: I (5x, scale bar $500 \mu \mathrm{m})$ and $\mathbf{J}(40 \mathrm{x}$, scale bar $50 \mu \mathrm{m})$. 


\section{Regulation of CXCL13 expression in THP-1 cells}

Our findings so far suggest enhanced expression of CXCL13 within the atherosclerotic lesion, at least partly localized to macrophages. We therefore next examined the expression of CXCL13 in THP-1 monocytes that had been activated by different stimuli with relevance to atherogenesis (e.g. inflammatory cytokines, TLR agonists, neurohormones, and platelets). In an attempt to mimic the in vivo situation within an inflammatory atherosclerotic lesion, the cells were preactivated with rhTNF $\alpha(5 \mathrm{ng} / \mathrm{ml})$ for 96 hours before experimental start. ${ }^{33}$ Both TLR2 (Pam3Cys) and TLR4 (LPS) agonists as well as releasate from thrombinactivated platelets and the $\beta$-adrenergic receptor agonist isoproterenol, but not IL-1 $\beta$, enhanced CXCL13 levels at both the mRNA ( 6 hours) and protein levels (24 hours), although the rather modest effect of isoproterenol was only seen at the protein level (Figure 4A-B).

A

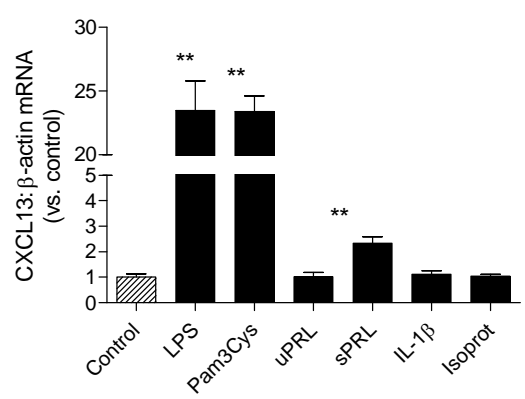

C

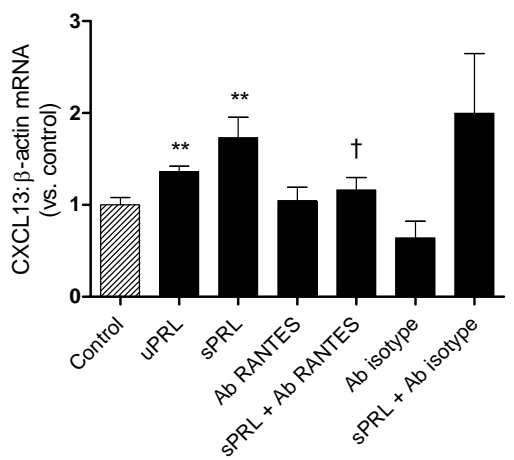

B

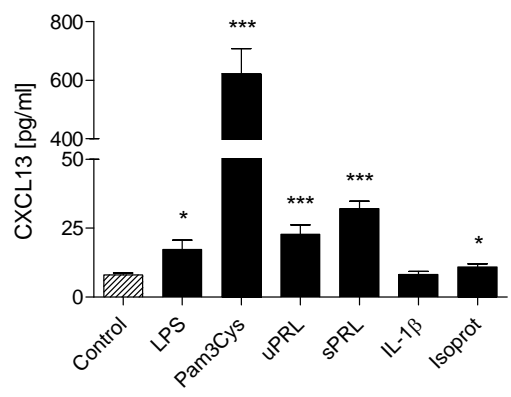


Figure 4. Regulation of CXCL13 in TNF $\alpha$ pre-activated THP-1 monocytes. A-B, the effect of LPS (5 ng/ml), Pam3Cys $(1 \mu \mathrm{g} / \mathrm{ml})$, relaseate from un-stimulated (uPRL) and thrombinactivated (sPRL) platelets, IL-1 $\beta(1 \mathrm{ng} / \mathrm{ml})$, and isoproterenol (Isoprot, $20 \mu \mathrm{M})$ on the mRNA (A) and protein (B) levels of CXCL13 after culturing for 6 and 24 hours, respectively. C, the effect of releasate from thrombin-activated platelets (SPRL) on the mRNA levels of CXCL13 in THP-1 monocytes with or without co-culturing with neutralizing antibodies (Ab) against RANTES or isotype-matched control antibodies after culturing for 6 hours. In all experiments, THP-1 cells were pre-activated with TNF $\alpha(5 \mathrm{ng} / \mathrm{ml})$ for 96 hours prior to experimental start. mRNA levels were assessed by real-time RT-PCR in relation to the control gene $\beta$-actin, and CXCL13 protein levels in cell supernatants were measured by EIA. Data are mean \pm SEM $(n=4-8) .{ }^{*} P<0.05,{ }^{* *} P<0.01$, and $* * * P<0.001$ versus controls (vehicle). $+P<0.05$ versus $S P R L$ without neutralizing antibodies against RANTES.

\section{The platelet-mediated increase in CXCL13 expression in THP-1 monocytes involves RANTES}

Upon activation, platelets release the content of their secretory granules, and this platelet releasate comprises a multitude of inflammatory and vasoactive substances, which can activate adjacent cells such as monocytes/macrophages. ${ }^{35}$ As shown in Figure 4C, a neutralizing antibody against RANTES, but not against other platelet derived cytokines (e.g. LIGHT, CD40L, and DKK-1 (data not shown), significantly attenuated the induction of CXCL13 in TNF- $\alpha(5 \mathrm{ng} / \mathrm{ml})$ pre-activated THP-1 cells that had been exposed to releasate from activated platelets for 6 hours, suggesting that platelet-derived RANTES could contribute to the plateletmediated induction of CXCL13 in these cells.

\section{Anti-apoptotic effects of CXCL13 in THP-1 macrophages}

Activation of CXCR5 has been shown to exert anti-apoptotic effects in B cell malignancies. ${ }^{23}$ In order to elucidate any consequences of the raised CXCL13 expression in atherosclerotic disorders, we examined the ability of CXCL13 to modulate lipid-induced apoptosis in PMA-differentiated macrophages. By using VAD-FMK-FITC as a marker of caspase activity, we observed that CXCL13 almost completely abolished the 7-ketocholesterol-mediated increase in total caspase 
activity (Figure 5A). Moreover, we found attenuating effects of CXCL13 on the 7ketocholesterol-mediated up-regulation of both initiator (e.g. caspase-8) and executioner (e.g. caspase-3 and -7) caspases as assessed by RT-PCR (Figure 5B-D). Finally, by using Annexin $\mathrm{V}$ binding as a marker of apoptosis, we showed that the pro-apoptotic effect of 7-ketocholesterol was significantly attenuated by CXCL13 (Figure 6A-B). A significant anti-apoptotic effect of CXCL13 was also seen when CXCL13 was added to cell cultures together with the DNA damaging agent camptothecin.

A

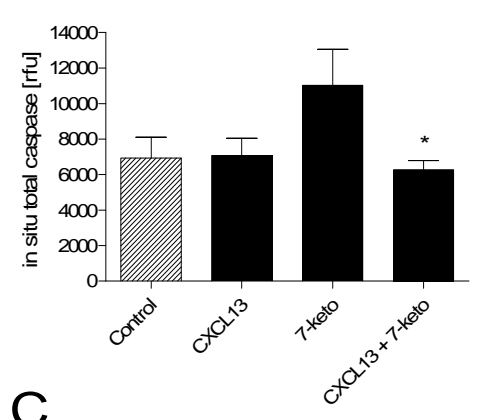

C

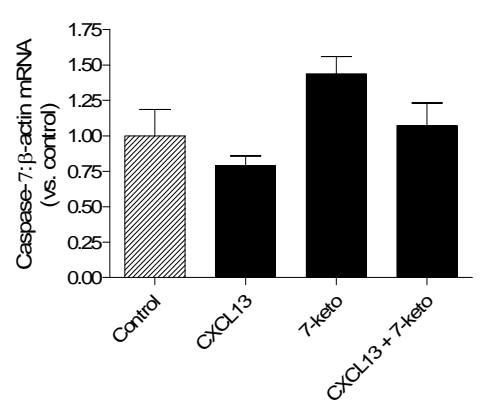

B
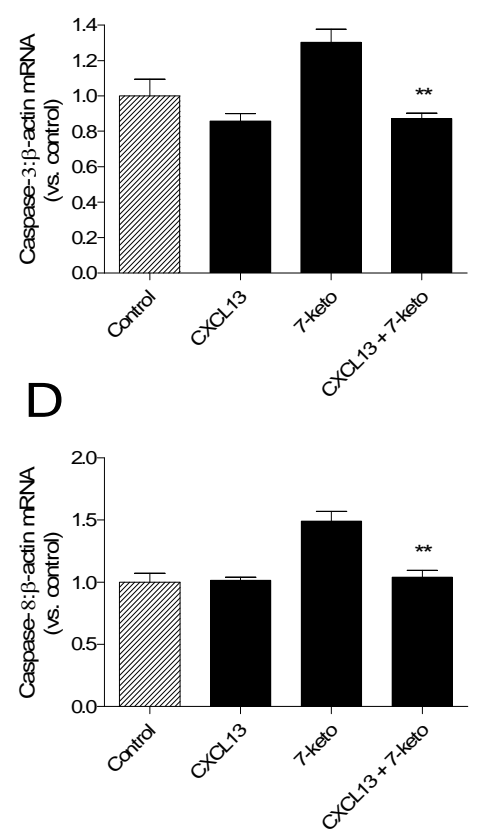

Figure 5. CXCL13 down-regulates caspase activity in THP-1 macrophages. PMA differentiated THP-1 macrophages were stimulated for 24 hours with or without 7ketocholesterol (7-keto, $40 \mu \mathrm{g} / \mathrm{ml})$, rhCXCL13 $(200 \mathrm{ng} / \mathrm{ml})$, or a combination thereof. A, total caspase activity as assessed by staining with the fluorescently labeled irreversible lipid soluble caspase inhibitor FITC-VAD-FMK. B-D, mRNA levels of different caspases in relation to the control gene $\beta$-actin. Control cells were receiving vehicle. Data are expressed as mean \pm SEM $(n=4-6) .{ }^{*} P<0.05$ versus 7 -ketocholesterol without rhCXCL13. rfu, relative fluorescence units. 


\section{Chapter 4}

\section{Anti-apoptotic effects of CXCL13 in vascular SMC}

As described above, CXCL13 and CXCR5 were expressed in vascular SMC, and the association of CXCL13 expression to plaque echogenicity may suggest that CXCL13 also could influence SMC apoptosis. Indeed, CXCL13 significantly attenuated caspase-3 and -7 activity in SMC that had been exposed to 7-ketocholesterol for 12 hours (Figure $6 \mathrm{C}$ ). The anti-apoptotic effect of $\mathrm{CXCL13}$ was even more pronounced when analyzing histone-associated DNA fragments by EIA, a method for direct assessment of apoptosis, in SMC (Figure 6D).

A
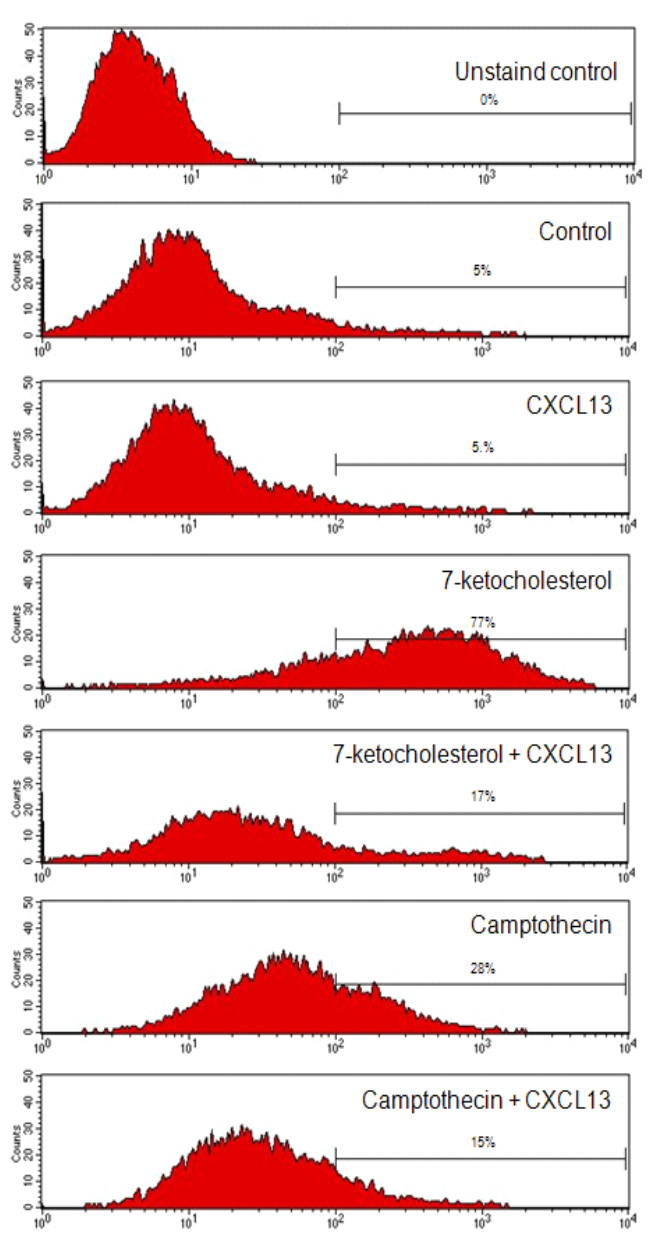
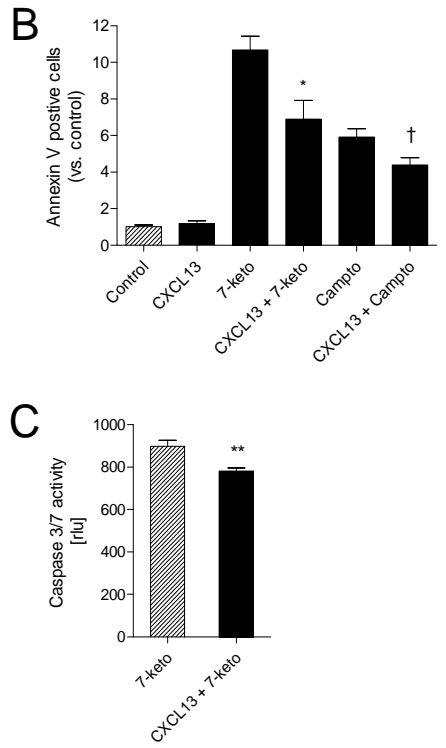

D

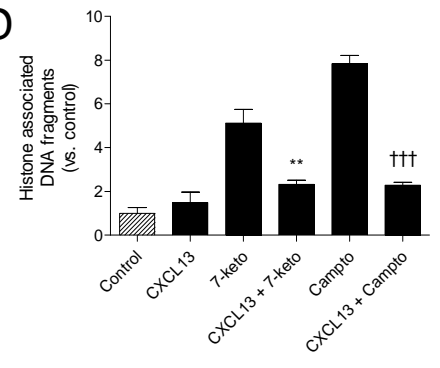


Figure 6. CXCL13 exerts anti-apoptotic effect in THP-1 macrophages and SMC. PMA differentiated THP-1 macrophages were stimulated for 24 hours with or without 7ketocholesterol (7-keto, $40 \mathrm{\mu g} / \mathrm{ml}$ ), camptothecin (Campto, $10 \mathrm{mM}$ ), rhCXCL13 (200 $\mathrm{ng} / \mathrm{ml}$ ), or a combination thereof. A-B, the degree of early apoptosis assessed by flow cytometric detection of Annexin V-FITC expressed as percentage of Annexin $\mathrm{V}$ positive cells $(n=7)$. Panel A shows flow cytometry data from one representative experiment. The presence of apoptotic cells is demonstrated by increased fluorescence intensity (gate). C, the effect of 7-ketocholesterol $(40 \mu \mathrm{g} / \mathrm{ml})$ with and without rhCXCL13 $(200 \mathrm{ng} / \mathrm{ml})$ on caspase-3 and -7 activity in SMC after culturing for 12 hours $(n=8)$. D, the degree of apoptosis, as assessed by EIA measurements of histone-associated DNA fragments, in SMC there were exposed to 7-ketocholesterol $(40 \mu \mathrm{g} / \mathrm{ml})$ and camptothecin $(10 \mu \mathrm{M})$ for 12 hours with and without $\mathrm{rhCXCL13}(200 \mathrm{ng} / \mathrm{ml})(\mathrm{n}=3-4)$. Data are expressed as mean \pm SEM. ${ }^{*} P<0.05$ and ${ }^{* *} P<0.01$ versus 7 -ketocholesterol without rhCXCL13; $+P<0.05$ and $+++P<0.001$ versus camptothecin without CXCL13. rlu, relative luminescence units.

CXCL13 increases arginase-1, TGF- $\beta$, and IL-10 levels in THP-1 monocytes and influences collagen synthesis in SMC

The ability of monocytes/macrophages to produce arginase-1, an enzyme involved in the production of the collagen residues proline and hydroxyproline, and the anti-inflammatory cytokines TGF- $\beta$ and IL-10, markedly contributes to their capacity to resolve inflammation. ${ }^{10,}{ }^{36}$ As shown in Figure 7A, CXCL13 significantly increased the expression of arginase-1, TGF- $\beta$, and IL-10 in TNF- $\alpha$ (5 $\mathrm{ng} / \mathrm{ml}$ ) pre-activated THP-1 cells after culturing for 6 hours. Finally, although CXCL13 had no effect on its own, it totally abolished the suppressive effect of IL$1 \beta(0.1 \mathrm{ng} / \mathrm{ml})$ on total collagen synthesis in SMC that had been cultured for 48 hours (Figure 7B). 

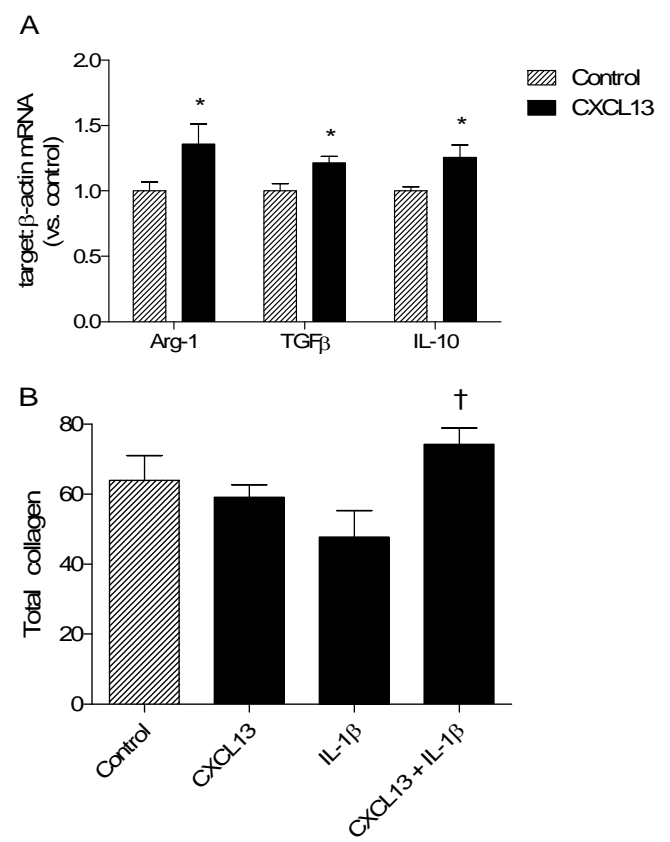

Figure 7. CXCL13 up-regulates arginase-1, TGF- $\beta$, and IL-10 in THP-1 monocytes and modulates collagen synthesis in SMC. $\mathbf{A}$, the effect of rhCXCL13 $(200 \mathrm{ng} / \mathrm{ml})$ on mRNA levels of arginase-1, TGF-b, and IL-10 in THP-1 monocytes after culturing for 6 hours. Prior to experiment start, THP-1 cells were pre-activated with TNF $\alpha(5 \mathrm{ng} / \mathrm{ml})$ for 96 hours. mRNA levels were measured by real-time RT-PCR in relation to the control gene $\beta$-actin. $\mathbf{B}$, the effect of rhCXCL13 $(200 \mathrm{ng} / \mathrm{ml}), \mathrm{IL}-1 \beta(0.5 \mathrm{ng} / \mathrm{ml})$, or a combination thereof on total collagen synthesis in SMC after culturing for 48 hours. $\left[{ }^{3} \mathrm{H}\right]$-Proline incorporation was used as a marker for collagen synthesis. Data are expressed as mean $\pm \operatorname{SEM}(n=3-6)$. ${ }^{*} P<0.05$ versus controls (vehicle). $+P<0.05$ versus IL-1b without rhCXCL13.

\section{Regulation and effects of CXCL13 in primary monocytes}

To validate our experiments in THP-1 cells, we examined the regulation of CXCL13 in primary monocytes from healthy controls $(n=7)$. Basically, we found similar pattern of regulation of CXCL13 in primary monocytes as in THP-1 cells, but with some interesting differences. First, while both TLR2 and TLR4 activation increased CXCL13 expression in THP-1 monocytes, only LPS enhanced CXCL13 expression in primary monocytes (Figure 8A). Second, while the enhancing effect of LPS was seen in control cells and in cells that were pre-activated with TNF- $\alpha(5 \mathrm{ng} / \mathrm{ml})$ 
(data not shown), the enhancing effect of releasate from thrombin-activated platelets on CXCL13 expression in primary monocytes was restricted to preactivated cells (Figure 8B). This latter finding may be relevant to the situation during plaque rupture where platelets interact with monocytes/macrophages within an inflamed microenvironment. Finally, as in THP-1 cells, CXCL13 attenuated the pro-apoptotic effect of 7-ketocholesterol and camptothecin in primary monocytes as assessed by EIA measurements of histone-associated DNA fragments (Figure $\mathbf{8 C}$ ).

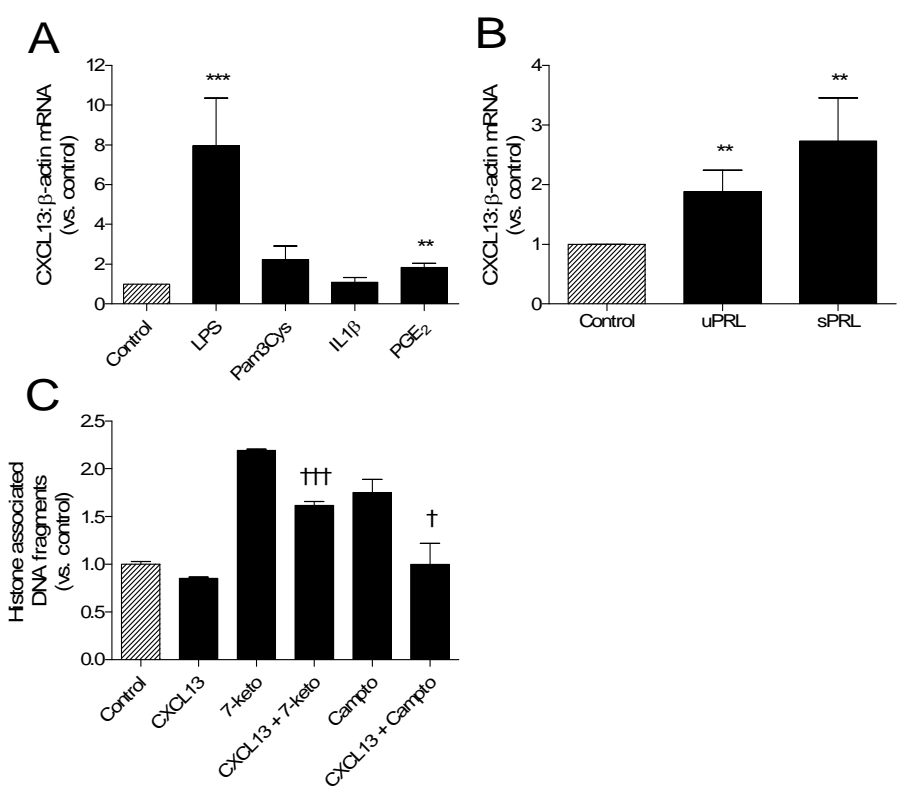

Figure 8. Regulation and effects of CXCL13 in primary monocytes. A, the effect of LPS (5 $\mathrm{ng} / \mathrm{ml})$, Pam3Cys $(1 \mu \mathrm{g} / \mathrm{ml})$, and IL-1 $\beta(1 \mathrm{ng} / \mathrm{ml})$ on the mRNA levels of CXCL13 in primary monocytes after culturing for 6 hours. $B$, the effect of relaseate from un-stimulated (uPRL) and thrombin-activated (sPRL) platelets on mRNA levels of CXCL13 in primary monocytes after culturing for 6 hours. C, the degree of apoptosis, as assessed by EIA measurements of histone-associated DNA fragments, in primary monocytes that were exposed to 7 ketocholesterol (7-keto, $40 \mu \mathrm{g} / \mathrm{ml}$ ) and camptothecin (Campto, $10 \mu \mathrm{M}$ ) for 18 hours with and without rhCXCL13 $(200 \mathrm{ng} / \mathrm{ml})$. Note, while the monocytes in panel A were cultured for 48 hours without any stimulants before experimental start, the cells in panel $B$ were pre-activated with TNFa $(5 \mathrm{ng} / \mathrm{ml})$ for 48 hours. mRNA levels were assessed by real-time RT-PCR in relation to the control gene $\beta$-actin. Data are expressed as mean \pm SEM $(n=3-8)$. 
Chapter 4

$* * P<0.01$ and $* * * P<0.001$ versus control (vehicle). $+P<0.05$ and $+\dagger+P<0.001$ versus camptothecin or 7-ketocholesterol without rhCXCL13.

\section{Effects of CXCL13 in carotid plaques}

To further evaluate the in vivo relevance of our findings, we examined the effect of rhCXCL13 on freshly isolated carotid plaque samples, obtained from patients that had been suffering from symptoms within 1 month and that were undergoing carotid endarterectomy $(n=7)$. Comparable to the effects in THP-1 monocytes, CXCL13 enhanced the expression of arginase-1, IL-10 and TGF- $\beta$ in carotid plaque after culturing for 6 hours as assessed by real-time RT PCR, although the effect on TGF- $\beta$ did not reach statistical significance (Figure 9A). The significant increase in arginase-1 and IL-10 mRNA levels within CXCL13 stimulated plaques was confirmed at the protein level in plaque lysates as assessed by western blotting (Figure 9B, arginase-1) and EIA (Figure 9C, IL-10). Interesting, however, while mRNA levels of TGF- $\beta$ tended to increase in the plaque lysates, protein levels of TGF- $\beta$ tended to decrease in the plaque lysates and to increase in plaque supernatants (Figure 9D). This may suggest that while the IL-10 protein is plaque associated, TGF- $\beta$ seems to be released upon CXCL13 activation. 


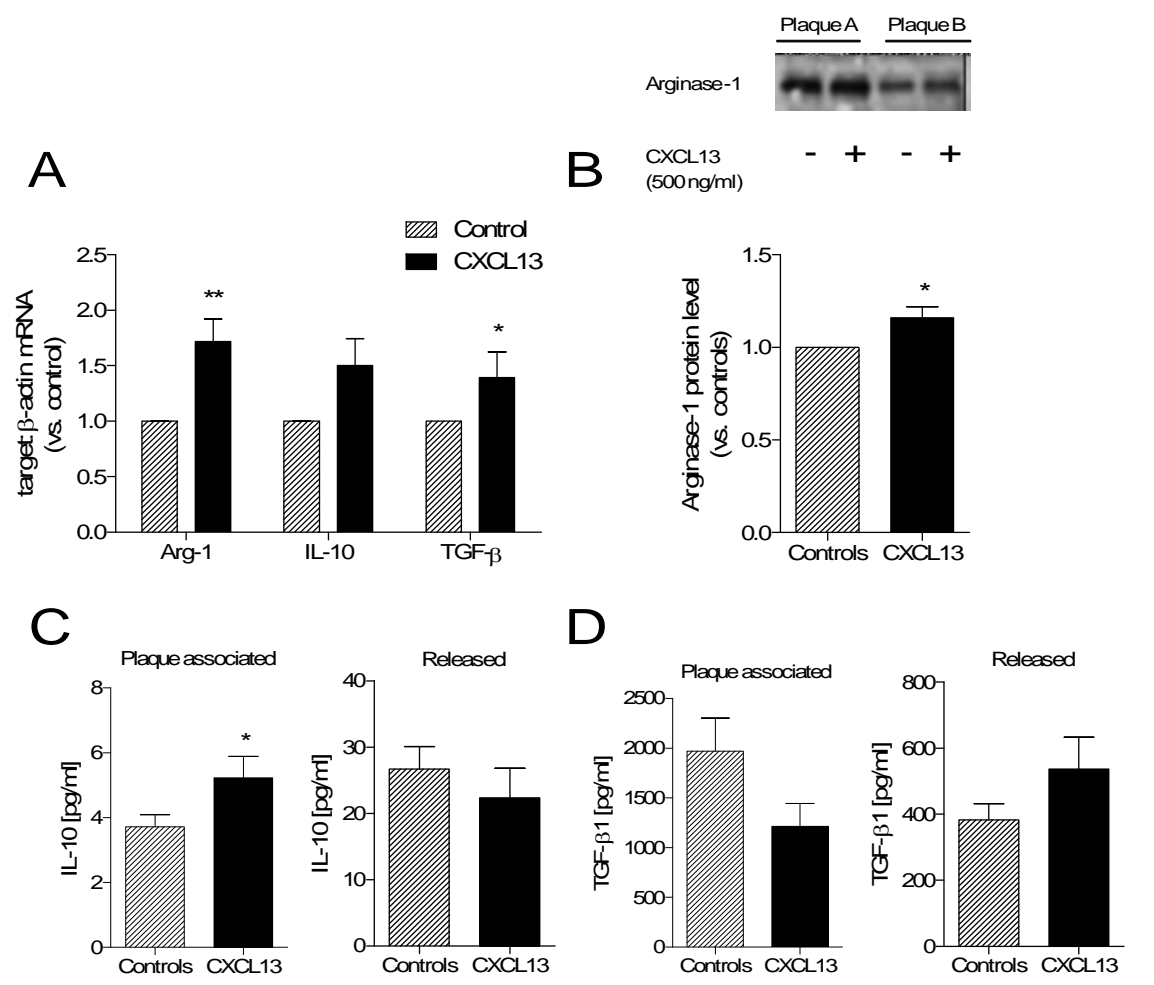

Figure 9. The effect of CXCL13 in atherosclerotic carotid plaques after culturing for 6 hours. The figure shows the effect of rhCXCL13 $(500 \mathrm{ng} / \mathrm{ml})$ on mRNA (A) and protein (BD) levels of arginase-1 (Arg-1), IL-10 and TGF- $\beta$ in freshly isolated carotid plaque samples obtained from patients that had been suffering from symptoms within 1 month and that were undergoing carotid endarterectomy $(n=7)$. A, mRNA levels of these mediators as assessed by real-time RT-PCR in relation to the control gene $\beta$-actin. $\mathbf{B}$, protein levels of arginase-1 in plaque lysates as assessed by western blotting. The upper part shows blots from two representative carotid plaques. The lower panels show protein levels of IL-10 (C) and TGF- $\beta$ (D) as assessed by EIA in plaque lysates (plaque associated) and plaque supernatants (released). Data are expressed as mean \pm SEM. ${ }^{*} P \leq 0.05$ and ${ }^{* *} P<0.01$ versus control (vehicle). 


\section{Discussion}

The CXCL13/CXCR5 dyad has not previously been linked to atherosclerosis, and in the present study we show (i) increased expression of CXCL13 in both carotid and coronary atherosclerosis. (ii) Within the atherosclerotic lesion, high CXCL13 expression was correlated with time since latest symptoms tended to correlate with increased plaque echogenicity, suggesting an association between CXCL13 and a stable plaque phenotype. Our in vitro and ex vivo findings showing that CXCL13 (iii) is up-regulated in monocytes upon TLR (TLR2 and TLR4) and platelet activation, (iv) exerts anti-apoptotic effects in primary monocytes, THP-1 macrophages and SMC, ( $v$ ) increases arginase-1, TGF- $\beta$, and IL-10 expression in THP-1 monocytes and samples from carotid plaques, and (vi) counteracts the IL$1 \beta$-mediated decrease in collagen synthesis in SMC, further suggesting a plaque stabilizing role for CXCL13, potentially representing a counteracting mechanism to inflammation.

While CXCR5 was originally shown to promote B cell activation, more recent studies have shown that this receptor is also expressed on activated T cells, macrophages, and dendritic cells. ${ }^{14,19}$ Recently, Gräbner et al. reported increased expression of CXCL13 in SMC of the aortic adventitia of aged $\mathrm{ApoE}^{-/-}$mice, secondary to increased lymphotoxin $\beta$ receptor signaling. ${ }^{37}$ In the present study we extend these finding by showing strong immunostaining of CXCR5 and CXCL13 in SMC of human atherosclerotic lesions. We also demonstrate that CXCL13 exerted anti-apoptotic effects and counteracted the IL-1ß-mediated decrease in collagen synthesis in SMC. The strong expression of CXCR5 within normal human arteries could suggest a role for CXCR5 also in normal vascular physiology that involves modulation of SMC phenotype. Our findings further underscore that chemokines, including homeostatic chemokines such as CXCL13, may have effects beyond that of chemotaxis and leukocyte activation.

A major finding in the present study was that CXCL13 down-regulated apoptosis in primary monocytes, THP-1 macrophages and SMC secondary to exposure of modified cholesterol and a DNA damaging agent. The pathological and clinical significance of apoptosis in atherosclerosis remains controversial. On the one hand, anti-apoptotic effects could increase cell build-up in the intimal compartment, leading to narrowing of the lumen and enhanced atherogenesis, particularly in the early stage of this disorder. ${ }^{38}$ On the other hand, apoptosis of 
SMC could lead to weakening of the fibrous cap, and macrophage apoptosis could induce a pro-coagulant phenotype within the lesion, contributing to plaque destabilization and thrombus formation. ${ }^{39,40}$ Moreover, removal of apoptotic and necrotic cells by macrophages is of major importance to resolve inflammation, ${ }^{41}$ and macrophage apoptosis could therefore be detrimental in particular in relation to plaque stability.

In addition to apoptosis, matrix regulation and inflammation is of major importance for plaque stability. Herein we found that CXCL13 induced the expression of arginase-1, TGF- $\beta$, and IL-10 in monocytes/macrophages, suggesting that CXCL13 may turn these cells into a phenotype that could contribute to tissue repair and resolution of inflammation. ${ }^{36}$ In support of a CXCL13-induced increase in tissue repair, CXCL13 seemed to counteract the down-regulation of collagen synthesis in SMC that were exposed to inflammatory mediators. The ability of CXCL13 to enhance the expression of arginase-1, TGF- $\beta$ and IL-10 in freshly isolated carotid plaques further support plaque stabilizing properties of CXCL13.

Based on the present study, we suggest the following hypothesis (Figure 10): (i) CXCR5 is constitutively expressed at a relatively high level in normal and atherosclerotic vessels. (ii) Activation of TLRs and platelets promote enhanced expression of CXCL13 within an unstable atherosclerotic lesion. (iii) This upregulation of CXCL13 may result in anti-inflammatory and anti-apoptotic effects as well as enhancing effect on collagen synthesis, potentially representing a counteracting mechanism during plaque destabilization.

The present study has some limitations. The ex vivo experiments in human carotid plaques included few patients and sampling errors and carotid plaque heterogeneity are potential methodological bias. The low number of controls in the plaque analyses (e.g. non-atherosclerotic arteries) is another limitation. Nonetheless, our findings may suggest that the CXCL13/CXCR5 dyad could represent a protective and resolving response to plaque inflammation, promoting an anti-inflammatory phenotype in macrophages and a stabilizing phenotype in SMC. However, further studies, including studies in experimental atherosclerosis, will have to be performed to make any firm conclusion on the role of CXCL13/CXCR5 in atherogenesis. 


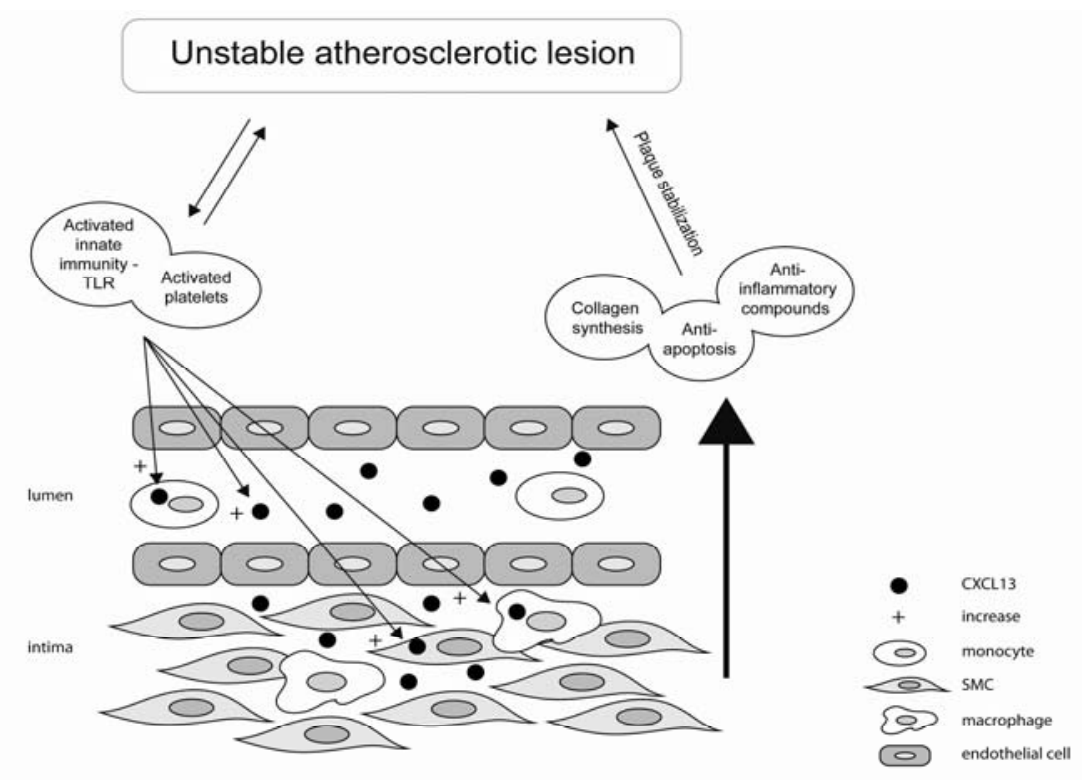

Figure 10. The figure summarizes our hypothesis. (i) CXCR5 is constitutively expressed at a relatively high level in normal and atherosclerotic vessels. (ii) Activation of TLRs and platelets promote enhanced expression of CXCL13 within an unstable atherosclerotic lesion. (iii) This up-regulation of $\mathrm{CXCL} 13$ may result in anti-inflammatory and antiapoptotic effects as well as enhancing effect on collagen synthesis, potentially representing a counteracting mechanism during plaque destabilization. 


\section{References}

1. McNeill E, Channon KM, Greaves DR. Inflammatory cell recruitment in cardiovascular disease: murine models and potential clinical application. Clin Sci. (Lond) 2010;118:641-655.

2. Hansson GK, Robertson AK, Soderberg-Naucler C. Inflammation and atherosclerosis. Annu Rev Pathol. 2006;1:297-329.

3. Zernecke A, Shagdarsuren E, Weber C. Chemokines in atherosclerosis: an update. Aterioscler Thromb Vasc Biol. 2008;28:1897-1908.

4. Aukrust P, Halvorsen B, Yndestad A, Ueland T, Oie E, Otterdal K et al. Chemokines and cardiovascular risk. Arterioscler Thromb Vasc Biol. 2008;28:1909-1919.

5. Gu L, Okada Y, Clinton SK, Gerard C, Sukhova GK, Libby P, Rollins BJ. Absence of monocyte chemoattractant protein-1 reduces atherosclerosis in low density lipoprotein receptor-deficient mice. Mol Cell. 1998;2:275-281.

6. Boring L, Gosling J, Cleary M, Charo IF. Decreased lesion formation in CCR2-/- mice reveals a role for chemokines in the initiation of atherosclerosis. Nature 1998;394:894.

7. Boisvert WA, Santiago R, Curtiss LK, Terkeltaub RA. A leukocyte homologue of the IL8 receptor CXCR-2 mediates the accumulation of macrophages in atherosclerotic lesions of LDL receptor-deficient mice. J Clin Invest. 1998;101:353-363.

8. Galkina E, Harry BL, Ludwig A, Liehn EA, Sanders JM, Bruce A, Weber C, Ley K. CXCR6 promotes atherosclerosis by supporting T-cell homing, interferon-gamma production, and macrophage accumulation in the aortic wall. Circulation. 2009;116:1801-1811.

9. Combadiére C, Potteaux S, Gao JL, Esposito B, Casanova S, Lee EJ et al. Decreased atherosclerotic lesion formation in CX3CR1/apolipoprotein E double knockout mice. Circulation. 2003;107:1009-1016.

10. Aslanian AM, Charo IF. Targeted disruption of the scavenger receptor and chemokine CXCL16 accelerates atherosclerosis. Circulation. 2006;114:583-590.

11. Braunersreuther V, Zernecke A, Arnaud C, Liehn EA, Steffens S, Shagdarsuren E et al. CCR5 but not CCR1 deficiency reduces development of diet-induced atherosclerosis in mice. Arterioscler Thromb Vasc Biol. 2007;27:373-379.

12. Zernecke A, Bot I, Djalali-Talab Y, Shagdarsuren E, Bidzhekov K, Meiler S et al. Protective role of CXC receptor 4/CXC ligand 12 unveils the importance of neutrophils in atherosclerosis. Circ Res. 2008;102:209-217.

13. Beyer T, Meyer-Hermann M. Mechanisms of organogenesis of primary lymphoid follicles. Int Immunol. 2008;20:615-623.

14. Muller G, Hopken UE, Lipp M. The impact of CCR7 and CXCR5 on lymphoid organ development and systemic immunity. Immunol Rev. 2003;195:117-135. 
15. Gunn MD, Ngo VN, Ansel KM, Ekland EH, Cyster JG, Williams LT. A B-cell-homing chemokine made in lymphoid follicles activates Burkitt's lymphoma receptor-1. Nature. 1998;391:799-803.

16. Weyand CM, Goronzy JJ. Ectopic germinal center formation in rheumatoid synovitis. Ann N Y Acad Sci. 2003;987:140-149.

17. Middel P, Raddatz D, Gunawan B, Haller F, Radzun HJ. Increased number of mature dendritic cells in Crohn's disease: evidence for a chemokine mediated retention mechanism. Gut. 2006;55:220-227.

18. Damås JK, Smith C, Øie E, Fevang B, Halvorsen B, Waehre T et al. Enhanced expression of the homeostatic chemokines CCL19 and CCL21 in clinical and experimental atherosclerosis: possible pathogenic role in plaque destabilization. Arterioscler Thromb Vasc Biol. 2007;27:614-620.

19. Schmutz C, Hulme A, Burman A, Salmon M, Ashton B, Buckley C et al. Chemokine receptors in the rheumatoid synovium: upregulation of CXCR5. Arthritis Res Ther. 2005; 7:R217-229.

20. Luchtefeld M, Grothusen C, Gagalick A, Jagavelu K, Schuett H, Tietge UJ et al. Chemokine receptor 7 knockout attenuates atherosclerotic plaque development. Circulation. 2010;122:1621-1628.

21. Ebert LM, Schaerli P, Moser B. Chemokine-mediated control of $T$ cell traffic in lymphoid and peripheral tissues. Mol Immunol. 2005;42:799-809.

22. Pereira JP, Kelly LM, Cyster JG. Finding the right niche: B-cell migration in the early phases of T-dependent antibody responses. Int Immunol. 2010;22:413-419.

23. Chunsong H, Yuling H, Li W, Jie X, Gang Z, Qiuping Z et al. CXC chemokine ligand 13 and $C C$ chemokine ligand 19 cooperatively render resistance to apoptosis in $B$ cell lineage acute and chronic lymphocytic leukemia CD23+CD5+ B cells. J Immunol. 2006;177:6713

24. Loetscher P, Moser B. Homing chemokines in rheumatoid arthritis. Arthritis Res. 2002;4:233-236.

25. Carlsen HS, Baekkevold ES, Johansen FE, Haraldsen G, Brandtzaeg P. B cell attracting chemokine 1 (CXCL13) and its receptor CXCR5 are expressed in normal and aberrant gut associated lymphoid tissue. Gut. 2002;51:364-371.

26. Mathiesen EB, Bonaa $\mathrm{KH}$, Joakimsen O. Echolucent plaques are associated with high risk of ischemic cerebrovascular events in carotid stenosis: the Troms $\varnothing$ study. Circulation. 2001;103:2171-2175.

27. Olofsson PS, Jatta K, Wågsäter D, Gredmark S, Hedin U, Paulsson-Berne $G$ et al. The antiviral cytomegalovirus inducible gene 5/viperin is expressed in atherosclerosis and regulated by proinflammatory agents. Arterioscler Thromb Vasc Biol 2005;25:e113. 
28. Sluimer JC, Kisters N, Cleutjens KB, Volger OL, Horrevoets AJ, van den Akker LH et al. Dead or alive: gene expression profiles of advanced atherosclerotic plaques from autopsy and surgery. Physiol Genomics 2007;30:335-341.

29. Virmani R, Kolodgie FD, Burke AP, Farb A, Schwartz SM. Lessons from sudden coronary death: a comprehensive morphological classification scheme for atherosclerotic lesions. Arterioscler Thromb Vasc Biol 2000;20:1262-1275.

30. Diez D, Wheelock AM, Goto S, Haeggstrom JZ, Paulsson-Berne G, Hansson GK et al. The use of network analyses for elucidating mechanisms in cardiovascular disease. Mol Biosyst 2010;6:289-304.

31. Stylianou E, Aukrust P, Muller F, Nordoy I, Froland SS. Complex effects of interferonalpha on the cytokine network in HIV infection-possible contribution to immunosuppression. Cytokine 2001;14:56-62.

32. Staff AC, Ranheim T, Halvorsen B. Augmented PLA2 activity in pre-eclamptic decidual tissue--a key player in the pathophysiology of 'acute atherosis' in pre-eclampsia? Placenta 2003;24:965-973.

33. Otterdal K, Smith C, Oie E, Pedersen TM, Yndestad A, Stang E et al. Platelet-derived LIGHT induces inflammatory responses in endothelial cells and monocytes. Blood. 2006;108:928-935.

34. Olofsson PS, Soderstrom LA, Jern C, Sirsjo A, Ria M, Sundler et al. Genetic variants of TNFSF4 and risk for carotid artery disease and stroke. J Mol Med. 2009;87:337-346.

35. Coppinger JA, Maguire PB. Insights into the platelet releasate. Curr Pharmaceut Design. 2007;13:2640-2646

36. Nathan C, Ding A. Nonresolving inflammation. Cell. 2010;140:871-882.

37. Grabner R, Lotzer K, Dopping S, Hildner M, Radke D, Beer M, et al. Lymphotoxin beta receptor signaling promotes tertiary lymphoid organogenesis in the aorta adventitia of aged $\mathrm{ApoE}^{-/}$mice. J Exp Med. 2009;206:233-248.

38. Geng YJ, Libby P. Progression of atheroma: a struggle between death and procreation. Arterioscler Thromb Vasc Biol. 2002;22:1370-1380.

39. Halvorsen B, Waehre T, Scholz H, Clausen OP, von der Thusen JH, Muller F et al. Interleukin-10 enhances the oxidized LDL-induced foam cell information of macrophages by antiapoptotic mechanisms. J Lipid Res. 2005;46:211-219.

40. Martinet W, Kockx MM. Apoptosis in atherosclerosis: focus on oxidized lipids and inflammation. Curr Opin Lipidol. 2001;12:535-541.

41. Huynh ML, Fadok VA, Henson PM. Phosphatidylserine-dependent ingestion of apoptotic cells promotes TGF-beta1 secretion and the resolution of inflammation. $J$ Clin Invest. 2002;109:41-50. 


\section{Chapter 5}

\section{Interruption of the CXCL13/CXCR5 axis attenuates atherosclerosis by perturbing monocyte/granulocyte homeostasis in mice}

Isabelle Daissormont, Tom Seijkens, Erwin Wijnands, Karsten Hartvigsen, Christoph Binder, Esther Lutgens, Bente Halvorsen, Pal Aukrust, Martin Lipp, Uta Höpken, Erik Biessen 


\section{Chapter 5}

\section{Abstract}

CXCL13 is a homeostatic chemokine instrumental in guided lymphocyte and dendritic cell trafficking towards lymphoid organs and stromal tissue. Evidence is culminating that in various chronic immune disorders extranodal CXCL13 expression at the site of inflammation contributes to the disease. Here we addressed the role of CXCL13 and its receptor CXCR5 in atherosclerosis development in LDLr ${ }^{-1-}$ mice. Hematopoietic deficiency of both CXCR5 and CXCL13 attenuated atherosclerosis but did not impair lymphocyte homing towards the vessel wall. Deficiency of CXCR5 and CXCL13, both in hyper- and normolipidemic mice, resulted in impaired monocyte/granulocyte homeostasis, featured by reduced M-CSF and G-CSF plasma levels and decreased monocyte/granulocyte levels in circulation and spleen. Moreover, Ly $6 \mathrm{C}^{\text {high }} / \mathrm{Ly} 6 \mathrm{C}^{\text {low }}$ ratio was impaired as well. Our data reveal a new role for CXCL13 and CXCR5 in monocyte/granulocyte homeostasis, not only under conditions of hyperlipidemia but also in normolipidemic mice. 


\section{Introduction}

Atherosclerosis is a chronic inflammatory disease typified by the subendothelial accumulation of lipid material and inflammatory cells in large and middle-sized arteries. ${ }^{1,2}$ Atherosclerosis becomes clinically manifest only at a late stage, when initial lesions have developed into complex fibroatheromatous lesions with a thin fibrous cap and a large lipid core that is vulnerable to rupture and thrombosis, the actual cause of acute cardiovascular complications such as a myocardial infarction or stroke. Both the initiation and progression of the atherosclerotic plaque towards a rupture-prone, unstable plaque are driven by the recruitment of specific leukocyte subsets. ${ }^{3}$ This process was shown to be guided by chemokines, small cytokines with chemotactic activity, such as CCL2, CCL3, CXCL10, CX3CL1, CCL5, CXCL16 and more recently CCL19/21.,4 While most of these chemokines are upregulated in response to inflammatory stimuli in order to control immune responses, homeostatic chemokines are constitutively expressed by tissue to regulate leukocyte trafficking to and compartmentalization in lymphoid organs. ${ }^{5}$ Recently, these homeostatic chemokines has been attributed a broader function in immune response modulation in lymphoid and non-lymphoid tissue ${ }^{6,7}$ and in the induction of cell survival and angiogenesis. ${ }^{8-10}$

One of these homeostatic chemokines, CXCL13, formally known as Blymphocyte chemoattractant (BLC) in mice and B-cell-attracting chemokine 1 (BCA-1) in human, is highly expressed by stromal tissue and follicular dendritic cells and is important for guidance of lymphocytes and dendritic cells (DCS) in secondary lymphoid organs. ${ }^{6,11-13}$ CXCL13 functions through its only receptor CXCR5 (also referred to as Burkitt Lymphoma Receptor 1 (BLR1)). Impaired CXCR5 function has been shown to result in dystargeted lymphocyte homing and aberrant germinal centre organisation. ${ }^{11,14}$ CXCL13 has been found to be upregulated in the central nervous system (CNS) during experimental autoimmune encephalomyelitis (EAE) and to be involved in the induction of white matter inflammation. ${ }^{15}$ In tuberculosis, CXCL13 has been shown to regulate granulocyte formation and phagocytosis. ${ }^{16}$ In addition, CXCL13 and CXCR5 have both been shown to play a role in B cell chronic lymphocytic leukemia by regulating cell positioning. ${ }^{12}$ Although at present not much is known on the role of CXCL13/CXCR5 in atherosclerosis, a role in disease development can be inferred from its prominent expression in atherosclerotic lesions and in particular the 
lesion adventitia (Smedbakken et al., unpublished data). Moreover, CXCL13 has been shown to be expressed by macrophages, the main leukocyte represented within atherosclerotic lesions. ${ }^{17}$ In addition, the CXCR5/CXCL13 axis has been shown to be dysregulated in unstable coronary and carotid atherosclerotic lesions and in unstable angina pectoris patients, who displayed increased plasma CXCL13 levels and decreased circulating T cell expression of CXCR5 (Smedbakken et al., unpublished data). Collectively, these findings may point to a causal role of CXCL13 in the pathophysiology of atherosclerosis.

In the present study, we investigated the role of the CXCR5/CXCL13 axis in hematopoietic cells on atherosclerotic lesion formation in mice. Hereto, we generated $\mathrm{LDLr}^{-/}$mice with hematopoietic deficiency of CXCR5 as well as of CXCL13 by bone marrow transplantation and addressed effects on plaque formation, composition and stability but also lymphocyte trafficking and leukocyte homeostasis.

\section{Materials and Methods}

Animals

$\mathrm{C} 57 \mathrm{BI} / 6 \mathrm{~J}, \mathrm{CXCL} 13^{-1-18}$ and $\mathrm{CXCR5}{ }^{-/}$mice, ${ }^{11}$ the latter two backcrossed more than 10 times to $\mathrm{C} 57 \mathrm{BI} / 6 \mathrm{~J}$ background, were obtained from the breeding facility at the Max-Delbrück-Center for Molecular Medicine in Berlin. $\mathrm{LDLr}^{-/-}$mice were bred at the animal facility from the University of Maastricht. All animal work was approved by the regulatory authority of Maastricht University and performed in compliance with the Dutch government guidelines.

\section{Bone marrow transplantation}

Female LDLr ${ }^{-/-}$mice of 12 weeks old $(n=35)$ were housed under filtertop cages and given antibiotics supplemented water (Neomycin $(100 \mathrm{mg} / \mathrm{L}$; Gibco) and Polymyxin B sulfate ( $60.000 \mathrm{U} / \mathrm{L}$; Gibco)), starting 2 weeks before until 6 weeks after bone marrow transplantation. Mice were irradiated ( $9 \mathrm{~Gy}$ ) and received $10^{7}$ bone marrow cells isolated by tibia/femur lavage from C57BI/6J $(n=11), \operatorname{CXCL13}^{-/-}(n=11)$ or $\mathrm{CXCR5}^{--}(\mathrm{n}=13)$ mice. Six weeks after bone marrow transplantation, mice were 
placed on western type diet ( $0.25 \%$ cholesterol, Special Diets Services). Four weeks later, a collar was placed around the left and right carotid artery to induce atherosclerosis development ${ }^{19}$ and mice were fed a western type diet for eight more weeks.

\section{Atherosclerosis experiments}

Mice were euthanized by an overdose pentobarbital $(115 \mathrm{mg} / \mathrm{kg})$ and perfused through the left cardiac ventricle with $\mathrm{PBS}\left(\mathrm{NaCl} / \mathrm{Na}_{2} \mathrm{HPO}_{4} / \mathrm{KH}_{2} \mathrm{PO}_{4} ; \mathrm{pH}\right.$ 7.4) containing sodium nitroprusside $(0.1 \mathrm{mg} / \mathrm{ml}$; Sigma) and $1 \%$ paraformaldehyde (PFA). The right common carotid artery was removed, fixed overnight in $1 \%$ PFA and paraffin-embedded sections $(4 \mu \mathrm{m})$ were cut. To determine plaque area $\left(\mu \mathrm{m}^{2}\right)$, cross sections at $100 \mu \mathrm{m}$ intervals throughout the common carotid artery were stained for hematoxylin and eosin (HE). Plaque collagen content was assessed by Sirius Red staining and expressed as a percentage of plaque area. For plaque composition analysis, immunohistochemistry was performed for T cells (CD3, Dako), macrophages (mac-3, BD-Pharmingen) and granulocytes (Ly6G, BDPharmingen). Slides were analyzed in a blinded manner using a Leica DM3000 light microscope (Leica Microsystems) coupled to a computerized morphometric system (Leica Qwin 3.5.1). Total plasma cholesterol levels were measured in duplicate using a colorimetric assay (CHOD-PAP, Roche).

\section{Flow cytometry}

Blood, spleen and peripheral lymph nodes (a mixture of mesenteric, mandibular and axillary lymph nodes) ( $n=10 /$ group) were isolated, processed and stained for

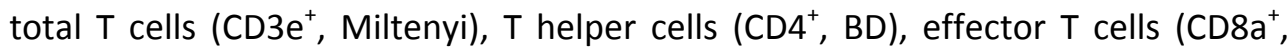
$B D)$, regulatory $T$ cells $\left(C D 4^{+} C D 25^{+} F_{0 x p} 3^{+}\right.$, eBioscience), activated T cells (CD44 ${ }^{\text {high }}$, eBioscience), B cells $\left(B 220^{+}, B D\right)$, monocytes (CD11b $\left.{ }^{\text {high }}{\text { Ly } 6 G^{\text {low }}}, B D\right)$ and granulocytes (CD11 $b^{\text {high }}$ Ly6G $\left.G^{\text {high }}, B D\right)$. Tibia and femur ( $n=8 /$ group) were isolated, processed and stained for hematopoietic stem cells (HSC) (Lin Sca- $1^{+} \mathrm{c}-\mathrm{kit}^{+}$,

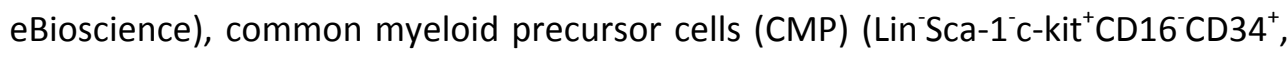
eBioscience), myeloid/dendritic cell precursor cells (MDP) (c-kit ${ }^{\text {int }} \mathrm{CD} 135$ $\mathrm{CD} 115^{+} \mathrm{CD} 11 \mathrm{~b}^{+}$, eBioscience), monocytes and granulocytes. Surface exposed 
Chapter 5

CXCR5 expression on monocytes was analyzed after staining with a CXCR5 antibody (BD).

Analysis of plasma cytokine and antibody profile

Plasma cytokine expression of M-CSF, G-CSF, GM-CSF, IFN- $\gamma$, IL-10, IL-17, MCP-1 and TNF- $\alpha$ was determined with a multiplex assay (Bio-Rad). Levels of CXCL13 (R\&D Systems) expression were determined by (sandwich) ELISA. Plasma autoantibody titers were determined by chemiluminescent ELISA as previously described. ${ }^{20,21}$

\section{CFU assay}

Unfractioned bone marrow cells were isolated from wild-type, CXCL13 ${ }^{-/}$and $\mathrm{CXCR5}^{-/}$mice. $1 \times 10^{4}$ bone marrow cells were cultured in $2 \mathrm{~mL}$ semi-solid methylcellulose medium supplemented with growth factors (MethoCult, Stem Cell Technologies, Grenoble, France) at $37^{\circ} \mathrm{C}, 98 \%$ humidity, and $5 \% \mathrm{CO}_{2}$ for 7 days. Total colonies, CFU-GEMM, CFU-GM, CFU-M, and CFU-G colonies were blindly scored after 7 days using an inverted microscope.

\section{Statistical analysis}

Data are expressed as mean \pm SEM and Mann-Whitney $U$ test was used to compare individual groups of animals. Data were considered statistically significant at $\mathrm{P}<0.05$.

\section{Results}

\section{Hematopoietic deficiency of CXCR5 retards atherosclerosis development}

CXCL13 was seen to be highly expressed in the adventitia of the atherosclerotic vessel wall (Figure 1A). Given its function in T/B cell homing, we hypothesized that CXCL13 might be responsible for T/B cell accumulation in the vessel wall and thus 
in atherosclerosis. To investigate the role of the CXCL13/CXCR5 axis in atherosclerosis, $\mathrm{LDLr}^{-1-}$ mice were irradiated and transplanted with wild-type or $\mathrm{CXCR5}^{-1}$ bone marrow. After recovery, mice were placed on western type diet and carotid artery lesions were induced by semi-constrictive collar placement. Body weight as well as plasma cholesterol levels were equal between wild-type (body weight $(\mathrm{g}): 20.4 \pm 0.9$ and plasma cholesterol levels $(\mathrm{pg} / \mathrm{ml}): 1085 \pm 89.6)$ and CXCR5 (body weight (g): $20.0 \pm 0.4$ and plasma cholesterol levels $(\mathrm{pg} / \mathrm{ml}): 1067 \pm$ 67.8) deficient transplanted mice. Hematopoietic deficiency of CXCR5 reduced plaque development in the carotid artery (Figure 1B) and induced a more stable plaque phenotype characterized by reduced necrotic core size (Figure 1C) and collagen deposition (Figure 1D). As CXCR5 is mainly involved in lymphocyte trafficking, we analyzed plaque and adventitial $\mathrm{CD}^{+} \mathrm{T}$ and $\mathrm{B}$ cell content. Surprisingly, CXCR5 deficiency did not result in impaired $\mathrm{CD}^{+} \mathrm{T}$ cell recruitment to the plaque and adventitia (Figure 1E). The number of $B$ cells present in the adventitia in both groups was very low, probably due to the early stage of lesion progression (data not shown). ${ }^{22}$ Collectively, these data demonstrate that CXCR5 deficiency attenuates atherosclerosis, but does not alter lymphocyte recruitment to lesion and adventitia. 
A
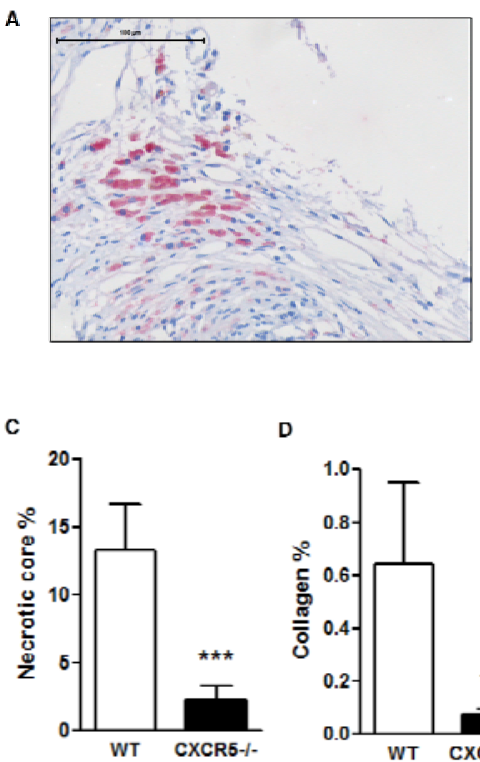

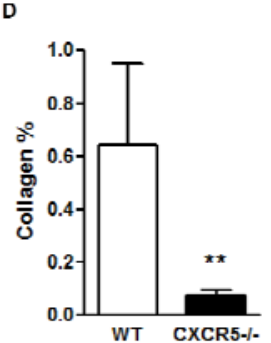

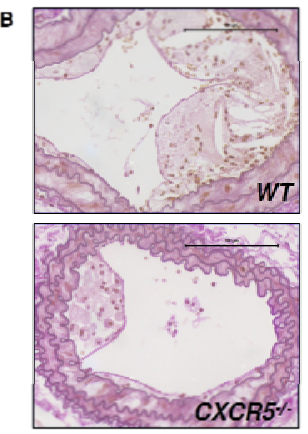
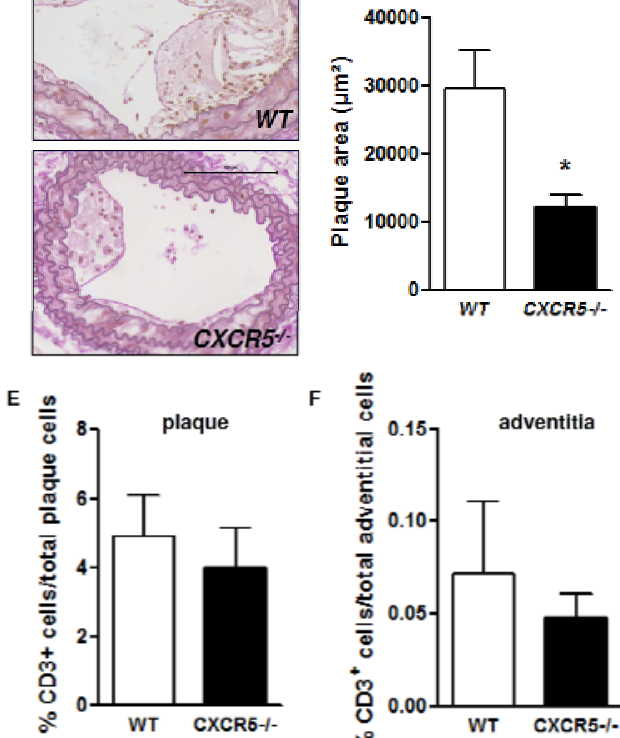

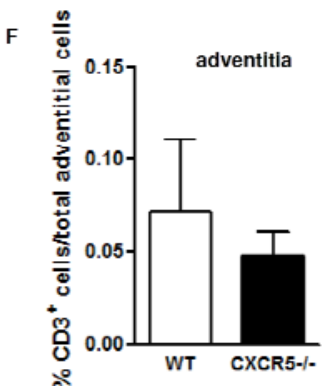

Figure 1. Hematopoietic deficiency of CXCR5 results in a decrease in atherosclerotic plaque development in mice. A, Immunohistochemistry for CXCL13 in a mouse atherosclerotic carotid lesion. To study effects of hematopoietic CXCR5 on atherosclerosis development, we performed a bone marrow transplantation in $\mathrm{LDLr}^{-1-}$ mice $(\mathrm{n}=24)$. Mice received either wild-type $(n=11)$ or $\mathrm{CXCR}^{-1-}(n=13)$ bone marrow. Six weeks later mice were placed on a western-type diet $(0.25 \%$ cholesterol) for 12 weeks. B, Right carotid artery was stained with haematoxylin and eosin (HE) to analyze the extent of atherosclerosis (plaque volume, $\left.\mu \mathrm{m}^{3}\right)$. C, Necrotic core area is presented as the percentage of lipid core area over plaque area. D, Plaque collagen content is expressed as the percentage of collagen over plaque area. $\mathbf{E}, \mathrm{CD}^{+} \mathrm{T}$ cell infiltration in the plaque and adventitia (percentage of $\mathrm{CD} 3^{+} \mathrm{T}$ cells over total cells per plaque and adventitia). ${ }^{*} P<0.05$, $* * P<0.005, * * * P<0.0005$.

CXCR5 deficiency impairs lymphocyte homing towards peripheral lymph nodes and does not affect plasma IgM/G titers

To investigate whether lymphocyte homing towards lymphoid tissue was impaired in CXCR5 deficient mice, we analyzed peripheral lymph node T/B cell content. $B$ cell (Figure $2 \mathrm{~A}$ ) and $\mathrm{CD} 4^{+}$regulatory $\mathrm{T}$ cell (Figure $2 \mathrm{~B}$ ) content of peripheral lymph 
nodes was lowered in CXCR5 deficient mice, which coincides with previous findings. ${ }^{6,12}$ In line, $\mathrm{B}$ (Figure $2 \mathrm{C}$ ) and $\mathrm{CD}^{+} \mathrm{T}$ (Figure 2D) cell numbers in circulation were increased. There was no difference in $T$ cell activation status between control and CXCR5 deficient mice (Figure 2E). Thus, CXCR5 deficient mice show attenuated lymphocyte homing towards lymphoid tissue, which is in concordance with previous findings. ${ }^{11}$
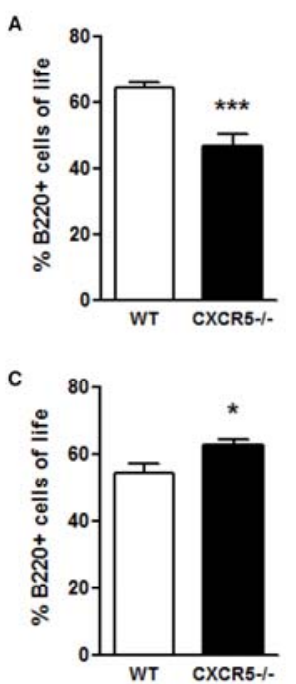

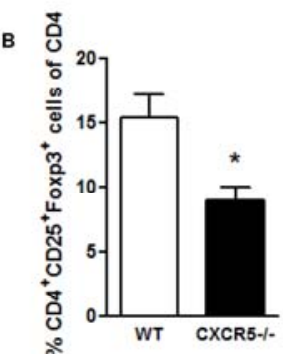

D

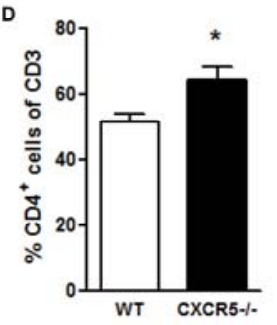

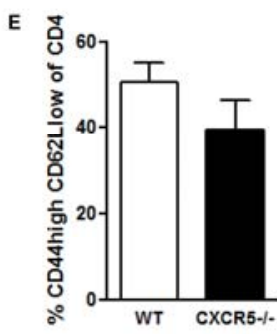

Figure 2. Deficiency of CXCR5 leads to impaired lymphocyte homing to peripheral lymph nodes. Depicted are the results of FACS analysis on peripheral lymph nodes and blood from $\mathrm{LDLr}^{-1-}$ mice transplanted with wild-type $(\mathrm{n}=11)$ and $\mathrm{CXCR}^{-1-}(\mathrm{n}=13)$ bone marrow. A, $B$ cell $\left(B 220^{+}\right)$and $B$, regulatory $\mathrm{T}$ cell $\left(\mathrm{CD} 4^{+} \mathrm{CD} 25^{+} \mathrm{Foxp}^{+}\right)$content in peripheral lymph nodes. C, Percentage of $\mathrm{B}$ cells and $\mathrm{D}, \mathrm{CD}^{+}{ }^{+} \mathrm{T}$ cells in circulation. $\mathrm{E}$, Percentage of CD44 ${ }^{\text {high }} \mathrm{CD} 2 \mathrm{~L}^{\text {low }} \mathrm{CD}^{+} \mathrm{T}$ cells in spleen. ${ }^{*} P<0.05,{ }^{* * *} P<0.0005$.

Next, we investigated whether CXCR5 deficiency affected B cell responses. Total natural immunoglobulin (Ig)M antibody titers were unaltered in CXCR5 deficient mice (Figure 3A). While CuOx-LDL specific IgM production was slightly decreased, $\alpha M D A-L D L, \alpha T 15 i^{+}$and $\alpha P C-B S A$ IgM titers were unchanged (Figure 3B). Likewise, total IgG (Figure 3C) and IgG1/IgG2b (Figure 3D) plasma levels were unchanged. CXCR5 deficiency did not seem to affect the general inflammation 
status either as plasma levels of IFN- $\gamma$, TNF- $\alpha$ and IL-10 were unaltered (Figure 3E).
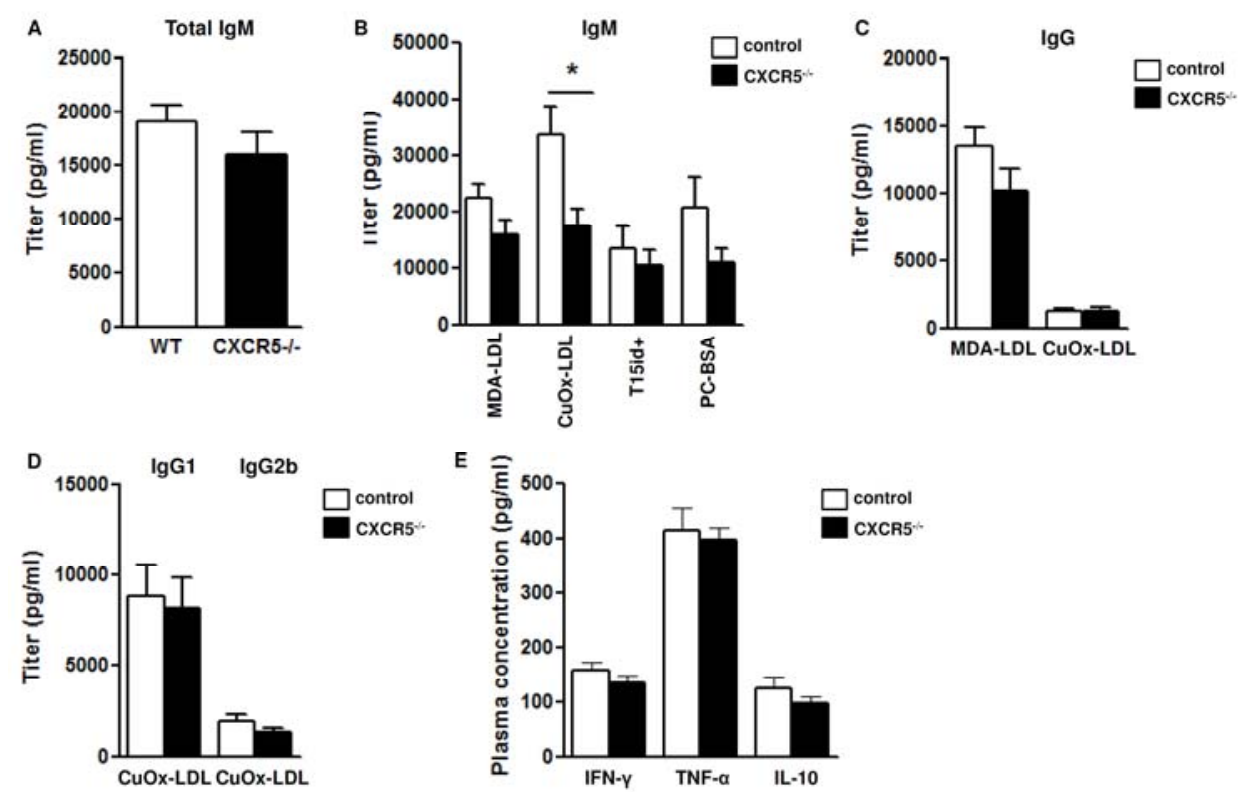

Figure 3. Hematopoietic deficiency of CXCR5 does not interfere with B cell responses and general inflammation status. Depicted are the results of circulating plasma immunoglobulin levels from $L D L r^{-/-}$mice transplanted with wild-type $(n=11)$ versus CXCR5 deficient $(n=13)$ bone marrow. A, Total IgM plasma levels. B, Plasma IgM titers of $\alpha M D A-$ LDL, $\alpha$ CuOx-LDL, $\alpha$ T15id+ and $\alpha$ PC-BSA. C, Plasma IgG titers of $\alpha M D A-L D L$ and $\alpha C u O x-L D L$. D, CuOx-LDL specific IgG1 and IgG2b plasma levels. E, Plasma cytokine levels of IFN- $\gamma$, TNF$\alpha$ and IL-10. ${ }^{*} P<0.05$.

\section{Hematopoietic deficiency of CXCL13 attenuates atherosclerosis development}

As CXCL13 is a homeostatic chemokine constitutively expressed by lymphatic endothelial cells and fibroblasts in the adventitia and CXCL13 was seen to be expressed by adventitial leukocytes as well, we addressed whether the reduced atherogenic response in CXCR5 deficient mice was driven by and attributable to hematopoietic or non-hematopoietic CXCL13. Mice were irradiated, transplanted with CXCL13 deficient bone marrow, placed on western type diet and equipped with perivascular carotid collars to induce lesions. CXCL13 deficient chimeras had 
equal body weight and plasma cholesterol levels as wild-type controls (data not shown). CXCL13 plasma levels were decreased in the CXCL13 deficient chimeras (Figure 4A). Similar to CXCR5 deficient mice, hematopoietic deficiency of CXCL13 retarded plaque development (Figure 4B) and reduced necrotic core size (Figure 4C). Collagen content was unchanged (data not shown). Moreover, CXCL13 deficiency did not affect $\mathrm{CD}^{+} \mathrm{T}$ cell recruitment to plaque and adventitia (Figure 4D). Plaques of $\mathrm{CXCL}_{3}{ }^{-/}$chimeras had albeit diminished expression of $\mathrm{CXCL} 13$ (Figure 4E).
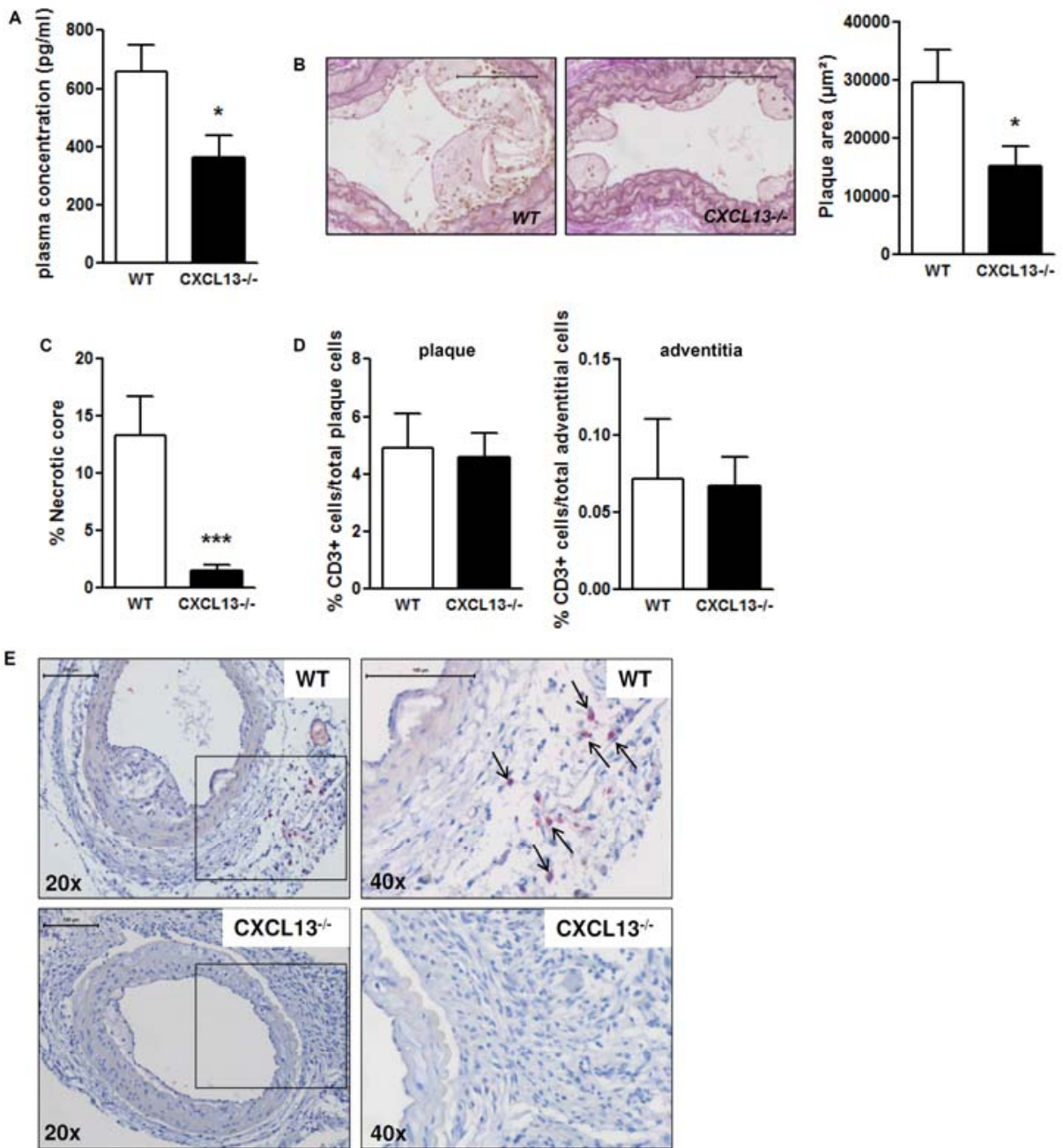
Figure 4. Hematopoietic deficiency of CXCL13 attenuates atherosclerosis development. To study effects of hematopoietic CXCL13 on atherosclerosis, we performed a bone marrow transplantation in $\mathrm{LDLr}^{-/}$mice $(\mathrm{n}=22)$. Mice received wild-type $(\mathrm{n}=11)$ or $\mathrm{CXCL} 13^{-/}$ $(n=11)$ bone marrow. Six weeks later mice were placed on a western type diet for 12 weeks. A, CXCL13 plasma levels. B, Right carotid artery was stained with haematoxylin and eosin (HE) to analyze the extent of atherosclerosis (plaque volume, $\mu \mathrm{m}^{3}$ ). $\mathbf{C}$, Necrotic core area is represented as the percentage of lipid core area over plaque area. $D, \mathrm{CD}^{+} \mathrm{T}$ cell infiltration is represented as the percentage of $\mathrm{CD}^{+} \mathrm{T}$ cells over total cells per plaque and adventitia. E, CXCL13 immunohistochemistry in atherosclerotic lesions from wild-type and CXCL13 deficient bone marrow chimeras. ${ }^{*} P<0.05, * * * P<0.0005$.

\section{CXCL13 deficiency does not affect lymphocyte homing towards lymphoid tissue}

In contrast to the striking effects observed for CXCR5 deficiency, hematopoietic deficiency of CXCL13 did not result in impaired homing of $B$ cells towards peripheral lymph nodes (Figure 5A), while compartmentalization of $\mathrm{CD}^{+} \mathrm{T}$ cells (Figure $5 \mathrm{~B}$ ), $\mathrm{CD} 8^{+} \mathrm{T}$ cells (Figure $\mathbf{5 C}$ ) and $\mathrm{CD} 4^{+}$regulatory $\mathrm{T}$ cells was unchanged as well (Figure 5D). This suggests that also under conditions of hyperlipidemia as associated systemic low grade inflammation, T/B cell trafficking is largely dependent on CXCL13 of non-hematopoietic origin, such as stromal cells and lymphatic endothelial cells, as previously suggested for normolipidemic mice. ${ }^{6,11,12}$
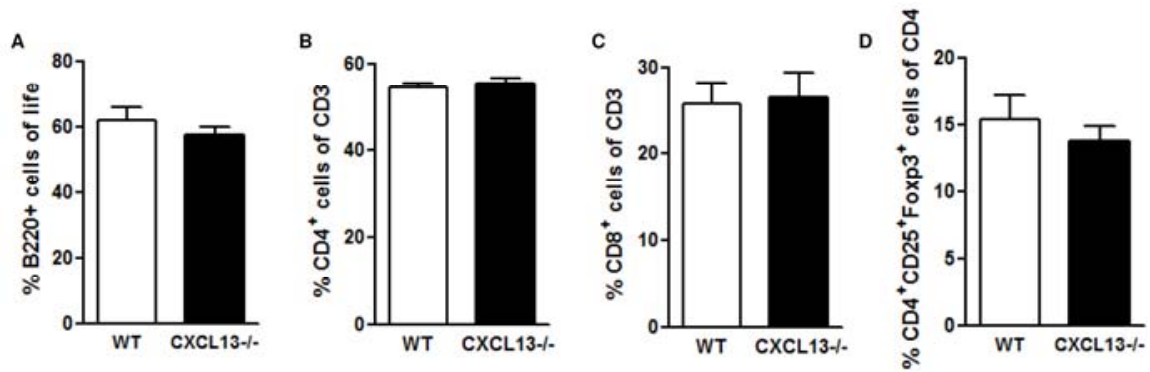

Figure 5. Deficiency of CXCL13 does not alter peripheral lymph node B and T cell contents. Depicted are the results of flow cytometry analysis on peripheral lymph nodes from $\mathrm{LDLr}^{-/-}$mice transplanted with wild-type $(n=11)$ and $\mathrm{CXCL13}^{-/-}(n=11)$ bone marrow. $A$, $\mathrm{B}$ cell $\left(\mathrm{B} 22 \mathrm{O}^{+}\right)$and $\mathrm{B}, \mathrm{CD} 4^{+}, \mathrm{C}, \mathrm{CD} 8^{+}$and $\mathrm{D}$, regulatory $\mathrm{T}$ cell $\left(\mathrm{CD4}^{+} \mathrm{CD} 25^{+} \mathrm{Foxp}^{+}\right)$content in peripheral lymph nodes. 
CXCL13 and CXCR5 deficiency results in decreased circulating and splenic monocyte and granulocyte numbers

As CXCL13 and CXCR5 deficiency both resulted in a decrease in atherosclerosis without influencing plaque lymphocyte accumulation, we sought to investigate whether lack of CXCL13/CXCR5 attenuated atherogenesis by interfering with function or activity of other leukocyte subsets than lymphocytes. We did not observe differences in macrophage plaque content between wild-type versus CXCL13 and CXCR5 deficient mice despite the delayed plaque progression (Figure 6A). Strikingly, hematopoietic deficiency of both CXCL13 and CXCR5 resulted in a significant reduction in circulating pro-inflammatory Ly $6 \mathrm{C}^{\text {high }}$ monocyte numbers (Figure 6B), translating in lower Ly6 $\mathrm{C}^{\text {high }} / \mathrm{Ly} 6 \mathrm{C}^{\text {low }}$ ratio (Figure $6 \mathrm{C}$ ). In addition, the number of circulating granulocytes was significantly decreased in the CXCL13 deficient mice (Figure 6D), which is compatible with the observed decrease in plaque granulocyte content of these mice, albeit that numbers were low (Figure 6E). This suggests that blood monocytes may express functional CXCR5 receptor, a notion that was confirmed at protein level (Figure 6F). Of note, the number of

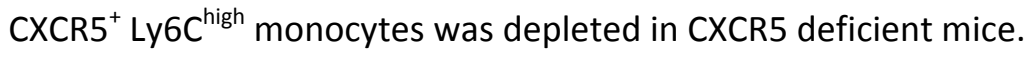
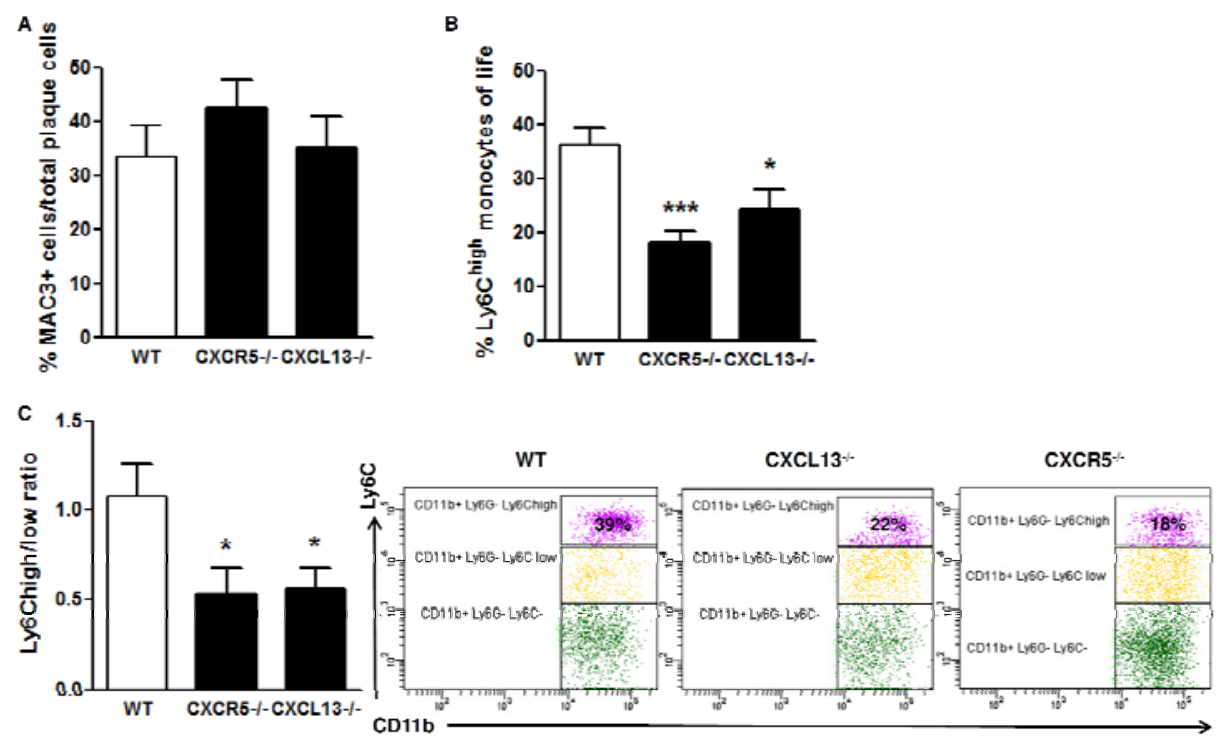
Chapter 5
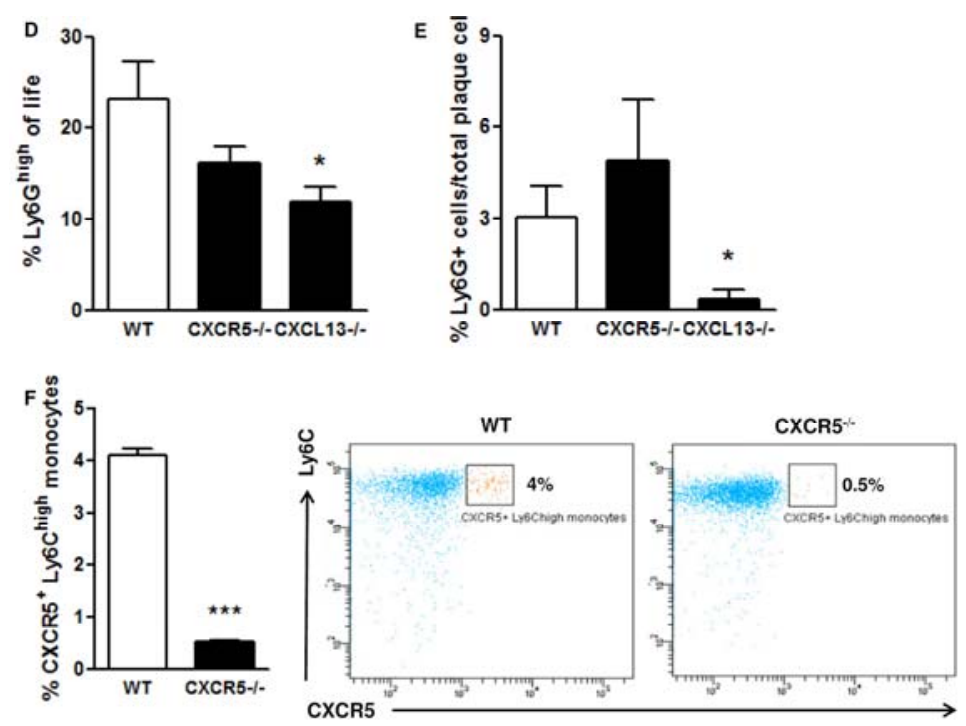

Figure 6. Hematopoietic deficiency of CXCR5 and CXCL13 in atherosclerotic LDLr ${ }^{-/-}$mice results in a decrease in circulating inflammatory monocytes and granulocytes. $\mathrm{A}, \mathrm{MAC}-3^{+}$ cell content in atherosclerotic lesions from wild-type $(n=11)$ versus CXCR5 ( $n=13)$ and CXCL13 $(n=11)$ deficient mice. Data are represented as the percentage of MAC- $3^{+}$cells over total plaque cells. B, Percentage of Ly $6 C^{\text {high }}$ monocytes in blood. C, Ly6C $C^{\text {high }} / \mathrm{Ly} 6 \mathrm{C}^{\text {low }}$ ratio in blood. D, Percentage of circulating $\mathrm{CD} 11 \mathrm{~b}^{\text {high }}{\text { Ly } 6 \mathrm{G}^{\text {high }}}_{\text {granulocytes. }} \mathbf{E}, \mathrm{Ly} \mathrm{G}^{+}$cell content is represented as the percentage of $\mathrm{Ly}_{6 \mathrm{G}}{ }^{+}$cells over total plaque cells. F, Flow cytometry analysis of CXCR5 expression on circulating CD11 $\mathrm{b}^{+} \mathrm{Ly}_{6 \mathrm{C}^{\text {high }}}$ monocytes in wildtype and CXCR5 deficient chimeras. ${ }^{*} P<0.05, * * * P<0.0005$.

The reduction in Ly6 $\mathrm{C}^{\text {high }}$ monocytes (Figure 7A) and concomitant decrease in Ly6C $\mathrm{C}^{\text {high }} / \mathrm{Ly} 6 \mathrm{C}^{\text {low }}$ ratio (Figure 7B) manifested not only in hyperlipidemic, but also in normolipidemic CXCL13 and CXCR5 knock-out mice. Granulocyte levels were decreased as well (Figure 7C). At an absolute level, the number of Ly6C $C^{\text {high }}$ monocytes (Figure 7D) and granulocytes (Figure 7F) was decreased as well in spleen, although this effect reached significance only in the CXCR5 knock-out mice. In addition, the absolute Ly $6 C^{\text {high }} /$ Ly $6 C^{\text {low }}$ ratio in spleen was decreased, both in CXCL13 and in CXCR5 knock-out mice (Figure 7E). 

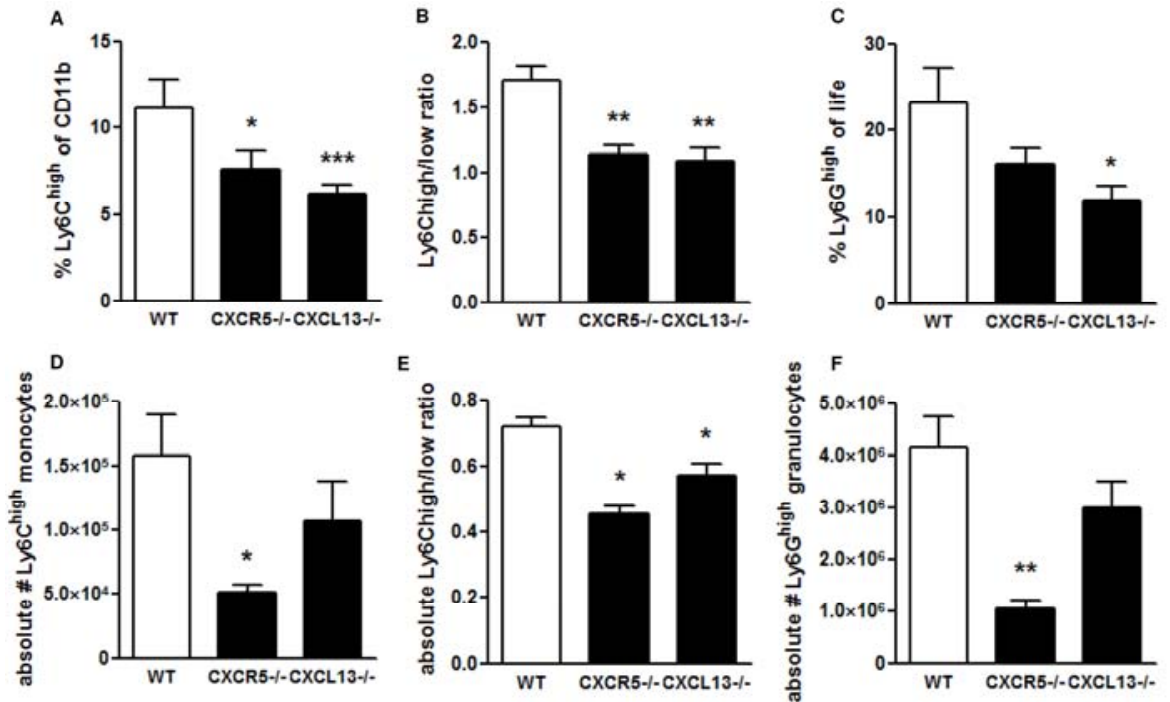

Figure 7. Deficiency of CXCL13 and CXCR5 in normolipidemic mice results in impaired monocyte and granulocyte levels in circulation and spleen. To investigate whether the effects on myelopoiesis were restricted to atherosclerotic conditions, FACS analysis was performed on blood from wild-type $(n=8), \mathrm{CXCL}^{-/-}(n=6)$ and $\mathrm{CXCR}^{-/-}(n=6)$ mice on chow diet. A, Percentage of circulating Ly6C $C^{\text {high }}$ monocytes. B, Ly $6 C^{\text {high }} /$ Ly $6 C^{\text {low }}$ ratio in blood. C, Percentage of Ly6G ${ }^{\text {high }}$ granulocytes in blood. D, Absolute numbers of Ly $6 C^{\text {high }}$ monocytes in spleen. $\mathbf{E}$, Absolute Ly6C $\mathrm{C}^{\text {high }} / \mathrm{Ly} 6 \mathrm{C}^{\text {low }}$ ratio in spleen. $\mathbf{F}$, Absolute numbers of Ly $6 \mathrm{G}^{\text {high }}$ granulocytes in spleen. ${ }^{*} P<0.05, * * P<0.005, * * * P<0.0005$.

\section{CXCL13/CXCR5 deficiency perturbs monocyte/granulocyte homeostasis}

The decrease in monocyte/granulocyte numbers in CXCR5 and CXCL13 deficient mice points to a role for the CXCR5/CXCL13 axis in monocyte/granulocyte homeostasis. Therefore, we investigated whether the CXCR5/CXCL13 axis is involved in the myelopoiesis regulation. Indeed, plasma levels of macrophage colony-stimulating factor (M-CSF) and granulocyte colony-stimulating factor (GCSF) were diminished in CXCL13 and CXCR5 deficient mice (Figure 8A), in support of the above hypothesis, although plasma levels of relevant cytokines such as II17, IL-6, (data not shown), IL-10, TNF- $\alpha$ and IFN- $\gamma$ were unchanged (Figure 3E). Flow cytometry analysis of bone marrow cells from normolipidemic CXCL13 and CXCR5 knock-out mice revealed a similar decrease in the $L y 6 C^{\text {high }} /$ Ly $6 C^{\text {low }}$ ratio 
(Figure 8B), but absolute Ly6 $\mathrm{C}^{\text {high }}$ monocyte (Figure 8C) and granulocyte numbers (Figure 8D) were not significantly altered. No differences were observed in common myeloid precursor (CMP) (Figure 8E) and monocyte dendritic cell precursor (MDP) cell numbers (Figure $\mathbf{8 F}$ ) in bone marrow. In keeping with the latter, colony forming unit (CFU) assay analysis revealed no effect of disruption of the CXCL13/CXCR5 axis on monocyte development in vitro (Figure 8G). Altogether, these data suggest that the CXCL13/CXCR5 axis is not critically involved in myelopoiesis. Moreover, given the fact that absolute monocyte and granulocyte numbers in bone marrow were not increased, the decreased monocyte/granulocyte levels seen in circulation and spleen could not be assigned to impaired monocyte/granulocyte mobilization either.
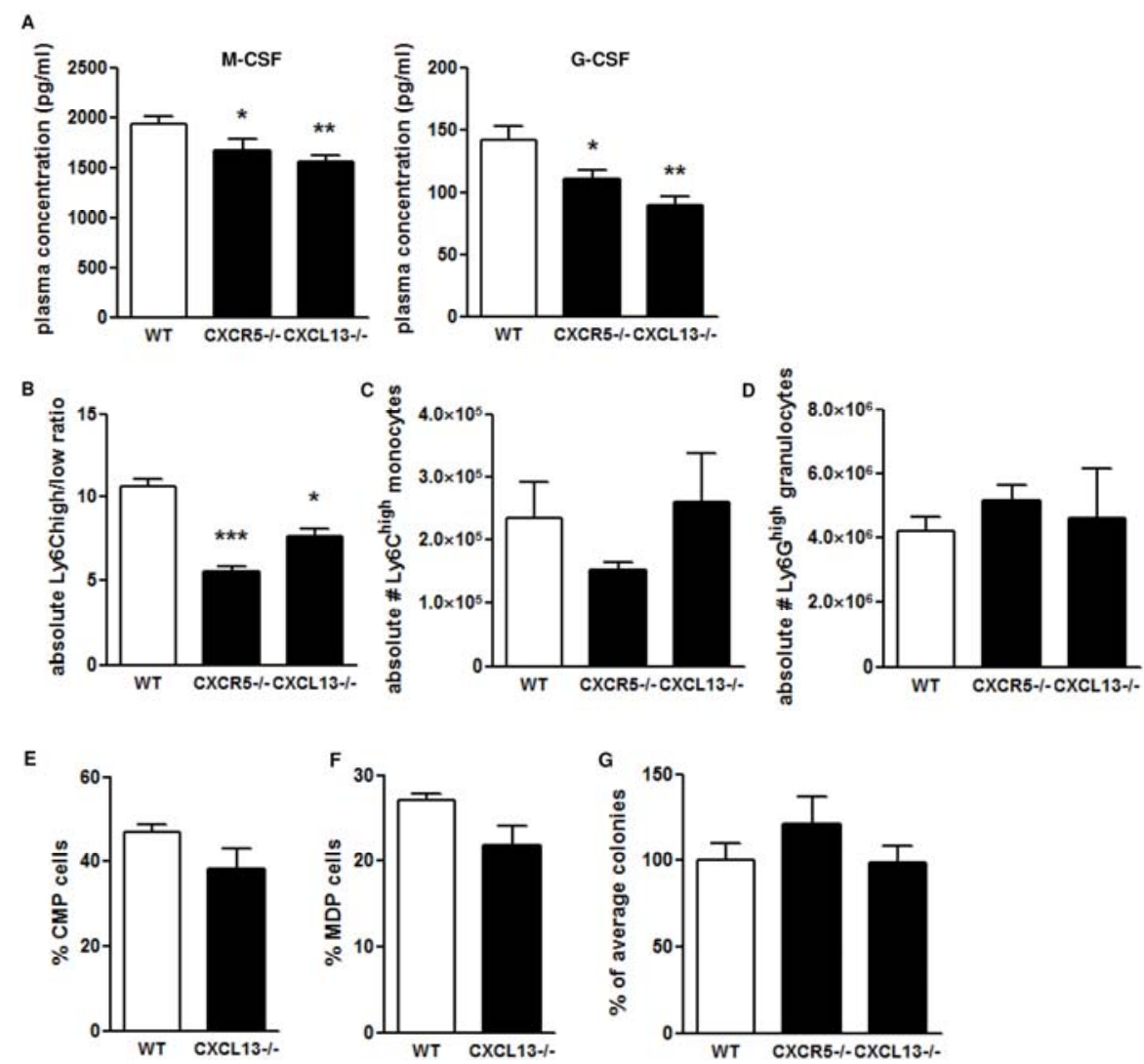

Figure 8. Myeloid cell development is unaltered in CXCR5 and CXCL13 deficient mice. A, Plasma levels of M-CSF and G-CSF. Depicted are the results of FACS analysis on bone marrow from wild-type, CXCR5KO and CXCL13KO ( $n=5 /$ group) mice. B, Absolute 
Ly6C $\mathrm{C}^{\text {high }} /$ Ly6C $\mathrm{C}^{\text {low }}$ ratio in bone marrow. C, Absolute Ly6C $\mathrm{C}^{\text {high }}$ monocyte numbers in bone marrow. D, Absolute $\mathrm{CD} 11 \mathrm{~b}^{\text {high }}$ Ly6G ${ }^{\text {high }}$ granulocytes in bone marrow. E, Percentage of common myeloid precursor cells (CMP) (Lin Sca-1 $1^{-}$c-kit $\left.{ }^{+} \mathrm{CD} 16^{-} \mathrm{CD} 34^{+}\right)$. F, Percentage of myeloid/dendritic cell precursor cells (MDP) (c-kit ${ }^{\text {int }} \mathrm{CD} 135^{\circ} \mathrm{CD} 115^{+} \mathrm{CD} 11 \mathrm{~b}^{+}$). G, CFU assay (Percentage of average colonies in response to G-CSF, M-CSF and GM-CSF). ${ }^{*} P<0.05$, ${ }^{* *} P<0.005,{ }^{* * *} P<0.0005$.

\section{Discussion}

In the present study we have uncovered a hitherto unknown role for the CXCL13/CXCR5 axis in monocyte/granulocyte homeostasis. In a mouse model of atherosclerosis, we show that hematopoietic deficiency of CXCL13 and CXCR5 results in impaired monocyte/granulocyte homeostasis, characterized by decreased circulating monocyte and granulocyte levels and decreased M-CSF and G-CSF plasma levels, conducing to attenuated atherosclerotic plaque development.

Hematopoietic deficiency of CXCR5 disrupted lymphocyte accumulation in lymphoid tissue, also under conditions of hyperlipidemia, which is in line with previous findings in normolipidemic mice. ${ }^{6,11,18}$ In contrast, CXCL13 deficient mice did not show any impairment in lymphocyte accumulation, indicating that in the latter mice non-hematopoietic CXCL13 produced by (lymphatic) endothelial cells can be held accountable for the lymphocyte compartmentalization. CXCL13 is a homeostatic chemokine, the expression of which can be induced by certain inflammatory stimuli in other cell types such as present in the vessel wall (Smedbakken et al., unpublished data). Therefore, we hypothesized that disruption of chemokine signaling through CXCR5 might cause an impairment of lymphocyte recruitment to the vessel wall, and in this manner alter the atherogenic response. Our studies however show that while plaque size was diminished, $\mathrm{CXCR}^{-/-}$deficiency did not interfere with lymphocyte content of the atherosclerotic vessel wall, suggesting that the CXCL13/CXCR5 axis is not crucial for lymphocyte recruitment into the vessel wall.

While a lack in receptor and ligand both inhibited plaque development, and both genotypes led to altered monocyte presence and skewing in circulation, it is conceivable that the anti-atherogenic effect of blunted CXCL13/CXCR5 function is in part attributable to effects exerted on this subset, and that hematopoietic 
CXCL13 acts in an autocrine manner to alter monocyte skewing. We show that CXCR5 is expressed on mouse monocytes, which is surprising given that expression of CXCR5 was believed to be restricted to B cells and helper T cells in lymphoid tissue. ${ }^{11}$ However, this observation was made under steady-state conditions and not under hyperlipidemic and chronic low grade inflammatory processes such as atherosclerosis. Indeed, recent studies have already alluded to functional CXCR5 expression on circulating monocytes from rheumatoid arthritis (RA) patients. ${ }^{23}$ Furthermore, CXCL13 has been shown to induce chemotaxis of peripheral blood monocytes in vitro, which was inhibited by addition of antiCXCR5 antibody. ${ }^{24}$ Interestingly, only a minor subset of circulating Ly6C $C^{\text {high }}$ monocytes $( \pm 4 \%$ ) were seen to express CXCR5, pointing to the presence of a specific monocyte subset that could be accountable for the Ly $6 C^{\text {high }} / L y 6 C^{\text {low }}$ shift.

Our data suggest that the CXCL13/CXCR5 axis is involved in the regulation of monocyte/granulocyte homeostasis, under normo- and hyperlipidemic conditions. CXCL13 and CXCR5 deficient mice both showed a decrease in circulating proinflammatory Ly $6 \mathrm{C}^{\text {high }}$ monocytes and granulocytes associated with a dysbalanced Ly $6 C^{\text {high }} /$ Ly $6 C^{\text {low }}$ ratio. Moreover, plasma levels of major growth factors in myeloid development, M-CSF, which was shown to stimulate monocytosis, ${ }^{25}$ and G-CSF, were decreased, another indication that the CXCL13/CXCR5 axis is involved in myelopoiesis regulation. However, the fact that absolute monocyte and granulocyte numbers in bone marrow and blood were unchanged, the lack of effect of CXCL13/CXCR5 deficiency on common myeloid precursor and monocytedendritic cell precursor cell populations, and on G-, GM- and M-CFU all weaken/disqualify this notion.

Ly6 $\mathrm{C}^{\text {high }}$ monocytes, a pro-inflammatory monocyte subset that is implicated in first line defense against pathogens, are released upon inflammatory stimuli and are documented to be efficiently recruited to the atherosclerotic plaque. Increased Ly6 $\mathrm{C}^{\text {high }} / \mathrm{Ly} 6 \mathrm{C}^{\text {low }}$ ratio therefore is deemed pro-atherogenic. ${ }^{26}$ The reduced ratio in CXCL13 and CXCR5 deficient chimeras could therefore well have contributed to the diminished atherosclerotic burden in these mice. The major question stands how CXCL13/CXCR5 is impacting monocyte skewing. Conceivably, this axis might be involved in cell survival/turnover of LyC6 ${ }^{\text {high }}$ and Ly6C $\mathrm{C}^{\text {low }}$ monocytes, in analogy to the chemokine receptor, CX3CR1, which was reported to be required for monocyte homeostasis by regulating cell survival. ${ }^{27}$ Relevant in 
this light, CXCL13 has been shown to induce B cell survival through inactivation of the pro-apoptotic transcription factor FOXO3a in B-chronic lymphocytic leukemia. ${ }^{28,29}$ Moreover, CXCR5 can activate the PI3K/AKT pathway, a key regulator of cell survival. ${ }^{30}$ Finally, M-CSF has been shown to promote monocyte survival, ${ }^{31}$ suggesting that the decreased M-CSF plasma levels in CXCR5 and CXCL13 deficient mice could well induce apoptosis. These effects may conspire to a diminished survival of monocyte subsets in CXCL13/CXCR5 deficient chimeras. Further study will have to elucidate whether and how exactly the CXCL13/CXCR5 axis is involved in monocyte and granulocyte survival in the context of atherosclerosis.

In conclusion, we are the first to describe a pro-atherogenic role of the CXCL13/CXCR5 dyad in atherosclerosis, an effect that is likely attributable to its impact on monocyte/granulocyte homeostasis, rather than to effects on the mobilization of leukocyte subsets that are regularly associated with CXCL13/CXCR5 function. Our data identify the CXCL13/CXCR5 axis as an important regulator of this process in inflammatory conditions and thus as a new target for studying the role of monocyte homeostasis in atherosclerosis.

\section{References}


1. Weber C, Zernecke A, Libby P. The multifaceted contributions of leukocyte subsets to atherosclerosis: lessons from mouse models. Nature Rev Immunol. 2008;10:802-815. Review.

2. Libby P, Ridker PM, Maseri A. Inflammation and atherosclerosis. Circulation. 2002;105:1135-1143. Review.

3. Weber C. Chemokines in atherosclerosis, thrombosis and vascular biology. Arterioscler Thromb Vasc Biol. 2008;28:1896.

4. Daissormont IT, Kraaijeveld AO, Biessen EA. Chemokines as therapeutic targets for atherosclerotic plaque destabilization and rupture. Future Cardiol. 2009;5:273-284.

5. Luther SA, Bidgol A, Hargreaves DC, Schmidt A, Xu Y, Paniyadi J, Matloubian M, Cyster JG. Differing activities of homeostatic chemokines CCL19, CCL21, and CXCL12 in lymphocyte and dendritic cell recruitment and lymphoid neogenesis. J Immunol. 2002;169:424-433.

6. Gunn MD, Ngo VN, Ekland EH, Cyster JG, Williams LT. A B-cell homing chemokine made in lymphoid follicles activates Burkitt's lymphoma receptor-1. Nature. 1998;394:799-803.

7. Weyand CM, Goronzy JJ. Ectopic germinal center formation in rheumatoid synovitis. Ann N Y Acad Sci. 2003;987:140-149.

8. Cuesta-Mateos C, López-Giral S, Alfonso-Pérez M, de Soria VG, Loscertales J, GuaschVidal S, Beltrán AE, Zapata JM, Muñoz-Calleja C. Analysis of migratory and prosurvival pathways induced by the homeostatic chemokines CCL19 and CCL21 in Bcell chronic lymphocytic leukemia. Exp. Hematol. 2010;38:756-764.

9. Meier R, Muhlethaler-Mottet A, Flahaut M, Coulon A, Fusco C, Louache F, Auderset K, Bourloud KB, Daudigeos E, Ruegg C, Vassal G, Gross N, Joseph JM.. The chemokine receptor CXCR4 strongly promotes neuroblastoma primary tumor and metastatic growth, but not invasion. PLOS ONE. 2007;2:e1016.

10. Salcedo R, Wasserman K, Young HA, Grimm MC, Howard OM, Anver MR, Kleinman HK, Murphy WJ, Oppenheim WJ. Vascular endothelial growth factor and basic fibroblast growth factor induce expression of CXCR4 on human endothelial cells: In vivo neovascularization induced by stromal-derived factor-1-alpha. Am J Pathol. 1999;154:1125-1135.

11. Forster R, Mattis AE, Kremmer E, Wolf E, Brem G, Lipp M. A putative chemokine receptor, BLR1, directs $B$ cell migration to defined lymphoid organs and specific anatomic compartments of the spleen. Cell. 1996;87:1037-1047.

12. Burkle A, Niedermeier $M$, Schmitt-Graff A, Wierda WG, Keating MJ, Burger JA. Overexpression of the CXCR5 chemokine receptor, and its ligand, CXCL13 in B-cell chronic and lymphocytic leukemia. Blood. 2007;110:3316-3325. 
13. Ansel K, Harris R, Cyster J. CXCL13 is required for B1 cell homing, natural antibody production and body cavity immunity. Immunity. 2002;16:67-76.

14. Muller G, Hopken UE, Lipp M. The impact of CCR7 and CXCR5 on lymphoid organ development and systemic immunity. Immunol Rev. 2003;195:117-135.

15. Bagaeva LV, Rao P, Powers JM, Segal BM. CXC chemokine ligand 13 plays a role in experimental autoimmune encephalomyelitis. J Immunol. 2006;176:7676-7685.

16. Khader SA, Rangel-Moreno J, Fountain JJ, Martino CA, Reiley WW, Pearl JE, Winslow JM, Woodland DL, Randall TD, Cooper AM. In a murine tuberculosis model, the absence of homeostatic chemokines delays granuloma formation and protective immunity. J Immunol. 2009;183:8004-8014.

17. Moreth K, Brodbeck R, Babelova A, Gretz N, Spieker T, Zeng-Brouwers J, Pfeilschifter J, Young MF, Schaefer RM, Schaefer L. The proteoglycan biglycan regulates expression of the $B$ cell chemoattractant CXCL13 and aggravates murine lupus nephritis. J Clin Invest. 2010;120:4251-4272.

18. Ansel KM, Ngo VN, Hyman PL, Luther SA, Förster R, Sedgwick JD, Browning JL, Lipp $M$, Cyster JG. A chemokine-driven positive feedback loop organizes lymphoid follicles. Nature. 2000;406:309-324.

19. Von der Thusen J, Van Berkel T, Biessen E. Induction of rapid atherogenesis by perivascular carotid collar placement in apolipoprotein E-deficient and low-density lipoprotein receptor-deficient mice. Circulation. 2001;103:1164-1170.

20. Binder CJ, Hörkkö S, Dewan A, Chang MK, Kieu EP, Goodyear CS, Shaw PX, Palinski W, Witztum JL, Silverman GJ. Pneumococcal vaccination decreases atherosclerotic lesion formation: molecular mimicry between Streptococcus pneumoniae and oxidized LDL. Nat Med. 2003;9:736-743.

21. Chou MY, Fogelstrand L, Hartvigsen K, Hansen LF, Woelkers D, Shaw PX, Choi J, Perkmann T, Bäckhed F, Miller YI, Hörkkö S, Corr M, Witztum JL, Binder CJ. Oxidation-specific epitopes are dominant targets of innate natural antibodies in mice and humans. J Clin Invest. 2009;119:1135-1349.

22. Kyaw T, Tay C, Khan A, Dumouchel V, Cao A, To K, Kehry M, Dunn R, Agrotis A, Tipping $\mathrm{P}$, Bobik A, Toh BH. Conventional B2 cell depletion ameliorates whereas its adoptive transfer aggravates atherosclerosis. J Immunol. 2010;185:4410-4419.

23. Schmutz C, Hulme A, Burman A, Salmon M, Ashton B, Buckley C, Middleton J. Chemokine receptors in the rheumatoid synovium: upregulation of CXCR5. Arthritis Res Ther. 2005; 7:R217-229.

24. Pandruvada SN, Yuvaraj S, Liu X, Sundaram K, Shanmugarajan S, Ries WL, Norris JS, London SD, Reddy SV. Role of CXC chemokine ligand 13 in oral squamous cell carcinoma associated osteolysis in athymic mice. Int J Cancer. 2010;126:2319-2329. 
25. Burgess AW, Metcalf D, Kozka IJ, Simpson RJ, Vairo G, Hamilton JA, Nice EC. Purification of two forms of colony-stimulating factor from mouse $L$ cell conditioned medium. J Biol Chem. 1985;260:16004-16011.

26. Swirski FK, Libby P, Aikawa E, Alcaide P, Luscinskas FW, Weissleder R, Pittet MJ. Ly6 Chi monocytes dominate hypercholesterolemia-associated monocytosis and give rise to macrophages in atheromata. J Clin Invest. 2007;117:195-205.

27. Landsman L, Bar-On L, Zernecke A, Kim KW, Krauthgamer R, Shagdarsuren E, Lira S, Weissman I, Weber C, Jung S. CX3CR1 is required for monocyte homeostasis and atherogenesis by promoting cell survival. Blood. 2009;113:963-972.

28. Ticchioni $M$, Essafi $M$, Jeandel PY, Davi F, Cassuto JP, Deckert M, Bernard A. Homeostatic chemokines increase survival of B-chronic lymphocytic leukemia cells through inactivation of transcription factor FOXO3a. Oncogene. 2007;26:7081-7091.

29. Hu C, Xiong J, Zhang L, Huang B, Zhang Q, Li Q, Yang M, Wu Y, Wu Q, Shen Q, Gao Q, Zhang K, Sun Z, Liu J, Jin Y, Tan J. PEG10 activation by co-stimulation of CXCR5 and CCR7 essentially contributes to resistance to apoptosis in $\mathrm{CD} 19^{+} \mathrm{CD} 34^{+} \mathrm{B}$ cells from patients with B cell lineage acute and chronic lymphocytic leukemia. Cell Mol Immunol. 2004;1:280-294.

30. El Haibi CP, Sharma PK, Singh R, Johnson PR, Suttles J, Singh S, Lillard JW Jr. PI3Kp110-, Src-, FAK-dependent and DOCK2-independent migration and invasion of CXCL13-stimulated prostate cancer cells. Mol Cancer. 2010;9:85.

31. Curry JM, Eubank TD, Roberts RD, Wang Y, Pore N, Maity A, Marsh CB. M-CSF signals through the MAPK/ERK pathway via Sp1 to induce VEGF production and induces angiogenesis in vivo. PLOS ONE. 2008;3:e3405. 
The role of CXCL13 and CXCR5 in mouse atherosclerosis 
Part II 


\section{Chapter 6}

\section{Plasmacytoid dendritic cells protect against atherosclerosis by tuning $\mathrm{T}$ cell proliferation and activity}

Isabelle Daissormont, Anette Christ, Lieve Temmerman, Stefan Sampedro Millares, Tom Seijkens, Marco Manca, Mat Rousch, Marjorie Poggi, Louis Boon, Chris van der Loos, Mat Daemen, Esther Lutgens, Bente Halvorsen, Pal Aukrust, Edith Janssen, Erik Biessen

Circulation Research 2011;109(12):1387-1395 


\section{Chapter 6}

\section{Abstract}

Unlike conventional dendritic cells $(c D C)$, plasmacytoid $D C s(p D C)$ are poor in antigen presentation and critical for type I interferon response. While proposed to be present in human atherosclerotic lesions, their role in atherosclerosis remains elusive.We show that $\mathrm{pDC}$ are scarcely present in human atherosclerotic lesions, and almost absent in mouse plaques. Surprisingly, pDC depletion by $120 \mathrm{G} 8 \mathrm{mAb}$ administration was seen to promote plaque $T$ cell accumulation and exacerbate lesion development and progression in $\mathrm{LDLr}^{-/}$mice. PDC depletion was accompanied by increased $\mathrm{CD}^{+} \mathrm{T}$ cell proliferation, IFN- $\gamma$ expression by splenic $\mathrm{T}$ cells and plasma IFN- $\gamma$ levels. Lymphoid tissue pDC from atherosclerotic mice showed increased indoleamine 2,3-dioxygenase (IDO) expression and IDO blockage abrogated the $\mathrm{pDC}$ suppressive effect on $\mathrm{T}$ cell proliferation. In conclusion, our data reveal a protective role for pDC in atherosclerosis, possibly by dampening $\mathrm{T}$ cell proliferation and activity in peripheral lymphoid tissue, rendering $\mathrm{pDC}$ an interesting target for future therapeutic interventions. 


\section{Introduction}

Plasmacytoid dendritic cells ( $\mathrm{pDC}$ ) are a subset of dendritic cells derived from both myeloid and lymphoid precursors in bone marrow, and constitute only $0.1-0.5 \%$ of the total leukocyte pool in blood and peripheral lymphoid tissue. As the main type I interferon (IFN) producing cells, pDC have a critical role in detection of and host defense against bacterial and viral infection, but also in sensing RNA/DNA and immune complexes. Upon stimulation, pDC produce large amounts of type I interferons (IFN- $\alpha$, IFN- $\beta$, IFN- $\omega$ and IFN- $\lambda$ ) in a toll-like receptor (TLR) 7 and 9 dependent manner, thereby inducing effector $T$ and natural killer (NK) cell activation and linking innate and adaptive immunity. ${ }^{1}$ PDC differ from conventional dendritic cells $(\mathrm{CDC})$ in that they are poor $\mathrm{T}$ cell activators due to low expression of major histocompatibility complex class-II (MHC-II) and costimulatory molecules. ${ }^{2,3}$

The presence of $\mathrm{pDC}$ in human atherosclerotic lesions has been documented in $1995^{4}$ and was subsequently confirmed by C. Weyand and co-workers. ${ }^{5}$ PDC $\left(C D 4^{+} C^{C D} 45 R^{+} A^{+} I L-3 \alpha(C D 123)^{+} I L T 3^{+} I L T 1^{-} C^{-} D 11^{-}\right)$were reported to be expressed in the shoulder region of human plaques where they are believed to regulate $T$ cell function, even in the absence of antigen recognition. CpG induced IFN- $\alpha$ release by $\mathrm{pDC}$ effected a 10-fold up regulation of tumor necrosis factor-related apoptosis-inducing ligand (TRAIL) expression on $\mathrm{CD}^{+} \mathrm{T}$ cell surface, thereby promoting vascular smooth muscle cell (VSMC) and endothelial cell (EC) apoptosis, processes that are generally deemed deleterious for plaque stability. However, these in vitro data leave unaddressed whether pDC are instrumental in plaque destabilization in vivo.

While viral infection associated acute pDC activation results in massive type I IFN release, chronic activation of pDC in the absence of infection was reported to cause severe autoimmune diseases. For instance, in experimental autoimmune encephalomyelitis pDC were shown to exert overt pathogenic activity, mainly by enhancing T helper 17 (Th17) dependent immune responses. ${ }^{6}$ In patients with systemic lupus erythematosus, $\mathrm{pDC}$ activity and IFN- $\alpha / \beta$ release correlated with disease activity and severity. ${ }^{7,8}$ Conversely, evidence is culminating that immature and alternatively activated pDC have the capacity to dampen chronic low grade inflammation and autoimmune diseases, including diabetes type I, asthma and transplant rejection, possibly by suppressing $\mathrm{CD} 8^{+}$effector $\mathrm{T}$ cell and inducing $\mathrm{CD} 4^{+} \mathrm{CD} 25^{+}$regulatory $\mathrm{T}$ cell (Treg) function by the release of tolerogenic molecules such as indoleamine 2,3-dioxygenase (IDO) or programmed death- 
Chapter 6

ligand 1 (PD-L1). ${ }^{9-13}$ Altogether, these observations show that $\mathrm{pDC}$ are very plastic cells with the capacity to produce high levels of type I IFN and activate the adaptive immune system in infection on one hand and to regulate inflammation by inhibiting effector $\mathrm{T}$ cell and inducing regulatory $\mathrm{T}$ cell responses on the other hand.

In this study, we addressed the actual role of pDC in atherosclerosis by a lossof-function approach, providing evidence for an IDO-dependent $T$ cell suppressive activity of pDC in human and mouse atherosclerosis.

\section{Materials and methods}

\section{Atherosclerosis induction and $p D C$ depletion in mice}

Female $\mathrm{LDLr}^{-/-}$mice, obtained from The Jackson Laboratoy and backcrossed at least 11 times to $\mathrm{C} 57 \mathrm{BI} / 6$, were placed on high fat diet containing $0.25 \%$ cholesterol (Special Diets Services, Witham, Essex, UK). Two weeks later, atherosclerotic lesions were induced in the carotid artery by bilateral placement of semi-constrictive collars. ${ }^{14}$ To study effects of pDC depletion on atherosclerosis development, a pDC depleting antibody, $120 \mathrm{G} 8$ (250 $\mu \mathrm{g} / \mathrm{mouse} /$ injection, Bioceros, Utrecht, the Netherlands), was administered 4 times per week i.p. for 3,5 weeks starting at the time of collar placement $(n=19)$ after which mice were sacrificed. From these mice, also the aortic root was analyzed to study effects of pDC depletion on natural atherosclerosis development. To study effects of pDC depletion on progression of atherosclerosis, $120 \mathrm{G} 8$ (250 $\mu \mathrm{g} / \mathrm{mouse} /$ injection, Bioceros, Utrecht, the Netherlands) was administered 4 times per week i.p for 3 weeks starting at 4 weeks after collar placement, once initial lesions had formed $(n=17)$. As control antibody, an isotype control (GL113) was used. All animal work was approved by the regulatory authority of Maastricht University and performed in compliance with the Dutch government guidelines.

\section{Histology of mouse atherosclerotic lesions}

Mice were euthanized by an overdose pentobarbital $(115 \mathrm{mg} / \mathrm{kg})$ and perfused through the left cardiac ventricle with PBS ( $\mathrm{NaCl} / \mathrm{Na}_{2} \mathrm{HPO}_{4} / \mathrm{KH}_{2} \mathrm{PO}_{4}, \mathrm{pH}$ 7.4) containing sodium nitroprusside $(0.1 \mathrm{mg} / \mathrm{ml}$, Sigma) and $1 \%$ paraformaldehyde 
(PFA). The right common carotid artery and the heart were removed, fixed overnight in 1\% PFA and paraffin-embedded sections $(4 \mu \mathrm{m})$ were cut. To determine plaque volume in the carotid artery, plaque area was measured for consecutive cross sections at $100 \mu \mathrm{m}$ intervals over a carotid artery segment that covered the entire plaque. To measure plaque volume in the aortic root, plaque area was measured for each valve for consecutive sections at $20 \mu \mathrm{m}$ intervals that covered the entire lesion. Collagen content was detected by sirius red staining and expressed as a percentage of plaque area. ${ }^{15}$ Slides were analyzed in a blinded manner using a Leica DM3000 light microscope (Leica Microsystems) coupled to a computerized morphometric system (Leica Qwin 3.5.1).

\section{Immunohistochemistry}

Immunohistochemical stainings were performed on paraffin carotid artery sections for CD3 (DAKO), Siglec-H/440c (Hycult Biotechnology) and $\alpha$-smooth muscle actin (ASMA) (DAKO). Slides were analyzed blindly using Leica Qwin program. The number of positive cells was measured and expressed as a percentage of total number of cells in the plaque. For ASMA, the number of positive cells was expressed as a percentage of plaque area.

\section{Flow cytometry}

Blood, spleen and peripheral LN were removed before perfussion and used for FACS analysis of pDC (CCR9 ${ }^{\text {high }}$ PDCA- $1^{\text {high }}$, eBioscience), CDC (CD11c ${ }^{\text {high }}$, eBioscience), $T$ cells $\left(C D 3 \mathrm{e}^{+}\right.$, Miltenyi), $T$ helper cells $\left(C D 4^{+}, B D\right)$, effector $T$ cells $\left(\mathrm{CD} 8 \mathrm{a}^{+}, \mathrm{BD}\right)$, activated $\mathrm{T}$ cells $\left(\mathrm{CD} 44^{\text {high }}\right.$, eBioscience), regulatory $\mathrm{T}$ cells (CD4 ${ }^{+} \mathrm{CD} 25^{+}$Foxp3 $^{+}$, eBioscience), B cells (B220 $\left.{ }^{+}, \mathrm{BD}\right)$, monocytes (CD11b ${ }^{\text {high }} \mathrm{Ly} 6 \mathrm{G}^{-}$, $\mathrm{BD})$, granulocytes (Ly6G ${ }^{\text {high }} \mathrm{CD} 11 \mathrm{~b}^{\text {high }}$ ) and NK cells (NK1.1 $\left.{ }^{+} \mathrm{CD} 3^{-}\right)$. For $\mathrm{pDC}$ and $\mathrm{CDC}$ analysis, spleen and peripheral LN were enzyme treated (liberase $(0.2 \mathrm{mg} / \mathrm{ml}$, Gibco) and DNAse (0.2 mg/ml, Roche)) for 30 minutes in RPMI medium, before antibody incubation to release DC from the tissue. FACS analysis was performed with FACS Canto II (BD).

\section{Plasma cytokine and lipid analysis}


Chapter 6

Plasma cholesterol levels were measured in duplicate using a colorimetric assay (CHOD-PAP, Roche). Mouse and human plasma levels of IFN- $\alpha$ were measured by sandwich ELISA (PBL Interferon Source). Cytokine analysis of mouse IFN- $\gamma$ was performed using the Bio-Plex Pro assay (Bio-Rad). To verify functional ablation of pDC after 120G8 treatment, control and 120G8 treated mice ( $n=5$ per group) received subcutaneous injection with CpG (CpG-ODN 1585, type A, $40 \mu \mathrm{g} / \mathrm{mouse}$, Invivogen) and were sacrificed 6 hours later to measure IFN- $\alpha$ plasma levels. ELISA plates were used from Greiner Bio-One (Alphen a/d Rijn, the Netherlands).

\section{Mouse PDC and T cell isolation by Fluorescence Activated Cell Sorting (FACS)}

Splenic PDC (PDCA- ${ }^{\text {high }}$ CCR9 ${ }^{\text {high }}$ ) and T cells $\left(\mathrm{CD}^{+}\right)$were isolated from $\mathrm{LDLr}^{-/-}$mice, either on high fat diet $(0,25 \%$ cholesterol) (group of atherosclerotic mice, $n=8$ ) either on normal diet (group of non-atherosclerotic mice, $n=8$ ), by FACSAria. The purity of the sorted pDC (PDCA- $1^{\text {high }}$ CCR9 ${ }^{\text {high }}$ ) was $98.3 \%$, for the $\mathrm{CD}^{+}{ }^{+}$cells $95 \%$.

\section{RNA isolation and Quantitative real-time PCR}

RNA from sorted cells was isolated using the ${ }^{\circledR}$ Trizol (Invitrogen) method. Isolated pDC were analyzed for gene expression of mouse PD-L1 (5'-ccatcctgttgttcctcattg$3^{\prime}$ and $3^{\prime}$-gttcactcttacgatctacacct-5'), mouse IDO (5'-actgtgtcctggcaaactggaag- $3^{\prime}$ and $3^{\prime}$-gagataaccacctttagcgtcgaa- $\left.5^{\prime}\right)$ and mouse IFN- $\alpha$ ( $5^{\prime}$-cattctgcaatgacctccac- $3^{\prime}$ and $3^{\prime}$-cacgtccttaaaggggact- $\left.5^{\prime}\right)$. Isolated $\mathrm{CD}^{+} \mathrm{T}$ cells were analyzed for expression of mouse IFN- $\gamma$ (5'-tggctgtttctggctgttactg-3' and $3^{\prime}$-actgtacttttaggacgtctcg-5'). Isolated human pDC from blood were analyzed for gene expression of human IFN$\alpha$ (5'-aatggccttgacctttgctt-3' and 3'-cgttcagttcgacgagacac-5').

\section{BrdU labeling and cell analysis}

$\mathrm{LDLr}^{-/-}$mice on high fat diet treated either with $120 \mathrm{G} 8(\mathrm{n}=4)$ or GL113 $(\mathrm{n}=4)$ received BrdU i.p. injections $(0.8 \mathrm{mg} /$ day) for 5 consecutive days. BrdU incorporation in $\mathrm{CD}^{+}$and $\mathrm{CD} 8^{+}$T cells was assessed using a FITC BrdU flow kit (BD) according to manufacturer's instructions. Cells were analyzed using FACS CANTO II. 


\section{OT-1 and OT-2 antigen specific $T$ cell proliferation experiment}

$\mathrm{LDLr}^{-/}$recipient mice ( $\mathrm{n}=4120 \mathrm{G} 8$ versus $\mathrm{n}=4 \mathrm{GL113}$ treated mice) on high fat diet received i.v. $1 \times 10^{6}$ CFSE-labeled purified OVA-specific OT-1/CD45.1 or OT$2 / C D 90.1$ cells together with $2 \times 10^{6}$ non-transgenic purified $\mathrm{CD}^{+} / \mathrm{CD} 90.1$ or $\mathrm{CD}^{+} / \mathrm{CD} 45.1 \mathrm{~T}$ cells that served as an internal control. The next day, mice received i.v. $10^{6}$ irradiated $(1500 \mathrm{rad}) \mathrm{Kb}^{-/}$-actmOVA or $\mathrm{C} 3 \mathrm{H}$-actmOVA cells. Three days later, OT-1/CD90.1 and OT-2/CD45.1 proliferation and expansion were determined based on CFSE dilution and the ratio of OT-1/CD45.1 to CD90.1 control $\mathrm{CD}^{+} \mathrm{T}$ cells and OT-2/CD90.1 to CD45.1 control CD4 ${ }^{+} \mathrm{T}$ cells. In parallel, $5 \times 10^{6}$ splenocytes were restimulated with OVA 257-264 or OVA 323-339 peptide (A\&A labs, San Diego, CA) in the presence of Brefeldin A for 5 hours. Surface staining for CD8/CD4 (BD) and CD45.1/CD90.1 (eBioscience) was performed.

\section{PDC-T cell co-culture}

PDC were isolated from spleen from a BI6 FLt3L $\left(3 \times 10^{6}\right)$ treated $\mathrm{LDLr}^{-/-}$mouse on high fat diet using PDCA-1 microbeads (Miltenyi). $\mathrm{CD}^{+} \mathrm{T}$ cells were isolated from spleen of a PDC depleted $\mathrm{LDLr}^{-/-}$mouse on high fat diet by staining $\mathrm{T}$ cells with a biotinylated CD4 (Biolegend) and CD8 (Biolegend) antibody and using a biotin isolation kit (Miltenyi). PDC and $\mathrm{CD}^{+} \mathrm{T}$ cells were co-cultured in a 96 well plate coated with anti-CD3/CD28 $(0.1 \mu \mathrm{g} / \mathrm{ml})$ in a $1: 6$ ratio $\left(1 \times 10^{5} \mathrm{pDC}\right.$ and $6 \times 10^{5} \mathrm{~T}$ cells, respectively) for 3 days in iDMEM medium supplemented with either 1-MT (Sigma Aldrich, $100 \mu \mathrm{M})$ or anti-PD-L1 $\left(20 \mu \mathrm{g} / \mathrm{ml}\right.$, Bioceros). Seventy-two hours later, CD3 ${ }^{+}$ $\mathrm{T}$ cell proliferation was assessed by $3[\mathrm{H}]$-thymidine incorporation and plotted as relative proliferation index, being the ratio of $\mathrm{T}$ cell proliferation in the presence and absence of pDC. In parallel cultures, purified $\mathrm{CD4}^{+} \mathrm{T}$ cells were CFSE labeled prior to stimulation and proliferation was determined by flow cytometry 72 hours later upon. 
Chapter 6

For micro-array analysis, total RNA was extracted from carotid artery sections obtained from autopsy (Department of Pathology, University Hospital Maastricht, Maastricht, the Netherlands) (early $(n=13)$ and advanced stable $(n=16)$ lesions) and surgery (Department of Surgery, Maasland Hospital Sittard, Sittard, the Netherlands) (advanced stable $(n=21)$ and advanced unstable $(n=23)$ lesions). For real-time PCR analysis, RNA was isolated from carotid artery sections obtained from surgery (Department of Surgery, Maasland Hospital Sittard, Sittard, the Netherlands) (advanced stable $(n=12)$ and advanced unstable $(n=12)$ lesions). Plaques were staged by histological analysis of adjacent slides according to Virmani et al. at which intimal thickening (IT) were characterized as early, thick fibrous cap atheroma ( $\mathrm{TkfCA}$ ) as advanced stable, and intraplaque hemorrhaged lesions (IPH) as advanced unstable lesions, respectively. ${ }^{16}$ Immunohistochemical stainings were performed on paraffin carotid artery sections from advanced stable $(n=22)$ and ruptured lesions $(n=22)$ from surgery for CD123 (Sigma Prestige), BDCA-4 (R\&D Systems), ASMA (Dako) and CD68 (Dako). The purity of the BDCA-4 antibody was checked by flow cytometry by comparing mean fluorescence intensity (MFI) of BDCA-4 expression on $\mathrm{pDC}$ versus $B$ cells, $T$ cells and monocytes. Double staining slides were analyzed with the Nuance spectral imaging system (Caliper Life Science / Cambridge Research Instrumentation, Woburn, MA, USA). Spectral imaging data sets were taken from $420-720 \mathrm{~nm}$ at 20 $\mathrm{nm}$ intervals using a DM-5000 Leica microscope system at 20x (plan apo). Spectral libraries of single-red (Vector Red), single-blue (Vector Blue), and natural occurring iron pigments were obtained from the control slides. The resulting library was applied to the double stained slides to spectrally dissect/unmix them into individual component images using the Nuance ${ }^{\mathrm{TM}} 3.0$ software. ${ }^{17}$ Pseudocolor images showing co-localization, as well as an exclusive image of colocalization, were generated with the Nuance 3.0 software. Quantitative assessment of co-localization and pixel-based measurement of the individual markers per microscopic field was done with the same software.

\section{Micro-array analysis of human atherosclerotic lesions}

RNA was isolated using the Guanidine Thiocyanate $(\mathrm{GTC}) / \mathrm{CsCl}$ gradient method and a NucleoSpin RNA II kit (Macherey-Nagel GmbH \& Co. KG). ${ }^{18}$ RNA concentration was determined using the Nanodrop ND-1000 and the RNA quality 
obtained using the RNA 6000 Nano/Pico LabChip (Agilent 2100 Bioanalyzer) where the RIN (RNA integration number) was determined. Samples where the RIN number was lower than 5.6 were excluded from the study. The mean RIN was $7.2 \pm 0.49$. Samples from autopsy were individually hybridized to HGU133 2.0 Plus arrays (Affymetrix, Santa Clara, California, USA) and samples from surgery to Illumina Human Sentrix-8 V2.0 BeadChip ${ }^{\circledR}$ (Illumina Inc., San Diego, California, USA). Analysis has been performed in R. ${ }^{19}$ For autopsy samples, preprocessing was performed with affy using the Robust MultiArray (RMA) normalization. ${ }^{20}$ For surgery samples, preprocessing was performed by lumi using the Variance Stabilizing Transform (VST) normalization. ${ }^{21}$ Differential expression has been assessed separately for the two sets of data by fitting each gene against a linear model across the given arrays with limma. ${ }^{22}$ Empirical Bayesian shrinkage of the standard errors have been used to moderate t-statistics, F-statistics, and log-odds of differential expression. The resulting ordered dataset has been queried for the set of genes of interest and their results are hereby presented. The adjusted $\mathrm{p}$ values presented in the results are corrected according to the Benjamini and Hochberg False Detection Rate method. ${ }^{23}$

\section{PDC isolation from human blood}

PDC were collected from healthy controls $(n=15)$ and patients with carotid endarterectomy ( $n=14)$. PDC were isolated from blood (Lymphoprep ${ }^{\mathrm{TM}}$ Isolation). From this, the B220 positive fraction was depleted with magnetic beads (Miltenyi Biotec) after which pDC were isolated from the negative fraction using a BDCA-4 isolation kit (Miltenyi Biotec). The purity for BDCA-4 $4^{+}$pDC, as assessed by flow cytometry (CD123 $3^{\text {high }}$ BDCA- $2^{\text {high }}$ ) was $96 \%$. RNA was isolated using the Trizol method. Gene expression profile was analyzed by real-time PCR. Patients for this study were recruited at the Department of Cardiology, University Hospital Oslo, Oslo, Norway. The study included 14 patients $(7$ male, 7 female, average age of 67 ) with high-grade internal carotid stenosis $(\geq 70 \%)$, diagnosed and classified by precerebral color duplex and CT angiography according to consensus criteria. For comparison, blood was collected from 15 healthy controls, comparable to the patient group for age, sex and smoking habits. The controls were health care workers, consecutively recruited from the same area of Norway as the patients. All human work was approved by the Ethical Committee of the University Hospital 
Chapter 6

Oslo. Signed informed consent for participation in the study was obtained from all individuals.

\section{Statistical analysis}

Data are expressed as mean \pm SEM and Mann-Whitney $U$ test was used to compare individual groups of animals. Data are considered statistically significant at $\mathrm{P}<0.05$.

\section{Results}

\section{PDC are scarce in human and mouse atherosclerotic lesions}

Concordant with previous observations, ${ }^{5} \mathrm{CD} 123^{+}$pDC were seen to be present in human atherosclerotic lesions and their presence increases with plaque progression $(P<0.05)$ (Figure 1A). Of note, CD123 stained cells were found to show considerable co-localization with macrophages (Figure 1B) and vSMC (Figure 1C), supporting earlier findings from van Vré et al. showing that CD123 is not a specific marker for human $\mathrm{pDC} .{ }^{24}$ Next, we considered BDCA-4 as a more selective human pDC marker. ${ }^{25}$ Flow cytometry on human whole blood samples confirmed the high specificity of this marker for human $\mathrm{pDC}$, as it was virtually absent on circulating monocyte, B cell, T cell and granulocyte subsets (data not shown). Surprisingly, $\mathrm{BDCA}-4^{+}$staining revealed the scanty presence of $\mathrm{pDC}$ in human plaques; moreover BDCA $-4^{+}$cell expression did not differ between stable and unstable advanced atherosclerotic lesions (Figure 1D). In agreement, micro-array (Figure 1E) and real-time PCR analysis (data not shown) failed to demonstrate differential expression of established $\mathrm{pDC}$ markers during plaque progression. Likewise, pDC were almost absent in mouse carotid and aortic artery lesions of $\mathrm{LDLr}^{-/-}$and $\mathrm{ApoE}$ I- mice as well (data not shown), although we did observe few scattered pDCs in the adventitia (Figure 1F). 

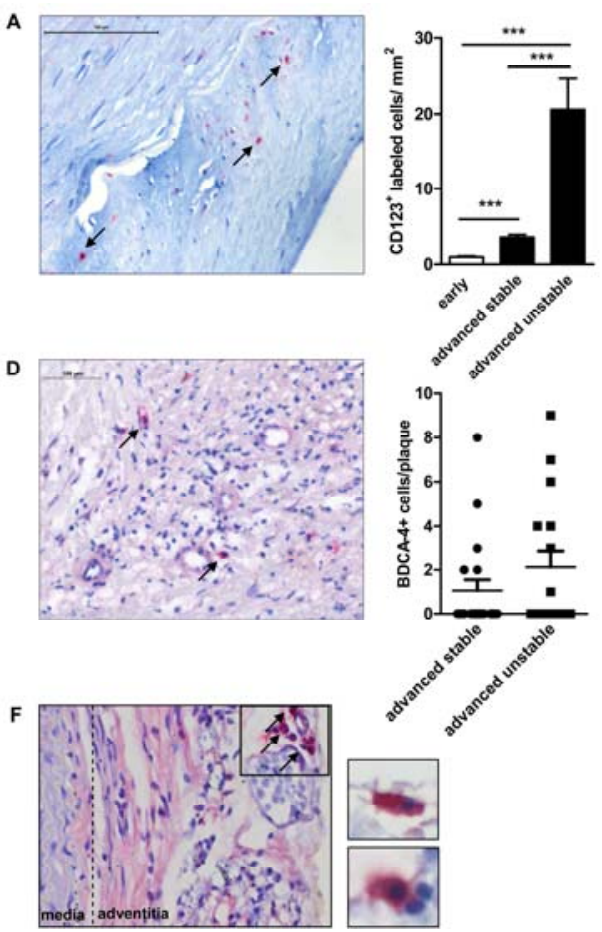

B
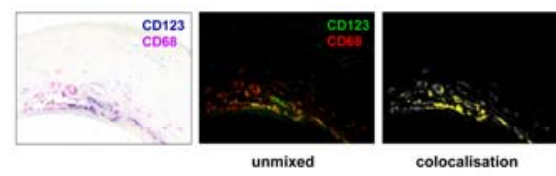

unmixed
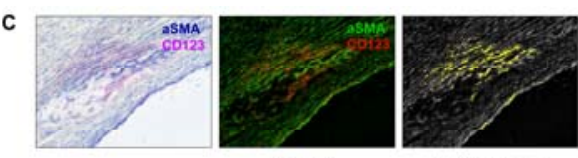

unmixed

colocalisation

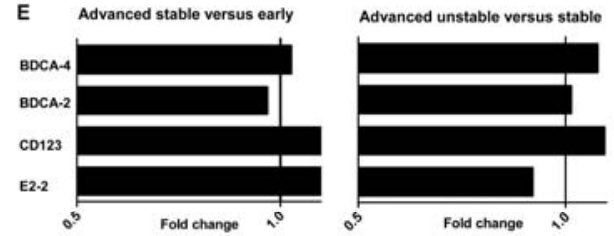

Figure 1. PDC are scarce in human and mouse atherosclerotic lesions. Microscopic analysis of human atherosclerotic lesions. A, Immunohistochemistry for CD123 and quantitative measurement of $\mathrm{CD}_{12} 3^{+} \mathrm{pDC}$ in early (intimal thickening, $\mathrm{n}=12$ ), stable advanced (thick fibrous cap atheroma, $n=13$ ) and unstable advanced (intraplaque hemorrhage, $n=10$ ) human carotid artery atherosclerotic lesions. B, Co-localization for CD123 (blue) and $\mathrm{CD}^{+} 8^{+}$macrophages (red). Slides were analyzed with MultiSpectral Imaging and each set of two pictures on the right side represents a composite fluorescentlike image in pseudo-colors of the left picture and was obtained after unmixing the individual colors red and blue with spectral imaging. Co-localization of fluorescent red and green is represented in yellow. Spectral imaging analysis of this double-stained series clearly shows co-localization of $\mathrm{CD} 123^{+}$cells and macrophages. C, Co-localization for CD123 (red) and SSMA $^{+}$smooth muscle cells (blue). D, Immunohistochemistry for BDCA-4 and quantitative measurement of BDCA $-4^{+}$cells in advanced stable $(n=16)$ and unstable $(n=19)$ human carotid artery lesions. $E$, Micro-array analysis on human carotid artery lesions (early $(n=13)$ vs advanced stable $(n=16)$ and advanced stable $(n=21)$ vs vulnerable $(n=23)) ~ F$, Immunohistochemistry for Siglec-H (440c) in mouse carotid lesions. PDC were detected in the adventitia where they were present in small clusters near to vasa vasora, showing a typical plasmacytoid morphology. 
Chapter 6

\section{Effective and selective depletion of pDC in mice by $120 \mathrm{G} 8$ antibody treatment}

Next, we addressed the specificity of pDC depletion by $120 \mathrm{G} 8 \mathrm{mAb}$, which recognizes PDCA-1 (also referred to as bone marrow stromal cell antigen 2 (BST2)), a marker specifically expressed on mouse pDC. $120 \mathrm{G} 8$ significantly depleted (>90\%) pDC numbers in blood and spleen $(P<0.05)$ (Figure 2A). PDC repopulation started already 24 hours after a single $120 \mathrm{G} 8$ administration and full recovery was obtained after 72 hours (Figure $3 \mathbf{A}$ ), necessitating an every two daily 120G8 dose regimen for effective and persistent pDC depletion. It has been reported that in vitro PDCA-1 expression is upregulated at mRNA level in other cell types in response to viral infection or exposure to inflammatory stimuli, which theoretically could thwart the depletion specificity. ${ }^{26}$ In our study, $120 \mathrm{G} 8$ treatment did neither affect cDC (Figure 2B), nor B cell numbers (Figure 2C). Also monocyte and granulocyte levels were unchanged (Figure 3B-C). Moreover, assessment of PDCA-1 expression by flow cytometry showed that in high fat diet fed $\mathrm{LDLr}^{-/}$mice PDCA-1 expression is completely restricted to pDC (Figure 2D). These data demonstrate that in our mouse model of atherosclerosis pDC depletion by $120 \mathrm{G} 8 \mathrm{mAb}$ was effective and specific. To investigate whether prolonged antibody administration by itself could modulate immune responses, we compared the T cell activation status between GL113 and PBS treated mice and did not find a difference in the number of CD44 ${ }^{\text {high }} \mathrm{T}$ cells (Figure 3D). At a functional level $120 \mathrm{G} 8$ treatment almost abrogated CpG induced pDC activation in vivo, as judged by the 6-fold attenuated induction in plasma IFN- $\alpha$ release upon CpG injection in $120 \mathrm{G} 8$ treated versus control mice $(P<0.05$; Figure $2 \mathrm{E})$. While pDC activity and TLR 7/9 function appear to be intact, under conditions of hyperlipidemia, baseline plasma IFN- $\alpha$ levels remained unchanged after pDC depletion, both in the plaque initiation and progression study. This suggests that an atherogenic stimulus per se does not increase IFN- $\alpha$ release by peripheral pDCs and/or that $\mathrm{pDC}$ are under these conditions not the major source of circulating IFN- $\alpha$. 

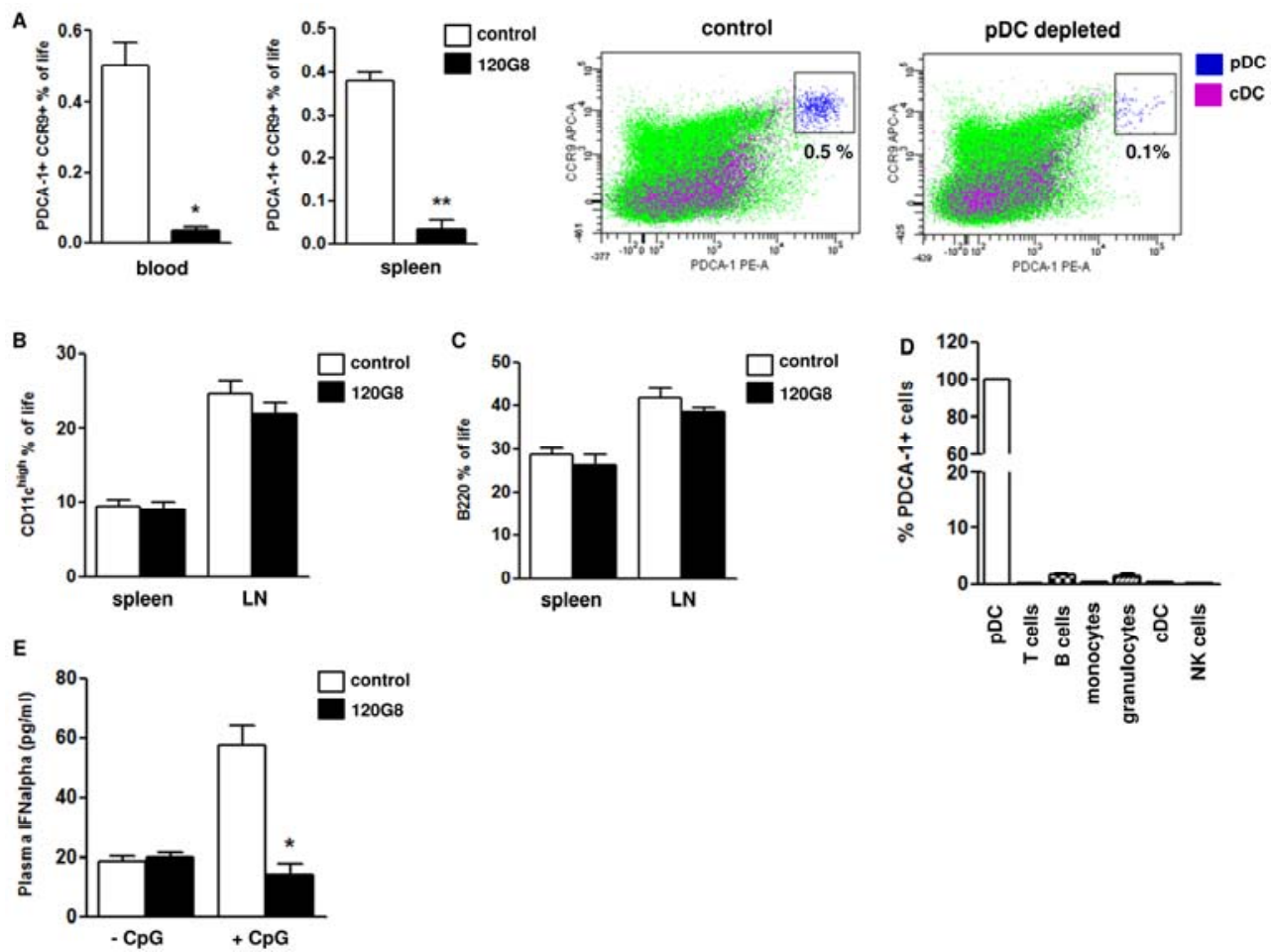

Figure 2. Effective and selective depletion of $\mathrm{pDC}$ in $\mathrm{LDLr}^{-/-}$mice by $120 \mathrm{G8}$ administration. Depicted are the results of flow cytometry from $\mathrm{LDLr}^{-1-}$ mice on high fat diet treated with GL113 $(n=6)$ or $120 \mathrm{G} 8(n=6)$ for 3 weeks. A, PDC (PDCA $-1^{+}$CCR9 $^{+}$) numbers in blood and spleen. $B, C D C\left(C D 11 C^{\text {high }}\right)$ and $C, B$ cell $\left(B 220^{+}\right)$numbers in spleen and peripheral lymph nodes. D, PDCA-1 expression on pDC, T cells $\left(\mathrm{CD}^{+}\right), \mathrm{B}$ cells $\left(\mathrm{B}^{+} 2 \mathrm{O}^{+}\right)$, monocytes (CD11 $b^{\text {high }}$ Ly6G $\left.^{-}\right)$, granulocytes (CD11 $b^{\text {high }}$ Ly6G $\left.{ }^{\text {high }}\right), C D C\left(C D 11 c^{\text {high }}\right)$ and NK cells (NK1.1 ${ }^{\text {high }}$ CD3 $^{-}$) from spleen. E, CpG stimulation in GL113 $(n=5)$ versus $120 G 8(n=5)$ treated mice. 
A
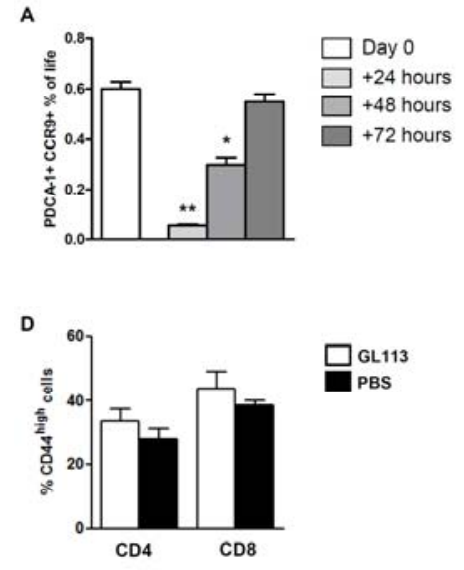
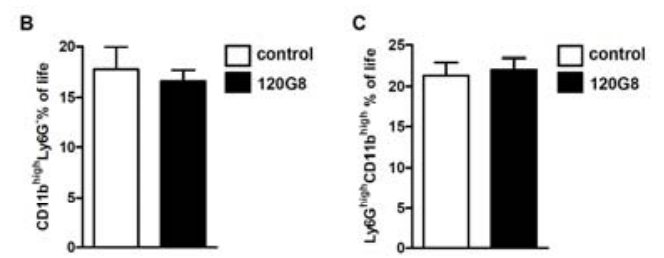

Figure 3. Efficiency and specificity of pDC depletion by $120 \mathrm{G} 8 \mathrm{mAb}$. A, Time-span of pDC depletion by $120 \mathrm{G} 8 \mathrm{mAb}$. $\mathrm{LDIr}^{-/-}$mice on high fat diet received one single dose of $120 \mathrm{G} 8$ $(250 \mu \mathrm{g} /$ mouse) via i.p. injection and pDC recovery was analyzed 24,48 and 72 hours later in blood ( $n=3$ per group). B, Flow cytometry analysis of circulating monocytes $\left(C D 11 b^{\text {high }}\right.$ Ly6G $\left.^{-}\right), \mathbf{C}$, granulocytes (CD11 $b^{\text {high }}$ Ly6G $^{\text {high }}$ ) and D, activated (CD44 $\left.{ }^{\text {high }}\right) \mathrm{CD}^{+}$and $\mathrm{CD}^{+}{ }^{\mathrm{T}}$ cells from $\mathrm{LDLr}^{-/}$mice on high fat diet treated with GL113 $(\mathrm{n}=6)$ versus $120 \mathrm{G} 8(\mathrm{n}=6)$ for 3 weeks.

\section{Depletion of pDC accelerates atherosclerosis in $\mathrm{LDLr}^{-/-}$mice}

To address the role of pDC in atherosclerosis, we examined lesion development and progression in $\mathrm{LDLr}^{-/-}$mice fed a high fat diet. For plaque initiation, 120G8 treatment was started at time of collar placement, whereas for plaque progression, it was started at week 4 after collar placement, once initial lesions had formed. $120 \mathrm{G} 8$ treatment did not affect body weight, nor did it lead to overt pathogenic responses. $120 \mathrm{G} 8$ treatment tended to decrease plasma cholesterol levels initially (1384 \pm 78.53 vs $1126 \pm 46.28 \mathrm{pg} / \mathrm{ml}$ in control and $120 \mathrm{G} 8$ treated mice, respectively), but this effect was blunted at later stages of plaque development (1097 \pm 44.83 vs $1231 \pm 72.31 \mathrm{pg} / \mathrm{ml}$ in control and $120 \mathrm{G} 8$ treated mice, respectively) (Table 1 ). 
Table 1. Body weight and plasma cholesterol levels

\begin{tabular}{lcc}
\hline & Control Ab & 120G8 mAb \\
\hline Body weight initiation study $(\mathrm{g})$ & $21.10 \pm 0.23$ & $20.11 \pm 0.42$ \\
Body weight progression study $(\mathrm{g})$ & $21.90 \pm 0.43$ & $22.75 \pm 0.31$ \\
Plasma cholesterol levels initiation study $(\mathrm{pg} / \mathrm{ml})$ & $1384 \pm 78.53$ & $1126 \pm 46.2^{*}$ \\
Plasma cholesterol levels progression study $(\mathrm{pg} / \mathrm{ml})$ & $1097 \pm 44.83$ & $1231 \pm 72.31$ \\
\hline
\end{tabular}

$(* P<0.05)$

To our surprise, atherosclerosis considerably deteriorated after pDC depletion. Plaque volume was 2 -fold increased in the plaque initiation study $\left(1.4 \times 10^{7} \pm\right.$ $2.6 \times 10^{6}$ vs $2.7 \times 10^{7} \pm 4.7 \times 10^{6} \mu \mathrm{m}^{3}$ in control and $120 \mathrm{G} 8$ treated mice, respectively) $(P<0.05)$ (Figure $4 \mathrm{~A})$, while we observed a 3 -fold increase in plaque progression compared to plaques at baseline $\left(1.4 \times 10^{7} \pm 2.5 \times 10^{6}\right.$ vs $5.4 \times 10^{7} \pm 7.2 \times 10^{6} \mu \mathrm{m}^{3}$ in control baseline and $120 \mathrm{G} 8$ treated mice, respectively) $(P<0.0005)$ versus only 2fold for the GL113 Ab treated mice $\left(1.4 \times 10^{7} \pm 2.5 \times 10^{6}\right.$ vs $3.3 \times 10^{7} \pm 7.5 \times 10^{6} \mu \mathrm{m}^{3}$ in control baseline and GL113 treated mice, respectively) $(P<0.05)$ (Figure 4B). Likewise, $\mathrm{pDC}$ depletion induced a more unstable plaque phenotype in the progression study, characterized by necrotic core expansion (Figure 4C) and diminished cap VSMC content (Figure 4D). There was no difference in plaque collagen content (data not shown). In addition to the carotid artery, we also examined atherosclerosis development in the aortic root, showing an essentially similar aggravation of lesion formation after pDC depletion ( $P<0.05$; Figure $4 \mathrm{E})$. Thus our data point to an unexpected protective role of $\mathrm{pDC}$ in atherosclerosis, which is in contrast to the prevailing notion that PDC might promote atherosclerosis by activating $T$ cells in a type-I IFN dependent manner. ${ }^{5,27}$ Moreover, given the fact that atherosclerotic lesions are virtually devoid of pDC, they most likely exert their atheroprotective effect by modulating immune responses in the periphery and/or adventitia. 

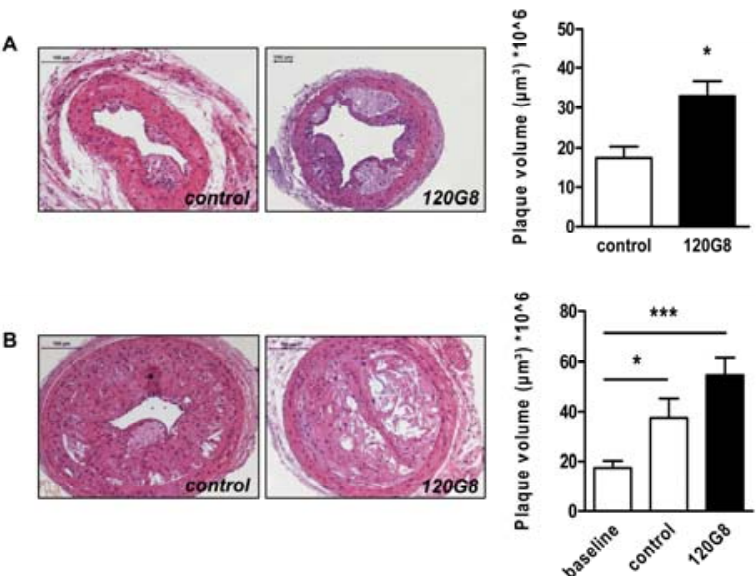

E
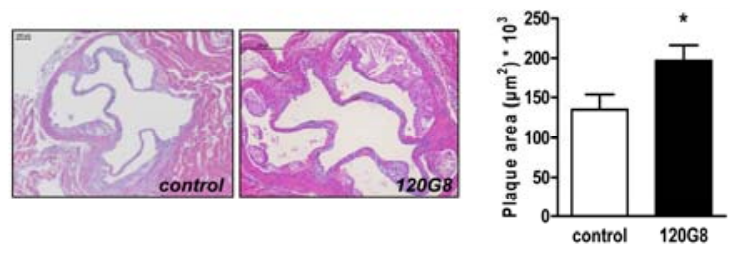
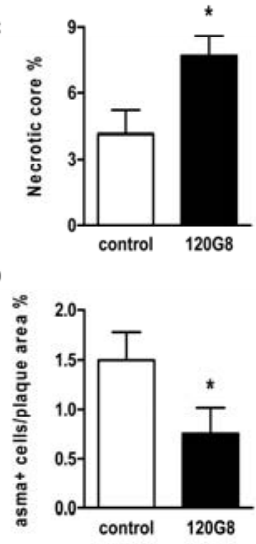

Figure 4. PDC depletion significantly deteriorates atherosclerotic plaque development and progression in $\mathrm{LDLr}^{-/-}$mice. A, Effects of $\mathrm{pDC}$ depletion on atherosclerosis development (collar model) (GL113 ( $n=9)$ vs $120 \mathrm{G} 8(\mathrm{n}=10)$ treated mice). Right carotid artery was stained with hematoxylin and eosin (HE) to analyze the extent of atherosclerosis (plaque volume, $\mu \mathrm{m}^{3}$ ). B, Effects of pDC depletion on atherosclerosis progression (collar model) (GL113 baseline $(n=9)$, GL113 $(n=8)$ and $120 \mathrm{G} 8(n=9)$ treated mice). GL113 baseline group represents plaque formation at start of antibody treatment. Right carotid artery was stained with HE and atherosclerotic lesion burden was analyzed (plaque volume, $\mu \mathrm{m}^{3}$ ). C, Necrotic core area is represented as the percentage of lipid core area over plaque area. Data are represented for the plaque progression study. D, ASMA content is presented as the percentage of $\mathrm{aSMA}^{+}$positive cells per plaque area. Data are represented for the plaque progression study. E, Effects of pDC depletion on atherosclerosis development in the aortic root (GL113 (n=9) vs $120 \mathrm{G} 8(n=10)$ treated mice). The aortic root was stained with $\mathrm{HE}$ to analyze the extent of atherosclerosis (plaque area, $\mu \mathrm{m}^{2}$ ). 
PDC exert their atheroprotective effect by regulating $\mathrm{CD}^{+} \mathrm{T}$ cell proliferation and function in lymphoid tissue

As a next step, we examined effects of pDC depletion on plaque composition to address the potential mechanisms responsible for the protective effects of $p D C$ in atherosclerosis. We found that $\mathrm{pDC}$ depletion led to an increase in lesional $\mathrm{T}$ cell accumulation $(P<0.05$; Figure $\mathbf{5 A}$ and Figure $\mathbf{6 A})$. The scarce presence of $\mathrm{pDC}$ in mouse atherosclerotic lesions suggests that the increased $T$ cell infiltration into the lesions most likely reflects peripheral modulation of T cell function. Indeed, blood and spleen $T$ cell content was increased in pDC depleted mice $(P<0.05$; Figure 5B), suggesting that $\mathrm{pDC}$ interfere with $\mathrm{T}$ cell homeostasis.

A

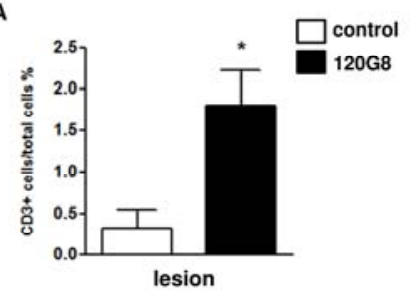

C
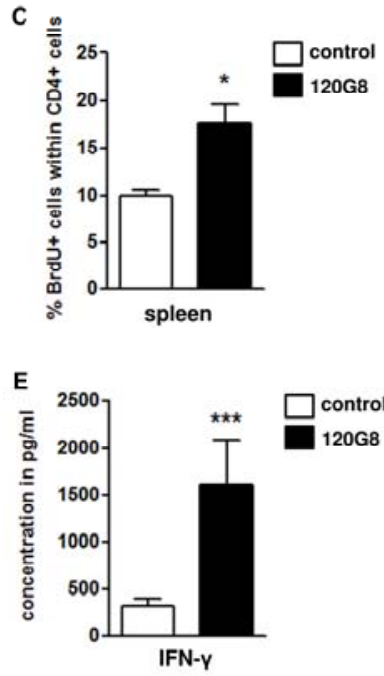
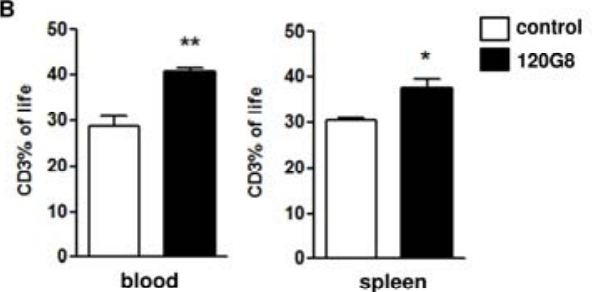

D

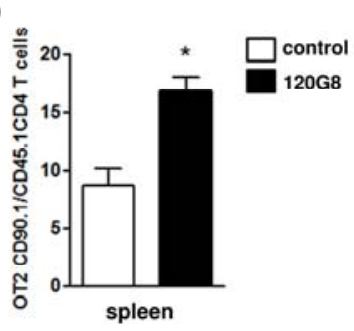

F

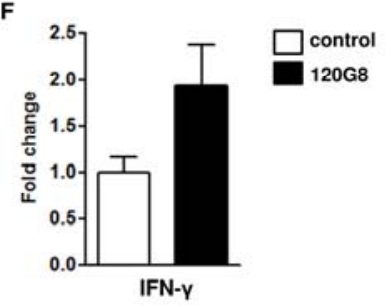

Figure 5. pDC depletion results in increased $\mathrm{CD} 4^{+} \mathrm{T}$ cell proliferation. $\mathrm{A}, \mathrm{CD}^{+} \mathrm{T}$ cell content in mouse atherosclerotic lesions (collar model) (GL113 ( $n=9)$ vs $120 \mathrm{G} 8$ ( $n=10)$ treated mice). Data are represented for the plaque initiation study. B, Flow cytometry analysis for $\mathrm{CD}^{+} \mathrm{T}$ cells in blood and spleen. $\mathrm{C}$, BrdU staining of $\mathrm{CD}^{+}{ }^{+} \mathrm{T}$ cells in spleen from GL113 $(n=4)$ vs $120 \mathrm{G} 8(n=4)$ treated $\mathrm{LDLr}^{-/-}$mice on high fat diet. $\mathrm{D}$, OT-2 $\mathrm{CD}^{+}$T cell 
proliferation in spleen in response to ovalbumin challenge (OVA $A_{323-339}$ ) in GL113 $(n=4)$ versus $120 \mathrm{G} 8(n=4)$ treated $\mathrm{LDLr}^{-/}$mice on high fat diet. E, IFN- $\gamma$ plasma levels $(n=8$ GL113 vs $n=8$ 120G8). F, IFN- $\gamma$ gene expression by splenic $\mathrm{CD}^{+}$T cells isolated from GL113 $(n=8)$ versus $120 \mathrm{G} 8(\mathrm{n}=8)$ treated mice.

As $\mathrm{pDC}$ have been reported to induce regulatory $\mathrm{T}$ cell expansion, ${ }^{11,28}$ we investigated whether the increase in plaque $\mathrm{CD}^{+} \mathrm{T}$ cell content is owing to decreased Treg numbers or function and an associated failure to control T cell responses. However, we did not observe a difference in blood and spleen Treg numbers between $120 \mathrm{G} 8$ and GL113 treated LDLr ${ }^{-1-}$ mice (Figure 6B). In keeping, IL-10 plasma levels did not differ as well (Figure $6 \mathrm{C}$ ). To address whether the increase in T cells resulted from increased proliferation or survival, we examined $T$ cell proliferation in vivo. Spleens of $\mathrm{pDC}$ depleted mice were enriched in $\mathrm{BrdU}^{+}$ $\mathrm{CD}^{+}\left(P<0.05\right.$; Figure $5 \mathrm{C}$ ) but not $\mathrm{CD}^{+} \mathrm{T}$ cells (Figure 6D). Moreover, $\mathrm{T}$ cell proliferation appeared to be antigen-dependent in that ovalbumin (OVA) challenge led to augmented proliferation of OT-2 $\mathrm{CD}^{+}{ }^{+}$cells $(P<0.05$; Figure 5D) but not OT-1 CD8 ${ }^{+}$T cells (Figure 6E) in pDC depleted versus non-depleted mice. In addition, these findings also show that the increased proliferation is not due to intrinsic $T$ cell effects, as both innate and administered $T$ cell proliferation was increased, but to changes in the environment in pDC depleted mice. In parallel to increased T cell proliferation, IFN- $\gamma(P<0.0005$; Figure 5E) as well as IL- 6 and MCP1 plasma levels (Figure 6F) were seen to be increased after pDC depletion. FACS sorted $\mathrm{CD}^{+} \mathrm{T}$ cells (purity 95\%) from spleens of $\mathrm{pDC}$ depleted $\mathrm{LDLr}^{-/-}$mice tended to have increased IFN- $\gamma$ expression ( $P=0.07$; Figure $5 \mathrm{~F}$ ). In addition, $\mathrm{CD}^{+} \mathrm{T}$ cells isolated from atherosclerotic (high fat diet fed) $\mathrm{LDLr}^{-1-}$ mice expressed higher levels of GATA-3 (Th2 marker) as well as of t-bet (Th1 marker) compared to T cells isolated from non-atherosclerotic mice (chow diet fed) mice (Figure 6G). PDC depletion abrogated this effect for GATA-3 but not t-bet, suggesting that pDC might help to dampen the high fat diet induced Th1 shift in LDLr ${ }^{-1-}$ mice. Overall, these data further substantiate a tolerogenic activity of pDC under atherogenic conditions, probably by suppressing $\mathrm{T}$ cell proliferation and function. 

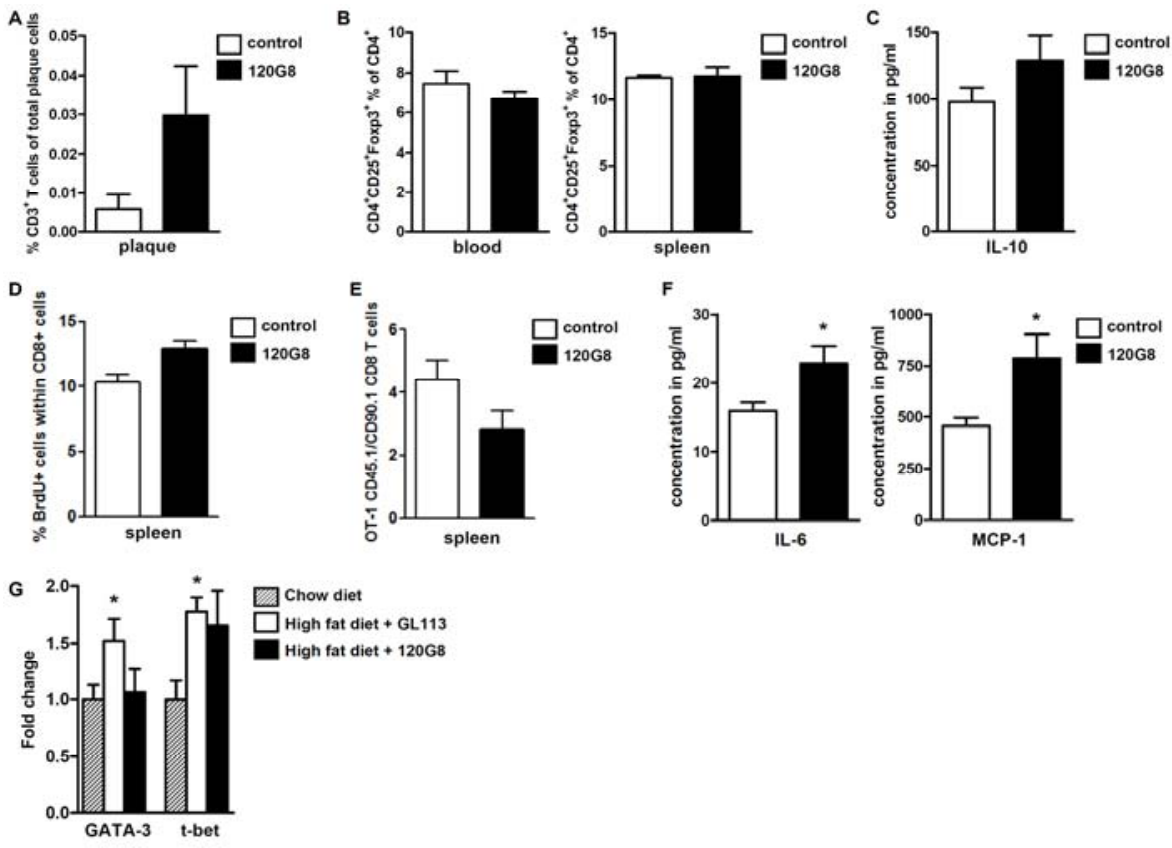

Figure 6. T cell analysis of atherosclerotic mice treated with $\mathrm{GL113}$ versus $120 \mathrm{G8} . \mathrm{A}, \mathrm{CD} 3^{+}$ T cell content in mouse atherosclerotic lesions (aortic root) (GL113 ( $n=9)$ vs 120G8 ( $n=10)$ treated mice, $P=0.08$ ). Data are represented for the plaque initiation study. $\mathbf{B}$, Depicted are the results of flow cytometry analysis for regulatory $T$ cell numbers in blood and spleen from LDLr ${ }^{-/}$mice on high fat diet treated with GL113 $(n=9)$ and $120 \mathrm{G} 8(\mathrm{n}=10)$. C, IL10 plasma levels. $\mathbf{D}$, BrdU staining of $\mathrm{CD}^{+}{ }^{+} \mathrm{T}$ cells in spleen from $\mathrm{LDLr}^{-/-}$mice on high fat diet treated with GL113 $(n=4)$ versus $120 \mathrm{G} 8(\mathrm{n}=4)$. E, OT-1 CD8 ${ }^{+}$T cell proliferation in spleen in response to ovalbumin challenge ( $n=4$ /group). F, IL- 6 and MCP-1 plasma levels ( $n=8$ GL113 vs $n=8$ 120G8). G, Real-time PCR analysis of $\mathrm{CD}^{+}$T cells sorted from spleen from $\mathrm{LDLr}^{-/-}$mice on chow diet $(n=5)$ and high fat diet treated with GL113 $(n=5)$ and $120 \mathrm{G} 8$ $(n=5)$.

\section{PDC suppress $\mathrm{CD4}^{+} \mathrm{T}$ cell proliferation in an IDO-dependent manner}

To address the underlying mechanism for the $T$ cell suppressive capacity of pDC in atherosclerosis, we compared the expression of known key regulators of pDC tolerogenicity, such as indoleamine 2,3-dioxygenase (IDO), IL-10, programmed death ligand-1 (PD-L1) and inducible costimulator-ligand (ICOS-L), by PDC isolated from chow (non-atherosclerotic mice) versus high fat diet (atherosclerotic mice) 


\section{Chapter 6}

fed $\mathrm{LDLr}^{-/}$mice (purity 98.3\%). Expression of PD-L1 and IDO ( $P<0.05$; Figure 7A), but not IL-10 and ICOS-L (data not shown), was significantly elevated in PDC from high fat diet versus chow fed mice. Importantly, $\mathrm{CD}^{+} \mathrm{T}$ cells isolated from spleen of $\mathrm{pDC}$ depleted atherosclerotic mice, co-cultured with $\mathrm{pDC}$ in the presence of 1methyl-trypthophan (1-MT), an IDO blocker, but not anti-PD-L1, displayed markedly induced $T$ cell proliferation $(P<0.05$; Figure $7 B)$, suggesting that $\mathrm{pDC}$ suppress $\mathrm{T}$ cell proliferation in an IDO dependent manner. The 1-MT induced CD4 $4^{+}$ $\mathrm{T}$ cell mitogenic response was confirmed by flow cytometry (Figure $\mathbf{7 C}$ ), showing a similar increment in $\mathrm{CD}^{+} \mathrm{T}$ cell proliferation after co-culture with $\mathrm{pDC}$ in the presence of 1-MT. Baseline levels of IFN- $\alpha$ in plasma of high fat diet versus chow fed $\mathrm{LDLr}^{-/}$mice were unaltered (Figure 7D), as well as IFN- $\alpha$ expression by pDC (Figure 7E), firmly establishing that in mice pro-atherogenic conditions per se do not promote IFN- $\alpha$ release and immunogenic activity. Moreover, we extend these findings to the human context, as like in $\mathrm{LDLr}^{-/}$mice, IFN- $\alpha$ plasma levels were also seen to be unchanged (Figure 7F) and IFN- $\alpha$ expression by $\mathrm{pDC}$ even significantly lowered in atherosclerotic patients versus healthy controls $(P<0.05$; Figure 7G). Altogether, our data indicate that both in mice and man, conditions of chronic atherosclerosis do not trigger pDC immunogenic activity, IFN- $\alpha$ release and ensuing $T$ cell activation and proliferation. Rather, this milieu may even consolidate $\mathrm{pDC}^{\prime} \mathrm{s}$ innate tolerogenic capacity to suppress T cell proliferation. ${ }^{29}$ 


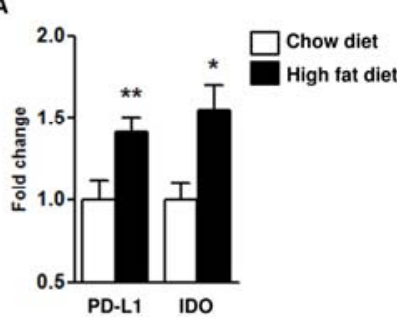

D

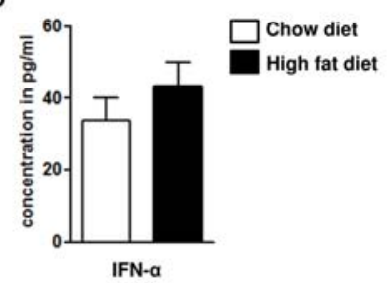

F

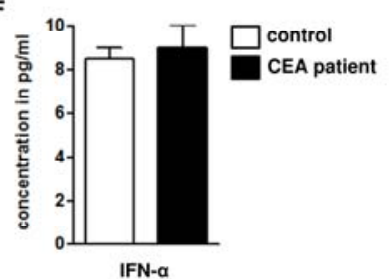

B

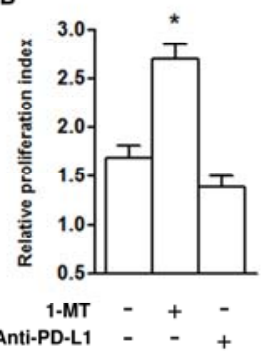

C
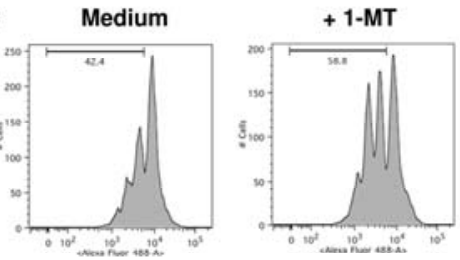

CFSE

E
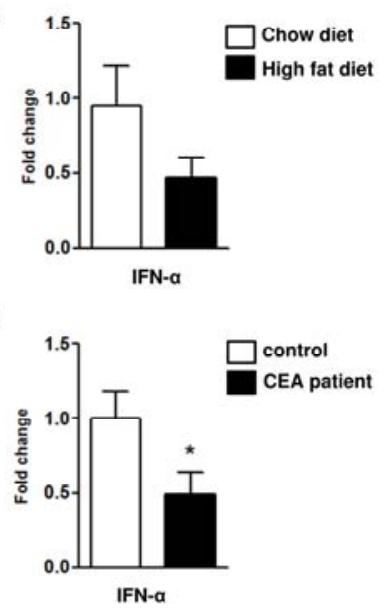

Figure 7. PDC suppress $\mathrm{CD4}^{+} \mathrm{T}$ cell proliferation in an IDO-dependent manner. A, PD-L1 and IDO gene expression by pDC isolated from spleen from atherosclerotic (high fat diet, $\mathrm{n}=8$ ) and non-atherosclerotic mice (chow diet, $\mathrm{n}=8$ ). B, In vitro co-culture of $\mathrm{pDC}$ and $\mathrm{CD}^{+}$ $\mathrm{T}$ cells (in quatro) isolated from spleen from $\mathrm{LDLr}^{-/-}$mice on high fat diet in the presence or absence of 1-MT $(100 \mu \mathrm{M})$ or anti-PD-L1 $(20 \mu \mathrm{g} / \mathrm{ml})$. T cell proliferation was assessed by $3[\mathrm{H}]$-thymidine incorporation and plotted as relative proliferation index, being the ratio of $T$ cell proliferation in the presence and absence of $\mathrm{PDC}$. This experiment was reproduced twice and gave similar results. C, In vitro co-culture of pDC and CFSE labeled $\mathrm{CD}^{+}{ }^{+}$cells (in duplo) isolated from spleen from $\mathrm{LDLr}^{-/}$mice on high fat diet in the presence or absence of 1-MT $(100 \mu \mathrm{M})$. D, IFN- $\alpha$ plasma levels and $\mathbf{E}, \mathrm{IFN}-\alpha \mathrm{pDC}$ gene expression in atherosclerotic (high fat diet, $\mathrm{n}=8$ ) versus non-atherosclerotic (chow diet, $\mathrm{n}=8$ ) $\mathrm{LDLr}^{-1}$ mice. F, IFN- $\alpha$ plasma levels and $\mathbf{G}$, IFN- $\alpha$ pDC gene expression in atherosclerotic patients (carotid endarterectomy (CEA), $n=14$ ) versus healthy controls $(n=15)$. 


\section{Discussion}

In this study, we are the first to demonstrate a contributory role for pDC in atherosclerosis. Despite the scarce presence of $\mathrm{pDC}$ in mouse atherosclerotic lesions, depletion of pDC in $\mathrm{LDLr}^{-/}$mice by $120 \mathrm{G} 8 \mathrm{mAb}$ aggravated atherosclerosis development and progression. Lesions of pDC depleted mice were characterized by increased $T$ cell accumulation and a more unstable plaque phenotype, which, as we show, is likely linked to a deficiency in pDC associated epitope specific dampening of T cell response.

We demonstrate selective and almost complete pDC depletion by the use of $120 \mathrm{G} 8 \mathrm{mAb}$ in $\mathrm{LDLr}^{-1-}$ mice. PDCA-1 expression was exclusively restricted to the pDC population and no other leukocyte subsets other than pDC were depleted. These findings confirm previous reports which highlight the specificity of the $120 \mathrm{G} 8 \mathrm{mAb}$, all showing selective depletion of $\mathrm{PDC}$ in blood, bone marrow, LN, thymus and non-lymphoid organs of C57BI6 mice but not of CD4/CD8 T cells, DX5 $5^{+}$ NK en $\mathrm{CD} 19^{+} \mathrm{B}$ cells. ${ }^{30-33}$ Alternative $\mathrm{pDC}$ ablation or depletion models currently available such as IKAROS and IRF8 (mutant) all suffer from major effects on nonpDC subsets, while the CD11c.CRE $E_{x} 22^{f /-}$ and the BDCA-2.hDTR mice are interesting new models for future ablation studies.

Our data point to an unexpected atheroprotective activity of pDC, which is in contrast to previous findings pointing towards a pro-atherogenic function. ${ }^{5}$ This notion was largely based on guilt by association, in that 1 ) plaques were seen to express $\mathrm{CD}_{123^{+}}$and IFN- $\alpha^{+}$cells, in particular when progressed to an unstable phenotype, 2) CpG induced pDC activation in vitro led to type I IFN release, and 3) type I IFN were recently reported to contribute to atherosclerosis in $\mathrm{ApoE}^{-/}$and $\mathrm{LDLr}^{-/-}$mice by stimulating macrophage recruitment. ${ }^{27}$ The data presented in this study justify a minor adjustment of this assumption. First, unlike BDCA-4, CD123 staining may not be entirely reflective of the plaque's pDC content as macrophages and VSMCs appear to express this marker as well and as CD123 ${ }^{+}$ cells often lack characteristic plasmacytoid morphology. This observation concurs with recent findings by van Vré et al., showing that CD123 is not a specific pDC marker staining also for endothelial cells in human atherosclerotic lesions. ${ }^{24}$ As a result, the actual plaque pDC content may not only be lower than originally envisioned, but also does not markedly increase with progression of disease. This also implies that pDC effects may be precipitated primarily in the periphery rather 
than within the plaque itself. Second, we show here that $\mathrm{DDC}$ are not the prime source of plasma IFN- $\alpha$ at baseline, and that IFN- $\alpha$ release by $\mathrm{pDC}$ into the circulation is boosted by $\mathrm{CpG}$ treatment, however not by atherogenic conditions. Apparently, atherogenic stimuli per se do not induce pDC activation. Moreover, in atherosclerotic mice, circulating IFN- $\alpha$ originates from other cell types than pDC but may be derived from macrophages. Third, we failed to demonstrate progressively increased expression of IFN- $\alpha$ (by micro-array or real-time PCR analysis) by circulating pDC from atherosclerotic mice and by human pDC from patients with stable versus unstable disease and by unstable versus stable endarterectomy lesions, confirming that in chronic inflammatory processes such as atherosclerosis TLR7/9 activation of pDC is not very prominent. Collectively, our data indicate that $\mathrm{pDC}$ exert their atheroprotective effect primarily by modulating extravascular immune responses.

Our studies also provide a plausible mechanism by which $\mathrm{pDC}$ suppress $\mathrm{CD} 4^{+} \mathrm{T}$ cell proliferation under conditions of atherosclerosis. PDC isolated from spleens from atherosclerotic mice had a 2-fold increase in expression of tolerogenic molecules IDO and PD-L1 compared to PDC isolated from non-atherosclerotic mice. IDO is an intracellular tryptophan catabolizing enzyme which has been attributed suppressive activity on CDCs and stimulatory activity on Tregs. ${ }^{34}$ PD-L1 is an inhibitory co-stimulatory molecule which interacts with programmed death1 (PD-1) on $\mathrm{CD}^{+} \mathrm{T}$ cells to suppress their viability and activity. ${ }^{35}$

Moreover, co-culture of $\mathrm{pDC}$ with T cells in the presence of 1-MT, an IDO blocker, but not anti-PD-L1, showed increased T cell proliferation, suggesting that PDC suppress $T$ cell proliferation in an IDO dependent manner. These observations correspond with previous reports in which pDC were shown to induce tolerance in other low grade chronic inflammatory and autoimmune diseases. ${ }^{9,10,34-36}$ The tolerogenic function of pDC was seen to depend on cytokine/ligand activation. For instance, B7-1 (CD80) engagement by Cytotoxic Tlymphocyte Antigen-4 (CTLA-4Ig), that of CD200R1 by CD200lg and B7-1/B7-2 (CD80/CD86) by CD28lg all have been shown to be able to induce the release of IDO by pDC, leading to the suppression of T cells. ${ }^{37}$ It remains to be established which activation pathway is involved in atherosclerosis. Thus, in analogy, during atherosclerosis pDC not only maintain their immature tolerogenic state, but even invigorate their inborn dampening activity so that they can control T cell activity. 


\section{Chapter 6}

If the same also holds for brief episodes of fulminant plaque inflammation (acute myocardial infarction), remains to be established.

In conclusion, this manuscript is the first to unveil a protective role for pDC in an established mouse model of atherosclerosis, throughout disease progression. Given the virtual absence of $\mathrm{pDC}$ in the plaque itself, $\mathrm{pDC}$ most likely exert their activity extravascularly, by dampening $T$ cell proliferation and function in an IDO dependent manner. While these findings identify $\mathrm{pDC}$ as an interesting new target for therapeutic intervention studies, they warrant further study to elucidate the actual pathways underlying the augmented tolerogenic activity of pDC under conditions of atherosclerosis.

\section{Acknowledgments}

We thank Prof. dr. W. Buurman from Hycult Biotechnology for supplying us the 440c antibody, and Vigdis Bjerkeli and Cassandra Hennies for technical assistance. 


\section{References}

1. Kadowaki N, Ho S, Antonenko S, Malefyt RW, Kastelein RA, Bazan F, Liu YJ. Subsets of human dendritic cell precursors express different toll-like receptors and respond to different microbial antigens. J Exp Med. 2001;194:863-869.

2. Asselin-Paturel C, Boonstra A, Dalod M, Durand I, Yessaad N, Dezutter-Dambuyant C, Vicari A, O'Garra A, Biron C, Brière F, Trinchieri G. Mouse type I IFN-producing cells are immature APCs with plasmacytoid morphology. Nat Immunol. 2001;2:11441150.

3. Cella M, Facchetti F, Lanzavecchia A, Colonna M. Plasmacytoid dendritic cells activated by influenza virus and CD40L drive a potent TH1 polarization. Nat Immunol. 2000;1:305-310.

4. Bobryshev YV, Lord RS. Ultrastructural recognition of cells with dendritic cell morphology in human aortic intima. Contacting interactions of vascular dendritic cells in athero-resistant and athero-prone areas of the normal aorta. Arch Histol Cytol. 1995;58:307-322.

5. Niessner A, Sato K, Chaikof EL, Colmegna I, Goronzy JJ, Weyand CM. Pathogensensing plasmacytoid dendritic cells stimulate cytotoxic T-cell function in the atherosclerotic plaque through interferon-alpha. Circulation. 2006;114:2482-2489.

6. Isaksson $M$, Ardesjö B, Rönnblom L, Kämpe $O$, Lassmann $H$, Eloranta $M L$, Lobell $A$. Plasmacytoid DC promote priming of autoimmune Th17 cells and CEA. Eur J Immunol. 2009;39:2925-2935.

7. Crow MK, Kirou KA, Wohlgemuth J. Microarray analysis of interferon-regulated genes in SLE. Autoimmunity. 2003;36:481-490.

8. Baechler EC, Batliwalla FM, Karypis G, Gaffney PM, Ortmann WA, Espe KJ, Shark KB, Grande WJ, Hughes KM, Kapur V, Gregersen PK, Behrens TW. Interferon-inducible gene expression signature in peripheral blood cells of patients with severe lupus. Proc Natl Acad Sci U S A. 2003;100: 2610-2615.

9. Arpinati M, Chirumbolo G, Urbini B, Perrone G, Rondelli D, Anasetti C. Role of plasmacytoid dendritic cells in immunity and tolerance after allogeneic hematopoietic stem cell transplantation. Transpl Immunol. 2003;11:345-356. Review.

10. de Heer HJ, Hammad H, Soullié T, Hijdra D, Vos N, Willart MA, Hoogsteden HC, Lambrecht BN. Essential role of lung plasmacytoid dendritic cells in preventing asthmatic reactions to harmless inhaled antigen. J Exp Med. 2004;200:89-98.

11. Moseman EA, Liang X, Dawson AJ, Panoskaltsis-Mortari A, Krieg AM, Liu YJ, Blazar $B R$, Chen W. Human plasmacytoid dendritic cells activated by CpG oligodeoxynucleotides induce the generation of $\mathrm{CD} 4+\mathrm{CD} 25+$ regulatory $\mathrm{T}$ cells. $J$ Immunol. 2004;173:4433-4442. 


\section{Chapter 6}

12. Swiecki M, Colonna M. Unraveling the functions of plasmacytoid dendritic cells during viral infections, autoimmunity and tolerance. Immunol Rev. 2010;234:142162.

13. Abe M, Metes D, Thomson AW. Dendritic cells and regulation of alloimmune responses: relevance to outcome and therapy of organ transplantation. Expert Rev Clin Immunol. 2005;1:419-430.

14. Von der Thüsen JH, Van Berkel TJ, Biessen EA. Induction of rapid atherogenesis by perivascular carotid collar placement in apolipoprotein E-deficient and low-density lipoprotein receptor-deficient mice. Circulation. 2001;103:1164-1170.

15. Lutgens E, Gorelik L, Daemen MJ, De Muinck ED, Grewal IS, Koteliansky VE, Flavell RA. Requirement for CD154 in the progression of atherosclerosis. Nat Med. 1999;5:1313-1316.

16. Virmani R, Kolodgie FD, Burk AP, Farb A, Schwartz SM. Lessons from sudden coronary death: a comprehensive morphological classification scheme for atherosclerotic lesions. Arterioscler Thromb Vasc Biol. 2000;20:1262-1275.

17. van der Loos $\mathrm{CM}$. Multiple immunoenzyme staining: methods and visualizations for the observation with spectral imaging. J Histochem Cytochem. 2008;56:313-328.

18. Sambrook J, Fritsch E, Maniatis T. Molecular cloning: a laboratory manual, Vol 2. Cold Spring Harbor, NY: Cold Spring Harbor Laboratory Press; 1989.

19. R development Core Team. R: A language and environment for statistical computing. $R$ foundation for Statistical Computing, Vienna, Austria. ISBN 3-900051-07-0, URL http://www.R-project.org. 2010.

20. Gautier L, Cope L, Bolstad BM, Irizarry RA. Affy--analysis of Affymetrix GeneChip data at the probe level. Bioinformatics. 2004;20:307-315.

21. Du P, Kibbe WA, Lin SM. Lumi: a pipeline for processing Illumina microarray. Bioinformatics. 2008;24:1547-1548.

22. Smyth G. Limma: linear models for microarray data. In: 'Bioinformatics and Computational Biology Solutions using R and Bioconductor', Gentleman R, Carey V, Dudoit S, Irrizary R, Huber W, Ed Springer, New York, pages 397-420. 2005.

23. Benjamini $Y$, Hochberg $Y$. Controlling the false discovery rate: a practical and powerful approach to multiple testing. J R Statistic Soc B. 1995;57:289-300.

24. Van Vré EA, Bosmans JM, Van Brussel I, Maris M, De Meyer GR, Van Schil PE, Vrints CJ, Bult H. Immunohistochemical characterisation of dendritic cells in human atherosclerotic lesions: possible pitfalls. Pathology. 2011;43:239-247.

25. Colonna M, Trinchieri G, Liu YJ. Plasmacytoid dendritic cells in immunity. Nat Immunol. 2004;5:1219-1226. Review.

26. Blasius AL, Giurisato E, Cella M, Schreiber RD, Shaw AS, Colonna M. Bone marrow stromal cell antigen 2 is a specific marker of type I IFN-producing cells in the naïve 
mouse, but a promiscuous cell surface antigen following IFN stimulation. J Immunol. 2006;177:3260-3265.

27. Goossens P, Gijbels MJ, Zernecke A, Eijgelaar W, Vergouwe MN, van der Made I, Vanderlocht J, Beckers L, Buurman WA, Daemen MJ, Kalinke U, Weber C, Lutgens E, de Winther MP. Myeloid type I interferon signaling promotes atherosclerosis by stimulating macrophage recruitment to lesions. Cell Metabolism. 2010;12:142-153.

28. Sharma MD, Baban B, Chandler P, Hou DY, Singh N, Yagita H, Azuma M, Blazar BR, Mellor AL, Munn DH. Plasmacytoid dendritic cells from mouse tumor-draining lymph nodes directly activate mature Tregs via indoleamine 2,3-dioxygenase. J Clin Invest. 2007;117:2570-2582.

29. Maldonado RA, Von Andrian UH. How tolerogenic dendritic cells induce regulatory $T$ cells. Adv Immunol. 2010;108:111-165.

30. GeurtsvanKessel CH, Willart MA, van Rijt LS, Muskens F, Kool M, Baas C, Thielemans K, Bennett C, Clausen BE, Hoogsteden HC, Osterhaus AD, Rimmelzwaan GF, Lambrecht BN. Clearance of influenza virus from the lung depends on migratory langerin+ but not plasmacytoid dendritic cells. J Exp Med. 2008;205:1621-1634.

31. Jongbloed SL, Benson RA, Nickdel MB, Garside P, Mclnnes IB, Brewer JM. Plasmacytoid dendritic cells regulate breach of self-tolerance in autoimmune arthritis. J Immunol. 2009;182:963-968.

32. Smit JJ. Rudd BD, Lukacs NW. Plasmacytoid dendritic cells inhibit pulmonary immunopathology and promote clearance of respiratory syncytial virus. J Exp Med. 2006;203:1153-1159.

33. Xanthou G, Alissafi T, Semitekolou M, Simoes DC, Economidou E, Gaga M, Lambrecht BN, Lloyd CM, Panoutsakopoulou V. Osteopontin has a crucial role in allergic airway disease through regulation of dendritic cell subsets. Nat Med. 2007;13:570-578.

34. Nikolic T, Welzen-Coppens JM, Leenen PJ, Drexhage HA, Versnel MA. Plasmacytoid dendritic cells in autoimmune diabetes - potential tools for immunotherapy. Immunobiology. 2009;214:791-799. Review.

35. Mueller SN, Vanguri VK, Ha SJ, West EE, Keir ME, Glickman JN, Sharpe AH, Ahmed R. PD-L1 has distinct functions in hematopoietic and non-hematopoietic cells in regulating $\mathrm{T}$ cell responses during chronic infection in mice. J Clin Invest. 2010;120:2508-2515.

36. Manches O, Munn D, Fallahi A, Lifson J, Chaperot L, Plumas J, Bhardwaj N. HIVactivated human plasmacytoid DCs induce Tregs through an indoleamine 2,3dioxygenase-dependent mechanism. J Clin Invest. 2008;8:3431-3439.

37. Fallarino F, Orabona C, Vacca C, Bianchi R, Gizzi S, Asselin-Paturel C, Fioretti MC, Trinchieri G, Grohmann U, Puccetti P. Ligand and cytokine dependence of the 


\section{Chapter 6}

immunosuppressive pathway of tryptophan catabolism in plasmacytoid dendritic cells. Int Immunol. 2005;17:1429-1438. 



\section{Chapter 7}

\section{Adventitial lymphatic capillaries in plaque $\mathbf{T}$ cell drainage and progression: an explorative study}

Isabelle Daissormont, Timo Rademakers, Saskia de Jager, Lauran Stöger, Ilze Bot, Peter van Santbrink, Kari Alitalo, Erik Biessen 


\section{Abstract}

Lymphatic capillaries play an important role in lymphocyte and dendritic cell trafficking as well as analyte communication between inflammatory sites and draining lymph nodes. The finding that the adventitia of human atherosclerotic vessels is enriched not only in T cells but also in lymphatic capillaries has inspired us to address the role of these lymphatic capillaries in regulating $T$ cell influx into the adventitia in $\mathrm{ApoE}^{-/-}$mice. Intravenous administration of $\mathrm{CD}^{+} \mathrm{T}$ cells resulted in CXCR3 dependent accumulation of $\mathrm{CD}^{+} \mathrm{T}$ cells in the adventitia of the atherosclerotic vessel wall, at which $\mathrm{T}$ cell presence displayed an overt gradient from adventitia (high) to intima (scarce). Second, we show that, as in human, in mice the lymphatic capillary density in adventitia expands during plaque development. Removal of the draining lymph node and its efferent lymphatic vessel resulted in an increase in plaque volume, accompanied by increased $C D 3^{+}$ plaque and adventitial T cell numbers. Local inhibition of CXCR3 led to a significant expansion of the lymphatic capillary bed in the adventitia, with a concomitant decrease in plaque $\mathrm{CD}^{+}$and $\mathrm{CXCR} 3^{+} \mathrm{T}$ cell numbers. These data demonstrate that lymphatic capillaries in the adventitia are able to modulate atherosclerosis development, in part by regulating $T$ cell influx to and $T$ cell efflux from the adventitia. 


\section{Introduction}

The response to injury paradigm in atherosclerosis attributes vascular inflammation to leukocytes that have extravasated from the luminal endothelium into the intima. Upon injury, luminal endothelial cells upregulate a range of adhesion molecules and selectins and release chemokines such as CCL2 in order to attract monocyte subsets to the vessel wall. ${ }^{1-3}$ In addition, T cells and dendritic cells are being attracted to the vessel wall in a similar manner in order to regulate inflammation. ${ }^{4,5}$ Therefore, most studies thus far have focused on luminal endothelium as major entry port for leukocyte infiltration to the intima. However, the adventitia could function as an entry port as well given its high leukocyte content.

The adventitia is the outer layer of the vessel wall and is a highly organized tissue characterized by stromal tissue, vasculature and the presence of several leukocyte subsets. The contribution of the adventitia to the development and progression of atherosclerosis has been largely overlooked in the past decades. However, there is growing evidence for a crucial role of the adventitia in vascular inflammation..$^{6-9}$ In contrast to the intima, the adventitia is enriched in B cells, which were shown to exert both pro- and anti-atherogenic effects. ${ }^{10-14}$ Moreover, adventitial tissue is a major site of $\mathrm{T}$ cell accumulation in mouse atherosclerotic vessels. ${ }^{15,16}$ Regulatory $T$ cells are scarcely present in the intima, but more abundant in the adventitia. ${ }^{17}$ The same holds for mast cells which are virtually absent in the intima but present in the adventitia. ${ }^{18}$ Moreover, dendritic cells are recruited to the intima and adventitia, where they are located in clusters near $T$ cells, suggesting a role for antigen presentation in the adventitia. ${ }^{10}$ In addition, the adventitia is a highly vascularized tissue, and the vasa vasora have been shown to expand with atherosclerosis progression. ${ }^{19,20}$

The presence of lymphatic capillaries has been demonstrated in the adventitia of human atherosclerotic vessels. ${ }^{21}$ The number of adventitial lymphatic capillaries has been shown to increase with severity of atherosclerosis, ${ }^{22}$ suggesting a link between lymphatic capillaries and disease progression. Although a role of adventitial lymphatic capillaries in atherosclerosis has not yet been documented, lymphatic capillaries conceivably are involved in the regulation of inflammation, by draining antigen-presenting cells from the site of inflammation, here the adventitia, to the draining lymph node, where lymphocytes will be 
sensitized and activated to migrate via efferent lymphatic vessels into the bloodstream towards the adventitia, probably via the vasa vasorum.

In this study, we addressed the actual role of adventitial lymphatic capillaries in atherosclerosis, providing evidence for a protective role of lymphatic capillaries partly by drainage of $\mathrm{T}$ cells. In addition, we show that Interferon- $\gamma$-inducible Protein-10 (IP-10) is one of the driving factors in adventitial lymphangiogenesis and $T$ cell trafficking to the plaque.

\section{Materials and Methods}

Analysis of lymphatic capillaries and $\mathrm{CD}^{+} \mathrm{T}$ cells in the adventitia of nonatherosclerotic versus atherosclerotic mice

Male ApoE $^{-/}$mice $(n=21)$, obtained from The Jackson Laboratory and backcrossed at least 11 times to $\mathrm{C} 57 \mathrm{Bl} / 6$, were placed on western type diet containing $0.25 \%$ cholesterol (Special Diets Services, Witham, Essex, UK). Atherosclerotic lesions were induced in the carotid artery by bilateral placement of semi-constrictive collars. ${ }^{23}$ To study the expression of lymphatic capillaries and $\mathrm{CD}^{+} \mathrm{T}$ cells in the adventitia of early lesions, mice $(n=9)$ were sacrificed 4 weeks after collar placement. The expression of lymphatic capillaries and $\mathrm{CD}^{+} \mathrm{T}$ cells in the adventitia of advanced lesions was studied in mice $(n=6)$, sacrificed 8 weeks after collar placement. ApoE ${ }^{-/-}$mice without collar placement $(n=6)$ served as control.

\section{In vivo T cell trafficking experiments}

To investigate whether $T$ cells enter the atherosclerotic vessel wall via the adventitia, $\mathrm{CD}^{+} \mathrm{T}$ cells were isolated from spleen of wild-type and $\mathrm{CXCR}^{-1-24}$ mice using a CD3 isolation kit (BD Biosciences) and were pre-stimulated with $1 \mathrm{ng} / \mathrm{mL}$ IL-2 (Sigma-Aldrich). ApoE ${ }^{-/}$mice $(n=7)$ were placed on western type diet and received 4 weeks after collar placement i.v. a 1:1 mixture of CMFDA-labeled WT $\left(10^{7}\right.$ cells) and CMTPX-labeled CXCR3 ${ }^{--}\left(10^{7}\right.$ cells) T cells. Twenty-four hours later, mice were sacrificed and perfused with phosphate buffered saline (PBS). Right carotid artery was removed, embedded in Tissue Tek (Miles Inc) and snap-frozen at $-160^{\circ} \mathrm{C}$. Frozen sections $(5 \mu \mathrm{m})$ were cut over a segment covering the entire 
plaque and nuclei were counterstained with DAPI (Sigma-Aldrich). Overlay images were acquired using a Leica DM5000B fluorescence microscope. Analysis was performed in a blinded manner. The number of $T$ cells present in the adventitia was expressed per $10 \mu \mathrm{m}$ segment plaque. All animal work was approved by the regulatory authority of Maastricht University and performed in compliance with the Dutch government guidelines.

\section{Lymph node and vessel dissection in mice}

Male $\mathrm{ApoE}^{-/-}$mice $(\mathrm{n}=27)$ were placed on western type diet and perivascular collars were placed around the carotid arteries to induce atherosclerosis development as described previously. ${ }^{23}$ To investigate whether there is local transport of cells between the lymph node next to the bifurcation of the carotid artery (cervical lymph node) and the adventitia, the lymph node together with its efferent vessel were removed at point of collar placement $(n=14)$. As control, mice $(n=13)$ only received collar placement. At sacrifice mice from the lymph node dissection group did not show any signs of edema in the neck region. To investigate whether lymph node and vessel dissection per se could induce inflammation, a control study was performed in which normolipidemic wild-type mice received collar placement $(n=6)$ or a combination of collar placement and lymph node and lymph vessel dissection $(n=5)$. Mice were sacrificed 4 weeks after collar placement.

\section{Local IP-10 inhibition in mice}

Male ApoE $^{-/-}$mice $(n=20)$ were placed on western type diet and atherosclerotic lesions in the carotid artery were induced by perivascular collar placement. To inhibit the local IP-10 gradient in the adventitia, lentivirus encoding IP-10 antagonist (IP-10 AT, $10^{8}$ virus particles per mouse) ${ }^{25}$ or Green Fluorescent Protein (GFP) control entrapped in F127 pluronic gel was administered perivascularly proximal to the collar at the time of collar placement ( $n=10$ IP-10 AT versus $n=10$ control). Mice were sacrificed 4 weeks later. Briefly, lentivirus was produced in HEK 239T cells cultured in RPMI containing 4,5 g/L glucose, 10\% Fetal Calf Serum 
(FCS), $2 \mathrm{mmol} / \mathrm{L} \mathrm{L-glutamine,} 100 \mathrm{U} / \mathrm{mL}$ penicillin and $100 \mu \mathrm{g} / \mathrm{mL}$ streptomycin (all from PAA, Cölbe, Germany). The IP-10 antagonist expression vector (pRRI-cPPtCMV.SDF-1á(P2G): LV.IP-10 AT) $)^{25}$ was constructed by inserting IP-10 AT sequence into the pRRI-cPPt-CMV-PreSIN lentivector (LV.Empty) using Smal digestion. Virus was produced as described and virus titers were determined essentially as described by Sastry et al. ${ }^{26}$ Viral integrants were determined by qPCR analysis (forward primer: GTGCAGCAGCAGAACAATTTG, reverse primer: CCCCAGACTGTGAGTTGCAA). For the culturing of lenti-viruses, petridishes from Greiner Bio-One were used (639161, Alphen a/d Rijn, the Netherlands).

\section{Histology of mouse atherosclerotic lesions}

Mice were euthanized by an overdose pentobarbital $(115 \mathrm{mg} / \mathrm{kg})$ and perfused through the left cardiac ventricle with $\mathrm{PBS}\left(\mathrm{NaCl} / \mathrm{Na}_{2} \mathrm{HPO}_{4} / \mathrm{KH}_{2} \mathrm{PO}_{4}, \mathrm{pH}\right.$ 7.4) containing sodium nitroprusside $(0.1 \mathrm{mg} / \mathrm{ml}$, Sigma) and $1 \%$ paraformaldehyde (PFA). The right common carotid artery was removed, fixed overnight in 1\% PFA and paraffin-embedded sections $(4 \mu \mathrm{m})$ were cut. To determine plaque volume in the carotid artery, sections were stained for haematoxylin/eosin (HE) and plaque area was measured for consecutive cross sections at $100 \mu \mathrm{m}$ intervals over a carotid artery segment that covered the entire plaque. Slides were analyzed in a blinded manner using a Leica DM3000 light microscope (Leica Microsystems) coupled to a computerized morphometric system (Leica Qwin 3.5.1). ${ }^{27}$

\section{Immunohistochemistry}

Immunohistochemical staining on mouse paraffin carotid artery sections was performed for lyve-1 (Abcam), CD3 (DAKO), Mac-3 (BD), CXCR3 (Sanbio/MBL) and IP-10 (R\&D). The number of lyve- $1^{+}$lymphatic capillaries was expressed as percentage of adventitial area. The number of $\mathrm{CD}^{+}, \mathrm{CXCR3}^{+}$and mac3 $^{+}$cells was expressed as percentage of total plaque or adventitial cells. Slides were analyzed blindly using Leica Qwin software. 
Flow cytometry and plasma total cholesterol measurement

Blood, spleen and peripheral lymph nodes were removed before perfusion ( $n=10 /$ group) and used for FACS analysis of monocytes (CD11b high $L y 6 G^{-}, B D$ ), granulocytes (CD11 $b^{\text {high }}$ Ly6G $\left.\mathrm{G}^{\text {high }}, \mathrm{BD}\right), \mathrm{T}$ helper cells $\left(\mathrm{CD} 4^{+}, \mathrm{BD}\right)$, effector $\mathrm{T}$ cells $\left(C D 8 a^{+}, B D\right)$ and activated $T$ cells $\left(C D 44^{\text {high }}\right.$, eBioscience). FACS analysis was performed with FACS CANTO II (BD).

\section{Real-time PCR analysis of human atherosclerotic lesions}

RNA was isolated from carotid artery sections obtained from surgery (Department of Surgery, Maasland Hospital Sittard, Sittard, the Netherlands) (advanced stable $(n=9)$ and advanced unstable $(n=13)$ lesions). Plaques were staged by histological analysis of adjacent slides according to Virmani et al. ${ }^{28}$ at which thick fibrous cap atheromas were categorized as advanced stable and intraplaque hemorrhaged lesions as advanced unstable lesions. Lesions were analyzed for gene expression of human IP-10 (5'-TATTCCTGCAAGCCAATTTT-3' and 3'ACTTTCGTCAATCGTTCCTT-5').

\section{Statistical analysis}

Data are expressed as mean \pm SEM and Mann-Whitney $U$ test was used to compare individual groups of animals. Data are considered statistically significant at $P<0.05$.

\section{Results}

Lymphatic capillaries are present in the adventitia of mouse atherosclerotic lesions and their presence increases with plaque development

First, we investigated the presence of lymphatic capillaries in the adventitia of mouse atherosclerotic lesions. The adventitia appears to be, not only rich in vasa vasorum, but also in lymphatic capillaries, making both a possible entrance for $T$ cells (Figure 1A). Concordant with observations in human atherosclerotic 


\section{Chapter 7}

lesions, ${ }^{22}$ we observed that the adventitial lymphatic capillary density increases with disease development. Of note, lymphatic capillary numbers in the adventitia were already significantly increased early on in plaque development (Figure 1B). However, we did not observe any further expansion of the adventitial lymphatic vessel bed at later stages of plaque development, suggesting that lymphatic expansion occurs already early on in plaque development.
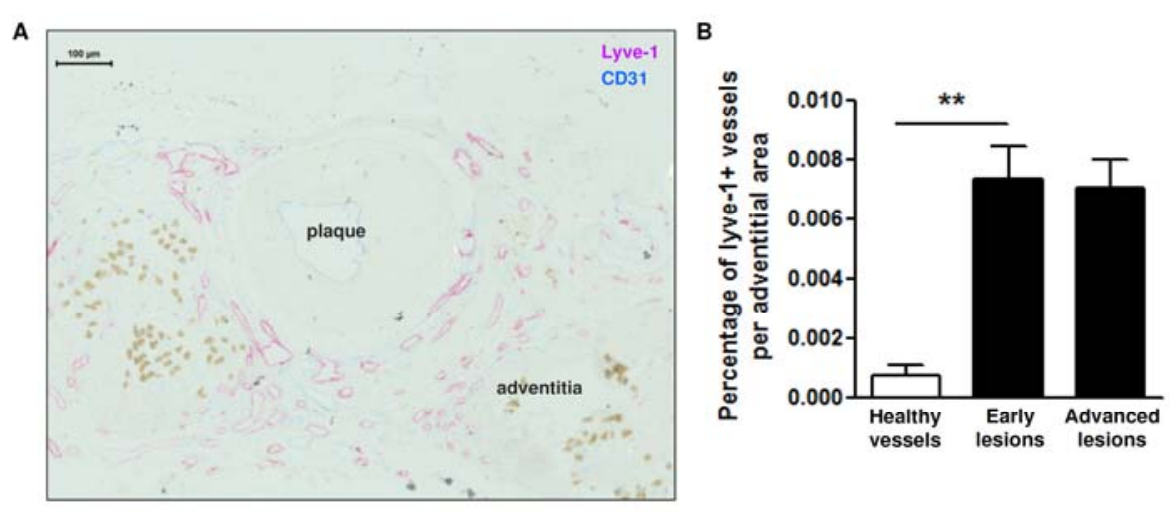

Figure 1. The presence of lymphatic capillaries in the adventitia of atherosclerotic lesions. A, Immunohistochemistry for Lyve $-1^{+}$lymphatic capillaries (purple) and CD31 $1^{+}$ vasa vasorum (blue) in mouse carotid atherosclerotic lesions. B, The percentage of lyve- $1^{+}$ lymphatic capillaries per adventitia area of healthy $(n=6)$ versus early $(n=9)$ and advanced $(\mathrm{n}=6)$ mouse carotid atherosclerotic lesions. ${ }^{* *} P<0.005$.

$\mathrm{CD}^{+} \mathrm{T}$ cells are highly expressed in the adventitia of mouse atherosclerotic lesions and enter the vessel wall via the adventitia in a CXCR3 dependent manner

Concordant with previous observations, ${ }^{9,15}$ we observed that the adventitia of mouse atherosclerotic lesions expresses high numbers of $\mathrm{CD}^{+}{ }^{+} \mathrm{T}$ cells (Figure 2A). In fact, the adventitia contains much more $\mathrm{T}$ cells than the intima. ${ }^{10} \mathrm{~T}$ cell accumulation starts already early on in plaque initiation, while adventitial $T$ cell levels tend to decrease with plaque progression (Figure 2B). This observation fueled the hypothesis that rather than entering the plaque via the luminal endothelium, $\mathrm{CD}^{+} \mathrm{T}$ cells may well invade the atherosclerotic vessel wall via the 
adventitia to contribute to atherosclerosis initiation from that location. To address this question, CMFDA labeled $\mathrm{CD}^{+} \mathrm{T}$ cells were administered via i.v. injection in $\mathrm{ApoE}^{-/-}$mice on western type diet 4 weeks after collar placement. We observed a clear-cut gradient in $\mathrm{CD}^{+} \mathrm{T}$ cell density from the adventitia (high numbers) via the media (intermediate numbers) to the intima (low numbers), in support of the above hypothesis (Figure $\mathbf{2 C}$ ). In search of chemokines that are driving adventitial T cell accumulation, we zoomed in on IP-10, which was seen to be highly expressed in the adventitia (Figure 2D) and by interacting with CXCR3 is a major mediator of $\mathrm{T}$ cell chemotaxis. ${ }^{29}$ To investigate whether $\mathrm{T}$ cell migration towards the adventitia occurred in a CXCR3 dependent manner, we administered a mixture of CMFDA-labeled wild-type and CMTPX-labeled $\mathrm{CXCR}^{-1-} \mathrm{CD}^{+} \mathrm{T}$ cells via i.v. injection into $\mathrm{ApoE}^{-/}$mice on western type diet 4 weeks after collar placement. In contrast to wild-type $\mathrm{T}$ cells, $\mathrm{CXCR}^{-1-} \mathrm{T}$ cell migration towards the adventitia was impaired (Figure 2E), showing that $T$ cell migration into the adventitia is largely CXCR3 dependent.
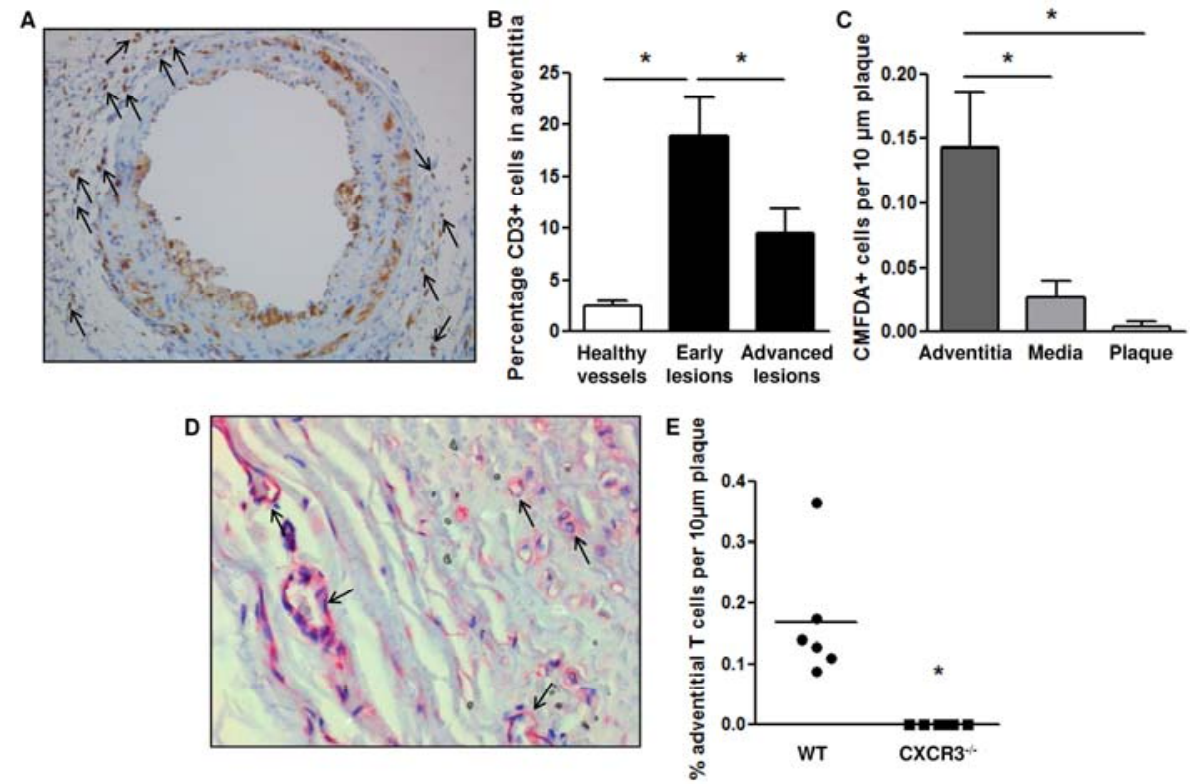

Figure 2. Expression and migration of $\mathrm{CD}^{+} \mathrm{T}$ cells in the adventitia. $\mathrm{A}$, Immunohistochemistry for CD3 in mouse carotid atherosclerotic lesions. Arrows indicate the presence of $\mathrm{CD}^{+} \mathrm{T}$ cells in the adventitia. $\mathrm{B}$, The percentage of $\mathrm{CD}^{+} \mathrm{T}$ cells per adventitia area of healthy vessels $(n=6)$ versus early $(n=9)$ and advanced $(n=6)$ mouse 
carotid atherosclerotic lesions. $C, \mathrm{ApoE}^{-/-}$mice $(n=7)$ were placed on western type diet and received 4 weeks after collar placement $10^{7}$ CMFDA labeled WT $\mathrm{CD}^{+} \mathrm{T}$ cells via i.v. injection. Represented is the number of CMFDA labeled T cells that have migrated 24 hours later into the adventitia, media and plaque. D, Immunohistochemistry for IP-10 in the adventitia of mouse carotid atherosclerotic lesions. Arrows indicate the expression of IP-10 in the adventitia. E, ApoE ${ }^{-/-}$mice $(n=6)$ were placed on western type diet and received 4 weeks after collar placement a 1:1 mixture of $10^{7}$ CMFDA labeled WT and $10^{7}$ CMTPX labeled $\mathrm{CXCR}^{-/-} \mathrm{CD}^{+} \mathrm{T}$ cells via i.v. injection. Represented is the percentage of WT and $\mathrm{CXCR}^{-/}$T cells that have migrated into the adventitia 24 hours later. ${ }^{*} P<0.05$.

\section{Lymph node and lymph vessel dissection deteriorates atherosclerosis development in $\mathrm{ApoE}^{-/}$mice by promoting $\mathrm{T}$ cell accumulation inside the lesion and adventitia}

One of the lymph nodes most proximal to the carotid artery plaque is located at the carotid artery bifurcation, the cervical lymph node. An efferent lymphatic vessel is originating from this lymph node, running parallel to the carotid artery. To address whether lymphatic capillaries in the adventitia are in direct contact with this lymph node, the cervical lymph node and its efferent vessel were removed at point of collar placement in $\mathrm{ApoE}^{-/}$mice on western type diet (Figure 3A). First, we investigated whether lymph node dissection by itself induced local inflammation in the adventitia. The number of $\mathrm{CD} 45^{+}$leukocytes was equal between control mice and mice with lymph node dissection (Figure 3B). In addition, it did not affect circulating monocyte numbers (Figure $\mathbf{3 C}$ ) and spleen and peripheral lymph node $\mathrm{CD}^{+} \mathrm{T}$ cell content (Figure 3D) were unchanged. Lymph node dissection did not affect body weight either $(29.23 \pm 0.48 \mathrm{~g}$ and 27.64 $\pm 0.52 \mathrm{~g}$ in control versus lymph node dissected mice, respectively). To our surprise, lymph node dissection aggravated atherosclerotic plaque development (Figure 3E). Lymph node dissected mice displayed increased adventitial (Figure 3F) and intimal $\mathrm{CD}^{+} \mathrm{T}$ cell content (Figure 3G) Plaque macrophage content remained unaltered (Figure $\mathbf{3 H}$ ). Removal of the draining lymph node did not affect the number of lymphatic capillaries in the adventitia (Figure 31). Altogether, these data point to a protective role of adventitial lymphatic capillaries in atherosclerosis development, possibly by draining $\mathrm{T}$ cells and/or $\mathrm{T}$ cell activating 
cytokines from the plaque and thereby dampening inflammation in the vessel wall.

A

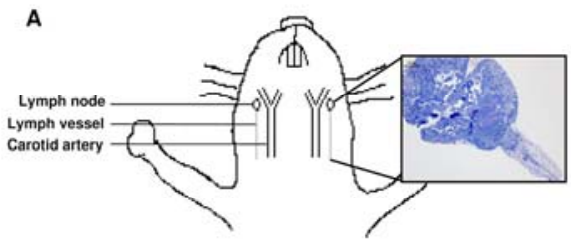

C
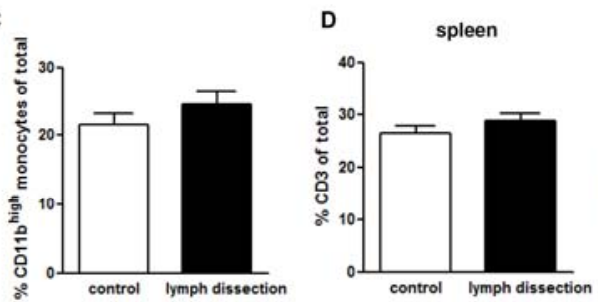

B

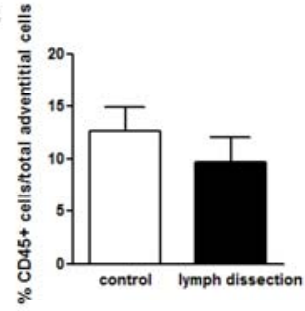

Lymph node

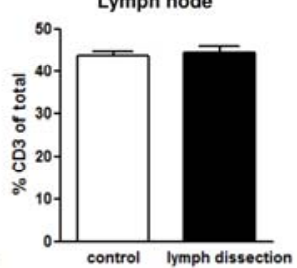

control lymph dissection
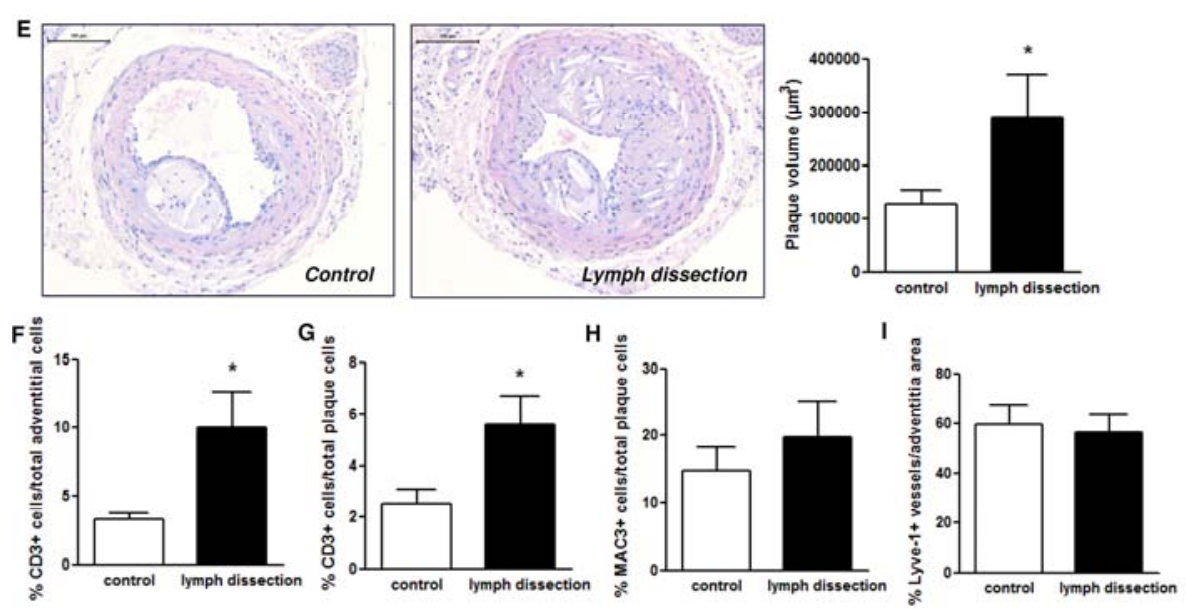

Figure 3. Lymph node dissection results in an aggravation of plaque development in mice, characterized by an accumulation of $\mathrm{CD3}^{+} \mathrm{T}$ cells within the vessel wall. A, Draining lymph node and efferent vessel were excised in the lymph node dissection group. B, Lymph node dissection by itself did not induce inflammation in the vessel wall. Represented is the percentage of $C D 45^{+}$leukocytes in the adventitia of control $(n=6)$ and lymph node dissected $(n=5)$ WT mice. C, Flow cytometry analysis for $C D 11 b^{\text {high }}$ monocytes in blood. D. Flow cytometry analysis for $\mathrm{CD}^{+} \mathrm{T}$ cells in spleen and peripheral lymph nodes. $\mathrm{E}, \mathrm{ApoE}^{-/-}$mice were placed on western type diet. At point of collar placement the draining lymph node was dissected ( $n=13$ control versus $n=14$ lymph node dissection). Mice were 


\section{Chapter 7}

sacrificed 4 weeks later. Right carotid artery was stained with haematoxylin/eosin to analyze the extent of atherosclerosis (plaque volume, $\mu \mathrm{m}^{3}$ ). F, Effects of lymph node dissection on the percentage of $\mathrm{CD}^{+} \mathrm{T}$ cells in the adventitia and $\mathbf{G}$, plaque. $\mathbf{H}$, The relative plaque Mac $-3^{+}$macrophage abundance. I, Percentage of lyve- $1^{+}$lymphatic capillaries per adventitia area. ${ }^{*} P<0.05$.

\section{Adventitial lymphangiogenesis is regulated by IP-10}

As previously described, IP-10, a major T cell chemoattractant, is highly expressed in mouse and human atherosclerotic lesions and its expression increases with plaque progression in humans (Figure 4A). Interestingly, IP-10 has also been attributed anti-angiogenic activity. ${ }^{30,31}$ This dual function prompted us to study whether the progressively increasing plaque IP-10 expression not only affects T cell influx, but also can be held accountable for the halted (lymph)angiogenic response at later stages of plaque development. To this end we have focally overexpressed IP-10 antagonist (IP-10AT) by perivascular administration of a pluronic gel containing lentiviral IP-10AT. Adventitial cells were transfected efficiently (Figure 4B). Compatible with its anti-(lymph)angiogenic activity, local IP-10 inhibition let to a significant increase in the number of lymphatic capillaries in the adventitia (Figure $4 \mathrm{C}$ ) but did not affect the arterial capillary bed, the vasa vasorum (Figure 4D). As expected, IP-10AT overexpression almost ablated plaque $\mathrm{CD}^{+}$(Figure 4E), as well as $\mathrm{CXCR}^{+} \mathrm{T}$ cell numbers (Figure 4F). However, $\mathrm{CD}^{+} \mathrm{T}$ cell numbers in adventitia, the actual site of overexpression, were unchanged (Figure 4G). 

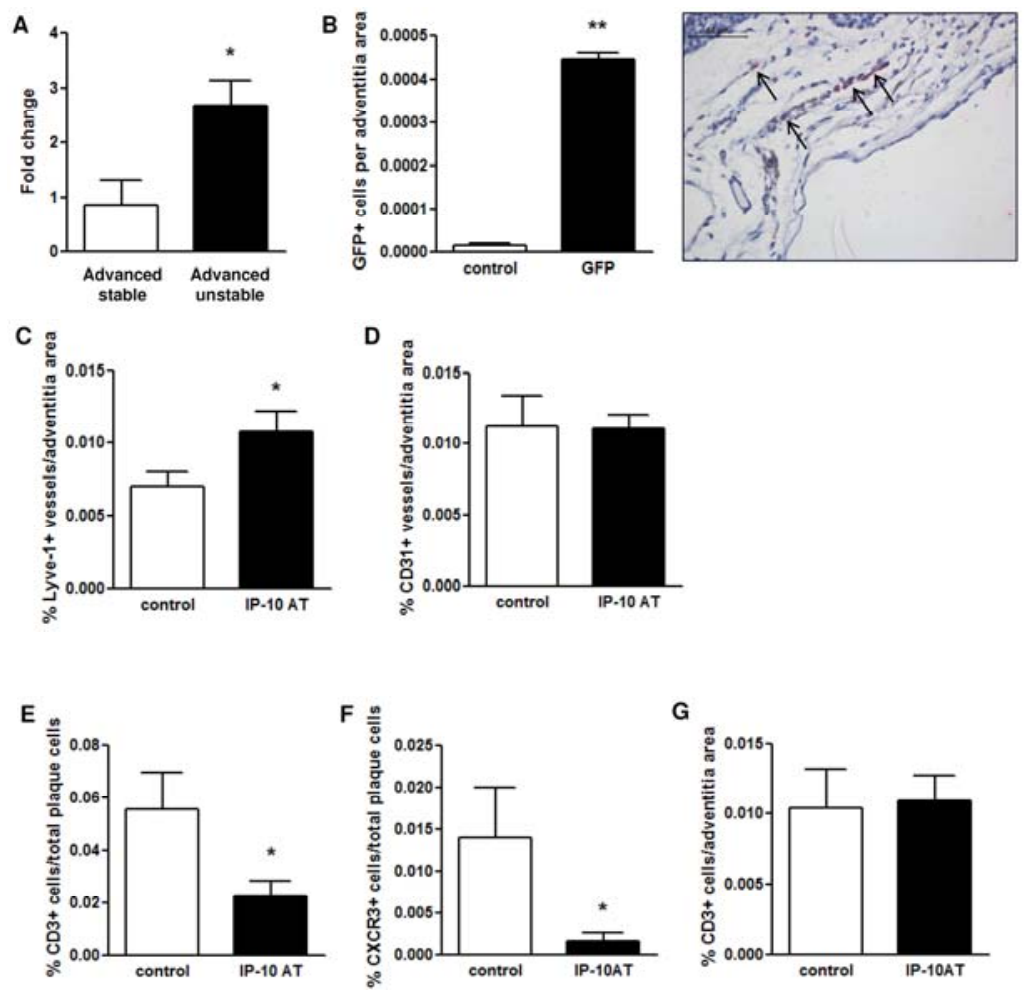

Figure 4. The development of adventitial lymphatic capillaries is regulated by IP-10. A. Real-time PCR analysis of human stable $(n=9)$ and unstable $(n=13)$ advanced carotid atherosclerotic lesions. B. ApoE ${ }^{-/-}$mice were placed on western type diet and were administered perivascularly an IP-10 antagonist (IP-10AT) at the same time of collar placement via a pluronic gel ( $n=10 /$ group). Mice were sacrificed 4 weeks later. Represented is the number of Green Fluorescent Protein (GFP) ${ }^{+}$cells per adventitia area in control versus IP-10AT/GFP mice. C. Percentage of lyve- $1^{+}$lymphatic capillaries per adventitia area. D. Percentage of $\mathrm{CD} 1^{+}$arterial capillaries (=vasa vasorum) per adventitia area. E. Percentage of $\mathrm{CD}^{+}$cells per total plaque cells. F. Percentage of $\mathrm{CXCR}^{+}$cells per total plaque cells. G. Percentage of $\mathrm{CD}^{+} \mathrm{T}$ cells per adventitia area. ${ }^{*} P<0.05,{ }^{* *} P<0.005$. 


\section{Discussion}

In this study, we are the first to describe a role for adventitial lymphatic capillaries in plaque inflammation and atherosclerosis in mice. We show that the adventitial lymphatic capillary bed is expanded early on in the atherogenic process, concomitantly with the increase in plaque $\mathrm{CD}^{+} \mathrm{T}$ cell content. Combined dissection of the plaque draining lymph node and its efferent lymphatic vessel prior to the atherogenic stimulus resulted in an aggravation of atherosclerosis development, at which lesions were characterized by increased $T$ cell accumulation in plaque and adventitia. $\mathrm{CD}^{+} \mathrm{T}$ cells were found to enter the atherosclerotic vessel wall in a CXCR3 dependent manner, mainly via the adventitia. Adventitial blockage of CXCR3 signaling with an IP-10 antagonist resulted in expansion of adventitial lymphatic capillaries and to decreased plaque T cell content.

A first intriguing finding was that during atherosclerosis in $\mathrm{ApoE}^{-/-}$mice the adventitial lymphatic capillary bed is massively expanded, already at very early stages of disease development. These data correspond with previous findings in humans in which the lymphatic capillary content of carotid artery plaques was seen to increase with severity of atherosclerosis. ${ }^{22}$ Although the exact trigger for adventitial lymphangiogenesis during atherosclerosis remains to be established, it is conceivable that it is related to the augmented production of growth factors such as, Vascular Endothelial Growth Factors (VEGFs), and pro-lymphangiogenic cytokines/chemokines in the inflamed plaque and adventitia. ${ }^{32}$ VEGF expression in the atherosclerotic vessel wall has been documented in several studies and their overexpression was shown to accelerate atherosclerosis by inducing monocyte activation, adhesion and migration and by enhancing vascular permeability. ${ }^{33-35}$ In a rabbit model of atherosclerosis, adventitial delivery of adenoviruses encoding VEGF-A, VEGF-D and VEGF-D $\Delta N \Delta C$ resulted in increased atherosclerosis development. ${ }^{36}$ Moreover, adventitial gene transfer via an adenovirus encoding VEGF-E resulted in an increase in neointimal formation in rabbits. ${ }^{37}$ VEGF-E chimera transduced arteries were characterized by an increase in proliferating cells and adventitial angiogenesis, suggestive of a role of the VEGFR-2/VEGF-E pathway in intimal hyperplasia. In addition to VEGFs, various chemokines have been shown to regulate lymphangiogenesis. CCL21, which is expressed in the adventitia, and its receptor CCR7 were both reported to be involved in the 
induction of lymphangiogenesis. ${ }^{38} \mathrm{~A}$ similar regulatory role in lymphangiogenesis was proposed for the CXCL13/CXCR5 axis. ${ }^{39}$ Altogether, these data suggest that adventitial lymphangiogenesis is induced in response to inflammation.

As a next question, we sought to explore the role of adventitial lymphatic capillaries in atherosclerosis. Given the role of lymphatic vessels in dendritic cell trafficking to the draining lymph node to activate $T$ cells, we hypothesized that removal of the draining lymph node might result in impaired T cell activation and consequently reduced plaque inflammation. Surprisingly, removal of the putative plaque draining lymph node located proximal to the carotid artery bifurcation, resulted in an aggravation, not diminishment, of atherosclerosis, featured by $\mathrm{CD}^{+}$ $T$ cell accumulation in plaque and adventitia. These data suggest that the lymphatic capillaries in the adventitia are in contact with this lymph node, are involved in drainage of $T$ cells, and thus play a role in the regulation of inflammation in the vessel wall. In addition to $T$ cells, adventitial lymphatic capillaries could also help to prevent edema, inflicted by the leaky plaque, drain plaque cytokines and in this way regulate inflammatory responses, and mediate efflux of lipid particles, be it leukocyte ingested or in lymph from the plaque in analogy to its role in chylomicron transport. ${ }^{40}$

The adventitia has previously been proposed to constitute an important gateway for leukocytes to the plaque, a notion referred to as the "outside-in" hypothesis. ${ }^{9}$ This hypothesis was supported by findings by Ley and co-workers that $T$ cells can enter atherosclerotic lesions via the adventitia in a L-selectin dependent manner. ${ }^{16}$ In addition, Eriksson and co-workers further substantiate this finding by demonstrating that leukocytes enter the plaque in a L- and Pselectin dependent manner via microvessels sprouting from the adventitia. ${ }^{41}$ Our data show that a sizable portion of $\mathrm{T}$ cells enter the atherosclerotic vessel wall via the adventitia. In fact, T cells migrate primarily to the adventitia, then the media and to a lesser extent to the intima. Moreover, we show that $\mathrm{T}$ cell influx into the adventitia is CXCR3 dependent. The CXCR3 pathway has been implicated in T cell chemotaxis and atherosclerosis before. The main chemokine to activate CXCR3 and attract activated T cells, Interferon Inducible Protein-10 (IP-10), is secreted by activated T cells, fibroblasts and endothelial cells. ${ }^{42-44}$ We show that IP-10 is highly expressed in the adventitia of atherosclerotic vessels. Next to its role in T cell chemotaxis, IP-10 was also attributed potent anti-angiogenic activity. ${ }^{30,45}$ Our 
study shows that adventitial blockage of IP-10 results in augmented lymphatic capillary density in the adventitia which was accompanied by decreased plaque $\mathrm{CD}^{+} \mathrm{CXCR3}^{+} \mathrm{T}$ cell presence, further supporting our previous findings that lymphatic capillary density is correlated with $T$ cell drainage to and from the plaque. The number of vasa vasora in the adventitia was unaffected, suggesting that IP-10 specifically inhibits lymphangiogenesis in the adventitia. Interestingly, the increase in adventitial lymphatic capillaries only affected T cell numbers in the plaque as T cell numbers in the adventitia were unaltered. In addition, the extent of atherosclerosis was unaffected as well (data not shown). This could be explained by the fact that in these mice the IP-10 chemotaxis gradient is impaired resulting in decreased migration of $T$ cells from the adventitia to the plaque, and as a consequent accumulation of $\mathrm{T}$ cells in the adventitia.

In conclusion, this study shows that adventitial lymphangiogenesis increases with plaque development. Draining lymph node dissection resulted in an unexpected aggravation of atherosclerosis, accompanied by increased plaque and adventitial $T$ cell content, probably due to disturbed drainage of $T$ cells. Lymphangiogenesis in the adventitia was shown to be regulated by IP-10 and be involved in T cell drainage. Further studies will have to give more insight into the role of adventitial lymphatic capillaries in atherosclerosis. 


\section{References}

1. Woollard KJ, Geissmann F. Monocytes in atherosclerosis: subsets and functions. Nature Reviews Cardiology. 2010;7:77-86.

2. Gautier EL, Jakubzick C, Randolph GJ. Regulation of the migration and survival of monocyte subsets by chemokine receptors and its relevance to atherosclerosis. Arterioscler Thromb Vasc Biol. 2009;29:1412-1418.

3. Tacke F, Alvarez D, Kaplan TJ, Jakubzick C, Spanbroek R, Llodra J, Garin A, Liu J, Mack M, van Rooijen N, Lira SA, Habenicht AJ, Randolph GJ. Monocyte subsets differentially employ CCR2, CCR5 and CX3CR1 to accumulate within atherosclerotic plaques. J Clin Invest. 2007;117:185-94.

4. Zhou X, Robertson AK, Hjerpe C, Hansson GK. Adoptive transfer of CD4+ T cells reactive to modified low-density lipoprotein aggravates atherosclerosis. Arterioscler Thromb Vasc Biol. 2006;26:864-870.

5. Weber C, Meiler S, Döring Y, Koch M, Drechsler M, Megens R, Rowinska Z, Bidzhekov K, Fecher C, Ribechini E, van Zandvoort M, Binder C, Jelinek I, Hristov M, Boon L, Jung $S$, Korn $T$, Lutz $M$, Förster I, Zenke $M$, Hieronymus $T$, Junt $T$, Zernecke A. CCL17expressing dendritic cells drive atherosclerosis by restraining regulatory $\mathrm{T}$ cell homeostasis in mice. J Clin Invest. 2011;121:2898-2910.

6. Wilcox JN, Scott NA. Potential role of the adventitia in arteritis and atherosclerosis. Int J Cardiol. 1996;54:S21-35.

7. Higuchi ML, Gutierrez PS, Bezerra HG, Palomino SA, Aiello VD, Silvestre JM, Libby P, Ramires JA. Comparison between adventitial and intimal inflammation of ruptured and nonruptured atherosclerotic plaques in human coronary arteries. Ar Qbras Cardiol. 2002;79:20-24.

8. Houtkamp MA, de Boer OJ, van der Loos CM, van der Wal AC, Becker AE. Adventitial infiltrates associated with advanced atherosclerotic plaques: structural organization suggests generation of local humoral immune responses. J Pathol. 2001;193:263269.

9. Maiellaro K, Taylor WR. The role of the adventitia in vascular inflammation. Cardiovasc Res. 2007;75:640-648. Review.

10. Moos MP, John N, Gräbner R, Nossmann S, Günther B, Vollandt R, Funk CD, Kaiser B, Habenicht AJ. The lamina adventitia is the major site of immune cell accumulation in standard chow-fed apolipoprotein E-deficient mice. Arterioscler Thromb Vasc Biol. 2005;25:2386-2391.

11. Kyaw T, Tipping $P$, Toh BH, Bobik A. Current understanding of the role of $B$ cell subsets and intimal and adventitial B cells in atherosclerosis. Curr Opin Lipidol. 2011;22:373-379. Review. 
12. Ait-Oufella H, Herbin O, Bouaziz JD, Binder CJ, Uyttenhove C, Laurans L, Taleb S, Van Vré E, Esposito B, Villar J, Sirvent J, Van Snick J, Tedgui A, Tedder TF, Mallat Z. B cell depletion reduces the development of atherosclerosis in mice. J Exp Med. 2010;207:1579-1587.

13. Major AS, Fazio S, Linton MF. B-lymphocyte deficiency increases atherosclerosis in LDL receptor-null mice. Arterioscler Thromb Vasc Biol. 2002;22:1892-1898.

14. Caligiuri G, Nicoletti A, Poirier B, Hansson GK. Protective immunity against atherosclerosis carried by $\mathrm{B}$ cells of hypercholesterolemic mice. J Clin Invest. 2002;109:745-753.

15. Zhao L, Moos MP, Gräbner R, Pedrono F, Fan J, Kaiser B, John N, Schmidt S, Spanbroek R, Lotzer K, Huang L, Ciu J, Rader DJ, Evans JF, Habenicht AJ, Funk CD. The 5-lipoxygenase pathway promotes pathogenesis of hyperlipidemia-dependent aortic aneurysm. Nat Med. 2004;10:966-973.

16. Galkina E, Kadl A, Sanders J, Varughese D, Sarembock U, Ley K. Lymphocyte recruitment into the aortic wall before and during development of atherosclerosis is partially L-selectin dependent. J Exp Med. 2006;203:1273-1282.

17. De Boer OJ, van der Meer JJ, Teeling P, van der Loos CM, van der Wal AC. Low numbers of Foxp3 positive regulatory $T$ cells are present in all developmental stages of human atherosclerotic lesions. PLOS ONE. 2007;2:e779.

18. Bot $I$, De Jager SC, Bot $M$, van Heiningen $S H$, de Groot $P$, Veldhuizen RW, van Berkel TJ, von der Thüsen JH, Biessen EA. The neuropeptide substance $P$ mediates adventitial mast cell activation and induces intraplaque hemorrhage in advanced atherosclerosis. Circ Res. 2010;106:89-92.

19. Kwon HM, Sangiorgi G, Ritman EL, McKenna C, Holmes DR, Schwartz RS, Lerman A. Enhanced coronary vasa vasorum neovascularization in experimental hypercholesterolemia. J Clin Invest. 1998;101:1551-1556.

20. Langheinrich AC, Michniewicz A, Bohle RM, Ritman EL. Vasa vasorum neovascularization and lesion distribution among different vascular beds in ApoE-//LDL-/- double knockout mice. Atherosclerosis. 2007;191:73-81.

21. Nakano T, Nakashima $Y$, Yonemitsu $Y$, Sumiyoshi S, Chen $Y X$, Akishima $Y$, Ishii T, lida $M$, Sueishi K. Angiogenesis and lymphangiogenesis and expression of lymphangiogenic factors in the atherosclerotic intima of human coronary arteries. Hum Pathol. 2005;36:330-340.

22. Drożdż K, Janczak D, Dzięgiel P, Podhorska M, Patrzałek D, Ziołkowski P, Andrzejak R, Szuba A. Adventitial lymphatics of internal carotid artery in healthy and atherosclerotic vessels. Folia Histochemica et cytobiologica. 2008;46:433-436. 
23. Von der Thüsen J, Van Berkel T, Biessen EAL. Induction of rapid atherogenesis by perivascular carotid collar placement in apolipoprotein E-deficient and low-density lipoprotein receptor-deficient mice. Circulation. 2001;103:1164-1170.

24. Hancock WW, Lu B, Gao W, Csizmadia V, Faia K, King JA, Smiley ST, Ling M, Gerard NP, Gerard C. Requirement of the chemokine receptor CXCR3 for acute allograft rejection. J Exp Med. 2000;192:1515-1519.

25. Hasegawa $H$, Inoue A, Kohno $M$, Muraoka M, Miyazaki T, Terada M, Nakayama T, Yoshie 0 , Nose M, Yasukawa M. Antagonist of interferon-inducible protein 10/CXCL10 ameliorates the progression of autoimmune sialadenitis in MRL/lpr mice. Arthritis Rheum. 2006;54:1174-1183.

26. Sastry L, Johnson T, Hobson MJ, Smucker B, Cornetta K. Titering lentiviral vectors:comparison of DNA, RNA and marker expression methods. Gene Therapy. 2002;9:1155-1162.

27. Lutgens E, Gorelik L, Daemen M, De Muinck E, Grewal I, Koteliansky V, Flavell R. Requirement for CD154 in the progression of atherosclerosis. Nat Med. 1999;5:13131316.

28. Virmani R, Kolodgie FD, Burk AP, Farb A, Schwartz SM. Lessons from sudden coronary death: a comprehensive morphological classification scheme for atherosclerotic lesions. Arterioscler Thromb Vasc Biol. 2000;20:1262-1275.

29. Taub DD, Lloyd AR, Conlon K, Wang JM, Ortaldo JR, Harada A, Matsushima K, Kelvin DJ, Oppenheim JJ. Recombinant human interferon-inducible protein 10 is a chemoattractant for human monocytes and $\mathrm{T}$ lymphocytes and promotes $\mathrm{T}$ cell adhesion to endothelial cells. J Exp Med. 1993;177:1809-1814.

30. Angiolillo AL, Sgadari C, Taub DD, Liao F, Farber JM, Maheshwari S, Kleinman HK, Reaman GH, Tosato G. Human interferon-inducible protein 10 is a potent inhibitor of angiogenesis in vivo. J Exp Med. 1995;182:155-162.

31. Luster AD, Greenberg SM, Leder P. The IP-10 chemokine binds to a specific cell surface heparan sulfate site shared with platelet factor 4 and inhibits endothelial cell proliferation. J Exp Med. 1995;182:219-231.

32. Xu X, Lu H, Lin H, Ni M, Sun H, Li C, Jiang H, Li F, Zhao Y, Zhang M, Zhang $Y$. Lymphangiogenesis promotes inflammation and neointimal hyperplasia after adventitia removal in the rat carotid artery. Int J Cardiol. 2009;134:426-427.

33. Barleon B, Sozzani S, Zhou D, Weich HA, Mantovani A, Marme D. Migration of human monocytes in response to vascular endothelial growth factor (VEGF) is mediated via the VEFG receptor flt-1. Blood. 1996;87:3336-3343.

34. Clauss M, Weich H, Breier G, Knies U, RockI W, Waltenberger J, Risau W. The vascular endothelial growth factor Flt-1 mediates biological activities. Implications for a 
functional role of placenta growth factor in monocyte activation and chemotaxis. $J$ Biol Chem. 1996;271:17629-17634.

35. Collins PD, Connolly DT, Williams TJ. Characterization of the increase in vascular permeability induced by vascular permeability factor in vivo. $\mathrm{Br} J$ Pharmacol. 1993;109:195-199.

36. Bhardwaj S, Roy $H$, Heikura T, Ylä-Herttuala S. VEGF-A, VEGF-D and VEGF-D ${ }^{\Delta N \Delta C}$ induced intimal hyperplasia in carotid arteries. Eur J Clin Invest. 2005;35:669-676.

37. Bhardwaj S, Roy H, Babu M, Shibuya M, Ylä-Herttuala S. Adventitial gene transfer of VEGFR-2 specific VEGF-E chimera induces MCP-1 expression in vascular smooth muscle cells and enhances neointimal formation. Atherosclerosis. 2011. In press.

38. Gräbner R, Lötzer K, Döpping S, Hildner M, Radke D, Beer M, Spanbroek R, Lippert B, Reardon CA, Getz GS, Fu YX, Hehlgans T, Mebius RE, van der Wall M, Kruspe D, Englert C, Lovas A, Hu D, Randolph GJ, Weih F, Habenicht AJR. Lymphotoxin â receptor signaling promotes tertiary lymphoid organogenesis in the aorta adventitia of aged ApoE ${ }^{-/-}$mice. J Exp Med. 2009;206:233-248.

39. Müller G, Lipp M. Concerted action of the chemokine and lymphotoxin system in secondary lymphoid-organ development. Curr Opin Immunol. 2003;15:217-224.

40. Ockner RK, Hughes FB, Isselbacher KJ. Very low density lipoproteins in intestinal lymph: origin, composition, and role in lipid transport in the fasting state. J Clin Invest. 1969;48:2079-2088.

41. Eriksson EE. Intravital microscopy on atherosclerosis in apolipoprotein E-deficient mice establishes microvessels as major entry pathways for leukocytes to advanced lesions. Circulation. 2011;124:2129-2138.

42. Farber JM. Mig and IP-10: CXC chemokines that target lymphocytes. J Leukoc Biol. 1997;61:246-257.

43. Taub DD, Lloyd AR, Conlon K, Wang JM, Ortaldo JR, Harada A, Matsushima K, Kelvin DJ, Oppenheim JJ. Recombinant human interferon-inducible protein 10 is a chemoattractant for human monocytes and T lymphocytes and promotes $\mathrm{T}$ cell adhesion to endothelial cells. J Exp Med. 1993;177:1809:1814.

44. Loetscher M, Loetscher P, Brass N, Meese E, Moser B. Lymphocyte-specific chemokine receptor CXCR3: regulation, chemokine binding and gene localization. Eur J Immunol. 1998;28:3696-3705.

45. Angiolillo AL, Sgadari C, Tosato G. A role for the interferon inducible protein 10 in inhibition of angiogenesis by interleukin-12. NY Acad Sci. 1996;796:158-167. 

Chapter 8

Discussion 


\section{General Discussion and Future Perspectives}

Much attention has been paid so far to processes in the plaque that contribute to the pathogenesis of atherosclerosis. However, evidence is mounting that local processes may be not completely self-contained but rather reflective of or modulated by peripheral phenomena. Lymphoid organs have been shown to play a key role in the development of atherosclerosis by representing the site of T cell activation and antibody production. ${ }^{1-3}$ Even stromal processes have been shown to affect immune responses in the plaque. ${ }^{4-7}$ The main goal of the studies presented in this thesis was to explore the impact of peripheral and extravascular events on local processes within the plaque. In the first part of this thesis we interrogated two homeostatic chemokines for their impact on peripheral immunity and how the latter will affect local immune responses in the plaque, CXCR4 and CXCR5. In one study we investigated how neutrophil CXCR4 expression controls their activity and half-life in the periphery and stromal tissue and how this affects atherosclerosis. In a second study we addressed the role of CXCL13 and its receptor, CXCR5, in T/B cell trafficking in the lymphoid compartment and the implications hereof for atherosclerosis. In the second part of this thesis, we sought to investigate how extravascular tissue can control local immune responses in the plaque. One target that caught our attention were plasmacytoid dendritic cells ( $p D C s)$, which are almost completely absent in atherosclerotic lesions. We have studied their role in atherosclerosis development and progression. In addition, we addressed the role of adventitial lymphatic capillaries on $\mathrm{T}$ cell trafficking to the atherosclerotic lesion and on plaque inflammation.

\section{Part I: Chemokines and extravascular immunity in atherosclerosis}

\section{CXCR4 blockage aggravates atherosclerosis by increasing neutrophil activity and survival}

Neutrophils are present in atherosclerotic lesions and have been associated with atherosclerosis development and destabilization. ${ }^{7-9}$ Under homeostatic conditions, neutrophils are retained within bone marrow via the expression of CXCR4 which interacts with its ligand, CXCL12, which is highly expressed in bone marrow. ${ }^{10,11}$ During inflammation associated maturation, neutrophils down 
regulate CXCR4 expression, are released from bone marrow into circulation, and migrate towards inflamed tissue mainly via CXCR2. Neutrophils are very shortlived, with a half-life of only $6,5 \mathrm{~h}$. Neutrophils that have not migrated towards inflamed tissue will up regulate CXCR4 expression and regress to the bone marrow where they will undergo apoptosis. These regressing cells are called senescent or aged neutrophils. ${ }^{12}$ In collaboration with Prof. Weber's group we have shown that inhibition of CXCR4 resulted in increased mobilization of neutrophils from bone marrow into circulation, resulting in increased neutrophil infiltration into atherosclerotic lesions. ${ }^{7}$ In Chapter 3, we extend these findings demonstrating that neutrophils which lack functional CXCR4 show increased cell survival as shown by reduced apoptosis and elevated expression of cell survival factor Akt. Moreover, activity of these neutrophils was increased as shown by elevated production of Reactive Oxygen Species and increased adhesive capacity. Our new data demonstrate that CXCR4 dysfunction leads to an increase of neutrophil halflife, senescence and activation, which promotes neutrophil adhesion to plaque endothelium, and in this way aggravates atherosclerosis in mice. In an attempt to extrapolate these findings to the human situation, we found that patients with acute cardiovascular disease showed decreased expression of CXCR4 on circulating neutrophils, suggesting that neutrophils in atherosclerotic patients have an increased adhesive activity and half-life.

Altogether, these findings illustrate the importance of functional CXCR4 expression by neutrophils to avoid uncontrolled inflammation and raise a note of caution regarding the use of pharmaceutical CXCR4 inhibitors like Plerixafor (AMD3100, Mozobil ${ }^{\mathrm{TM}}$ ) and AMD3465 in patients with $\mathrm{HIV}^{13,14}$ and cancer ${ }^{15-17}$, as it may be accompanied by undesired effects on atherosclerosis. In addition, our findings suggest that decreased CXCR4 expression levels on neutrophils might have value as prognostic biomarker to identify patients at risk for plaque destabilization or rupture. Increasing CXCR4 expression in vivo would not be beneficial as neutrophil release from bone marrow would be hampered. 


\section{The CXCL13/CXCR5 axis is implicated in atherogenesis by controlling monocyte/granulocyte homeostasis}

Next, we investigated the role of another chemokine, CXCL13, in atherosclerosis. CXCL13 is a homeostatic chemokine constitutively expressed by lymphoid tissue and is involved in T/B cell trafficking. ${ }^{18}$ In Chapter 4, we show that patients with atherosclerosis have increased plasma levels of CXCL13. In addition, CXCL13 was found to be highly expressed in human atherosclerotic lesions by plaque macrophages and vascular smooth muscle cells. This observation led us to investigate first the local effects of CXCL13 in atherosclerosis. In vitro analysis revealed that CXCL13 exerts anti-apoptotic effects on monocytes and vascular smooth muscle cells, suggesting a plaque stabilizing effect for CXCL13.

Next, we investigated extravascular effects of CXCL13. As we observed that CXCL13 is highly expressed in the adventitia of atherosclerotic lesions, we hypothesized that the CXCL13/CXCR5 dyad might be involved in regulating T/B cell homing to the atherosclerotic vessel wall. In Chapter $\mathbf{5}$ we show that hematopoietic deficiency of CXCR5 and CXCL13 in mice attenuates atherosclerosis development. However, homing of lymphocytes towards the vessel wall was not affected, neither were $B$ cell responses. Instead, effects seen on plaque development were found to be elicited by changes in monocyte/granulocyte homeostasis. Both hypercholesterolemic and normolipidemic mice lacking CXCL13 or CXCR5 expression showed decreased levels of circulating and splenic proinflammatory Ly6C $\mathrm{C}^{\text {high }}$ monocytes and granulocytes. Although plasma levels of $\mathrm{M}$ CSF and G-CSF were decreased, there was no effect on myeloid development, neither on monocyte/granulocyte mobilization from bone marrow into circulation, suggesting that the effects seen on monocyte/granulocyte homeostasis were attributable to effects on monocyte/granulocyte survival. This finding is in support with our previous findings in Chapter 4 in which CXCL13 was shown to exert anti-apoptotic effects on human primary monocytes.

Our findings thus suggest that the CXCL13/CXCR5 dyad is involved in monocyte/granulocyte survival. CXCL13 has been shown to induce B cell survival through inactivation of the pro-apoptotic transcription factor FOXO3a in B cell chronic lymphocytic leukemia. ${ }^{19} \mathrm{CXCL13}$ has also been shown to induce $\mathrm{T}$ cell survival. $^{20}$ Moreover, CXCR5 signaling leads to activation of the PI3K/AKT pathway, which is a key regulator of cell survival. ${ }^{21}$ In addition, the decreased M- 
CSF plasma levels that we observed in the CXCL13 and CXCR5 deficient mice could also point to a role for cell survival as M-CSF has been shown to promote monocyte survival. ${ }^{22}$ Our findings thus implicate that the CXCL13/CXCR5 dyad has a broader role than just regulating $T / B$ cell trafficking to secondary lymphoid tissue and that the local plaque stabilizing effects of CXCL13 and CXCR5 seem to be overruled by their peripheral effects which promote atherosclerosis. There is increasing interest for the development of CXCL13 and CXCR5 antagonists in the treatment of patients with asthma, ${ }^{23}$ rheumatoid arthritis, ${ }^{24}$ and systemic lupus erythematosus ${ }^{25}$ in which CXCL13 and CXCR5 have been shown to play a key role. Our findings implicate that these antagonists should be used with caution as they might disturb monocyte/granulocyte homeostasis. Further study will have to confirm whether the CXCL13/CXCR5 dyad indeed is involved in myeloid survival. A closer assessment of the apoptosis rate with wild-type and CXCR5 deficient monocytes, in the presence and absence of CXCL13, and measurement of the expression level of apoptotic genes and cell survival factors will be revealing.

\section{Part II: The impact of leukocyte subsets in extravascular tissue on atherosclerosis}

\section{Plasmacytoid dendritic cells protect against atherosclerosis by peripheral suppression of $\mathrm{T}$ cell responses}

In the second part of this thesis we investigated how leukocytes can regulate immune responses in the plaque from extravascular tissue. In Chapter 6 we demonstrated that pDCs protect against atherosclerosis in mice. Depletion of pDCs resulted in increased $T$ cell proliferation and activity, leading to $T$ cell infiltration into atherosclerotic lesions. Moreover, we provided evidence for a mechanism by which $\mathrm{pDC}$ suppress $\mathrm{T}$ cell responses. We found that $\mathrm{pDC}$ suppress $T$ cell proliferation in an indoleamine 2,3-dioxygenase (IDO) dependent manner. Given the almost complete absence of pDCs in human and especially mouse atherosclerotic lesions, we propose that pDC most likely exert their atheroprotective effect extravascularly, in lymphoid tissue given their effect on $T$ cell regulation. PDCs could also exert their function from the thymus as they have 
been shown to be present in the thymus. ${ }^{26}$ Moreover, the thymus is the major site for $T$ cell maturation and proliferation.

Our observations challenge previous findings of Weyand et al. suggesting that pDCs induce plaque destabilization via the release of interferon- $\alpha$ (IFN- $\alpha$ ), resulting in an up regulation of tumor necrosis factor-related apoptosis-inducing ligand (TRAIL) expression on $\mathrm{CD}^{+} \mathrm{T}$ cells, thereby promoting vascular smooth muscle cell and endothelial cell apoptosis and consequently thinning of the fibrous cap. ${ }^{27}$ PDCs indeed have been shown to release high levels of IFN- $\alpha$ but mainly in response to viral and bacterial antigens. ${ }^{28}$ In addition, pDCs release IFN$\alpha$ in response to neutrophil extracellular traps (NETs) ${ }^{29}$ and DNA/LL-37 complexes. ${ }^{30}$ Hence, it is conceivable that advanced plaque constituents, such as cellular debris associated DNA released by necrotic cells, and possibly complexed by anti-bacteriocide proteins and pro-oxidant milieu, has the capacity to activate pDCs in a toll-like receptor dependent fashion. ${ }^{31}$ However, as we have shown, pDCs are almost completely absent in human and especially in mouse atherosclerotic lesions, rendering it very unlikely that they are responsible for IFN$\alpha$ release in the plaque. Moreover, no co-localization of pDCs with IFN- $\alpha$ in human atherosclerotic lesions has been demonstrated so far. Thus, pDCs probably regulate immune responses from the periphery.

By nature, (immature) pDCs are regulatory or tolerogenic $\mathrm{DCs}^{32,33}$ and are induced to act immunogenic (mature pDCs) upon toll-like receptor (TLR) 7 and 9 stimulation, resulting in the release of high levels of IFN- $\alpha$. Lymphoid pDCs isolated from non-atherosclerotic and atherosclerotic mice did not find any difference in IFN- $\alpha$ expression. Also in humans, there was no difference in IFN- $\alpha$ expression by $\mathrm{pDC}$ isolated from healthy controls and carotid endarterectomy patients, excluding that peripheral pDCs have been triggered to release high levels of potentially pro-atherogenic IFN- $\alpha$. Instead, we found that pDCs isolated from atherosclerotic mice expressed higher levels of tolerogenic molecules indoleamine 2,3-dioxygenase and programmed death-ligand 1 compared to pDCs isolated from non-atherosclerotic mice. These observations are in line with previous findings in chronic inflammatory diseases in which pDCs were shown to induce immune tolerance via the release of tolerogenic molecules. ${ }^{34-36}$ During chronic low-grade inflammation and autoimmunity, co-stimulatory molecules such as CD200, CTLA-4 and B7-1 were suggested to induce the release of tolerogenic molecules by 
pDCs. ${ }^{37,38}$ The exact trigger for increased tolerogenic pDC activity during atherosclerosis remains to be established. Therefore, it would be interesting to compare protein expression profile of thymus and lymph nodes from atherosclerotic and non-atherosclerotic mice and test the ability of differentially expressed proteins to induce pDC tolerogenicity.

Importantly, it should be noted that our findings apply to conditions of stable disease and/or low-grade inflammation. During acute events such as intraplaque hemorrhage or plaque rupture, it may well be that pDCs act immunogenic in response to changes in their environment as pDCs are very plastic cells. Given the almost complete absence of pDCs in ruptured and intraplaque hemorrhaged human atherosclerotic lesions, they most likely will exert their immunogenic function from extravascular tissue as well, like tolerogenic pDCs. The exact trigger for pDC immunogenicity in extravascular tissue remains to be established. Whether or not pDCs exert their tolerogenic and immunogenic activity in an epitope specific fashion, also during atherosclerosis, remains elusive at this point.

In conclusion, our studies have identified pDCs as an interesting new therapeutic target for clinical studies related to atherosclerosis and have opened the search for strategies to enhance the number of immature tolerogenic pDCs in vivo. In addition, the function of pDCs in human atherosclerosis would need to be further investigated as humans encounter viruses and bacteria throughout life, which could induce immunogenic pDC activity.

\section{Adventitial lymphatic capillaries are involved in atherosclerosis by regulating $\mathbf{T}$ cell drainage}

Next, we investigated the role of adventitial lymphatic capillaries and T cells in atherosclerosis development. Although the presence of lymphatic capillaries in the adventitia has been recognized already since several decades, ${ }^{39}$ their clinical relevance remains poorly understood. In Chapter 7 we explored the role of adventitial lymphatic capillaries in atherosclerosis. We found that the number of lymphatic capillaries increases during plaque development. These data correspond with previous findings in which the number of lymphatic capillaries was found to be increased during atherosclerosis development. ${ }^{40} \mathrm{We}$ hypothesized that these adventitial lymphatic capillaries will help to drain 
cytokines and leukocytes from plaque and adventitia to the draining lymph node and that removal of the draining lymph node may impair the regulation of inflammation in the adventitia and consequently in the plaque. Removal of the draining lymph node resulted in an accumulation of $T$ cells not only in the adventitia but also in the plaque and consequently in a deterioration of plaque development. In addition, we show that T cells mainly enter the atherosclerotic vessel wall via the adventitia. As removal of the draining lymph node did not decrease $T$ cell influx into the adventitia, naïve and activated $T$ cells probably enter the adventitia via the vasa vasora, as has been suggested already before. ${ }^{41}$ Adventitial lymphangiogenesis is believed to be triggered by growth factors, such as Vascular Endothelial Growth Factor (VEGF) $C$ and $D^{42}$ and cytokines/chemokines, such as CXCL13 and CCL21, ${ }^{43,44}$ released by leukocytes in the adventitia and plaque. Indeed, VEGF-C has been found to be expressed in the adventitia of atherosclerotic lesions, ${ }^{45}$ while VEGF-D is expressed by atherosclerotic lesions as well. ${ }^{46}$ In addition, we show that adventitial lymphangiogenesis is inhibited by Interferon- $\gamma$ Inducible Protein-10 (IP-10) as local inhibition of IP-10 resulted in an increase in adventitial lymphangiogenesis and a decrease in plaque $T$ cell content. Altogether, these data suggest that $T$ cells enter the plaque via the adventitia in a CXCR3 dependent manner and that adventitial lymphatic capillaries drain T cells from the atherosclerotic vessel wall to the lymph node, where they will be drained away via the efferent lymphatic vessel, in order to regulate inflammation. Regardless of this issue, the increased $T$ cell response in the vessel wall might be due to a decreased infiltration of induced regulatory $T$ cells into the adventitia, which normally would be activated in the draining lymph node. This still remains to be investigated. In addition, to better understand the role of adventitial lymphatic capillaries in atherosclerosis, an additional loss-offunction study should be performed in which adventitial lymphangiogenesis is inhibited in order to investigate whether interrupted lymphangiogenesis will impact atherosclerosis and effect an inverse pattern on T cell influx. Moreover, in vivo imaging of cell trafficking through adventitial lymphatic capillaries would be of major asset to better understand their function. It would be interesting to find out whether T cells indeed travel through these lymphatic capillaries towards the draining lymph node. 
One of the open questions remains how modulation of adventitial inflammation will affect immune responses in the intima. So far, there has been no real evidence that inflammatory cells can traverse the media to communicate between the adventitia and intima. Moreover, the media is even thought to be one of the few immunoprivileged sites where inflammatory cells are absent. ${ }^{47}$ Nevertheless, studies in aged $\mathrm{ApoE}^{-/}$mice have demonstrated that the adventitia and intima communicate through lymph node like conduits that connect tertiary lymphoid organs in the adventitia with smooth muscle cells in the media. ${ }^{43}$ Of note, the formation of vessel associated tertiary lymphoid tissue (VALT) was seen to be restricted to the abdominal aorta of aged mice. We here show that adventitial lymphangiogenesis already takes place early on in atherosclerosis, and even in young mice, clearly indicating that lymphangiogenesis plays a role in early plaque development. Interestingly, we did not observe the presence of intimal lymphatic vessels in early and advanced atherosclerosis, implying that leukocyte transfer from adventitia to the intima and vice versa does not proceed via lymph vessels in our mouse model. However, the presence of lymphatic vessels in atherosclerotic lesions has been demonstrated in humans. ${ }^{48,49}$ An explanation for the absence of lymphatic capillaries in mouse as opposed to human lesions could be that in mice the arterial media is much thinner and less organized, facilitating $T$ cells to migrate directly through the media instead of via lymphatic vessels, as we have demonstrated in Chapter 7. In addition, mouse atherosclerotic lesions are more fibrotic and less calcified than human atherosclerotic lesions, which makes it possible for $T$ cells to migrate through the lesion to the media, which makes the presence of lymphatic vessels in the mouse lesion redundant. Moreover, distances are much longer in human vessels. Another interesting feature in human atherosclerotic lesions is edema, as has been demonstrated recently by Falk and co-workers. ${ }^{50}$ Angiogenesis has been demonstrated to be associated with edema, and the presence of lymphatic vessels in human atherosclerotic lesions may be regarded a countermeasure to minimize the extent of edema. Though lymphatic vessels seem to be absent in mouse atherosclerotic lesions, we believe that the mouse model is quite representative of human atherosclerosis and above all a powerful tool as it gives us the possibility to intervene in inflammatory processes in a controlled manner and gain more insight into the mechanisms in human atherosclerosis. 


\section{Chapter 8}

Further study will have to provide more insight into the mechanisms by which adventitial lymphatic capillaries regulate inflammation in the atherosclerotic vessel wall. In addition, our findings question studies in which blocking of lymphangiogenesis was proposed to be useful in progressive atherosclerosis. ${ }^{48}$

\section{Concluding remarks}

The findings presented in this thesis demonstrate that local processes in the plaque are mediated by peripheral and extravascular immune responses, which are controlled by chemokines and leukocytes. This novel concept provides new insights into the pathogenesis of atherosclerosis and is the basis for further research. 


\section{References}

1. Caligiuri G, Nicoletti A, Poirier B, Hansson GK. Protective immunity against atherosclerosis carried by $\mathrm{B}$ cells of hypercholesterolemic mice. J Clin Invest. 2002;109:745-753.

2. Mallat $Z$, Taleb S, Ait-Oufella $H$, Tedgui A. The role of adaptive $T$ cell immunity in atherosclerosis. J Lipid Res. 2009;50:S364-369.

3. Galkina E, Ley K. Immune and inflammatory mechanisms of atherosclerosis. Annu Rev Immunol. 2009;27:165-197.

4. Hernández-Presa M, Bustos C, Ortego M, Tuñon J, Renedo G, Ruiz-Ortega M, Egido J. Angiotensin-converting enzyme inhibition prevents arterial nuclear factor-kappa $B$ activation, monocyte chemoattractant protein-1 expression, and macrophage infiltration in a rabbit model of early accelerated atherosclerosis. Circulation. 1997;95:1532-1541.

5. Rauscher FM, Goldschmidt-Clermont PJ, Davis BH, Wang T, Gregg D, Ramaswami $P$, Pippen AM, Annex BH, Dong C, Taylor DA. Aging, progenitor cell exhaustion, and atherosclerosis. Circ Res. 2003;108:457-463.

6. Zhu S, Liu X, Li Y, Goldschmidt-Clermont PJ, Dong C. Aging in the atherosclerosis milieu may accelerate the consumption of bone marrow endothelial progenitor cells. Arterioscler Thromb Vasc Biol. 2007;27:113-119.

7. Zernecke A, Bot I, Djalali-Talab Y, Shagdarsuren E, Bidzhekov K, Meiler S, Krohn R, Schober A, Sperandio M, Soehnlein O, Bornemann J, Tacke F, Biessen EA, Weber C. Protective role of CXC receptor 4/CXC ligand 12 unveils the importance of neutrophils in atherosclerosis. Circ Res. 2008;102:209-217.

8. Dinerman JL, Mehta JL, Saldeen TG, Emerson S, Wallin R, Davda R, Davidson A. Increased neutrophil elastase release in unstable angina pectoris and acute myocardial infarction. J. Am Coll Cardiol. 1990;15:1559-1563.

9. Naruko T, Ueda M, Haze K, van der Wal AC, van der Loos CM, Ithoh A, Komatsu R, Ikura Y, Ogami M, Shimada Y, Ehara S, Yoshiyama M, Takeuchi K, Yoshikawa J, Becker AE. Neutrophil infiltration of culprit lesions in acute coronary syndromes. Circulation. 2002;106:2894-2900.

10. Martin C, Burdon PC, Bridger G, Gutierrez-Ramos JC, Williams TJ, Rankin SM. Chemokines acting via CXCR2 and CXCR4 control the release of neutrophils from the bone marrow and their return following senescence. Immunity. 2003;19:583-593.

11. Eash KJ, Greenbaum AM, Gopalan PK, Link DC. CXCR2 and CXCR4 antagonistically regulate neutrophil trafficking from murine bone marrow. J Clin Invest. 2010;1:24232431. 
12. Newman SL, Henson JE, Henson PM. Phagocytosis of senescent neutrophils by human monocyte-derived macrophages and rabbit inflammatory macrophages. J Exp Med. 1982;56:430-442.

13. Donzella GA, Schols D, Lin SW, Esté JA, Nagashima KA, Maddon PJ, Allaway GP, Sakmar TP, Henson G, De Clercq E, Moore JP. AMD3100, a small molecule inhibitor of HIV-1 entry via the CXCR4 co-receptor. Nat Med. 1998;4:72-77.

14. Esté JA, Telenti A. HIV entry inhibitors. The Lancet. 2007;370:81-88.

15. Vose JM, Ho AD, Coiffier B, Corradini P, Khouri I, Sureda A, Van Besien K, Dipersio J. Advances in the mobilization for the optimization of autologous stem cell transplantation. Leuk Lymphoma. 2009;50:1412-1421.

16. Burger JA, Peled A. CXCR4 antagonists: targeting the microenvironment in leukemia and other cancers. Leukemia. 2009;23:43-52.

17. Ruben JB, Kung AL, Klein RS, Chan JA, Sun Y, Schmidt K, Kieran MW, Luster AD, Segal RA. A small-molecule antagonist of CXCR4 inhibits intracranial growth of primary brain tumors. Proc Natl Acad Sci U S A. 2003;100:13513-13518.

18. Forster R, Mattis AE, Kremmer E, Wolf E, Brem G, Lipp M. A putative chemokine receptor, BLR1, directs $B$ cell migration to defined lymphoid organs and specific anatomic compartments of the spleen. Cell. 1996;87:1037-1047.

19. Ticchioni M, Essafi M, Jeandel PY, Davi F, Cassuto JP, Deckert M, Bernard A. Homeostatic chemokines increase survival of B-chronic lymphocytic leukemia cells through inactivation of transcription factor FOXO3a. Oncogene. 2007;26:7081-7091.

20. Quiping Z, Jie X, Youxin J, Qun W, Wei J, Chun L, Jin W, Yan L, Chunsong H, Mingzhen Y, Qingping G, Qun L, Kejian Z, Zhimin S, Junyan L, Jinquan T. Selectively frequent expression of CXCR5 enhances resistance to apoptosis in $\mathrm{CD}^{+} \mathrm{CD} 34^{+} \mathrm{T}$ cells from patients with T-cell-lineage acute lymphocytic leukemia. Oncogene. 2005;24:573584.

21. El Haibi CP, Sharma PK, Singh R, Johnson PR, Suttles J, Singh S, Lillard JW Jr. PI3Kp110-, Src-, FAK-dependent and DOCK2-independent migration and invasion of CXCL13-stimulated prostate cancer cells. Mol Cancer. 2010;9:85.

22. Curry JM, Eubank TD, Roberts RD, Wang Y, Pore N, Maity A, Marsh CB. M-CSF signals through the MAPK/ERK pathway via Sp1 to induce VEGF production and induces angiogenesis in vivo. PLoS ONE. 2008;3:e3405.

23. Baay-Guzman GJ, Huerta-Yepez S, Vega MI, Aguilar-Leon D, Campillos M, Blake J, Benes V, Hernandez-Pando R, Teran LM. Role of CXCL13 in allergic airway inflammation: novel therapeutic target. Chest. 2011. Epub Ahead of print.

24. Schmutz C, Hulme A, Burman A, Salmon M, Ashton B, Buckley C, Middleton J. Chemokine receptors in the rheumatoid synovium: upregulation of CXCR5. Arthritis Res Ther. 2005;7:R217-229. 
25. Wong CK, Wong PT, Tam LS, Li EK, Chen DP, Lam CW. Elevated production of B cell chemokine CXCL13 is correlated with systemic lupus erythematosus disease activity. J Clin Immunol. 2010;30:45-52.

26. Facchetti F, Vermi W, Mason D, Colonna M. The plasmacytoid monocyte/interferon producing cells. Virchows Arch. 2003;443:703-717.

27. Niessner A, Sato K, Chaikof EL, Colmegna I, Goronzy JJ, Weyand CM. Pathogensensing plasmacytoid dendritic cells stimulate cytotoxic T-cell function in the atherosclerotic plaque through interferon-alpha. Circulation. 2006;114:2482-2489.

28. Kadowaki N, Ho S, Antonenko S, Malefyt RW, Kastelein RA, Bazan F, Liu YJ. Subsets of human dendritic cell precursors express different toll-like receptors and respond to different microbial antigens. J Exp Med. 2001;194:863-869.

29. Lande R, Ganguly D, Facchinetti V, Frasca L, Conrad C, Gregorio J, Meller S, Chamilos G, Sebasigari R, Riccieri V, Bassett R, Amuro H, Fukuhara S, Ito T, Liu YJ, Gilliet M. Neutrophils acitivate plasmacytoid dendritic cells by releasing self-DNA-peptide complexes in systemic lupus erythematosus. Sci Transl Med. 2011;3:73ra19.

30. Ganguly D, Chamilos G, Lande R, Gregorio J, Meller S, Facchinetti V, Homey B, Barrat FJ, Zal T, Gilliet M. Self-RNA-antimicrobial peptide complexes activate human dendritic cells through TLR7 and TLR8. J Exp Med. 2009;206:1983-1994.

31. Lövgren T, Eloranta ML, Båve U, Alm GV, Rönnblom L. Induction of interferon-alpha production in plasmacytoid dendritic cells by immune complexes containing nucleic acid released by necrotic or late apoptotic cells and lupus IgG. Arthritis Rheum. 2004;50:1861-1872.

32. Kuwana M. Induction of anergic and regulatory T cells by plasmacytoid dendritic cells and other dendritic cell subsets. Hum Immunol. 2002;63:1156-1163.

33. Colonna M, Trinchieri G, Liu YJ. Plasmacytoid dendritic cells in immunity. Nat Immunol. 2004;1219-1226.

34. Isaksson $M$, Ardesjö $B$, Rönnblom L, Kämpe $O$, Lassmann $H$, Eloranta $M L$, Lobell $A$. Plasmacytoid DC promote priming of autoimmune Th17 cells and CEA. Eur J Immunol. 2009;39:2925-2935.

35. Crow MK, Kirou KA, Wohlgemuth J. Microarray analysis of interferon-regulated genes in SLE. Autoimmunity. 2003;36:481-490.

36. Baechler EC, Batliwalla FM, Karypis G, Gaffney PM, Ortmann WA, Espe KJ, Shark KB, Grande WJ, Hughes KM, Kapur V, Gregersen PK, Behrens TW. Interferon-inducible gene expression signature in peripheral blood cells of patients with severe lupus. Proc Natl Acad Sci U S A. 2003;100: 2610-2615.

37. De Heer HJ, Hammad H, Soullié T, Hijdra D, Vos N, Willart MA, Hoogsteden HC, Lambrecht BN. Essential role of lung plasmacytoid dendritic cells in preventing asthmatic reactions to harmless inhaled antigen. J Exp Med. 2004;200:89-98. 
38. Abe M, Metes D, Thomason AW. Dendritic cells and regulation of alloimmune responses: relevance to outcome and therapy of organ transplantation. Expert Rev Clin Immunol. 2005;1:419-430.

39. Schwartz CJ, Mitchell CR. Cellular infiltration of the human arterial adventitia with atheromatous plaques. Circulation. 1962;26:73-78.

40. Drożdż K, Janczak D, Dzięgiel P, Podhorska M, Patrzałek D, Ziołkowski P, Andrzejak R, Szuba A. Adventitial lymphatics of internal carotid artery in healthy and atherosclerotic vessels. Folia Histochemica et cytobiologica. 2008;46:433-436.

41. Galkina E, Kadl A, Sanders J, Varughese D, Sarembock IJ, Ley K. Lymphocyte recruitment into the aortic wall before and during development of atherosclerosis is partially L-selectin dependent. J Exp Med. 2006;203:1273-1282.

42. Xu X, Lu H, Lin $H, N i$, Sun $H$, Li C, Jiang $H$, Li F, Zhao $Y$, Zhang $M$, Zhang $Y$. Lymphangiogenesis promotes inflammation and neointimal hyperplasia after adventitia removal in the rat carotid artery. Int J Cardiol. 2009;134:426-427.

43. Gräbner R, Lötzer K, Döpping S, Hildner M, Radke D, Beer M, Spanbroek R, Lippert B, Reardon CA, Getz GS, Fu YX, Hehlgans T, Mebius RE, van der Wall M, Kruspe D, Englert C, Lovas A, Hu D, Randolph GJ, Weih F, Habenicht AJR. Lymphotoxin $\beta$ receptor signaling promotes tertiary lymphoid organogenesis in the aorta adventitia of aged ApoE ${ }^{-/-}$mice. J Exp Med. 2009;206:233-248.

44. Müller G, Lipp M. Concerted action of the chemokine and lymphotoxin system in secondary lymphoid-organ development. Curr Opin Immunol. 2003;15:217-224.

45. Xu X, Lu H, Lin H, Li X, Ni M, Sun H, Li C, Jiang H, Li F, Zhang M, Zhao Y, Zhang Y. Aortic adventitial angiogenesis and lymphangiogenesis promote intimal inflammation and hyperplasia. Cardiovasc Pathol. 2009;269-278.

46. Rutanen J, Leppänen $\mathrm{P}$, Tuomisto TT, Rissanen TT, Hiltunen MO, Vajanto I, Niemi M, Häkkinen T, Karkola K, Stacker SA, Achen MG, Alitalo K, Ylä-Herttuala. Vascular endothelial growth factor-D expression in human atherosclerotic lesions. Cardiovasc Res. 2003;59:971-979.

47. Dal Canto AJ, Swanson PE, O'Guin AK, Speck SH, Virgin HW. IFN-gamma action in the media of the great elastic arteries, a novel immunoprivileged site. J Clin Invest. 2001;107:R15-R22.

48. Kholová I, Dragneva G, Cermáková P, Laidinen S, Kaskenpää N, Hazes T, Cermáková E, Steiner I, Ylä-Herttuala S. Lymphatic vasculature is increased in heart valves, ischaemic and inflamed hearts and in cholesterol-rich and calcified atherosclerotic lesions. Eur J Clin Invest. 2011;41:487-497.

49. Nakano T, Nakashima Y, Yonemitsu Y, Sumiyoshi S, Chen YX, Akishima Y, Ishii T, lida $M$, Sueishi K. Angiogenesis and lymphangiogenesis and expression of 
lymphangiogenic factors in the atherosclerotic intima of human coronary arteries. Hum Pathol. 2005;36:330-340.

50. Kim WY, Christiansen EH, Thrysøe SA, Al-Mashladi RH, Bøtker HE, Bøttcher M, Holm $N R$, Falk E. First in vivo demonstration of coronary edema in culprit lesion of patient with acute coronary syndrome by cardiovascular magnetic resonance. Circ Cardiovasc Imaging. 2011;4:344-346. 


\section{Summary}

Atherosclerosis is a chronic inflammatory disease of middle-sized and large arteries that is characterized by the accumulation of lipids and inflammatory cells in the vessel wall, resulting in the formation of an atherosclerotic lesion. The attraction of these vascular inflammatory cells is orchestrated by chemokines. Chapter 2 provides an overview of the chemokines that have been implicated in atherosclerosis, and discusses their potential as biomarker of and therapeutic target for plaque destabilization and rupture.

While most chemokines are upregulated in response to inflammatory stimuli to control immune responses, homeostatic chemokines are constitutively expressed to regulate leukocyte trafficking to and compartmentalization in lymphoid organs. Recently, these homeostatic chemokines has been attributed a broader function in immune response modulation not only in lymphoid but also in non-lymphoid tissue and in the induction of cell survival and angiogenesis. In Chapter 3, we addressed, by a loss-of-function approach, the role of one of these homeostatic chemokines, CXCL12, and its receptor, CXCR4, in neutrophil senescence and implications thereof for murine atherosclerosis. Neutrophils lacking functional CXCR4 expression showed increased reactive oxygen species accumulation and increased adhesion to plaque endothelium, thereby aggravating atherosclerosis. These neutrophils displayed an enhanced circulation half-life. Importantly, patients with acute cardiovascular disease had decreased expression of CXCR4 on circulating neutrophils, substantiating the importance of neutrophil CXCR4 expression for disease development.

In Chapter 4, we investigated the role of another homeostatic chemokine, CXCL13, and its receptor, CXCR5, in atherosclerosis. Patients with angina pectoris and carotid artery atherosclerosis had increased CXCL13 plasma levels. Moreover, CXCL13 was expressed in human carotid atherosclerotic lesions, both in early as advanced (un)stable lesions, by adventitial cells but also by plaque macrophages and vascular smooth muscle cells. CXCL13 was seen to exert anti-apoptotic activity on monocytes and vascular smooth muscle cells, suggestive of a plaque stabilizing effect of CXCL13.

As the CXCL13/CXCR5 dyad is instrumental in T/B cell trafficking, and as both cell types have been attributed a major role in atherogenesis, we hypothesized that the CXCL13/CXCR5 axis might be involved in regulating T/B cell homing to 
and/or function in the atherosclerotic vessel wall. Given that CXCL13 is constitutively expressed in the adventitia where it co-localizes amongst others with plaque macrophages and fibroblasts, we sought to demonstrate in Chapter 5 the causal involvement of CXCL13 in atherosclerosis in mice. Hematopoietic deficiency of CXCL13 as well as of CXCR5 attenuated atherosclerosis development but did not affect lymphocyte homing towards the vessel wall. Instead, it appeared to alter monocyte/granulocyte function, and more in particular, interfered with survival of specific monocyte subsets, not only lowering monocyte levels but also skewing it towards the Ly6C(low) subsets. Lack of CXCL13/CXCR5 did not influence myeloid development and monocyte/granulocyte mobilization from bone marrow into circulation. These findings reveal a so far unknown role for CXCL13 and CXCR5 in monocyte/granulocyte homeostasis which is independent of the lipidemic status of the mice. We further show that, while our studies in Chapter 4 pointed to a plaque stabilizing activity of CXCL13, its peripheral effects seem to support a pro-atherogenic activity.

Our findings in Chapter 3 and 5 clearly illustrate that peripheral and perivascular immunity can affect atherosclerosis. In the second part of this thesis, we further explored how peripheral and extravascular immunity can modulate local processes in the plaque. In Chapter 6, we showed that plasmacytoid dendritic cells ( $p D C s$ ) suppress $T$ cell responses in the periphery, resulting in an attenuation of atherosclerosis development and progression. Moreover, we found that pDC suppress $T$ cell proliferation in an indoleamine 2,3-dioxygenase dependent manner. Given the almost complete absence of pDCs in human and especially mouse atherosclerotic lesions, we propose that pDC most likely exert their atheroprotective effect from the outside of the vessel wall, from lymphoid tissue or thymus given their effect on T cell regulation.

In Chapter 7, we explored the impact of lymphatic capillaries in the adventitia on plaque development and inflammation. We showed that adventitial lymphatic capillaries expand early on in plaque development. Therefore, we hypothesized that adventitial lymphatic capillaries could contribute to atherogenesis by draining cytokines and leukocytes from the adventitia to draining lymph nodes. Along that line, draining lymph node excision is expected to dampen adventitial and plaque inflammation. However, removal of the draining lymph node resulted in $\mathrm{T}$ cell accumulation not only in the adventitia but also in the plaque, and deteriorated plaque development. In addition, we showed that T cells mainly enter the 
atherosclerotic vessel wall via the adventitia in a CXCR3 dependent manner. Adventitial lymphangiogenesis was promoted by focal CXCR3 blockage and resulted in decreased plaque T cell content. Our findings thus suggest a protective effect of adventitial lymphatic capillaries in atherosclerosis. However, additional studies will be required to exclusively establish this hypothesis.

In Chapter 8 the major findings in Chapters 3 to 7 are discussed. We conclude that peripheral and extravascular immunity profoundly impact local processes in the plaque. The novel findings presented in this thesis thus provide new insights in the pathogenesis of atherosclerosis. 


\section{Samenvatting}

Atherosclerose, of aderverkalking, is een chronische ontstekingsziekte van de middelgrote en grote bloedvaten en wordt gekenmerkt door de ophoping van vetten en ontstekingscellen (inflammatoire cellen) in de vaatwand, resulterende in de vorming van een zogenaamde plaque. De plaque ontstaat wanneer het endotheel lokaal beschadigd raakt en ontstekingscellen aangetrokken worden om de schade te herstellen. Wanneer de plaque een zekere omvang bereikt, zal zich een kapsel van bindweefsel en gladde spiercellen vormen rondom de ontstekingshaard om de stabiliteit van de plaque te waarborgen. Dit kapsel kan echter afgebroken worden door een teveel aan ontstekingscellen. Als gevolg hiervan zal het fibreuze kapsel langzamerhand eroderen en de plaque instabiel worden (plaque destabilisatie), wat het risico vergroot dat zij onder stress zal openscheuren (plaque ruptuur). In dat geval komt het bloed in direct contact met de inhoud van de plaque en kan een bloedstolsel ontstaan. Dit stolsel kan het bloedvat afsluiten en daarmee de bloedtoevoer naar stroomafwaarts gelegen weefsel blokkeren, een proces dat, wanneer dit zich voordoet in de kransslagader, kan leiden tot een hartinfarct.

De aantrekking van ontstekingscellen naar de plaque is daarmee een bepalende factor niet alleen in de ontwikkeling van de plaque maar ook voor de ernst van de ziekte. Dit proces wordt gereguleerd door chemokines, kleine eiwitten die verantwoordelijk zijn voor de aantrekking (chemotaxis) van ontstekingscellen naar de ontstekingshaard. In Hoofdstuk $\mathbf{2}$ wordt een overzicht gegeven van alle chemokines die betrokken zijn bij atherosclerose. Bovendien worden de perspectieven van chemokines en remmers daarvan voor diagnostische respectievelijk therapeutische doeleinden bij atherosclerose gerelateerde aandoeningen besproken.

In het eerste deel van deze thesis werd de rol van chemokines in atherosclerose bestudeerd. We hebben onderzocht hoe chemokines ontstekingsprocessen buiten de vaatwand ("extravasculair" of "perifeer") beïnvloeden en wat het effect hiervan is op lokale ontstekingsprocessen in de plaque.

Het merendeel van de chemokines, de zogenaamde inflammatoire chemokines, worden verhoogd geproduceerd tijdens ontstekingsprocessen om op die manier de afweerreactie in gang te zetten dan wel te onderhouden. 
Samenvatting

Homeostatische chemokines daarentegen zijn chemokines die continu aangemaakt worden om het transport van ontstekingscellen naar en hun lokalisatie in de lymfeorganen te regelen. Uit recent onderzoek blijken de homeostatische chemokines ook een bredere functie te vervullen, in die zin dat ze betrokken zijn in de regulatie van afweerreacties in lymfe- en overige organen, in de cel-overleving alsook in de vorming van bloedvaten (angiogenese). In Hoofdstuk 3 hebben we de rol van één van deze homeostatische chemokines, CXCL12, en haar receptor, CXCR4, in neutrofiel veroudering onderzocht in een muizenmodel van atherosclerose. Neutrofielen zijn witte bloedcellen die een cruciale rol spelen bij het elimineren van bacteriën, virussen maar ook van andere schadelijke factoren. Neutrofielen uit muizen met een verminderde werking van CXCR4 vertoonden een verhoogde activiteit, gekenmerkt door een verhoogde aanmaak van reactieve zuurstofradicalen (oxidanten), die cel- en weefselschade kunnen veroorzaken. Daarnaast hechten deze neutrofielen ook beter aan de plaque, wat het proces van atherosclerose bevordert. Verrassend was dat deze neutrofielen een verlengde levensduur kenden en bij veroudering minder efficiënt uit de bloedsomloop verwijderd werden, hetgeen suggereert dat verouderde neutrofielen betrokken zijn bij atherosclerose. Dat deze bevinding mogelijk ook voor de mens geldt hebben we tenslotte weten aan te tonen in patiënten die lijden aan atherosclerose, aangezien hun neutrofielen een verlaagde CXCR4 productie bleken te vertonen.

In hoofdstuk 4 hebben we de rol van een ander homeostatisch chemokine, CXCL13, en zijn receptor, CXCR5, in atherosclerose onderzocht. De bloedwaarden van CXCL13 bleken sterk verhoogd in patiënten die lijden aan angina pectoris (een bepaalde hartkwaal en meestal de voorganger van atherosclerose, letterlijk "pijn aan de borst") of atherosclerose. Daarenboven was CXCL13 aanwezig in de vaatwand van deze patiënten. Dit CXCL13 werd vooral aangemaakt door macrofagen (een type ontstekingscel die veel voorkomt in de plaque) en gladde spiercellen, maar werd ook aangetroffen in het weefsel rondom de vaatwand, de zogenaamde adventitia. CXCL13 oefende een anti-apoptotische (verhinderen van celdood) werking uit op monocyten en gladde spiercellen, wat suggereert dat CXCL13 een plaque stabiliserende werking heeft.

Daar CXCL13 en CXCR5 normaal gesproken het transport van T en B cellen (twee andere typen ontstekingscellen) door het lichaam regelt, en deze celtypen 
een belangrijke rol spelen in atherosclerose, veronderstelden wij dat CXCL13 en CXCR5 vooral betrokken zijn bij T en B cel rekrutering naar en/of hun functie in de atherosclerotische vaatwand. Aangezien CXCL13 constant aangemaakt wordt door ontstekingscellen (bv. macrofagen) en bindweefselcellen in de adventitia, wilden we in Hoofdstuk 5 niet alleen nagaan wat de bijdrage is van CXCL13 aan atherosclerose, maar ook welk celtype hier met name voor verantwoordelijk was. Uitschakeling van CXCL13 of CXCR5 in witte bloedcellen leidde tot een vertraagde ontwikkeling van atherosclerose maar had geen effect op de rekrutering van $T$ en B cellen naar de vaatwand. Opmerkelijk was dat de functie van monocyten en granulocyten in deze muizen verstoord bleek, meer bepaald was er een verlaging in het aantal monocyten en granulocyten en een verschuiving van pro-

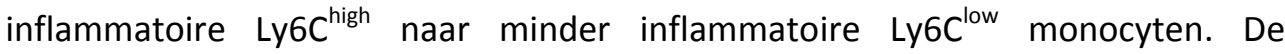
monocyt/granulocyt ontwikkeling, of hun mobilisatie vanuit het beenmerg naar het bloed bleek onaangetast, wat suggereert dat de afname in monocyten en granulocyten te wijten is aan een effect op de overleving van deze cellen in de bloedsomloop. Deze bevindingen onthullen een tot nu toe onbekende rol van CXCL13 en CXCR5 in monocyt/granulocyt functie en levensduur, die onafhankelijk is van het dieet van de muizen. Bovendien tonen we aan dat CXCL13 en CXCR5, in tegenstelling tot de in Hoofdstuk 4 geopperde hypothese (een plaque stabiliserend effect), de ontwikkeling van atherosclerose juist bevorderen door beïnvloeding van processen in de periferie.

De bevindingen in Hoofdstuk 3 en 5 tonen aan dat perifere en extravasculaire ontstekingsprocessen de ontwikkeling van atherosclerose sterk kan beïnvloeden. In het tweede deel van dit proefschrift zijn we hier dieper op ingegaan. In Hoofdstuk 6 tonen we aan dat plasmacytoïd dendritische cellen (pDCs) T cel reactie in de periferie onderdrukken, en daarmee de vorming van een atherosclerotische plaque afremt. Bovendien hebben we het enzyme weten te identificeren dat verantwoordelijk is voor de dempende werking van pDCs op de activatie van $T$ cellen, indoleamine 2,3-dioxygenase. Daar pDCs bijna totaal ontbreken in atherosclerotische plaques, zowel in de muis als de mens, kunnen we concluderen dat zij hun beschermende werking uitoefenen in de periferie, hoogstwaarschijnlijk in lymfeorganen en/of de thymus.

In Hoofdstuk $\mathbf{7}$ hebben we de rol van lymfevaten in de adventitia op plaque ontwikkeling onderzocht. Onze studies tonen aan dat het aantal lymfevaten in de 
adventitia toeneemt tijdens plaque ontwikkeling. Op basis hiervan is de hypothese opgesteld dat de lymfevaten door drainage/afvoer van ontstekingsmediatoren en -cellen uit de vaatwand, een belangrijke rol spelen in atherosclerose, en dat verwijdering van de lokale lymfeklier de ontsteking in de adventitia en plaque zou moeten verminderen. In tegenstelling tot onze verwachting bleek dit laatste echter te resulteren in een verhoogde opstapeling van $T$ cellen in de adventitia en de plaque, en de plaque ontwikkeling te verergeren. Bovendien tonen we aan dat $\mathrm{T}$ cellen de atherosclerotische vaatwand voornamelijk via de achterdeur, de adventitia, infiltreren en dat dit transport gestuurd wordt door de CXCR3 receptor. Lokale remming van CXCR3 verhoogde het aantal lymfevaten in de adventitia en verminderde de aanwezigheid van $T$ cellen in de plaque. Onze data wijzen er dus op dat adventitiale lymfevaatjes een beschermend effect hebben op atherosclerose. Nader onderzoek zal deze hypothese moeten bevestigen.

De bevindingen beschreven in Hoofdstuk 3 tot en met 7 worden in Hoofdstuk 8 tot slot bediscussieerd en in een breder kader geplaatst. We concluderen dat diverse perifere en extravasculaire immuunreacties lokale processen in de plaque sterk kunnen beïnvloeden. Dit proefschrift biedt in die zin dan ook een nieuw inzicht in het ontstaan van atherosclerose en vormt de basis voor verder onderzoek. 



\section{Curriculum Vitae}

\section{Personal information}

Name:

Date of birth:

Place of birth:

Nationality:

\section{Education}

August 2007 - February 2012

September 2006 - June 2007

September 2003 - June 2006

September 1997 - June 2003

International Research

2011

2010
Isabelle Truda Marie Nadine Daissormont

$10^{\text {th }}$ of July 1985

Liège (Belgium)

Belgian
University of Maastricht, the Netherlands PhD student

University of Hasselt, Belgium

Master in Biomedical Sciences

University of Hasselt, Belgium

Bachelor in Biomedical Sciences

OLVH, Tongeren, Belgium

Sciences-Mathematics Education

Dept. of Molecular Immunology,

Cincinnati Children's Hospital Medical

Center, Cincinnati, OH, USA

Prof. dr. E. Janssen (1 month)

Dept. of Internal Medicine, University

Hospital Oslo, Oslo, Norway

Prof. dr. P. Aukrust (1 month) 


\section{Scientific activities}

Daissormont I, Seijkens T, de Vries T, Postema J, Wijnands E, Christ A, Beckers L, Binder C, Lutgens E, Hoepken U, Lipp M, Aukrust P, Biessen EAL. The CXCL13CXCR5 axis contributes to atherosclerosis development in $\mathrm{LDLr}^{-/}$mice by regulating myeloid development. (oral presentation at the American Association of Immunologists Annual Meeting 2011, San Francisco) I Immunol. 2011;186:149.1.

Daissormont I, Christ A, Sampedro S, Seijkens T, Boon L, Van der Loos C, Halvorsen B, Aukrust P, Lutgens E, Daemen M, Biessen EAL. Plasmacytoid dendritic cell depletion augments CD8 T cell IFN-gamma associated atherogenic responses in a mouse model of atherosclerosis. (oral presentation at the American Association of Immunologists Annual Meeting 2011, San Francisco) J Immunol. 2011;186:147.18.

Daissormont I, Christ A, Sampedro S, Seijkens T, Boon L, Van der Loos C, Halvorsen B, Aukrust P, Lutgens E, Daemen M, Biessen EAL. Ablation of plasmacytoid dendritic cells exacerbates atherosclerosis by skewing $\mathrm{T}$ cell function. (oral presentation at the American Heart Scientific Sessions 2010, Chicago) Circulation. 2010; 122:A10123.

Daissormont I, Aukrust P, Lipp M, Biessen EAL. The CXCL13/CXCR5 axis contributes to atherosclerosis development in $\mathrm{LDLr}^{-/-}$mice by regulating lymphocyte migration to perivascular lymph organs (oral presentation at the European Society of Cardiology Conference - Frontiers in CardioVascular Biology 2010, Berlin).

Daissormont I, de Jager S, Bot I, Santbrink P, Biessen EAL. Focal inhibition of IP-10 in the adventitia of atherosclerotic lesions potently inhibits $T$ cell influx but not plaque burden (poster presentation at the European Vascular Genomics Network 2009, Marseille).

Daissormont I, de Jager S, Bot I, Van Santbrink P, Biessen EAL. Focal inhibition of IP-10 in atherosclerotic lesions potently inhibits T-cell influx but not plaque 
Curriculum vitae

initiation or progression (oral presentation at the American Heart Scientific Sessions 2008, New Orleans). Circulation. 2008; 118:S_309.

\section{Grants and Awards}

2010 Travel award for young investigators

American Heart Association (AHA) council on ATVB

$2010 \quad$ Travel grant

Dutch Heart Foundation

$2010 \quad$ First Contact Initiative Grant

European Society of Cardiology (ESC) 


\section{List of publications}

Daissormont I, Christ A, Temmerman L, Sampedro Millares S, Seijkens T, Manca M, Rousch M, Poggi M, Boon L, Van der Loos C, Daemen M, Lutgens E, Halvorsen $B$, Aukrust $P$, Janssen E, Biessen EA. Plasmacytoid dendritic cells protect against atherosclerosis by tuning $\mathrm{T}$ cell proliferion and activity. Circulation Research. 2011;109(12):1387-1395.

Daissormont I, Kraaijeveld AO, Biessen EA. Chemokines as therapeutic targets for atherosclerotic plaque destabilization and rupture. Future Cardiol. 2009;5(3):273284.

Thuijls G, de Haan JJ, Derikx JP, Daissormont I, Hadfoune M, Heineman E, Buurman WA. Intestinal cytoskeleton degradation precedes tight junction loss following hemorrhagic shock. Shock. 2009;31(2):164-169.

Bot I*, Daissormont I*, Zernecke A, Kramp B, de Jager S, Hérias V, Westra M, Bot $M$, van Santbrink P, van Berckel T, Su L, Skjelland M, Gullestad L, Halvorsen B, Aukrust P, Koenen RR, Weber C, Biessen EA. CXCR4 blockade induces atherosclerosis by perturbing neutrophil apoptosis and senescence. ${ }^{*}$ both authors contributed equally. In revision at the Eur Heart Journal.

Smedbakken L, Halvorsen B, Daissormont I, Ranheim T, Michelsen A, Skjelland M, Folkersen L, Krohg-Sørensen K, Russell D, Holm S, Ueland T, Fevang B, Hedin U, Yndestad A, Gullestad L, Hansson GK, Biessen EA, Aukrust P. Increased levels of the homeostatic chemokine CXCL13 in human atherosclerosis - potential role in plaque stabilization. Submitted.

Daissormont I, Seijkens T, Wijnands E, Hartvigsen K, Binder C, Lutgens E, Halvorsen B, Aukrust $P$, Lipp $M$, Höpken $U$, Biessen EA. Interruption of the CXCL13/CXCR5 axis attenuates atherosclerosis by perturbing monocyte/granulocyte homeostasis in mice. In preparation.

Daissormont I, Rademakers T, de Jager S, Stöger L, Bot I, van Santbrink P, Moreno $\mathrm{M}$, Nurmi H, Alitalo K, Biessen EA. Adventitial lymphatic capillaries in plaque T cell drainage and progression: an explorative study. In preparation. 


\section{Dankwoord}

Het is zover, ik ga promoveren! Graag wil ik van de gelegenheid gebruik maken iedereen te bedanken die heeft bijgedragen tot de realisatie van dit proefschrift.

Om te beginnen mijn promotor, professor Biessen. Beste Erik, bedankt om me 4 jaar geleden te hebben aangenomen om je nieuwe onderzoeksgroep in Maastricht mee op te starten. Je immense input en creativiteit hebben elk project één voor één uniek en uitdagend gemaakt. Je hebt me de vrijheid en vertrouwen gegeven zelf op verkenning te gaan, eigen ideeën te creëren, en hier heb ik ontzettend veel uit geleerd. Bedankt ook voor alle kansen die je me hebt gegeven.

Als tweede zou ik graag professor Buurman willen bedanken. Beste Wim, door jou heb ik eigenlijk zin gekregen om onderzoek te doen. Je hebt altijd in mij geloofd en hebt me gestimuleerd verder te doen. Het is voor mij een eer jou nu 4 jaar later weer tegen te komen, als voorzitter van de beoordelingscommissie nog wel!

Veel dank ook aan de andere leden van de beoordelingscommissie, professor Aukrust, professor Janssen en professor Lutgens voor het beoordelen van mijn proefschrift.

Dankjewel aan alle collega's op het pathologielab, zowel de cardio's als de mensen van epigenetica alsook de mensen aan de "klinische kant"! Bedankt aan Esther en Sylvia voor jullie geweldige input tijdens de werkbesprekingen en om mij op te vangen toen Erik er niet was. Bedankt aan de analisten, Anique, Clairy, Erwin, Jeffrey, Linda, Mat en Petra voor jullie ondersteuning. Ik heb veel AIO's en postdocs zien komen en gaan. Allereerst bedankt aan de oud-collega's, Dirk, Indira, Judith, Lili, Mathijs G., Veronica en Wouter die er waren toen ik pas begon en bij wie ik altijd terecht kon. Dear Lili, from the first day we have become good friends. I will mainly remember all the funny moments together. I hope we can make it one day to meet again. Mathijs G., je bent een enorme loyale collega! Eén uit de duizend! Succes met je nieuwe baan! Daarna zijn er heel wat nieuwe collega's bijgekomen, Anette (thanks for your help in the pDC project!), Bea, Brenda, Cora, David (good luck writing your thesis), Jeroen, Kani, Karen, Marco, Marjorie, Timo (bedankt voor je 2-foton hulp bij het lymfeproject), Tom (bedankt 
voor je bijdrage aan het CXCR5 project), bedankt en succes allemaal. Dear Bea, you were always the sunshine in the lab. We have spent a lot of time together chatting and laughing! Thanks for these fun moments! I will never forget our trip to Sevilla! Marjorie, nous sommes devenues des bonnes amies et je suis contente de t'avoir comme paranymph. Cette année je viendrai à Marseille, c'est promis! Verder veel succes ook aan de allernieuwste cardio's, Anjana, Bart, Lieve, Mathijs, Sofia en Thomas. Succes ook aan de "nieuwe" MOLGEN collega's, Ine, Marjo, Nadine en Emiel. Bedankt Marion voor je pathologisch advies. Bedankt ook aan mijn studenten Stefan, Jonne en Caroline voor jullie inzet. Jack, bedankt voor de kwanti-met hulp. Verder, dankjewel Kathleen voor de leuke babbels in de gang! Tot in Tongeren! Bedankt ook aan Benoit, Ilse, en alle anderen van het klinisch lab. Tot slot, bedankt Cor en Elly voor het regelen van de "praktische zaken" en in het bijzonder dank aan onze secretaresse Danielle. Lieve Danielle, als we behoefte hadden aan een babbel dan konden we altijd wel bij elkaar terecht! Dankjewel!

The realisation of this thesis has been made possible thanks to international collaborations. First, I would like to express my gratitude to professor Aukrust from the University Hospital in Oslo, Norway. Dear Pål, thank you for your collaboration and support in 4 out of 5 projects described in this thesis! Thank you for your tremendous help and loyalty. In addition, you also welcomed me in your lab for a stay of one month. I had a great time in Oslo! Thanks also to Bente who helped us a lot throughout these studies! Many thanks to Vigdis and Linda as well. Next, I would like to thank professor Janssen. Beste Edith, ik mocht een maand naar je lab om er onderzoek te doen naar pDCs. Ondanks het feit dat Cincinnati zowat de meest criminele stad bleek te zijn van de VS heb ik er een geweldige tijd beleefd. De samenwerking met jou was zeer productief en aangenaam en heeft geleid tot een mooie publicatie! Bedankt voor al je hulp! Finally, I would like to thank professor Höpken from the Max-Delbrück-Center in Berlin, Germany. Dear Uta, thank you for your help and input in the mouse CXCR5 project.

Ook zou ik graag de collega's in Leiden willen bedanken. Beste Ilze en Saskia, ik ben op die 4 jaar een aantal keren naar Leiden gereisd om experimenten uit te voeren onder jullie supervisie. Bedankt voor jullie inzet in het CXCR4 en IP-10 project. Succes in jullie verdere wetenschappelijke carrière. 
Het onderzoek beschreven in dit proefschrift was niet mogelijk geweest zonder de talloze muizen die gebruikt werden voor de beschreven studies. Dank aan alle CPV medewerkers, in het bijzonder Rik en Richard. Rik, zonder jou waren onze muisstudies echt niet mogelijk geweest. Bedankt voor de talloze collar plaatsingen en vooral bedankt om altijd flexibel te zijn! Hetzelfde geldt eigenlijk voor Richard. Ik heb het je niet altijd gemakkelijk gemaakt met mijn last-minute wijzigingen of verzoeken, maar telkens zorgde je ervoor dat het goed kwam. Verder ook dank aan Marjanne voor het regelen van de GGO en virus zaken.

Bedankt aan mijn vrienden om te zorgen voor de nodige ontspanning tijdens dit doctoraat. Hopelijk hebben we straks allemaal wat meer tijd voor elkaar. Isabelle, bedankt om mijn paranymf te zijn! We kennen elkaar ondertussen al een lange tijd, hebben vanalles meegemaakt samen, vooral veel leuke momenten en reizen! Dat gaan we in de toekomst zeker blijven proberen te doen. Sara, bedankt om een trouwe vriend te zijn. Anneke, Ellen en Anneleen, ons "Belgen clubje" in Maastricht, bedankt voor de gezellige lunch-momenten en nuttige tips.

Mijn familie en schoonfamilie, bedankt voor jullie blijk van interesse in mijn werk. Ik hoop dat jullie nu een beetje een idee hebben gekregen van wat ik heb gedaan de afgelopen 4 jaar. Ook hoop ik hierna eindelijk wat meer tijd te hebben voor jullie allemaal. Chère Nona, tu as toujours été là pour moi et j'aimerais te remercier pour ça. Je sais que Papau aurait voulu être avec nous aujourd'hui, dans notre coeur on pense beaucoup à lui. Mijn lieve zus, Ariane, bedankt om er altijd te zijn. Straks is het weer feest als jij en Yves in het huwelijksbootje treden! Mijn lieve ouders, woorden schieten tekort om uit te drukken hoeveel jullie betekenen voor mij en hoezeer ik jullie onvoorwaardelijke steun en liefde waardeer. Jullie hebben Ariane en mij altijd op de eerste plaats gezet. Alles zouden jullie doen voor ons. We kunnen altijd bij jullie terecht en dat is een fijn gevoel. Merci!

Tot slot, mijn lieve schat, Kris. Je kwam precies op het juiste moment in mijn leven! Je bent de perfecte wederhelft, de juiste balans, zalig gewoon. Bedankt om er altijd te zijn, voor je luisterend oor, voor je oprechte liefde, voor de ideale ontspanning! Ik kan niet wachten om te zien wat de toekomst voor ons in petto heeft. Ik zie je graag! 
